\title{
Small fiber neuropathy : a novel finding in sarcoidosis
}

Citation for published version (APA):

Hoitsma, E. (2005). Small fiber neuropathy : a novel finding in sarcoidosis. [Doctoral Thesis, Maastricht University]. Datawyse / Universitaire Pers Maastricht. https://doi.org/10.26481/dis.20050225eh

Document status and date:

Published: 01/01/2005

DOI:

10.26481/dis.20050225eh

Document Version:

Publisher's PDF, also known as Version of record

\section{Please check the document version of this publication:}

- A submitted manuscript is the version of the article upon submission and before peer-review. There can be important differences between the submitted version and the official published version of record.

People interested in the research are advised to contact the author for the final version of the publication, or visit the DOI to the publisher's website.

- The final author version and the galley proof are versions of the publication after peer review.

- The final published version features the final layout of the paper including the volume, issue and page numbers.

Link to publication

\footnotetext{
General rights rights.

- You may freely distribute the URL identifying the publication in the public portal. please follow below link for the End User Agreement:

www.umlib.nl/taverne-license

Take down policy

If you believe that this document breaches copyright please contact us at:

repository@maastrichtuniversity.nl

providing details and we will investigate your claim.
}

Copyright and moral rights for the publications made accessible in the public portal are retained by the authors and/or other copyright owners and it is a condition of accessing publications that users recognise and abide by the legal requirements associated with these

- Users may download and print one copy of any publication from the public portal for the purpose of private study or research.

- You may not further distribute the material or use it for any profit-making activity or commercial gain

If the publication is distributed under the terms of Article $25 \mathrm{fa}$ of the Dutch Copyright Act, indicated by the "Taverne" license above, 
ISBN 90-9018868-1

Production:

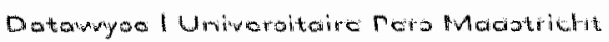

Cover design: $\odot$ Elske Hoitsma

Lay-out: Tiny Wouters

c. Elske Hoitsma, 2005

The copyright of the articles that have already been published or are in press has been transferred to the respective journals. e-mail address: elske.hoitsma@wanadoo.nl

Key words:

sarcoidosis, small fiber neuropathy,

neurosarcoidosis. 


\section{Small Fiber Neuropathy}

\section{a novel finding in sarcoidosis}




\section{nutrim intiliti}

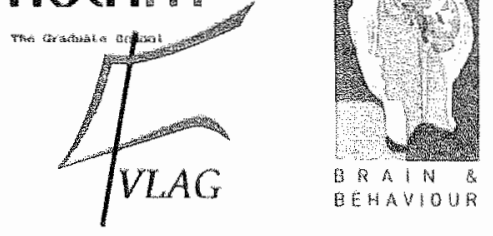

The study presented in this thesis was performed within the Nutrition and Toxicology Research Institute Maastricht (NUTRIM) which participates in the Graduate School VLAG (Food Technology, Agrobiotechnology, Nutrition and Health Sciences), accredited by the Royal Netherlands Academy of Arts and Sciences. 


\title{
Small Fiber Neuropathy
}

\section{a novel finding in sarcoidosis}

\author{
PROEFSCHRIFT \\ ter verkrijging van de graad van doctor \\ aan de Universiteit Maastricht, \\ op gezag van de Rector Magnificus, \\ Prof. Mr. G.P.M.F. Mols, \\ volgens het besluit van het College van Decanen, \\ in het openbaar te verdedigen \\ op vrijdag 25 februari 2005 om 14.00 uur
}

door

Elske Hoitsma

Geboren op 21 december 1971 te Geldrop 
Promotores

\author{
Prof dr d. Troost \\ Prof. dr. F. Spaans
}

Co-promotores
Dr. M. Drent
Dr. C.G. Faber

Beoordelingscommissie

Prof. dr. M.P. van Dieijen-Visser (voorzitter)

Prof. dr. D.M.F.M. van der Heijde

Prof. dr. M. van Kleef

Prof. dr. O.P. Sharma, Los Angeles County University of Southern California (LAC + USC) Medical Center, USA

Prof. dr. J.H.J. Wokke, Universitair Medisch Centrum (UMC), Utrecht 
Dit proefschrift is opgedragen aan alle sarcoidosepatiènten, die de aanleiding en mogelijkheden voor dit proefschrift gegeven hebben. 


\section{Contents}

Abbreviations

Chapter 1 General introduction

Chapter 2 Neurosarcoidosis: a clinical dilemma

Chapter 3 Small fiber neuropathy:

a common and important clinical disorder

Chapter 4 Impact of pain in a Dutch sarcoidosis patient population

Chapter 5 Sleep disturbances associated with periodic leg movements in chronic sarcoidosis

Chapter 6 Albnormal warm and cold sensation thresholds suggestive of small fiber neuropathy in sarcoidosis

Chapter 7 Simall fiber neuropathy in sarcoidosis

Chapter 8 The Small Fiber Neuropathy Screening List (SFNSL):

Construction and cross-validation in sarcoidosis patients

Chapter 9 Associalion of small fiber neuropathy with cardiac

sympathetic dysfunction in sarcoidosis

Chapter 10 Association of HLA DQB1*0602 in sarcoidosis patients with small fiber neuropathy

Chapter 11 Spectacular improvement of small fiber neuropathy in a sarcoidosis patient after treatment with infliximab

Chapter 12 Summary, general discussion and directions for future studies 
Samenvatting

Dankwoord

203

List of publications

209

Curriculum vitae

213

Appendix

Small Fiber Neuropathy Screening List (SFNSL)

217 


\section{Abbreviations}

\begin{tabular}{|c|c|}
\hline ACE & anglotensin converting enzyme \\
\hline AHI & apnea hypopnea index \\
\hline $\mathrm{APC}$ & antigen-presienting cells \\
\hline ART & antiretroviral therapy \\
\hline ASDA & American Sleep Disorders Association \\
\hline BAL & bronchoalweolar lavage \\
\hline $\mathrm{BM}$ & body mass index \\
\hline CAFT & cardiovascular autonomic function test \\
\hline $\mathrm{CAl}$ & central apnea index \\
\hline CHEPs & contact heat-evoked potential stimulators \\
\hline $\mathrm{CK}$ & creatin kinase \\
\hline CNS & central nervous system \\
\hline COPD & chronic obstructive pulmonary disease \\
\hline CPAP & continuous positive airway pressure \\
\hline CPT & current perception threshold testing \\
\hline $\operatorname{cs}$ & cold sensation \\
\hline CSF & cerebrospinal fluid \\
\hline CV & standard deviation $\times 100 \% /$ mean \\
\hline CXR & chest radiograph \\
\hline DLCO & diffusing capacity for carbon monoxide \\
\hline DSS & Dutch Sarcoidosis Society \\
\hline$E E G$ & electro-encephalography \\
\hline EMG & electromyography \\
\hline EOG & electro-oculography \\
\hline ESR & erythrocyte sedimentation rate \\
\hline FAS & fatigue assessment scale \\
\hline FEV & forced expiratory volume in one second \\
\hline FVC & forced vital capacity \\
\hline $\mathrm{Hb}$ & haemoglobin \\
\hline$H$ & hypopnea index \\
\hline HIV & human immunodeficiency virus \\
\hline HLA & human leukocyte antigen \\
\hline HIM & heart and mediastinum \\
\hline HRV & heart rate variability \\
\hline$H z$ & herz \\
\hline
\end{tabular}




\begin{tabular}{|c|c|}
\hline IAR & inferior-anterior ratios \\
\hline$\| / A$ & inferior and anterior \\
\hline$\| C D$ & intracardial defibrillator \\
\hline IENFD & intra-epidermal nerve fiber density \\
\hline IFN & interferon \\
\hline IL & interleukin \\
\hline IL2R & interleukin-2-receptor \\
\hline${ }^{23} \mathrm{H}-\mathrm{MIBG}$ & lodine-123 meta-iodobenzylguanidine \\
\hline IQR & interquartile range \\
\hline IVC & inspiratory vital capacity \\
\hline $\mathrm{KCO}$ & transfer coefficient of the luing for $\mathrm{CO}$ \\
\hline LDF & laser Doppler flowmetry \\
\hline LDI & laser Doppler imaging \\
\hline LIMAI & leg movement arousal index \\
\hline LMI & leg movement index \\
\hline MIBG & meta-iodobenzylguanidine \\
\hline MLE & method of levels \\
\hline MLI & method of limits \\
\hline MRI & magnetic resonance imaging \\
\hline MSLT & multiple sleep latency test \\
\hline MTX & methotrexate \\
\hline MUP & motor unit potential \\
\hline NADPH & nicotinamide adenine dinucleotide phosphatase \\
\hline NCS & nerve conduction studies \\
\hline NFKB & nuclear regulatory factor kappa-B \\
\hline NGF & nerve growth factor \\
\hline nh & number an hour \\
\hline NK-1R & neurokinin-1 receptor \\
\hline NNT & number needed to treat \\
\hline np & not present \\
\hline NPS & neuropathic pain scale \\
\hline NREM & non-rapid eye movement sleep \\
\hline NSAIDS & non steroidal anti-inflammatory drugs \\
\hline OAl & obstructive apnea index \\
\hline OSA & obstructive sleep apnea \\
\hline PeMax & maximal expiratory mouth pressure \\
\hline PGP & protein gene product \\
\hline PiMax & maximal inspiratory mouth pressure \\
\hline PLM & periodic leg movement \\
\hline
\end{tabular}




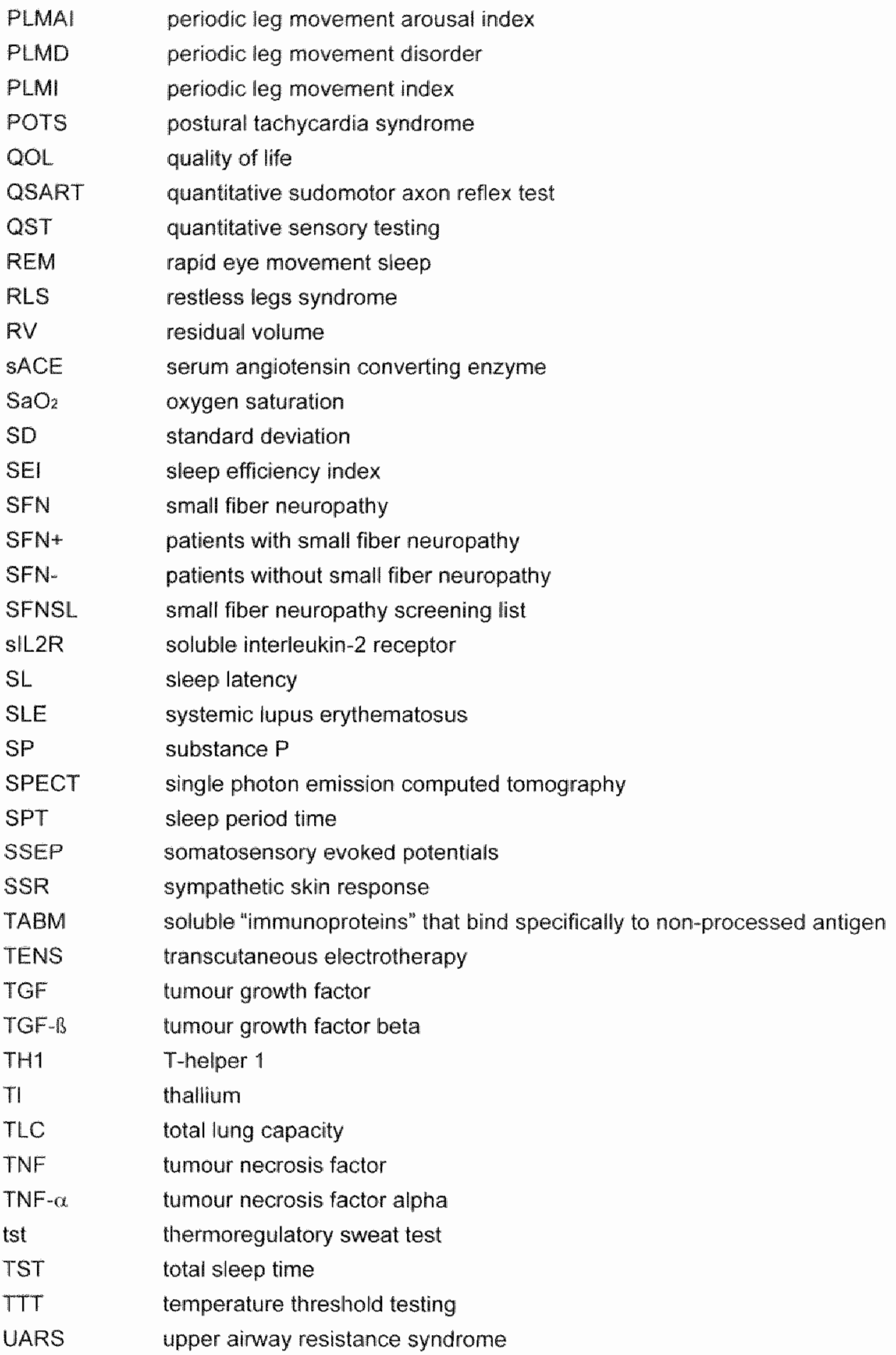


vs

versus

WASOG World Association of Sarcoidosis and Other Granulomatous Disorders WHOQOL-100 World Health Organisation Quality of Life assessment instrument WS warm sensation 
4 
Chapter 1

General introduction 


\section{Sarcoidosis}

Sarcoidosis has been known for more than 100 years; it was first described by the dermatologist Hutchinson, and several years later by two other dermatologists, Besnier and Boeck.

Sarcoidosis is a multi-organ inflammatory disorder that is characterized by a specific morphological hallmark, noncaseating granuloma (figure 1.1). ${ }^{\text {1.4 }}$ Although the exact etiology remains unknown, current evidence supports the concept that the pathogenesis of sarcoidosis involves a highly polarized T-helper 1 (Th1) immune response to pathogenic tissue antigens or specific environmental factors. 'Granuloma formation is regulated by a complex interaction between T-helper lymphocytes and macrophages, in which cytokines such as tumour necrosis factor (TNF)-a play an important role (figure 1.2$)^{4-7}$

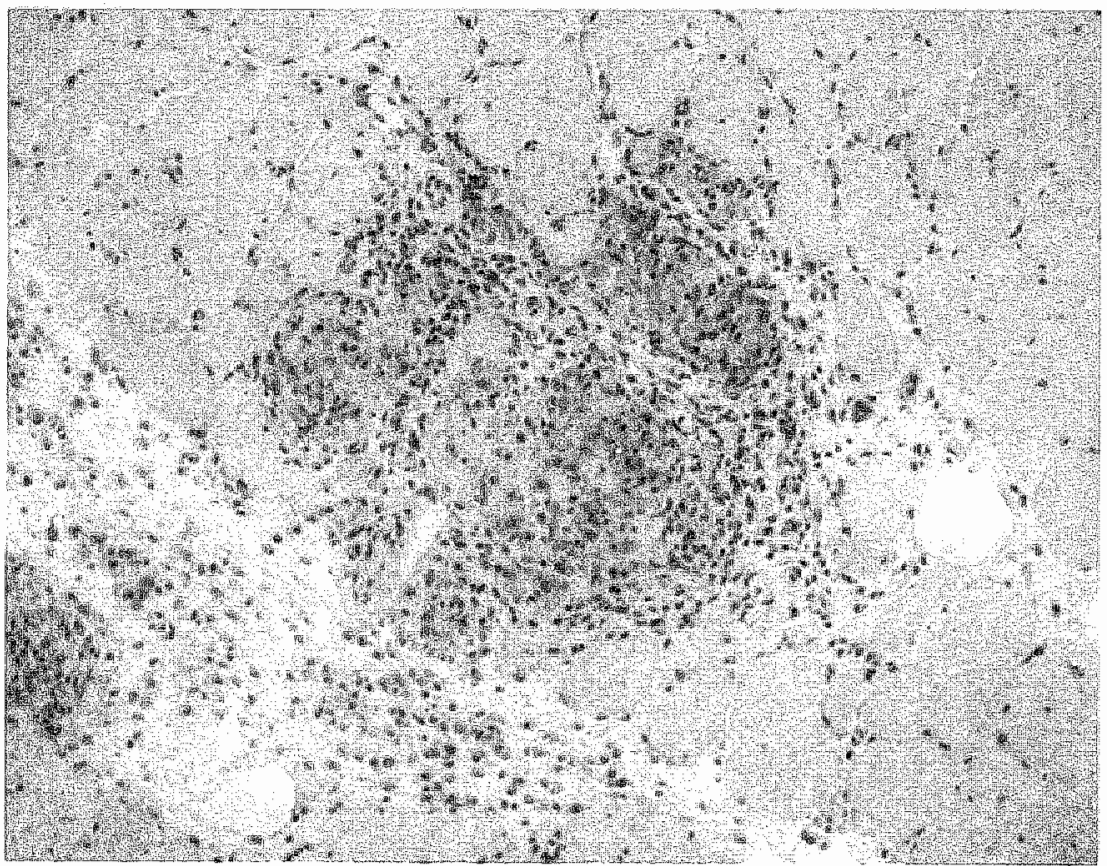

Figure 1.1. Noncaseating granuloma present in a biopsy obtained from the left quadriceps muscle of a sarcoidosis patient (100x) 
Conventional treatment is focused on attenuating granuloma formation with antimalarial drugs that inhibit antigen presentation or with nonspecific anti-inflammatory agents such as glucocorticosteroids, methotrexate, or azathioprine. Anti-TNF- $\alpha$ agents such as infliximab and thalidomide have recently shown some success in sarcoidosis. 4 , 15 Designing future therapies depends on improved knowledge of the critical immunological processes operative in different stages of disease. ${ }^{16}$

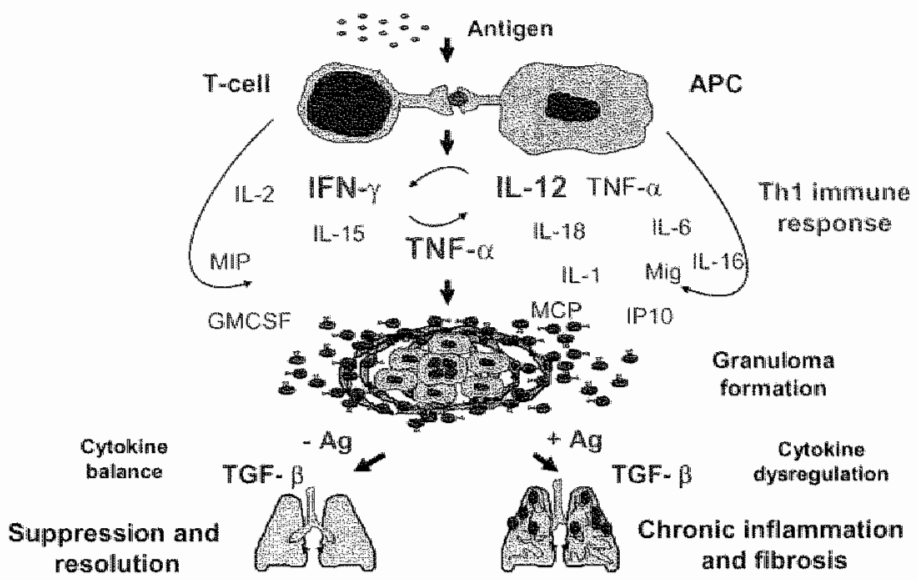

Figure 1.2. Hypothetical model of the pathogenesis of sarcoidosis. An inciting agent induces antigen-speicific Tht-mediated granulomatous inflammation with production of Th1 cytokines such as interferon ( $\mid F N$ ) $-Y$ and interleukin (IL)-2. Macrophages, actiwaled directly by the inciting agent and by IFNW: produce $\| \mathrm{L}-12$, TNF- $\mathrm{a}_{n}, \mathrm{H}-6$ and other cytokines important in cell activation, proliferation and recruitment. Activated irracrophages ard $T$-cels along with other affector cells such as fibroblasts. orchestrate the complex process of granuloma formation under the regulatory influence of local cylokine production. Removal of inciting agent allows immunosuppresslve cytokines such as tumour growth factor (TGF) 10 downregulate the immune response with return to cylokine homeostasis. Granuloma regression likely $00 \mathrm{curs}$ by bell apoptosis. Persistent antigenic stimulation results in cytokine dysregulation and possbly. T-coll autoimmune responses. If untreated, chronic antigenic stimulation and cytokine production results in tissue injury which" together with upregulated production of TCF $\beta$ and other profibrotic cylokines, lead to irreversible fibrosis (adapted with permission from Moller). 


\section{Clinical features of sarcoidosis}

The clinical course of sarcoidosis is highly variable and depends on ethnicity, duration of illness, site and extent of organ involvement, and activity of the granulomatous process, which shows a tendency to wax and wane. Mode of presentation varies from asymptomatic, to an "acute onset" presenting as Löfgren"s syndrome with erythema nodosum, fever, arthralgia and enlarged lymph nodes at the chest radiograph and finally to a chronic course, frequently accompanied with non-specific constitutional symptoms such as fatigue, pain, and general muscle weakness. The true number of asymptomatic patients cannot be reliably determined since in many of them the diagnosis is not established. Practically every organ can be involved. However, most cases (>90\%) have respiratory symptoms such as cough and dyspnoea and/or abnormal chest radiographs. Furthermore, the lymphoid system, skin, eyes, heart, nervous system, and liver may be involved. ${ }^{1,4,17}$

Prognosis of acute onset sarcoidosis is good and spontaneous remission usually occurs within two years while chronic sarcoidosis mostly has an insidious onset. The course of chronic sarcoidosis is often relapsing with resolution being less likely. In some of the cases the disease is progressive. Development of lung fibrosis, cardiac sarcoidosis and neurosarcoidosis are related to worse prognosis. Up to $5 \%$ will eventually die from sarcoidosis. ${ }^{2}$ A rare however dramatic complication in sarcoidosis is sudden death.

As mentioned above, many sarcoidosis patients suffer from apparently non-specific symptoms such as pain and fatigue. ${ }^{18-21}$ However, these symptoms do not often reflect disease activity. They have been so far an enigma to physicians treating sarcoidosis patients and are a major problem that has a great impact on the quality of life of sarcoidosis patients. ${ }^{21-24}$ The following cases illustrate some of these symptoms:

\section{Case 1}

A 55-year old male known with pulmonary sarcoidosis since two years was referred to the neurology department because of severe pain in hands and lower legs and feet with paraesthesias. He could not stand bed-clothes on his legs, and wore short trousers without socks in winter because he could not stand clothes on his lower legs. Furthermore, he was suffering from severe fatigue, profuse sweating, diarrhoea, bladder emptying difficulties, sicca syndrome, paroxysmall palpitations with dizziness after which he collapsed once, and erectile dysfunction. Neurological examination revealed no abnormalities except subjective dysesthesia of the lower legs and feet. Differential diagnosis included neuropathy with involvement of autonomic fibers. Electromyography, nerve conduction studies and cardiovascular autonomic function tests were normal. Temperature threshold testing (TTT) revealed abnormal temperature sensation 
compatible with small fiber neuropathy (SFN). He was treated with prednisone without any success, and subsequently put on methotrexate, again without any improvement. Neuropathic pain treatment ${ }^{25-28}$ with gabapentin, amitryptilin, carbamazepin, local capcaicin cream were all without benefit. Opioids gave some pain reduction and improved diarrhoea. However, after a few weeks he developed urine retention. At present the patient is severely disabled mainly because of severe pain and fatigue and had to stop working.

\section{Case 2}

A 39 year-old male known with pulmonary and neurological involvement (hydrocephalus) of sarcoidosis since 2000 presented at the neurology department for a second opinion in 2003 with symptoms of extreme fatigue, cognitive impairment, pain in paims and soles, weakness of the legs and finally dizziness and blurred vision while standing. He had been suffering from these symptoms since 2 years. Former elsewhere performed cerebral MRI revealed unchanged hydrocephalus without any parenchymal lesions and lumbar puncture had showed normal pressure and normal cell counts, protein, and glucose levels. The posture dependent symptoms in combination with pain in palms and soles were suspective of SFN. Therefore. TTT was performed revealing severely abnormal temperature sensation. Cardiovascular autonomic function testing showed a normal blood pressure response after changing position from supine to standing but an abnormal increase in heart rate (63 beats/minute; normally less than 30 beats/minute). Furthermore, blood pressure modulation frequency in the upright position was too low $(0.051 \mathrm{~Hz})$. Both results as well as the symptoms are consistent with the diagnosis of postural tachycardia syndrome (POTS). He was treated with hydration, increased salt intake and elastic support hose without much benefit. At present he is on fludrocortisone 50 ug daily with which he feels a bit better.

We observed that a similar pattern of symptoms occurred frequently in sarcoidosis patients consisting of peripheral pain, fatigue and vegetative symptoms such as diarrhoea, micturation disturbances, erectile dysfunction, sicca syndrome, sweating, heat intolerance, flushes, orthostatic pain in the coathanger area and recurrent collapses while under the shower. We assumed that this reoccurring pattern of symptoms was suggestive of the presence of SFN as a common complication in sarcoidosis. This hypothesis was the basis of this thesis. 


\section{Small fiber neuropathy}

SFN is a neuropathy selectively involving small diameter myelinated and unmyelinated nerve fibers. Interest in this disonder has considerably increased during the past few years. Routine electrodiagnostic studies, which primarily test large myelinated fiber function, are mostly normal in these patients. The syndrome of SFN has been an enigma to practitioners because of the unexplained contrast between severe pain in the extremities and a paucity of findings in neurological and electrophysiological examination. Recent advantages in diagnostic techniques. (TTT, cardiovascular autonomic function testing, and intra-epidermal nerve fiber density (IENFD) assessment in skin biopsy) facilitate objective confirmation of clinical diagnosis and the characterization of fiber type involvement in SFN. Diagnosis is made on the basis of the clinical features, normal nerve conduction studies, and abnormal specialized tests of small nerve fibers.

\section{Scope and aims of the study}

The aims of the present study were to explore the presence and different aspects of neurological involvement, pain and in particular SFN in sarcoidosis.

In chapter 2 the existing literature regarding neurosarcoidosis is reviewed to give an overview of the presient knowledge and dilemmas clinicians are faced with diagnosing and treating patients with neurosarcoidosis. An approach for the diagnosis of neurosarcoidosis, as well as treatment strategies, are discussed.

Chapter 3 reviews the literature regarding what is known about SFN. Furthermore, pathophysiology hypotheses and present treatment are described here. Finally, suggested areas of further research regarding SFN are discussed.

The aim of chapter 4 was to explore the presence and impact of pain in sarcaidosis. This was performed in a Dutch sarcoidosis population $(n=821)$ using questionnaires.

The aim of chapter 5 was to analyse the presence of sleep problems, restless legs and periodic leg movements in sarcoidosis.

In chapter 6 we describe the assessment of SFN in sarcoidosis using various types of testing: temperature threshold testing, sympathetic skin response and cardiovascular autonomic function testing.

The aim of chapter 7 was to further objectify the presence of SFN in sarcoidosis using skin biopsy.

The aim of chapter 8 was to develop and validate a list to screen for the presence of SFN. Besides for screening this list can be valuable in future longitudinal and therapeutic studies. 
The aim of chapter 9 was to investigate whether SFN in sarcoidosis might be associated with cardiac autonomic dysfunction. Therefore, we performed iodine-123 metaiodobenzylguanidine ( ${ }^{123}$-MIBG) scintigraphy, cardiovascular autonomic function testing and temperature threshold testing "besides several tests for cardiac evaluation to assess whether there is a relation between SFN with cardiac sympathetic dysfunction in sarcoidosis.

The aim of chapter 10 was to analyse the role of genetic factors in sarcoidosis related SFN. For this purpose the association between human leucocyte antigen (HLA), SFN and disease course in sarcoidosis was explored.

In chapter 11 the improvement of SFN in a refractory sarcoidosis patient after treatment with anti-TNF- $\alpha$ therapy (infliximab) is described.

in chapter 12 a summary and implications of the findings presented in this thesis are argued and directions for future research are briefly discussed. 


\section{References}

1. Hunninghake $G W$, Costabel $U$, Ando $M$. Baughman RP, Cordier JF, du Bois RM, Eklund $A$, Kitaichi M. Lynch J, Rizzato $G$. Rose $C$, Selroos $O$. Semenzato $G$. Sharma $O P$. ATSIERSNASOG statement on sarcoidosis. American Thoracic Society/European Respiratory SocietyrNorld Association of Sarcoidosis and other Granulomatous Disorders. Sarcoido. sis Vasc Diffuse Lung Dis 1999;16:149-73.

2. Newman LS, Rose CS, Maier LA. Sarcoidasis. N Engl J Med 1997;336:1224-34

3. Sharma OP. Sarcoidosis: a worldwide phenomenon. Sarcoidosis 1984:1:11-5.

4. Baughman RP, Lower EE, du Bois RM. Sarcoidosis. Lancet 2003;361:1111-8.

5. James DG, Milliams WJ. Immunology of sarcoidosis. Am J Med 1982;72:5-8.

6. Molier DR. Cells and cytokines involved in the pathogenesis of sarcoidosis. Sarcoidosis Vasc Diffuse Lung Dis 1999;16:24-31

7. Muller-Quernheirm J. Sarcoidlosis: immunopathogenetic concepts and their clinical application Eur Respir J 1998;12:716-38.

8. Baughman RP, Lower EE. Infliximab for refractory sarcoidosis. Sarcoidosis Vasc Diffuse Lung Dis 2001;18:70-4.

9. Carter JD, Valeriano $J$, Vasey $F B$, Bognar B. Pefractory neurosarcoidosis: a dramatic response to infliximab. Am J Med 2004:117:277-9.

10. Morcos Z. Refractory neurosarcoidosis responding to infliximab. Neurology 2003;60:1220-1.

11. Pettersen JA, Zochodne DW. Bell RB, Martin L, Hill MD. Refractory neurosarcoidosis responding to infliximab. Newrology 2002;59:1660-1.

12. Yee $A M$, Pochapin MB. Treatment of complicated sarcoidosis with infliximab anti-tumor necrosis factor-alpha therapy. Ann Intern Med 2001;135:27-31.

13. Sollberger M, Flur: F, Baumann T. Sonnet S, Tamm M. Steck AJ, Brutsche M. Successful treatment of steroid-refractory neurosarcoidosis with infliximab. I Neuro/ 2004:251:760-1.

14. Katz JM, Bruno MK, Winterkorn JM, Nealon N. The pathogenesis and treatment of optic disc swelling in neurosarcoidosis: a unique therapeutic response to infliximab. Arch Neurol 2003;60:426-30.

15. Baughman RP, Judson MA, Teirstein AS, Moller DR, Lower EE. Thalidomide for chronic sancoidosis. Chest 2002;122:227-32.

16. Moller DR. Treatment of sarcoidosis - from a basic science point of wiew. J Intem Med $2003,253: 31-40$.

17. Hoitsma $E$, Faber $C G$. Drent M, Sharma OP. Neurosarcoidosis: a clinical dilemma Lancet Newrol 2004;3:397-407

18. DeRemee RD. Dysphoria and Sarcoidosis. Sarcoidosis Vasc Diffuse Lung Dis 1998:15:21.

19. Sharma OP. Fatigue and sarcoidosis. Eur Respir $\downarrow$ 1999;13:713-4.

20. Drent M. Wimsberger RM, De Vires J, van Dieijen-Visser MP, Wouters EFM, Schols AMWJ. Association of fatigue with an acute phase response in sarcoidosis. Eur Respir J $1999 ; 13: 718-22$

21. Drent M. Sarcoidosis: benefits of a multidisciplinary approach. Eur I Intern Med 2003;14 $217-220$.

22. Wirnsberger RM, De Vries J, Breteler MHM, van Heck GL, Wouters EFM, Drent $M$ Evaluation of quality of life in sarcoidosis patients. Respir Med 1998:92:750-6.

23. De Vries J, Drent $M_{8}$ van Heck GL. Wouters EFM. Quality of life in sarcoidosis: a comparison between members of a patient organisation and a random sample. Sarcoidosis Vasc Diffuse Lung Dis 1998;15:183-8.

24. Drent M, Wirnsberger RM, Breteler MHM, Kock LM, De Vries J "Wouters EFM. Quality of life and depressive symptoms in patients suffering from sarcoidosis. Sarcoidosis Vasc Diffuse Lung Dis 1998;15:59-66. 
25. Hoitsma E, Reulen JPH, de Baets M. Drent M, Spaans F, Faber CG. Sinall fiber neuropathy: a common and important clinical disorder. Neurol Sci 2004;15:227:119-30.

26. Woolf CJ, Mannion RJ. Neuropathic pain: aetiology, symptoms, mechanisms, and management. Lancet 1999;353:1959-64.

27. Sindrup SH, Jensen TS. Efficacy of pharmacological treatments of neuropathic pain: an updlate and effect related to mechanism of drug action. Pain 1999;83:389-400.

28. Mendell JR, Sahenk $Z$. Clinical practice. Painful sensory neuropathy. $N$ Engl J Med 2003;348:1243-55. 
22 


\section{Chapter 2}

Neurosarcoidosis: a clinical dilemma

E Hoitsma, CG Faber, M Drent, OP Sharma 


\section{Abstract}

Sarcoidosis is an inflammatory multisystem disorder of unknown cause. Practically no organ is immune to sarcoidosis; most commonly, in up to $90 \%$ of patients, it affects the lungs. The nervous system is involved in 5-15\% of patients. Neurosarcoidosis is a serious and commonly devastating complication of sarcoidosis. Clinical diagnosis of neurosarcoidosis depends on the finding of neurological disease in multisystem sarcoidosis. As the disease can present in many different ways without biopsy evidence, solitary nervous-system sarcoidosis is difficult to diagnose. Corticosteroids are the drug of first choice. In addition, several cytotoxic dugs, including methotrexate. have been used to treat sarccidosis. The value of new drugs such as anti-tumour necrosis factor-a will be assessed. In this review we describe the clinical manifestations of neurosarcoidosis, diagnostic dilemmas and considerations, and therapy. 


\section{Introduction}

Sarcoidosis is an inflammatory multisystem disorder of unknown cause that can affect any part of the nervous system. The prevalence of clinical involvement of the nervous system is estimated to be about 5-15\%.12. However, the prevalence of subclinical neurosarcoidosis may be much higher. ${ }^{3.4}$ Post-mortem studies suggest that antemortem diagnosis is only made in $50 \%$ of patients with sarcoidosis with nervous system involvement $^{5}$ Because neurosarcoidosis may manifest in many different ways, diagnosis may be complicated..$^{2,36-10}$ Neurosarcoidosis can appear in an acute explosive fashion or as a slow, chronic illness. Furthermore, any part of the nervous system can be attacked by sarcoidosis but cramial nerves, the hypothalamus, and the pituitary gland are mast commonly involved. ${ }^{1}$ Sarcoid granulomas can affect the meninges, parenchyma of the brain, hypothalamus, brainstem, subependymal layer of the ventricular system, choroid plexuses, peripheral nerves, and blood vessels supplying the nervous structures. ${ }^{1,12}$ A third of patients with neurosarcoidosis have multiple neurological lesions. If neurological syndromes develop in a patient with active systemic sarcoidosis (proven by biopsy), the diagnosis is generally easy. However, without biopsy evidence of sarcoidosis at other sites, nervous-system sarcoidosis is difficult to diagnose. ${ }^{13}$ Neurological symptoms may also arise in the patients with inactive sarcoidosis. In such situations neurosarcoidosis may occupy a high place in the list of differential diagnoses, but histological evidence of granulomatous involvement of the nervous system is still needed in these cases. Furthermore, in a few patients sarcoidosis may selectively involve the nervous system. ${ }^{14.15}$ In such cases it is important not to confuse the non-specific local sarcoid reaction with multisystem sarcoidosis. ${ }^{16}$ Neurosarcoidosis is rare; most research reports small numbers of patients or case reports and prospective studies of neurosarcoidosis are scarce. ${ }^{\text {"7 }}$ Evidence-based recommendations consequently are lacking.

\section{Epidemiology and pathogenesis}

Sarcoidosis occurs worldwide, affecting people of all races, both sexes, and all ages; it is the second most common respiratory disease in young adults after asthma. The disease typically affects adults age between 20 years and 40 years. In Scandinavian countries and Japan there is a second peak incidence in women age more than 50 years. Estimates of prevalence range from one to 50 per 100000 individuals, and this varies among ethnic and racial groups. Sarcoidosis is most common among North Americans of African heritage and north European white people. ${ }^{18}$ 
Noncaseating epithelioid granulomas are the pathological hallmarks of sarcoidosis and reveal the inflammatory character of the disease. Granulomas are structured masses of activated macrophages and their derivatives (i.e., epitheloid and giant cells). Although the cause of sarcoidosis is unknown, there is evidence that sarcoidosis results from exposure of genetically susceptible hosts with increased Th1-immune response to specific environmental factors. ${ }^{10}$ The most compelling argument for a genetic mechanism is that there is occasional familial clustering of cases. Environmental factors involved in sarcoidosis can be grouped under infection (such as Mycobacterium tuberculosis and Propionibacterium acnes or $P$ granulosum) and non-infectious environmental exposures (such as pesticides and insecticides, pine pollen, sillica or talc, metal dusts, and man-made mineral fibers). ${ }^{18.19}$ Exposure to these factors can cause diseases that are histologically and clinically indistinguishable from sarcoidosis. This association supports environmental hypotheses as do reports of community outbreaks, a work-related risk of sarcoidosis for nurses, and an important study tracing case contacts on the Isle of Man. ${ }^{19}$ Further evidence is found in the inflammatory response in sarcoidosis, which is characterised by large numbers of activated macrophages and T lymphocytes bearing the CD4-helper phenotype, with a pattern of cytokine production that is most consistent with a Th1-type immune response triggered by an antigen. ${ }^{\sharp 8}$

\section{Neurological manifestations of sarcoidosis}

\section{Cranial neuropathy}

Cranial neuropathy seems to be the most common neurologilical complication of sarcoidosis. 'Cranial-nerve palsy may be caused by nerve granulomas, increased intracranial pressure or granulomatous basal meningitis. A peripheral seventh nerve palsy (Bell's palsy) is the most common cranial-nerve lesion, "and is in fact the most common neurological manifestation of sarcoidosis overall. ${ }^{239220-22}$ Bilateral dysfunction occurs both simultaneously and sequentially.

The optic nerve seems to be the second most commonly affected cranial nerve. ${ }^{20}$ Although sarcoid granulomas of the optic nerve are generally unilateral they may involve both nerves. ${ }^{23}$ Sarcoidosis of the optic nerve may occur without systemic involvement. ${ }^{24}$ When optic neuropathy occurs, especially in young patients, multiple sclerasis is considered a likely cause. In these cases, chest radiograph with evidence of sarcoidosis makes multiple sclerosis highly unlikely. Optic nerve involvement in sarcoidosis can be divided into a chronic progressive type that responds poorly to corticosteroids 25 and an acute type that responds to prednisone. ${ }^{2.25,20}$ 
Other cranial nerves may be affected as well. Cranial neuropathies may be single or multiple. ${ }^{27.28}$ Heerfordt's syndrome is a cranial neuropathy (mostly the facial nerve) with uveitis, parotid-gland enlargement, and fever. The syndrome is highly suggestive of sarcolidosis.

Horner syndrome (caused by disruption of the cervical sympathetic nervest as well as pupillary abnormalities, including internal ophthalmoplegia), Argyll-Robertson pupil and Adie's pupil have been described in sarcoidosis. ${ }^{21,29-32}$

\section{Papilledena}

The diagnosis of neurosarcoidosis should be considered in young adults, particularly women of childbearing age, with rapidly developing papilloedema, especially associated with the seventh or other nerve palsies. In patients with sarcoidosis, fundoscopy should be done; in those with papilloedema, imaging of the brain is indicated.

\section{Aseptic meningitis}

Meningeal symptoms may be acute or chronic. Symptoms and signs include fever, headache, neck rigidity, and sterile cerebrospinal fluid (CSF) with pleocytosis (particularly lymphocytes). ${ }^{33}$

Concentration of glucose in the C.SF may be low in about a fifth of patients. . $_{4}$ Sometimes mental status changes and polyradiculopathy are present. ${ }^{35,36}$ The basal meninges may be affected, resulting in cranial neuropathy. Chronic meningitis is commonly recurrent and requires long-term therapy, whereas acute meningitis responds favourably to corticosteroids. Cerebral herniation after lumbar puncture in sarcoid meningitis has been described in one patient. ${ }^{37}$ Arachnoid villi dysfunction may have contributed to very high intracranial pressures in this patient and lumbar puncture may have caused an acute pressure differential.

\section{Hydrocephalus}

Hydrocephalus is vare and may occur because of absorption disturbances ${ }^{12,4.38}$ or obstruction. $^{39,40}$ As well as headache and somnolence, hydrocephalus can cause amnesia, dementia, urinary incontinence, and gait disturbances. ${ }^{41.42}$

\section{Cerebral sarcoid lesions}

Granullomas may remain small or form large intracranial tumours and may be single or multiple. They can occupy extradural, subdural, and parenchymatous locations. ${ }^{436}$ Furthermore, periventricular white-matter lesions are observed. These lesions may resemble those seen in multiple sclerosis or as a result of vascular changes. Asympto- 
matic periventricular white-matter lesions without meningeal enhancement in patients with sarcoidosis age over 50 years are most likely not caused by sarcoidosis and can be thought of as age-related small-vessel disease.

The clinical features of mass lesions are similar to any space occupying intracranial mass. Granulomatous lesions are commonly found in the hypothalamus or pituitary gland. ${ }^{47-51}$ This may cause endocrine manifestations, such as diabetes insipidus, ${ }^{52}$ adenopituitary failure, ${ }^{53.54}$ amenorrhoea-galactorrhoea syndrome, ${ }^{50}$ isolated or in various combinations. Infratentoriall granulomas are less common than supratentorial but cerebellar masses also occur (figure 2.11).22 When no evidence of systemic sarcoidosis is found, differential diagnosis of pituitary lesions consists of pituitary adenoma and Iymphocytic adenohypophysitis. ${ }^{55}$ Because some physicians treat lymphocytic hypophysitis empirically based on MRI findings and overall diagnostic assessment, the need for biopsy is not clear.

Granulomatous cerebral angiitis also occurs in sarcoidosis. ${ }^{14,56}$ Ophthalmological screening can identify angiitis. Diffuse cerebral vasculopathy may cause psychosis, dementia, and epileptic seizures. ${ }^{38,57-61}$ Pseudotumour cerebri, caused by dural sinus thrombosis, has also been reported as a presenting symptom of neurosarcoidosis. ${ }^{62,63}$

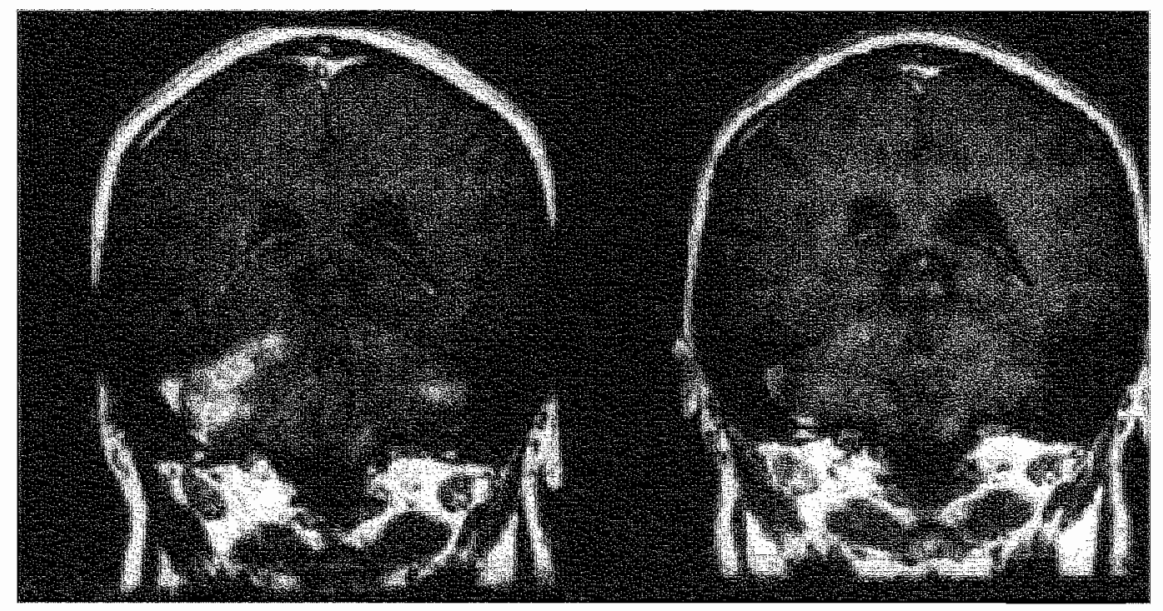

Figure 2.1 Left enhanced lesion in a middle aged. White male with multisystem sarcoidosis. A biopsy of the cerebelum showed noncaseating gramuloma. Right: resolution of the lesion after combined prednisione and thydroxychloroquine therapy. 


\section{Selzures}

Seizure may be the first consequence of neurosarcoidosis to appear. Any type of seizure may appear. In neurosarcoidosis seizures indicate chronicity and poor prognosis. $^{604}$

\section{Psychiatric symptoms}

Granulamatous infiltration of the central nervous system (CNS) may produce various mental symptoms. In a patient with multisystem sarcoidosis and unexplained mental deterioration, aggressive assessment of the CNS is indicated. Symptoms may respond

to corticoid therapy ${ }^{38.60}$ A subset of patients with sarcoidosis present with mild amnesic problems, without objective deterioration or neurological deficit. This might be related to fatigue. However, further study with neuropsychological testing is needed to explore this mypothesis.

\section{Spinal sarcoidosis}

Spinal sarcoidosis encompasses a range of intraspinal diseases, including arachnoiditis, extradural and intradural extramedullary lesions, and intramedullary lesions. 1,65,66 Intramedullary spinal involvement is one of the rarest neurological manifestations of the disease (figure 2.2). Granulomas are commonly clinically and radiologically indistinguishable from a malignant tumour of the spinal cord. ${ }^{67,68}$ Patients may present with transverse myelopathy with paraparesis or tetraparesis, ${ }^{65.69 .71}$ autonomic dysreflexia, ${ }^{72}$ radicular syndrome, ${ }^{65}$ and cauda equina syndrome. ${ }^{73-78}$

\section{Peripheral neuropathy}

Peripheral neuropathy is thought to be rare in sarcoidosis. ${ }^{79} .80$ The pattern of large fiber neuropathy reported in sarcoidosis includes multiple mono-neuropathies, polyradiculopathy. Guillain-Barré syndrome, and symmetric distal polyneuropathy, which may be sensorimotor, mostly sensory, or mostly motor. ${ }^{14,0-92}$ Epineural and perineural granulomas and granulomatous vasculitis can cause ischaemic axonal degeneration and demyelination owing to local pressure. ${ }^{79.34}$ Nerve biopsy may be helpful in the diagnosis of problems. In most patients the clinical course of sarcoid neuropathy is subacute ${ }^{83}$ and many patients seem to respond to corticosteroid therapy. ${ }^{\text {"7 }}$

\section{Small fiber neuropathy}

Small fiber neuropathy has been found in sarcoidosis ${ }^{93,94}$ and seems to be quite common. ${ }^{94}$ However, as standard nerve conduction tests measure only large-nerve fiber 
function, and because quantitative techniques for the assessment of small neve fibers are not routinely applied, the diagnosis of small fiber neuropathy can easily be missed. If the neuropathy is unrecognised, the symptoms may be enigmas to both patient and doctor. Recognition of small fiber neuropathy is important as it may cause disabling symptoms. Small fiber neuropathy may also involve autonomic nerve fibers. Whether life-threatening symptoms, such as cardiac arrhythmias, occur in sarcoidosis when cardiac autonomic denervation is involved needs further study. Small fiber neuropathy may also cause restless legs syndrome, ${ }^{95}$ which, like periodic leg-movement disorder, is associated with, and related to, sleep disturbances. Periodic leg-movement disorder and restlesslegs syndrome have been found in patients with sarcoidosis. ${ }^{96}$ The pathophysiology and treatment of small fiber neuropathy in sarcoidosis are unknown and need further study.
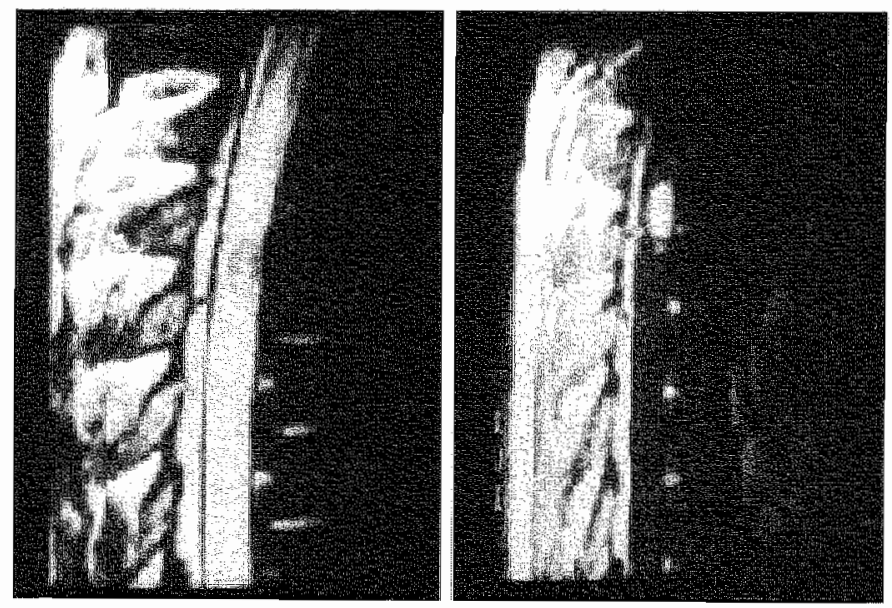

Figure 22 Left: unenhanced spinal cord lesion in a patient with sarcoidosis who developed marked weakness of the lower extrenities. Right: gadolinium-enhanced mage. The patient resporded to conicostercid treatment.

\section{Skeletal muscle involvement}

Muscle involvement may be symptomatic or asymptomatic. ${ }^{97.98}$ Asymptomatic granulow matous muscle involvement in sarcoidosis has been reported with a prevalence of $50-80 \%$ whereas symptomatic muscle involvement is much less common $(1.4-2.3 \%)^{100}$ Most patients present with pain, weakness, and tenderness of the 
involved muscles, and muscle atrophy; some have muscle cramps and contractures. ${ }^{100}$ Symptomatic involvement may be divided into the following types: a palpable nodular type, which is seen less frequently; an acute myositis, which is rare and seen more commonly in women; and a chronic myopathic type, which is more common, is slower in onset, and occurs later in life. ${ }^{98,100-102}$

Because most granulomatous infiltration is in connective tissue structures and necrosis of muscle fibers is uncommon, electromyography findings can be quite normal ${ }^{\text {gt }}$ However, electromyography can show myopathic changes. It may be difficult to distinguish myopathy caused by sarcoidosis from that caused by steroids, especially in chronic myopathy. In the first case steroids are indicated, whereas in the second case steroids should be tapered. Steroid myopathy is mostly seen in fluorinated corticosteroids (dexamethasone, triamcinolone, betamethasone; table 2.1). Muscle biopsy is most helpful here. In sarcoid myopathy lesions take the form of granulomata in connective tissue, particularly in a perivascular distribution. The lesions are quite focal and serial sections increase the chances of establishing diagnosis. ${ }^{93}$ In steroid myopathy typically type-2 fiber atrophy is found.

Table 2.1 Differences belween myopathy caused by sarcoidosis and myopathy caused by steroids

\begin{tabular}{|c|c|c|}
\hline Feature & Steroid-induced myopathy & Sarcoid myopathy \\
\hline Clinical features & Myalgia, proximal weakness, especially legs & $\begin{array}{l}\text { Myalgia; weakmess: proximals distal, } \\
\text { Sometimes palpable nodiules, contractures } \\
\text { or cramp }\end{array}$ \\
\hline $\mathrm{CK}$ & Mosilly normal & Sometimes hight \\
\hline Frequency & $2-24 \%$ in all patients receiving steroids & $\begin{array}{l}50 \% \text { of patients have granuldomas in their } \\
\text { muscles, which are commondy } \\
\text { asymptomatic }\end{array}$ \\
\hline EMG & Low armplitude MUPs of short duration & $\begin{array}{l}\text { Fibrillations and positive sharp waveg } \\
\text { Low ampituda MuPs of shart duration }\end{array}$ \\
\hline Biopsy & Type-2 fber atrophy & Myositis, nodular myositts \\
\hline
\end{tabular}

$C K=$ oreatin kinase; $E M G=$ glectromyography: MUP=motor hinit poterntial

\section{Diagnosis}

Nearly every neurological symptom could be caused by neurosarcoidosis. However, as the disease is rare, most physicians have little experience with it. The diagnosis of neurosarcoidosis requires a compatible clinical or radiological picture of sarcoidosis and histological confirmation of noncaseating granulomas. ${ }^{103,104}$ One can distinguish definite, probable, and possible neurosarcoidosis (table 2.2). ${ }^{105}$

Three different situations of patients presenting with neurological symptoms can be distinguished: a patient with histologilcally confirmed active systemic sarcoidosis; a 
patient with a history of sarcoidosis but with no evidence of disease activity; and a patient not known with sarcoidosis. In the first situation, neurological symptoms are most likely due to the confirmed systemic sarcoidosis and one is justified in starting therapy (figure 2.3).

Table 22 Criteria for the diagnosis of neurosarcoidosis, according to Zajieck at at. ${ }^{\text {res }}$

\begin{tabular}{|c|c|}
\hline \multirow[t]{3}{*}{ Definite } & Clinical presentation compatible with neurosarcoidosis \\
\hline & Exclusion of other possible causes \\
\hline & Positive nervous system histology \\
\hline \multirow[t]{4}{*}{ Probable } & Climical presentation compatible with neurosarcoidosis \\
\hline & Laboratory support of central nervous system inflammation \\
\hline & Exclusion of other possible causes \\
\hline & Evidence of systemic sarcoidosis \\
\hline \multirow[t]{2}{*}{ Possible } & Clinical presentation compatible with meurosarcoidosis \\
\hline & Exclusion of other possible causes \\
\hline
\end{tabular}

* High concentrations of cerebrospinal fuid (CSF) protein and high numbers of cells "the presence of oligoclonal bands, or magnetic nesonance imaging (MFl) evidence compatible with neurosarcoidosis

* Positive thistology or at least two indirect indicators from gallium scan, chest imaging, and serum angiotensin converting enzyme. Reproduced with permission from Oxford University Press. ${ }^{105}$

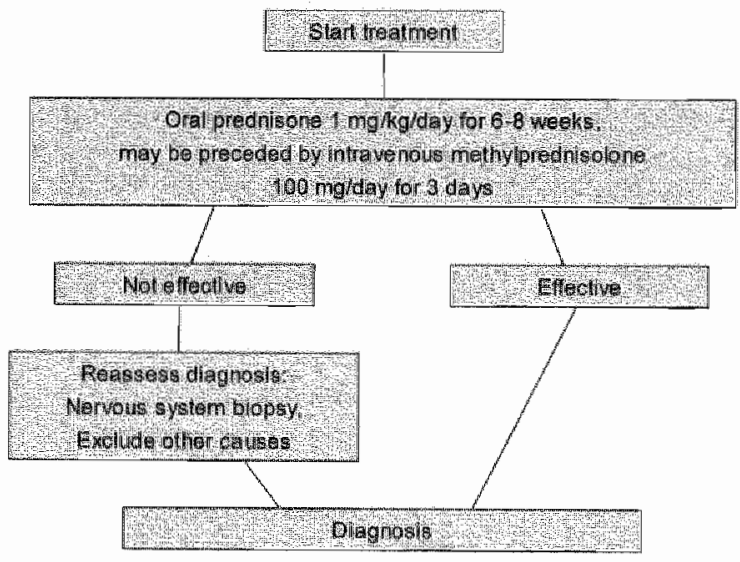

Figure 2.3 Diagnastic flow chart for patients with active systemic sarcoidosis and presentation of neurological symptoms. 
However, when treatment fails in these cases, diagnosis should be reassessed, other causes should be excluded and an attempt should be made to obtain biopsy at the appropriate site. In patients with a history of sarcoidosis who present with neurological symptoms, neurosarcoidosis will be considered early in the differential diagnosis. On the other hand, in the third situation neurosarcoidosis will rarely be considered at an early stage. Thus, neurosarcoidosis remains one of the more challenging diagnostic problems. ${ }^{106,107}$ The diagnostic approach in the second and third situation should be the same (figure 2.4). In cases with previous sarcoidosis new evidence of active sarcoidosis should be assessed, other causes need to be excluded and an effort should be made to obtain biopsy before treatment is started. ${ }^{104}$ Whole-body gallium scanning ${ }^{100} 100$ or fluorodeoxyglucose-PETscanning ${ }^{410}$ can be used to find other suitable sites for biopsy. The importance of histological verification in patients with previous sarcoidosis will be underlined in case reports 1 and 2 . The important lesson from the case reports is that a history of sarcoidosis does not necessarily mean that any new problem of the patient is automatically attributable to sarcoidosis. In our opinion the approach in such a patient should be the same as in a patient without a history of sarcoidosis (figure 2.4). While excluding other causes, the differential diagnosis of sarcoidosis should be taken into account (table 2.3). If no evidence of systemic sarcoidosis is found but a CNS biopsy reveals a sarcoid-like granulomatous reaction, one should be aware of the distinction between systemic neurosarcoidosis and a local (neurological) sarcoid-like reaction, particularly related to an old scar ${ }^{111}$ or a helminthic reaction (table 2.4). ${ }^{16.112}$

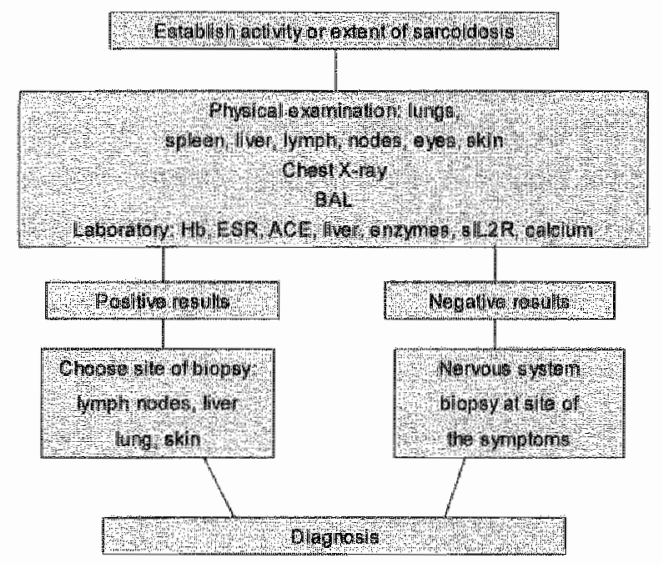

Figure 24 Diagnostic flow chart for patients with neurological symptoms with and without a history of sarcoidosis but without signs of actwe disease. BAL. = bronchoalweolar lawage; $H B=$ Haemoglobin; ESF = erythrocyte sadimentation rate; $\mathrm{ACE}=$ angiotensin conwerting enzyme; $s \mathrm{~L} 2 \mathrm{R}=$ solluble interleukin-2 receptor. 
Table 2.3 Differential diagnosis of neurosarcoidosis.

Infectious diserases

Granulomatous distases

Tumors

Vasculopathles

Systemic dilseases:

Lymphocytic adenohypophysitis

Neurological diseases

\author{
Leprosiy \\ Tubarculosïs \\ Whipple's disease \\ Toxoplasmosis \\ Nycos: \\ Helminithic infections \\ Treponemal infections \\ Lyme disease
}

Wegener"s granulomatosís

ChurgStrauss syndrome

Lymphomatoid granulomatosis

Neurolymphomas

Gliomas

Meringeomas

(leptomeningeal) metastases

Vascullits

Behcet s disease

Amyloidosis

Mutiple sclerosis

Acute demyelinating encephalomyelitis

Table 24 Differences between a non-specific local cerebral sarcoid-like granulomatous reaction and multisystem sarcoidosis

\begin{tabular}{|c|c|c|}
\hline Features & Local cerebral sarcoid reaction & Multisystem sarcoidosis \\
\hline Multiple organs involved & No, usually ore & Yes \\
\hline Age, years & Any & $20-50$ \\
\hline Chest rachograph & Wormat & Abnormas in $90 \%$ \\
\hline Delayed hypersensitivity & Normal & Depressied \\
\hline Elevaled serum ACE & «5\% & $360 \%$ \\
\hline BAL Iymphocytosis & Absent & Present \\
\hline Slit lamp exarnination & Normal & Pasitive $15-20 \%$ \\
\hline Hypercaloema & Absent & Present in $13 \%$ \\
\hline Gallitum body scam & Localizad uptake & Multisystem uptake \\
\hline
\end{tabular}

BAll =bronchoalveolar lavage; $A C E=$ angiotensin converting anzyme

\section{$\operatorname{coser}$}

A 55-year-old male with cough and fatigue had pulmonary sarcoidosis. His clinical presentation justified a wait-and-see policy and his symptoms gradually disappeared. After he had been asymptomatic for 8 months, he presented at the neurology depart- 
ment with headaches, diplopia, dysarthria, a painful right leg, and weakness of the right leg. Physical examination revealed $L 5$ radicular syndrome on the right leg, abducens paresis of the left eye, tongue paresis on the left side, facial paresis on the left side and dysarthria. No signs of active sarcoidosis were found. Chest radiograph showed no abnormalities and serum angiotensin converting enzyme (ACE) was within normal limits. Gadolinium enhanced MRI showed multifocal leptomeningeal lesions (a focal enhancing lesiom intradurally at the level of the fifth root intractanial enhancing lesions located ventrally of the medulla oblongata on the left side, at the left cerebellopontine angle, and lleft parasellar region). As the patient had a history of sarcoidosis and the clinical picture and imaging studies were compatible, he was thought to have neurosarcoidosis. Corticosteroid treatment was started. However, symptoms were progressive despite adequate dosage ( $1 \mathrm{mg} / \mathrm{kg}$ ). The patient was referred to our clinic for a second opinion. Biopsy samples of the fifth lumbar root lesion were taken and revealed metastasis of anaplastic seminoma.

Case 2

A 40-year-old male had hilar adenopathy and pulmonary infiltrate on a routine chest radiograph. Mediastinal-lymph-node biopsy samples showed noncaseating granulomas consistent with the diagnosis of sarcoidosis. He was treated with prednisone for 3 years. He remained asymptomatic for aimost 20 years. Then the patient developed multiple neurological symptoms including poor memory, inability to concentrate, tremors, insomnia, loss of balance, transient paraesthesias, and skin sensitivity. However, the patient had no fever, welight loss, anorexia, night sweats, chest pain, dyspnoea or cutaneous lesions. Because of his past history of sarcoidosis, the diagnosis of neurosarcoidosis was suspected. CSF sampling showed normal opening pressure and

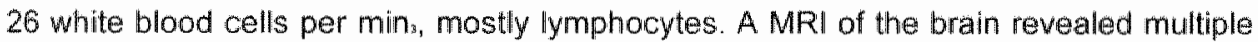
foci of abnormal enhancement with associated whitematter oedema in both cerebral hemispheres. There was a large enhancing lesion near the posterior horn of the left lateral ventricle. These lesions were consistent with intraparenchymal neurosarcoidosis. Intravenous methylprednisolone was given and the patient was put on prednisone $90 \mathrm{mg} / \mathrm{day}$. Over the next few days, his condition improved somewhat: he was able to do a few routine activities and his ataxia also improved. His prednisone was then gradually tapered to $40 \mathrm{mg} /$ day. At this point his symptoms reappeared. Methotrexate was added, but the patient continued to deteriorate. Cyclophosphamide was tried without any success. A brain biopsy sample was taken that showed B-cell lymphoma. 


\section{Systemic sarcoidosis and its diagnosis}

A patient's clinical presentation may be suggestive of systemic sarcoidosis (e.g., the presence of fatigue, weight loss, fever and the presence of features of sarcoidosis an chest radiography). Intrathoracic involvement is found in up to $90 \%$ of patients. Chest radiograph abnomalities can vary from sole bilateral hilar lymphadenopathy to extensive parenchymal disease and fibrosis. In general, chest radiographic appearances have been divided into five stages or types according to the modified Scadding criteria: stage 0 , no lung involvement; stage , bilateral hilar enlargement alone; stage II, hilar enlargement in association with interstitial lung disease; stage III, interstitial lung disease alone: and stage $V_{\text {: }}$ (a more recent addition to the original classification) requires radiographic evidence of lung fibrosis. ${ }^{113}$

There are no definite diagnostic blood "skin "or radiological imaging tests specific for the disorder. Serum concentrations of ACE have poor predictive value in sarcoidosis. ${ }^{114}$ Sensitivity of an increase in serum concentrations of ACE in neurosarcoidosis varies from $24 \%$ to $76 \%{ }^{103}$ Serum interleukin-2-receptor $(I L 2 R)$ is better than the more commonly used ACE for the monitoring of disease activity. ${ }^{114,115}$ Despite these limitations, serum concentration of $A C E$ is still the only serological marker recommended by the World Association of Sarcoidosis and Other Granulomatous Disorders (WASOG) in sarcoidosis. ${ }^{18}$ Analyses of fluid and cells retrieved by bronchoalveolar lavage have improved our understanding of the immunopathogenesis of sarcoidosis, but none of these findings are specific for sarcoidosis, including the CD4/CD8 lymphocyte ratio. ${ }^{19}$ The Kveim-Silzbach skin test, in which spleen or lymph node homogenate from a patient with sarcoidosis is injected intradermally and later a biopsy sample is taken, is not widely available, not well standardised, and not approved for general use by the Food and Drug Administration.

According to the latest recommendations as published by Baughman and colleagues, 116 diagnosis of sarcoidosis can be established by means of the following criteria: (1) the presence of granulomas in biopsy specimen without evidence of tuberculosis, fungus, malignancy, or other causes of granuloma, together with clinical features of sarcoidosis, support the diagnosis; (2) in the absence of biopsy material, clinical features such as bilateral hillar adenopathy on chest radiograph, erythema nodosum, uveitis, and macular papular skin lesions are suggestive of sarcoldosis. If there is no evidence of an alternative diagnosis and additional features highly suggestive of sarcoidosis are present, such as raised concentration of ACE, bronchoalveolar lavage fluid lymphocytosis. or lupus pernio, the diagnosis can also be confirmed. ${ }^{116}$ 


\section{Neuroimaging}

Neuroimaging studies, especially MRI, are the most sensitive diagnostic tools for the detection and localisation of neurological lesions. However, they are not specific as their appearences on radiography are highly variabale. ${ }^{117}$

\section{CSF analysis}

CSF abnormalities in meurosarcoidosis are usually nonspecific and include mild pleocytosis, high protein content, and, sometimes, slightly low glucose concentrations. Furthermore, increases in the concentration of ACE; ${ }^{18-124}$ igG-index, ${ }^{125-12 \%}$ oligoclonal bands, $^{9,125,126}$ CD4/CD8 Hymphocyte ratios, ${ }^{128}$ and lysosyme and p2-microglobulin concentrations $^{129}$ in CSF have been reported. About a third of patients with neurosarcoidosis have normal CSF. ${ }^{11,21,103}$ Moreover, in disorders such as multiple sclerosis and systemic lupus erythematosus similar CSF abnormalities may be found.

The concentration of ACE in the CSF seems to be high in more than thalf of the patients with neurrosarcoidosis. ${ }^{119}$ It must be emphasised, however, that high concentrations are not specific to neurosarcoidosis and have also been reported in CNS infections and malignant tumours. ${ }^{10,124}$ Several studies found significantly high concentrations of ACE in CSF in patients with active neurosarcoidosis compared with those in controls and patients with sarcoidosis without nervous-system involvement. ${ }^{118-124}$ Furthermore, serial measurements of the concentration of ACE in the CSF change with disease activity. ${ }^{122,123,130}$ However, neither was there relation found between serum and CSF concentrations of ACE in patients with neurosarcoidosis, nor was there any relation between serum concentrations and the clinical picture and CSF-total protein or CSF-albumin (increase of albumin concentration in the CSF is an indicator of function ing of the blood-brain barrier). Thus, ACE in the CSF is most probably synthesised in the nervous system and released by sarcoid granulomas in the CNS. In conclusion, determination of ACE concentration in the CSF is not specific for neurosarcoidosis but seems to be especially useful in the monitoring of disease activity and treatment response.

\section{Neurophysiological studies}

EEG may detect an early stage of acute encephalomeningitis and epileptic discharges caused by the neurosarcoidosis. Visual evoked potentials, brainstern evoked potentials and trigeminofacial reflexes can be useful in the detection of cranial neuropathy.

Electromyography (EMG) and nerve-conduction studies can show large fiber neuropathy and myopathy. whereas temperature threshold testing or skin biopsy are needed to assess small fiber neuropathy. The latter techniques are not yet routinely available. 
Assessment of autonomic dysfunction, which may be present in small fiber neuropathy, requires special equipment, such as quantitative sudomotor axon reflex festing. Cardiovascular autonomic function testing with the Ewing tests have a low sensitivity for autonomic dysfunction in small fiber neuropathy. ${ }^{4}, 131$ Testing of the sympathetic skin response is widely available but seems to be neither specific nor sensitive. ${ }^{94,132}$ Polysomnography with EMG monitoring can be helpful in revealing periodic leg movement disorder and sleep disturbances.

\section{Therapy}

\section{Drug therapy}

Given the morbidity and mortality of neurosarcoidosis, most authors recommend early treatment. However, clear guidelines and indications as well as prospective controlled studies are not available in neurosarcoidosis and prospective multicenter studies are needed. As a result, recommendations about treatment are based on experience rather than evidence.

Therapeutic medical options (figure 2.5) for neurosarcoidosis are similar to that in sarcoidosis at other locations and corticosteroids represent the drugs of first choice. ${ }^{133}$ Doses in neurosarcoidosis are higher than those advised for the treatment of other localisations of sarcoidosis, including pulmonary. In general, the initial recommended dose is $40 \mathrm{mg}$ daily, whereas in neurosarcoidosis an initial dose of $1 \mathrm{mg} / \mathrm{kg} / \mathrm{dlay}$ is typically recommended. In severe cases high doses of intravenous methylprednisolone may be used for a few days to obtain a high initial loading dose. Some may use bolus pulsed methylprednisolone once a week, eventually along with daily low doses of oral prednisone, or alternate day treatment to awoid the side-effects associated with long term, high-dose oral treatment. ${ }^{105}$ However, at present there is not enough evidence to recommend this. Although corticosteroids suppress inflammation in many patients, symptoms tend to recur in a subset of patients at doses of prednisone less than $10-25 \mathrm{mg} / \mathrm{day}$ or the equivalent in other corticoid types, making cessation of corticoids difficult. Furthermore, the incidence of steroid-related side-effects is extremely high with such long treatment. 


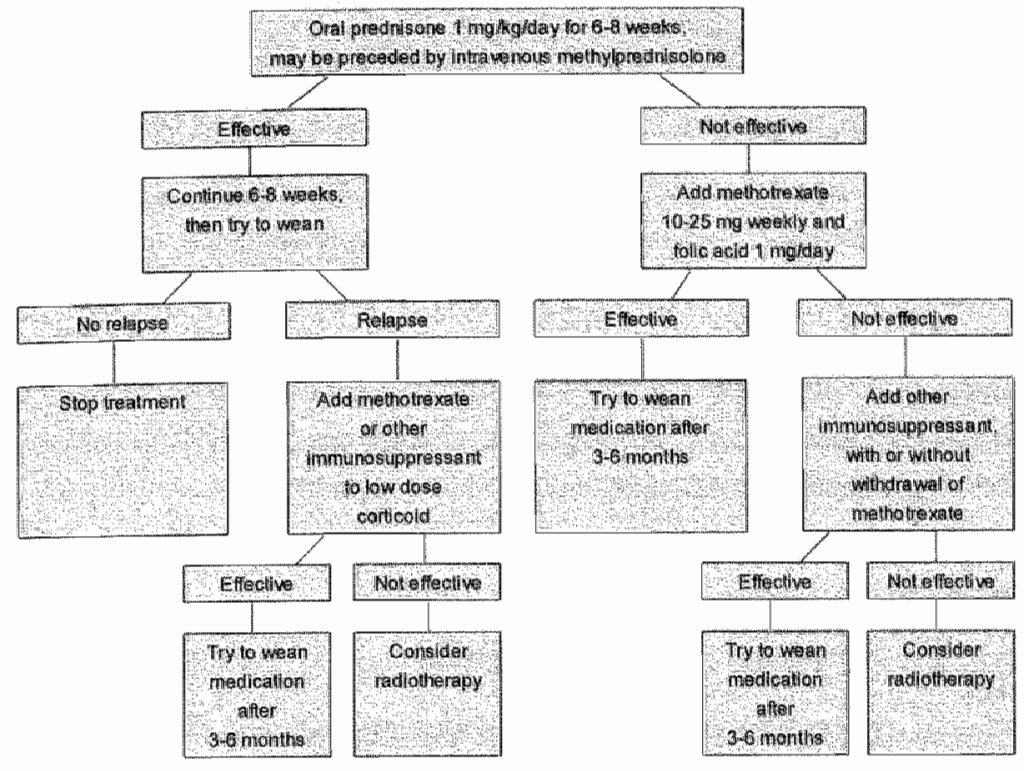

Figure 2.5 Therapeutic flow-chart for patients diagnosed with neurosarcoidosis."

* Recommendations are based on experience rather than ewidence.

In patients where corticasteroids may be contraindicated, cytotoxic drugs, such as methotrexate, azathioprine, ciclosporin, and cyclophosphamide, have been used. $^{105,134137}$ The choice for one or the other is more a matter of experience than of double-blind studies. On the basis of safety and efficacy, methotrexate and azathioprine may be preferred. Methotrexate has been the most widely reported drug for sarcoidosis and its use for sarcoidosis has been reviewed. ${ }^{13}$ It seems to be well tolerated and associated with minimall toxic effects. The major problem is liver toxicity for which regular blood tests are needed. Response rate of methotrexate in neurosarcoidosis is about $60 \%$, which is simillar to that in chronic sarcoidosis. ${ }^{136}$ Azathioprine is useful in chronic sarcoidosis, although others have been disappointed in its efficacy in patients with refractory sarcoidosis. ${ }^{139}$ Treatment with ciclosporin has also resulted in variable outcomes. $^{138}$ About $75 \%$ of neurosiarcoidosis patients respond to ciclosporin. ${ }^{134.135}$ Response rates of intravenously given cyclophosphamide seems to be about $60-80 \%$ in patients with corticosteroid resistant neurosarcoidlosis. ${ }^{136,13.7}$ A short course pulsed regimen seemed to minimise cumulative toxicity. ${ }^{137}$ The role of newer immunosuppres. sive drugs, such as mycophenolate mofetil, is unknown.

Drugs that change the immune system or block cytakine effect, have also been used for the treatment of patients with sarcoidosis. The antimalarial drugs chloroquine and hydroxychloroquine are usefull in the treatment of some patients with neurological 
sarcoidosis. ${ }^{140}$ Tumour necrosis factor $a$ is released at high concentrations by alveolar macrophages from patients with active sarcoidosis and the concentrations go down with corticosteroid or methotrexate therapy. ${ }^{38}$ These observations have led to studies of substances that suppress iumour-necrosis-factor release or block its effect on the cell. Immunomodulators known to suppress the release of tumour necrosis factor are thalidomide and infliximab. Infliximab has been shown effective in few cases with refractory sarcoidosis. In refractory neurosarcoidosis it may also be effective. ${ }^{141}$ The toxicity of treatment for up to 1 year is low. However, the effect of long-term treatment is still unknown. ${ }^{130}$ An important complication associated with infliximab has been the increased rate of tuberculosis. ${ }^{142}$ Side-effects and experience with certain drugs may play a part in drug choice (table 2.5).

Table 2.5 Treatment of neurosarcoidosis

\begin{tabular}{|c|c|c|c|}
\hline Modication & Starting dose & Side effects" & Remarks \\
\hline \multicolumn{4}{|l|}{ Corlicasterolds } \\
\hline Prednison & if mg/kg/day orally & $\begin{array}{l}\text { Osteoporosis, cushing } \\
\text { syndrome, hypertension, } \\
\text { dilabetes mellitus, ulcus } \\
\text { pepticum, psethotumour } \\
\text { cerebri, glaucoma, cataract, } \\
\text { euphoria, psychosis }\end{array}$ & \\
\hline Methylprednisolon & $\begin{array}{l}1000 \text { mglday for } 3 \text { days. } \\
\text { intravenous }\end{array}$ & Very rare & \\
\hline \multicolumn{4}{|l|}{ Cytotoxic agents ${ }^{\text {i* }}$} \\
\hline Methotrexate & $\begin{array}{l}10-25 \text { mglonce weekly orally } \\
\text { or subcutaneously }\end{array}$ & $\begin{array}{l}\text { Anemia, neutropenia, hepatic } \\
\text { dysfumction, pneumonitis }\end{array}$ & $\begin{array}{l}\text { Should be combined with } \\
\text { folic acid ( } 1 \text { mg/day orally) }\end{array}$ \\
\hline Cyclosporine & $\begin{array}{l}5 \mathrm{mg} / \mathrm{kg} / \mathrm{d} \text { aly, divided in } 2 \\
\text { doses orally }\end{array}$ & $\begin{array}{l}\text { Renal insufficiency } \\
\text { hwoerternsion }\end{array}$ & Expensive \\
\hline Azathloptin & 50 mg three thmes dally orally & $\begin{array}{l}\text { Anemia, neutropenia, } \\
\text { dysfunction }\end{array}$ & Cheapi \\
\hline Oyclophosphamide & $\begin{array}{l}50-200 \text { dally oratly } \\
500 \mathrm{mg} \text { arice every } 2-3 \\
\text { weeks, intrawenous }\end{array}$ & Cystitis, naultropenia: & $\begin{array}{l}\text { Monthy urinanalysis to } \\
\text { monitor for microsicopic } \\
\text { hemeluria }\end{array}$ \\
\hline \multicolumn{4}{|l|}{ Immunomodulators** } \\
\hline Hydroxychloroquilne & $200 \mathrm{mg} / \mathrm{deay}$ orally & $\begin{array}{l}\text { Retinopathy, otoloxic } \\
\text { myopathy, cardiomyopathy. } \\
\text { neuropathy, neuropsychiatric }\end{array}$ & $\begin{array}{l}\text { Routine eye examinations } \\
\text { every } 3 \times 6 \text { months }\end{array}$ \\
\hline Inthximab & $\begin{array}{l}3 \text { mglkg once in week } 1 \text {, } \\
\text { week } 3 \text {, and weelk } 5 \text {, than } \\
\text { once every } 6 \text { weeks, } \\
\text { intravenous }\end{array}$ & $\begin{array}{l}\text { Fever, headache, dizziness, } \\
\text { fushes, nausea, abdominal } \\
\text { pain, dyspepsia, fatigue. } \\
\text { myalgia, arthraligia, } \\
\text { polyneuropathy }\end{array}$ & $\begin{array}{l}\text { Tuberculosis screening is } \\
\text { indicated before treatment } \\
\text { is started } \\
\text { Contra-indicated in patients } \\
\text { with heart failure } \\
\text { Should be combined with } \\
\text { methotrexate }\end{array}$ \\
\hline
\end{tabular}

\footnotetext{
"All can cause infection because of immunosuppression: these drugs are generally used as adjuncts to low dose steroids, or as sterold sparing agents when long-term treatment is necessary. In reffractory patients, these drugs may be used in combination with highmodiose steroids.
} 


\section{Radiation}

There are several reports on radiation therapy in refractory neurosarcoidosis. ${ }^{143-146}$ Although ewidenced based recommendations cannot be provided, radiation therapy may be given in patients who do not respond to drug therapy.

\section{Neurosurgical treatment}

Neurosurgical resection of intracranial and spinal granutomas is only indicated in lifethreatening situations or when medical treatment is insufficient. However, extramedullary spinal lesions may be amenable to surgical resection with postoperative steroid therapy. ${ }^{147}$ Hydrocephalus typically needs ventriculo-peritoneal shunting. ${ }^{148,148}$

\section{Conclusions}

Neurosarcoidosis is a rare disease with many presentations. Although sporadic reports of small numbers of patients with neurosarcoidosis are published, little progress has been made in defining this condition in detail. Therefore, most clinicians are not confident in its diagnosis or treatment. There is a need for a multinational prospective study in order to develop diagnostic and therapeutic standards to bring this severe illiness under control. 


\section{References}

1. Stem BJ, Krumholz $A_{1}$ Johns $C$, Scott $P$, Nissim J Sarcoidosis and its neurological manifestations. Arch Neurol 1985;42:909-17.

2. James DG, Sharma OP. Neurosarcoidosis. Proc R Soc Med 1967;60:1169-70.

3. Sharma OP. Sharma AM. Sarcoidosis of the nervous system. A clinical approach. Arch Interm Med 1991:151:1317-21.

4. Manz HJ. Pathobiology of neurosarcoidosis and clinicopathologic correlation. Can J Neurol Scr 1983;10:50-5.

5. Wai $K_{0}$ Tachibania $T$, Takemura $T$, Matsui $Y$, Kitaichi M, Kawabata $Y$. Pathological studies on sarcoidosis autopsy. I. Epidemiological features of 320 cases in Japan. Acta Pathol Jpn $1993 ; 43: 372-6$

6. Burns TM. Neurosarcoidosis. Arch Neurol 2003;60:1166-8.

7. Minagar A, Hardjasudarma M, Kelley RE. Neurosarcoidosis. Neurology 2002;59:477.

B. Oksanen V. Neurosarcoidosis. Sarcoidosis 1994:11:76-9.

9. Scott TF. Neurosarcoidosis: progress and clinical aspects. Neurology 1993:43:8-12.

10. Chan Seem CP. Spokes EG. Neurosarcoidosis. Lancot 1985:2:1363.

11. Sharma OP. Neurosarcoidosis. Chest 1991;100:301-2.

12. Strefling AM, Summerville JW, Urich $H$. Involvement of choroid plexuses in neurosarcoidosis. Acta Neuropathol (Bent) 1987;74:402-4.

13. Kidd D, Beymon HL. The neurological complications of systemic sarcoidosis. Sarcoidosis Vasc Diffuse Lung Dis 2003;20:85-94

14. Oksanen $V$. Neurosarcoidosis: clinical presentations and course in 50 patients. Acta Nourol Scand 1986; $73: 283-90$

15. Pentland B, Mitchell JD, Cull RE, Ford MJ. Central nervous system sarcoidosis. $Q J$ Med $1985 ; 56: 457-65$

16. Sharma OP, Lamb $C$. Cancer in interstitial pulmonary fibrosis and sarcoidosis. Curr Opin Pulm Med 2003,9:398-401.

17. Allen RK, Sellars RE, Sandstrom PA. A prospective study of 32 patients with neurosarcaidosis. Sarcoidosis Vasc Diffuse Lung Dis 2003;20:118-25.

18. Hunninghake GW, Costabel $U$, Ando $M_{\text {s }}$ Baughman RP, Cordier $J F$, du Bois $R M$, Eklund $A$, Kitaichi $M$, Lynch $J$, Rizzato $G$, Rose $C$, Selroos $O$, Semenzato $G$, Sharma OP. ATS/ERS/WASOG statement on sarcoidosis. American Thoracic Society/European Respiratory Society/World Association of Sarcoidosis and other Granulomatous Disorders. Sarcoidosis Vasc Diffuse Lung Dis 1999;16:149.73.

19. Newman LS, Rose CS. Maier LA. Sarcoidosis. N Engl J Med 1997;336:1224-34.

20. Collover J. Sarcoidosis with involvement of the nervous system. Brain 1948;71:451-75.

21. Dellaney P. Neurologic manifestations in sarcoidosis: review of the literature, with a report of 23 cases. Ann Intern Med 1977;87:336-45

22. Sharma OP. Cardiac and neurologic dysfunction in sarcoidosis. Sarcoidosis 1997,18:813-25

23. Blain JG. Riley $W$, Logothetis J. Optic nerve manifestations of sarcoidosis. Arch Neurol $1965 ; 13: 307-9$

24. Wachtel AS, Saunders M. Optic nerve sarcoidosis. Mayo Clin Proc 1997;72:791.

25. Graham EM, Ellis CJ, Sanders MD. McDonald WI. Optic neuropathy in sarcoidosis. I Neurol Neurosung Psychiatry 1986:49:756-63.

26. Gelwan MJ, Kellen RI, Burde RM, Kupersmith MJ. Sarcoidosis of the anterior visual pathway: successes and tailures. I Neurol Neurosurg Psychiaty 1988:51:1473-80.

27. Bandyopadhyay T, Das D, Das SK, Ghosh A. A case of neurosarcoidosis presenting with multiple cranial nenve palsy. I Assoc Physicians India 2003;51:328-9.

28. Palacios $\mathbb{E}$, Rigby PL. Smith DL. Cranial neuropathy in neurosarcoidosis. Ear Nose Throat $J$ $2003 ; 82: 251-2$.

29. De Broff $B$, Donahue $S$. Bilateral optic neuropathy as the initial manifestation of systemic sarcoidosis. Am J Ophthawnol 1993;116:108-11. 
30. James DG, Zatouroff MA. Trowell $\jmath_{1}$ Rose FC. Papilledema in sarcoidosis. Br I Ophtalmol $1967: 51: 526-30$.

31. Karma A. Ocular sarcoidosis. Semin Respir Med 1992;131:425-31.

32. Westlake J. Heath JD. Spalton DJ. Sarcoidosis involving the optic nerve and hypothalamus. Arch Ophthalmol 1995,113:669-70.

33. Plotkin GR, Patel BR. Neurosarcoidosis presenting as chronic lymphocytic meningitis. Pa Med \#1986;89:36-7.

34. Powers WJ, Miller FM. Sarcoidosis mimicking glioma: Case report and review of of intracranial sarcoidosis like mass lesions. Newology 198, 31:907-10.

35. Mayer SA, Yim GK, Onesti ST, Lynch T, Faust PL, Marder K. Biopsy-proven isolated sarcoid meningitis. Case repont. J Neurosurg 1993;78:994-6.

36. Jensen $S$, Jensen IW. Bilateral papilledema with normal CT-scan in neurosarcoidosis. Acla Med Scand 1987:222:381-3.

37. Scott TF. Cerebral herniation after lumbar puncture in sarcoid meningitis. Clin Neurol Neurosurg 2000;102:26-8.

38. Willigers $H$, Koehler PJ. Amnesic syndrome caused by neurosarcoidosis. Clin Nourol Neurosurg 1993;95:131-5.

39. Kumpe DA, Rao CV, Garcia JH, Heck AF. Untracranial neurosarcoidosis. J Comput Assist Tomogr 1979;3:324-30.

40. Cahill DW. Salcman M. Neurosarcoidosis: a review of the rarer manifestations. Surg Neurol $1981,15: 204-11$.

41. Akhondi H. Barochia S, Holmstrom B, Williams MJ. Hydrocephalus as a presenting manifestation of neurosarcoidosis. South Med J 2003:96:403-6.

42. Maniker AH, Cho ES, Schulder M. Neurosarcoid infiltration of the ventricular catheter causing shunt failure: a case report. Surg Nourol 1997;48:527-9.

43. Veres L. Utz JP. Houser OW. Sarcoldosis presenting as a central nervous syistem mass lesion. Chest 1997;111:518-21.

44. Nowak DA, Widenka DC. Neurosarcoidosis: a review of its intracranial manifestation. $J$ Neurol 2001:248:363-72.

45. Stubgen JP. Neurosarcoidosis presenting as a retroclival mass. Surg Neurol 1995:43:85-7.

46. Gizzi MS, Lidov M, Rosenbaum D. Neurosarcoidosis presenting as a lumour of the basal ganglia and brainstem: sequential MRI. Neurol Res 1993;15:93-6.

47. Randewa HS, Davison $R$. Chamoun V. Bouloux PM. Isolated neurosarcoidosis - a diagnostic enigma: case report and discussion. Endocrine 2002:17:241-7.

48. Murialdo $G$. Tamagno $G$. Endocrine aspects of neurosarcoidosis. I Endocrinol Invest $2002 ; 25: 650-62$.

49. Gleckman AM, Patalas ED, Joseph JT. Sudden unexpected death resulting from hypothalamic sarcoidosis. Am If Forensic Med Pathol 2002;23:48-51.

50. Tamagno $G$, Murialdo $G$. Amenorrhea-galactorhea syndrome as an uncommon manifestathion of isolated neurosarcoidosis. Ann ltal Med hot 2001:16:260-6.

51. Salo N. Sze G, Kim JHH. Cystic pituitary mass in neturosarcoidosis. Am I Neuroradiol $1997 ; 18 ; 1182-5$.

52. Konrad D, Gartenmann $M$, Martin $E$, Schoenle EJ. Central diabetes insipidus as the first manifestation of neurosarcoidosis in a 10-year-old girl. Horm Res 2000;54:98-100.

53. Bullumann $C$, Faust $M$, Hoffmann $A$, Heppner $C$, Jockenhovel $F$, Muller-Wieland $D$, Krone $W$. Five cases with central diabetes insipidus and hypogonadism as first presentation of neurosarcoidosis. Eur J Endocrinol 2000; 142:365-72.

54. Guoth MS, Kim J, de Lotbiniere AC, Brines ML. Neurosarcoidosis presenting as hypopituitarism and a cystic pituitary mass. Am J Med Sci 1998;3\#5:220-4.

55. Ahmadi J, Meyers GS, Segall HD. Sharma OP, Hinton DR. Lymphocytic adenohypophysitis: contrast-enhanced MR imaging in five cases. Radiology 1995:195:30-4.

56. Urich $H$. Neurosarcoidosis or granulomatous angitis: a problem of definition. Mt Sinal J Med $1977: 44: 718-25$

57. Friedman $\mathrm{SH}$, Gould DJ. Neurosarcoidosis presenting as psychosis and dementia: a case report Int J Psychiatry Med 2002;32:401.3. 
58. Popli AP. Risperidone for the treatment of psychosis associated with neurosarcoidosis. I Clin Psychopharmacol 1997;17:132-3.

59. Bona JR. Fackler SM, Fendley MJ. Nemeroff CB. Neurosarcoidosis as a cause of refractory psychosis: a complicated case report. Am J Psychiatry $4998 ; 155: 1106-8$.

60. Sabaawi M, Gutierrez-Nunez J. Fragala MR. Neurosarcoidosis presenting as schizophrenform disorder Int J Psychiatry Med 1992;22:269-74.

61. Cuaplan L, Corbett J, Goodwin J, Thomas $C$, Shenker D, Schatz N. Neuro-ophthalmologic signs in the anguitic form of neurosarcoidosis. Neurology $1983: 33: 1130-5$.

62. Akova YA, Kansu T, Duman S. Pseudotumor cerebri secondary to dural sinus thrombosis in neurosarcoidosis. J Clin Neuroophthalmol 1993;13:188-9.

63. Redwood MD, Winer JB, Rossor $M$. Neurosarcoidosis presenting as benign intracranial hypertension. Eur Neurol 1990,30:282-3.

64. Krumholz A, Stern BJ. Stern EG. Clinical implications of seizures in neurosarcoidosis. Arch Newrol 1991;48:842-4.

65. Junger SS, Stern BJ, Levine SR, Sipos E, Marti-Masso JF. Intramedullary spinal sarcoidosis: clinical and magnetic resonance imaging characteristics. Neurology 1993:43:333-7.

66. Day AL. Sypert GW. Spinal cond sarcoidosis. Ann Neurol 1977;1:79-85.

67. Vinä FC. Rengachary S, Kupsky WJ. Spinal cord sarcoidosis: a diagnostic dilemma. Neurol Res 2001:23:347-52.

68. Rieger J. Hosten N. Spinal cord sarcoidosis. Neuroradiology 1994;36:627-8.

69. Sauter MK, Panitch HS, Kristt DA. Myelopathic neurosarcoidosis: diagnostic value of enthanced MRI. Neurology 1991;41:150-1.

70. Castellano-Sanchez AA. Extensive leptomeningeal and intraparenchymatous spinal cord neurosarcoidosis. South Med J 2000;93:815 7.

71. Hayat GR, Walton TP, Smith KR Jr, Martin DS, Manepalli AN. Solitary intramedullary neurosiarcoidosis: rolle of MRI in early detection. I Neuroimaging 2001:11:66-70.

72. Sakakibara $R$, Uchimaya $T$, Kuwubara $S$, Kawaguchi $N$, Nemoto I, Nakata $M$. Hattori $T$. Aulonomic dysreflexia due toneurogenic bladder dysfunction; an unusual presentation of spinal cord sarcoidosis. J Neurol Neurosurg Psychiatry 2001;71:819-20.

73. Prelog $K$, Blome $S$, Dennis $C$. Neurosarcoidosis of the conus medullaris and cauda equina. Australas Radiol 2003;47:295-7.

74. Shah JR, Lewis RA. Sarcoidosis of the cauda equina mimicking Guillain-Barre syndrome. I Nourol Sci 2003;208:113-7.

75. Abrey LE, Rosenblum MK, DeAngelis LM. Sarcoidosis of the cauda equina mimicking leptomeningeal malignancy. $J$ Nourooncol 1998;39:261-5.

76. Ku $A$, Lachmann $E_{1}$ Tunkel $R$, Nagler $W$. Neurosarcoidosis of the contus medullaris and caude equina presenting as paraparesis: case report and literature review. Paraplegia 1996;34: $116-20$

77. Verma KK, Forman AD, Fuller GN, Dimachkie MM, Vriesendorp FJ. Cauda equina syndrome as the isolated presentation of sarcoidosis. J Neurology 2000;247:573-4.

78. Fitzpatrick KJ, Chancellor MB, Rivas DA, Kumon H, Mandel S, Manon-Espaillat R. Urologic manifestation of spinal cord sarcoidosis. J Spinal Cord Med 1996;19:201-3.

79. Gainsborough N. Hall SM, Hughes RA, Leibowitz S. Sarcoid neuropathy. I Neurol $1991 ; 238: 177-80$.

80. Miller $R$, Sheron $\mathbb{N}$, Semple S. Sarcoidosis presenting with an acute Guillain-Barre syndrome. Postgrad Med J 1989;65:765-7.

81. Strickland-Marmol LB. Fessler RG, Rojiani AM. Necrotizing sarcoid granulomatosis mimicking an intracranial neoplasm: clinicopathologic features and review of the literature. Mod Pathol 2000;13:909-13.

82. On SJ. Sarcoid polyneuropathy: a histologically proved case. Ann Neurol 1980;7:178-81.

83. Said $G$, Lacroix $C$, Plante-Bordeneuve V, Le Page L, Pico $F$, Presles $O$. Senant J, Remy $P$, Rondepierre $P$, Mallecourt J. Nerve granulomas and vasculitis in sarcoid peripheral neuropathy: a clinicopathological study of 11 patients. Brain 2002;125:264-75. 
84. Nemni $R_{n}$ Galassi $G$, Cohen $M$, Hays AP, Gould $R$, Singh $N$, Bressman $S$, Gamboa ET. Symmetric sarcoid polyneuropathy: analysis of a sural nerve biopsy. Nowrology 1981:31:1217-23.

85. Vital C. Aubertin J, Ragnault JM, Amigues $H$, Mouton $L$, Bellance R. Sarcoidosis of the peripheral nerve: a histological and ultrastructural study of two cases. Acta Neuropathol $1982 ; 58: 111-4$.

86. Challenor $Y B$, Felton $C P, B r u s t ~ J C$. Peripheral nerve involvement in sarcoidosis: an electrodiagnostic study. J Neurol Neurosurg Psychiatry 1984:47:1219-22.

87. Galassi $G$, Gibertoni M, Mancini A, Nemni R, Volpi G, Merelli $E$, Vacca G. Sarcoidosis of the peripheral nerve: clinical electrophysiological and histological study of two cases. Eur Neurol 1984:23:459-65.

88. Elkin R, Willcox PA. Neurosarcoidosis. A report of 5 cases. S Afr Med J 1985;67:943-6.

89. Baron B, Goldberg AL, Rothfus WE, Sherman RL. CT features of sarcoid infiltration of a lumbosacral nerve root. J Comput Assist Tomogr 1989;13:364-5.

90. Matthews WB. sarcoid neuropathy. In: Dyck PJ, Thomas PK, Lambert EH, Bunge R, editors. Peripheral neuropathy. 2nd ed. Philadelphia: W.B. Saunders 1984:2018-26.

91. Scott TS, Brillman $J$, Gross JA. Sarcoidosis of the peripheral nervous system. Neurol Res 1993; 15:389-90.

92. Koffman B. Junck L, Elias SB, Feit HW, Levine SR. Polyradiculopathy in sarcoidosis. Muscle Nerve 1999;22:608-13

93. Hoitsma $E$, Marziniak $M$, Faber CG, Reulen JPH, Sommer C, De Baets M, Drent M. Small Fiber Neuropathy in Sarcoidosis. Lancet 2002,359:2085-6.

94. Hoitsma $E$, Drent M. Verstraete E, Faber CG. Troost J, Spaans F. Reulen JPH. Abnormal warm and cold sensation thresholds suggestive of small-fibre neuropathy in sarcoidosis. Clin Nourophysiol 2003:114:2326-33.

95. Polydefkis $M$, Allen RP, Hauer $P$, Earley $C J$, Griffin JW, McArthur JC. Subclinical sensory neuropathy in late-onset restless legs syndrome. Neurology 2000;55:1115-21.

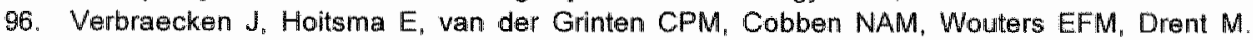
Sleep disturbance associated with periodic leg movements in chronic sarcoidosis. Sarcoidosis Vasc Diffuse Lung Dis 2004:21:137-46.

97. Alpert JN, Groff AE, Bastion FO. Blum MA. Acute polymyositis caused by sarcoidosis, report of a case and review of the literature. Mi Sinai J Med 1979;46:486-8.

98. Stjernberg $N$, Cajander $S$, Truedsson $H$, Uddenfeldt $P$. Muscle involvement in sarcoidosis. Acta Med Scand 1981;209:212-6.

99. Silverstein A, Siltzbach LE. Muscle involvement in sarcoidosis. Asymptomatic, myositis, and myopatthy. Arch Neurol 1969;21: 235-41.

100. Jamal MM. Cilursu AM. Hoffman EL. Sarcoldosis presenting as acute myositis. Report and review of the literature. I Rheumatol 1988;15:1868-71.

101. Nidiry JJ, Mines $S$, Hackney $R_{\text {v }}$ Nabhani H. Sarcoidosis: a unique presentation of dysphagia, myopathy, and photophobia. Am J Gastroenterol 1991;86:1679-82.

102. Fonseca GA, Baca S. Altman RD. Acute myositis and dermatitis as the initial presentation of sarcoidosis. Clin Exp Rheumatol 1993;11:553-6.

103. Lynch JP, 3rd. Neurosarcoidosis: how good are the diagnostic tests? I Nouroophthalmol $2003 ; 23: 187-9$.

104. Moore FG, Andermann F, Richardson d, Tampieri D, Giaccone $R$. The role of MRI and nerve root biopsy in the diagnosis of neurosarcoidosis. Can J Neurol Sci 2001;28:349-53.

105. Zajicek JP. Scolding NJ, Foster $O$, Rovaris M, Evanson J, Moseley IF, Scadding JW, Thompson EJ, Chamoun V. Miller DH, McDonald WI, Mitchell D. Central nervous system sarcoidosis--diagnosis and management. Qjm 1999:92:103-17.

106. Uchino M, Nagao T", Harada N. Shibata I, Hamatani S, Mutou H. Neurosarcoidosis without systemic sarcoidosis - case report. Neurol Med Chir (Tokyol 2001;41:48-51

107. Cipri S, Gambardella $G$, Campolo $C$, Mannino $R$, Consoli $D$. Unusual clincal presentation of cerebrall-isolated sarcoidosis. Case report and review of the literature. I Neurosurg $S c i$ $2000 ; 44: 140-4$. 
108. Israel HL, Abertine KH, Park CH, Patrick H. Whole-body gallium 67 scans. Role in diagnosis of sarcoidosis. Am Rev Respir Dis 1991:144:1182-6.

109. Jaman PR. Whyte MK, Glass DM, Peters AM. Case repont imaging of central nervous system sarcoidosis with gallum 67 single photon emission computed tomography. Br J Radiol 1996;69:192-4.

110. Dubey $N_{*}$ Miletich RS, Wasay M, Mechtler LL, Bakshi R. Role of fluorodeoxyglucose positron amission tomography in the diagnosis of neurosarcoidosis. I Neurof Sci 2002;205:77-81

111. Williams JW. The identffication of sarcoid granulomas in the nervous system. Proc Roy Soc Med $1967 ; 60: 38-40$.

112. Davis LE, Kornfeld $M$. Neurocysticercasis: neurologic, pathogenetic, diagnastic and therapeutic aspects. European Neurology 1991;31:229-40.

113. DeRemee RA. The roentgenographic staging of sarcoidosis. Historic and contemporary perspectives. Chest 1983;83:128-33

114. Rothkrantz-Kas $S_{\text {v }}$ van Dieijen-Visser MP, Mulder PGH, Drent M. Potential usefulness of inflammatory markers to imonitor respiratory functional impairment in sarcoidosis. Clin Chem 2003:49:1510-7.

115. Grutters JC, Fellrath JM, Mulder L, Janssen $R$, van den Bosch JMM, van Velzen-Blad $H$, Serum soluble interleukin-2 receptor measurement in patients with sarcoidosis: a clinical ovaluation. Chest 2003:124:186-95

116. Baughman RP, Lower EE, du Bois RM. Sarcoidosis. Lancet 2003;361:1111-8

117. Pickuth $D_{n}$ Splelmann RP, Heywang-Kobrunner $S H$. Role of radiology in the diagnosis of neurosarcoidosis. Eur Radiol 2000;10:941-4.

118. Tahmoush Au, Amir MS, Connor WW, Farry JK, Didato S, Ulhoa-Cintra A, Vasas JM, Schwartzman RJ, Israel HL. Patrick H. CSF-ACE activity in probable CNS neurosarcoidosis. Sarcoidosis Vasc Diffuse Lung Dis 2002:19:191-7.

119. Oksanen $\mathrm{V}$, Fyhrquist $\mathrm{F}$, Somer $\mathrm{H}$, Gronhagen-Riska $\mathrm{C}$. Angiotensin converting enzyme in cerebrospinal fluid: a new assay. Neurology 1985:35:1220-3.

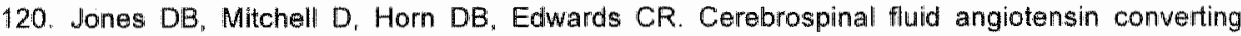
enzyme levels in the diagnosis of neurosarcoidosis. Scott Med $J 1991 ; 36: 144-5$.

121. Rubinstein I. Hoffstein V. Angiotensin-converting enzyme in neurosarcoidosis. Arch Neurol $1987 ; 44: 249-50$.

122. Oksanen $V$. Fyhrquist $F$, Gronhagen-Riska $C$. Somer $H$. CSF angiotensin-converting enzyme in neurosarcoidos is. Lancet 1985:1:1050-1.

123. Chan Seem CP. Norfolk G. Spokes EG. CSF angiotensin-converting enzyme in neurosarcoir dosis Lancer 1985; 1:456-7.

124. Schweisfurth $H_{1}$, Schioberg-Schiegnitz $S$, Kuhn $W$. Parusel B. Angiotensin I converting enzyme in cerebrospinal fluid of patients with neuralogical diseases. Klin Wochenschr $1987 ; 65: 955-8$

125. Borucki SJ, Nguyen BV, Ladoulis CT, McKendall RR. Cerebrospinal fluid immunoglobulin abnormalities in neurosarcoidosis. Anch Neurol 1989;46:270-3.

126. McLean BN, Mitchell DN, Thompson EJ. Local synthesis of specific IgG in the cerebrospinal fiuid of patients with neurosarcoidosis detected by antigen immunoblotting using Kweim material. J Neurol Sci 1990;99:165-75.

127. Scott TF, Seay AR, Goust JM. Pattern and concentration of lgG in cerebrospinal fluid in neurosarcoidosis. Neurology 1989;39:1637-9.

128. Juozevicius JL, Rynes RI. Increased helper/suppressor T-lymphocyte ratio in the cerebrospinal fluid of a patient with neurosarcoidosis. Ann Intern Med 1986;104:807-8

129. Oksanen $V$, Gronthagen-Riska $C$. Tikanoja $S$, Somer $H_{n}$ Fyhrquist $F$. Cerebrospinal flüd lysozyme and beta 2-microglobulin in neurosarcoidosis. I Neurol Sci 1986:73:79-8.7.

130. Oksanen $V$. New cerebrospinal fluid, meurophysiological and neuroradiological examinations in the diagnosis and follow-up of neurosarcoidosis. Sarcoidosis 1987,4:105-10.

131. Stewart JD, Low PA, Fealey RD. Distal small fiber neuropathy: results of tests of sweating and autonomic cardiovascular reflexes. Muscle Nerve 1992;15:661-5.

132. Lacomis D. Small-fiber neuropathy. Muscle Nene 2002;26:173-88.

133. Selroos O. Trealment of sarcoidasis. Sarcoidosis 1994:11:80-3. 
134. Agbogu BN, Stern BJ, Sewell C. Yang G. Therapeutic considerations in patients with refractory neurosarcoidosis. Arch Nourol 1995:52:875-9.

135. Stern BJ, Schonfeld SA, Sewell $C$, Krumholz $A$, Scott $P$. Belendiuk $G$. The treatment of neurosarcoidosis with cyclosporine. Arch Neurol 1992,49:1065-72.

136. Lower EE, Broderick JP, Brott $T G$, Baughman RP. Diagnosis and management of neurological sarcoidosis. Arch Intern Med 1997;157:1864-8.

137. Doty JD, Mazur JE, Judson MA. Treatment of corticosteroid-resistant neurosarcoidosis with a short-course cyclophosphamide regimen. Chest 2003;124:2023-6.

138. Baughman RP. Lower EE. A clinical approach to the use of methotrexate for sarcoidosis. Thorax 1999:54:742-6.

139. Baughman RP. Therapeutic aptions for sarcoidosis: new and old. Curr Opin Pulm Med $2002 ; 8: 464-9$.

440. Sharma OP. Effectiveness of chloroquine and hydroxychloroquine in treating selected patients with sarcoidosis with neurological involwement. Arch Neurol 1998:55:1248-54.

141. Pettersen $J_{A}$, Zochodne DW, Bell RB, Martin L, Hill MD. Refractory neurosarcoidosis responding to infliximab. Neurology 2002:59:1660-1.

142. Keane J, Gershon S, Wise RP, Mirabile-Levens E, Kasznica J, Schwieterman WD, Siegel JN, Braun MM. Tuberculosis associated with infliximab, a tumor necrosis factor alpha-neutralizing agent. N Engl J Med 2001;345:1098-104.

143. Menninger MD, Amdur R.J, Marcus RB Jr. Role of radiotherapy in the treatment of neurosarcoidosis. Am J Clin Oncol 2003;26:E115-8.

144. Kang $S$, Suh $\mathrm{JH}$. Radiation therapy for neurosarcoidosis: report of three cases from a single institution. Radiat Oncol investig 1999;7:309-12.

145. Rubinstein I, Gray TA, Moldofsky $H$, Hoffstein V. Neurosarcoidosis associated with hypersomnolence treated with corticosteroids and brain irradiation. Chest 1988;94:205-6.

146. Bejar JM, Kerby GR, Ziegler DK, Festoff BW. Treatment of central nervous system sarcoidosis with radiatherapy. Ann Neurol 4985:18:258-60.

147. Fried ED, Landalu AJ, Sher JH, Rao C. Spinal cord sarcoidosis: a case report and review of the literature. IAssoc Acad Minor Phys 1993:4:132-7.

148. Hesselmann $W$, Wedekind $C$, Terstegge $K$, Schulte $O$, Voges J, Krug $B$, Lackner $K$. An isolated fourth ventricle in neurosarcoidosis: MRII findings. Eur Radiol 2002;12 Suppl 3:51-3.

149. Foley KT, Howell JD, Junck L. Progression of hydrocephalus during corticosteroid therapy for neurosarcoidosis. Postgrad Med J 1989;65:481-4. 
4 


\section{Chapter 3}

Small fiber neuropathy: a common and important clinical disorder

E Hoitsma, JPH Reulen, M de Baets, M Drent,

F Spaans, CG Faber

J Neural Soi 2004;227:119-30 


\section{Abstract}

Small fiber neuropathy (SFN) is a neuropathy selectively involving small diameter myelinated and unmyelinated nerve fibers. Interest in this disorder has considerably increased during the past few years. It is often idiopathic and typically presents with peripheral pain and/or symptoms of autonomic dysfunction. Diagnosis is made on the basis of the clinical features, normal nerve conduction studies, and abnomal specialized tests of small nerve fibers. Among others, these tests include assezsment of epidermal nerve fiber density, temperature sensation tests for sensory fibers and sudomotor and cardiovagal testing (QSART) for autonomic fibers. Unless an underlying disease is identified, treatment is usually symptomatic and directed towards alleviation of neuropathic pain. 


\section{introduction}

Peripheral neuropathy can be categorized based on the function of the involved nerve fibers or on their diameter and conduction velocity. Regarding the functions of different nerve fibers, three types of peripheral nerve fibers can be distinguished: somatic motor fibers, somatic sensory fibers, and autonomic fibers. Sensory functions include sensation for touch, vibration, temperature and pain. Autonomic functions include sweating, bowel movements, lacrimation, sexual functions, blood pressure and heart rate variability. Based on size, large diameter myelinated (A-alpha and A-beta), medium size myelinated ( $A$-gamma), small diameter myelinated ( $A$-delta) and unmyelinated ( $C$ ) nerve fibers can be distinguished. A-alpha and A-beta nerve fibers carry motor functions, vibration sense and touch. A-gamma fibers carry motor function to muscle spindles. A-delta fibers and $C$ fibers carry temperature and pain sensation and autonomic functions. Small fiber neuropathies (SFN) preferentially affect small-callibre myelimated and unmyelinated fibers, lleaving the larger myelinated fibers relatively unaffected.

Routine electrodiagnostic studies, which primarily test large myelinated fiber function. are mostly normal in these patients. ${ }^{1-3}$ Therefore, the syndrome of SFN has been an enigma to practitioners because of the unexplained contrast between severe pain in the extremities and a paucity of neurological and electrophysiological findings. Recent advantages in diagnostic techniques (temperature threshold testing (TTT), intraepidermal nerve fiber density (IENFD) assessment in skin biopsy) facilitate objective confirmation of clinical diagnosis and the characterization of fiber type involvement in SFN. ${ }^{4.5}$ This paper reviews clinical features, diagnostic tests and underlying diseases. Furthermore, opportunities for future therapeutic as well as pathogenesis studies are discussed.

\section{Clinical features}

Though relatively few detailed descriptions of the clinical features have been pum blished $^{1-3.6,7}$, the clinical syndrome is a relatively stereotypical distinctive syndrome (table 3.1). Small fiber dysfunction can be defined as a generalised peripheral neuropathy in which the small diameter myelinated and unmyelinated nerve fibers are affected, either exclusively or to a much greater degree than the large diameter myelinated fibers. Although this definition is adequate for a conceptual image of SFN, it is not specific enough to apply in clinical and research settings. A good working definition was proposed by Stewart ef al. ${ }^{2}$ Features compatible with SFN include dysesthesia, along with abnormalities on neurologic examination, limited principally to small fiber dysfunc- 
tion. Exclusion criteria include proprioceptive loss in the toes, wibration loss at or above the ankles, any distal wasting or weakness, generalised areflexia, or abnormal findings on electromyography (EMG) or nerve conduction studies (NCS). Although Stewart's definition is quite specific and applicable, both clinically and for research, these delineations are empirical.

Table 3.1 Symptoms suggessuve of stmali fiber nouropathy

\begin{tabular}{|c|c|}
\hline \multirow[t]{4}{*}{ Sensory symptomas. } & -Pain" \\
\hline & - Paraesthesias \\
\hline & - Sheet intolerance \\
\hline & - Restless legs syndirome \\
\hline \multirow[t]{9}{*}{ Symptoms of autonomic dysfunction } & - Hypo-or hyperhidras is \\
\hline & - Dlarrhoea or constipation \\
\hline & - Urinary incontinence ar *retertion \\
\hline & - Gastroparesis \\
\hline & - Sicca syndrome \\
\hline & - Burry wision \\
\hline & Facial flushes \\
\hline & - Orthostatic intolierance \\
\hline & - Sexual dysfunction \\
\hline
\end{tabular}

- Pain in small fiber neuropathy is often burning, tingling, shooting. or prickling in character.

* Restluss legs syndrome is a disorder characterized by disagreeable leg sensations that usually occur prior to sleep onsat and that cause an almost irresistible urge to move.

Sensory symptoms in SFN typically consist of "positive" sensory symptoms, including pain and paraesthesias. ${ }^{-9}$ The pain is often of a burning, prickling, or shooting character. It may be worse at night and may interfere with sleep. Allodynia and cramps. may also occur. These cramps usually affect calf muscles, and may misiead clinicians. to think of other diagnosis if they are not aware of this feature. Some patients present with late-onset restless legs syndrome (RLS). ${ }^{10}$ Especially in RLS patients without a positive family history, SFN should be evaluated. However, not all patients with SFN suffer from pain. Patients may also have "negative" sensory symptoms, including numbness, lightness and coldness. Sensory symptoms are usually distal and "lengthdependent ${ }^{m}{ }^{11}$, but they may sometimes be patchy of asymmetrical. ${ }^{7,12,13}$ The latter may indicate that a pathological process takes place in the dorsal ganglion rather than a typical length-dependent neuropathy.

Because autonomic functions are also mediated by small myelinated and unmyelinated fibers, symptons of autonomic dysfunction may also occur. "These may involve increased or decreased sweating, facial flushing, skin discoloration, sicca syndrome, sexual dysfunction, diarrhoea or constipation. Symptoms of orthostatic hypotension seem to be uncommon except in disorders such as amyloidosis and diabetes. ${ }^{7}$ Occasionally, excessive localised sweating (e.g., face and chest) is associated with 
generalised hypohidrosis or anhidrosis, but it is only the excessive sweating that the patient is aware of. The degree and distribution of autonomic impairment in patients with painful feet have been evaluated in a prospective study by Novak et al. ${ }^{4}$ A preferential impairment was seen of cholinergic and skin vasomotor fibers, sparing systemic adrenergic fibers. It is important to remember that symptoms of autonomic dysfunction are not always sufficiently severe to be mentioned spontaneously by the patient. Furthermore, in clinical practice, subtle autonomic dysfunction such as acral vasomotor symptoms or mild distal extremity discoloration may not always be fully appreciated. Finally, as distal autonomic neuropathy often does not result in orthostatic hypotension, Ewing tests, which are widely used to assess autonomic function, frequently remain normal and hence autonomic dysfunction can easily be overlooked.

Some patients notice consistent worsening of symptoms with heat exposure, others with exposure to cold or with activity. Sometimes patients have increased sensitivity to pressure. Spontaneous exacerbations and remissions may also be presented. Finally, it is remarkable that many patients with SFN complain of severe and disabling fatigue.

\section{Diagnostic tests}

NCS and EMG, which are key in the evaluation of other (large fiber) neuropathies, are generally normal in patients with SFN. ${ }^{15}$ However, recent advantages in diagnoslic tests have facilitated confirmation of the clinical diagnosis of SFN. Nevertheless, a fundamental problem in evaluating diagnostic tests for SFN is that a gold standard for the disorder is lacking. Furthermore, in many patients, functionally different small fiber systems are affected selectively. In order to diagnose SFN and to evaluate the individual type of manifestation, complementary testing of several small somatic and autonomic fiber systems may be necessary. ${ }^{16}$ Finally, all abnormal test results must be interpreted, taking into account the patient's history, previous treatments, and other test results. Physicians, not tests, make diagnoses based on medical history, physical examination, test results, and clinical judigement. ${ }^{17}$

\section{Quantitative sensory testing}

Quantitative sensory testing (QST), which is becoming more and more available, has become an important tool in assessing the function of small as well as large sensory nerve fibers. ${ }^{1 B_{*} 19}$ Small calibre fibers are assessed by measuring temperature thresholds and heat pain thresholds, whereas large calibre fibers are assessed by vibration thresholds 
The method of temperature threshold testing (TT) has been reviewed by Yarnitsky. ${ }^{20}$ Thermal stimuli consist of a ramp of ascending (warm) and descending (cool) thermal energy delivered through a thermode. When symptoms are regarded as the golden standard, sensitivity of TTT ranges from 60 to $85 \%{ }^{3.14 .21-24}$ Differences in sensitivity may be due to technical and patient cohort factors. ${ }^{7}$ TTT is a psychophysical method and therefore requires the cooperation of the patient. This means that these tests are liable to loss of attention, especially in older subjects, and to malingering. ${ }^{98,25,26}$ Furthermore, it is important to remember that it is sensation which is assessed and not structural pathology. Finally it must be realised that the dysfunction causing an abnomal result may in principle be located anywhere between the skin and the sensory cortex. Using two types of testing as a control, the method of levels and the method of limits, false positive results may be reduced. 27,28

In their review of QST the Therapeutics and Technology Assessment Subcommittee of the American Academy of Neurology ${ }^{18}$ concluded that QST is a potentially useful tool for measuring sensory impairment. Abnormalities which are revealed by QST, however, must be interpreted in the context of a thorough neurological examination and other appropriate testing. ${ }^{18}$

\section{Current perception threshold testing}

Current perception threshold testing (CPT) is a sensory quantitative test performed with a microprocessor-controlled electrical neurostimulator which delivers sinusoidal electrical stimuli via surface electrodes at three different frequencies: 5,250 and $2.000 \mathrm{~Hz}$. So far, the only device to measure CPT is the Neurometer(e. Current intensity ranges from 0.01 to $9.99 \mathrm{~mA}^{29.30}$ The electrical current stimulates nerve fibers directly because the intensity is far below that required to stimulate the actual receptors in the skin. Patients are asked to identify the presence or absence of the stimulus through a "forced choice" protocol. From the fact that the perceived sensation varies with the stimulation frequency, it has been concluded that a frequency of $5 \mathrm{~Hz}$ activates $C$ fibers, A delta fibers are stimulated at $250 \mathrm{~Hz}$, and large A beta fibers are triggered with $2.000 \mathrm{~Hz}$. Similar to QST. CPT test requires active patient participation. It is not widely availabie. Furthermore, conflicting information and methodological problems exist regarding the utility of $\mathrm{CPT}{ }^{29}$

\section{Skin biopsy}

Epidermal nerves are the distal terminals of small dorsal root ganglia neurons that pierce the dermal-epidermal basement membrane and penetrate the epidermis. The discovery of the antibody to the neuropeptide protein gene product (PGP) $9.5^{31}$ made it possible to effectively stain most nerve fibers (figure 3.1). PGP 9.5 is a ubiquitin 
C-terminal hydrolase, and is enriched in epidermal neve fibers. ${ }^{32-35}$ Multiple studies have emphasized the importance of intra-epidermal nerve fiber density (IENFD) assessment using PGP-9.5 immunofuorescent staining in skin biopsy in the evaluation SFN. ${ }^{10,21,22.36-55}$ A punch biopsy is performed following established procedures ${ }^{47}$. mostly $10 \mathrm{~cm}$. above the lateral malleolus after local anesthesia with $1 \%$ lidocaine. The location of the biopsy is important as IENFD show significantly higher values at proximal sites compared to distal sites consistent with the nature of length dependent neuropathy. ${ }^{54,56}$ Therefore, a single biopsy site in the distal leg seems sufficient for the evaluation of clinically symmetric small-fiber sensory neuropathy. ${ }^{54}$

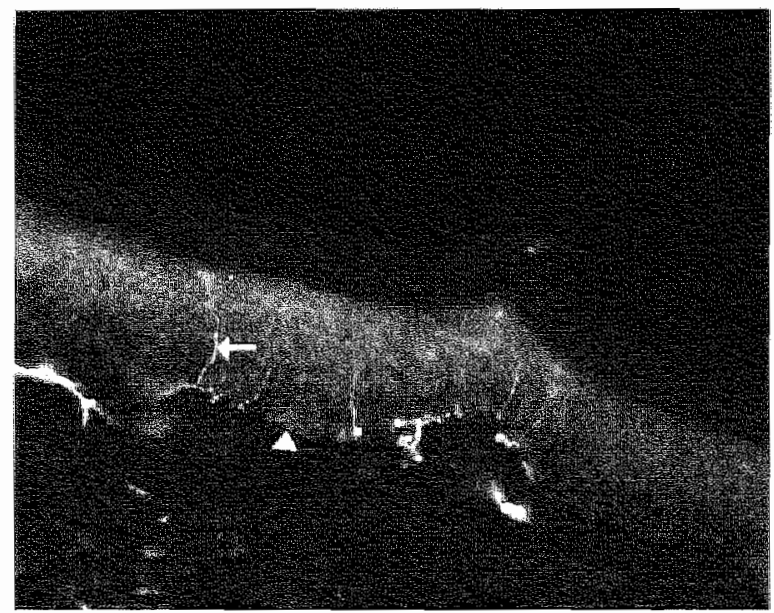

Figure 3.1 Magnification $200 x$. Punch skin biopsy from a hezalthy contral showing intraepidermal nerva flbers. Arrowintrapidermal nerve fiber. Arrowhead=basal membrane (above the basal membrame the epidermis is shown, under the basal membrane the dermis is shown)

In the main, two techniques for quantification of the number of small nerve fibers have been established. First, a technique using an image analysis system and confocal microscopy has been described ${ }^{47}$ and validated against an unbiased stereological technique. ${ }^{43}$ Second, Chien et al. ${ }^{54}$ investigated the feasibility of diagnosing small fiber sensory neuropathy by using only regular light microscopy independent of image analysis systems. The nerve fiber densities of both techniques were significantly correlated ( $r=0.99, p<0.0001)$.

Normative data for IENFD have been established for both techniques. ${ }^{22,43,47,54-549}$ In a systematic review and meta-analysis, Rosenberg et al. investigated the diagnostic value of skin biopsy in patients with small fiber neuropathy (submitted). Nine sludies were included. $14,21,22,39,40,47,55,57.5 \%$ From these 9 studies, sensitivity and specificity of skim 
biopsy appeared to be $69 \%$ and $97 \%$, respectively, in patients with symploms suggestive of SFN, but with normal NCS. They concluded that in this group of patients a positive skin biopsy is of important diagnostic walue.

Finally, focal epidermal nerve fiber swellings have been observed at a time when IENFD remain in the normal range and may be pre-degenerative. ${ }^{40.42 .59}$ However, its significance has not been well established. A limitation of skin biopsies is that they are available in only a few academic centers. The histological technique is moderately complicated, and before implementing it, a relatively large subset of healthy controls should be studied as the normative range is wide.

\section{Sural nerve biopsy}

Pathological diagnosis of neuropathy has traditionally depended on ultrastructural examination of nerve biopsy specimens, particularly for sensory neuropathies affecting unmyelinated and small myelinated nociceptive nerves. However, abnormalities may be subtle and difficult to recognize, and require electron microscopy with technically dernanding, precise morphometric studies. Moreover, nerve biopsy may eventually cause hypoesthesia, deafferentiating pain and neurinoma. Therefore, sensory nerve biopsies are not routinely indicated in evaluating patients with small fiber neuropathy, unless amyloidosis, vasculitis or another inflammatory process is suspected.

\section{Laser evoked potentials}

Evoked potentials to sensory and noxious stimulation of skin may provide objective information about the integrity of the nociceptive afferents as part of the peripheral nervous system as well as brain response to selective stimulation of certain types of sensory fibers. Thermal stimulation with an infrared $\mathrm{CO}_{2}$ laser results in a radiant heat pulse which is absorbed by superficial layers of the skin. It produces a rapid rise in skin temperature and generates a pure pain sensation, which is conveyed through both small myelinated A-delta and unmyelinated $C$ fibers to the cerebral cortex. Recordings with scalp electrodes reveal the occurrence of evoked potentials with long and uitra long latencies (200-500 $\mathrm{ms}$ and $750-1200 \mathrm{~ms}$ for $\mathrm{A}$-delta and $\mathrm{C}$ fibers, respectively). ${ }^{60.61} \mathrm{~A}$ cerebral potential at the vertex is generated and its amplitude correlates with the stimulus intensity and the reported intensity of the perceived pain. ${ }^{62}$ Repeated stimuli induce minimal habituation, and there is no evidence of tissue damage. ${ }^{30}$ The evoked cortical response has greater amplitude than early somatosensory evoked potentials and requires the averaging of $25-40$ responses. ${ }^{62}$ Although this test seems to have important merits its avallability is currently limited. ${ }^{63}$ 


\section{Contact heat-evoked potential stimulators}

Contact heat-evoked potential stimulators (CHEPs) have been difficult to elicit due to slow temperature rise times. A recently developed heat-foil with an extremely rapid heat rising time $\left(70^{\circ} \mathrm{C} / \mathrm{s}\right)$ can elicit pain and CHEPS. ${ }^{64-67}$ Recordings are made from the scalp area overlying the sensory-motor cortex, using scalp electrodes. At low stimulus intensity, only a shallow, very late positive wave is observed at the vertex $\mathrm{Cz}$ site. In contrast, three clear peaks (Cz/N550, Cz/P750 and Pz/P1000) can be identified and isolated at painful levels. The late Cz/N550 component may be in association with A-delta fiber activation since its conduction velocity has been estimated at $10 \mathrm{~m} / \mathrm{s}$. The very late PZ/N1000 component at 800-1000 ms may be in association with $C$ fiber activation, with the conduction velocity estimated at 2-3 m/s. Thus, the isolation of late $\mathrm{CZ} / \mathrm{N} 550$ and very late PZ/P1000 components may allow the inference of the integrity of A-delta and $C$ fiber peripheral afferent. However, the potential value and application of this technique requires further exploration.

\section{Microneurographic C fiber recordings}

Microneurographic $\mathrm{C}$ fiber recording is primarily a research tool, is time consuming and requires that both observer and patient be highly motivated for the successful acquisition of useful data. ${ }^{62.68}$ The examiner percutaneously inserts a special needle electrode (diameter 200 um, uninsulated tip of 1-15 um) into a nerve that innervates an area of the involved skin. The electrode is connected to an amplifier with attached audiomonitors and an ascilloscope to permit the examiner to monitor neural activity. The recordling of skin and muscle sympathetic activity, A-beta low-threshold mechanoreceptors, A-delta nociceptor and $\mathrm{C}$ nociceptor afferent activity can provide pathophysiological information regarding the mechanisms of the different kinds of neuropathic pain.

\section{Sympathetic skin response}

The sympathetic skin response (SSR) is an old, simple, widely available, and inexpensive method for assessing small fiber sudomotor function. It is a reflex change in the sweat-related electrical potential of an area of skin, as elicited by various unexpected "adrenergic" stimuli, such as an electric shock to a somatic nerve. The recording electrodes are commonly applied to the dorsal and ventral surfaces of the foot or hand. There is general agreement that a loss of SSR is abnormal. ${ }^{69}$ There is some controversy as to whether a reduction in electrical potential and a change in latency are reliable abnormalities. ${ }^{70}$ A major advantage is that it can be measured on routine electromyographic (EMG) equipment and that it can be performed in any EMG lab. ${ }^{71}$ However, sensitivity as well as specificity of the SSR are considered to be $10 w^{7,24,69,72}$ 


\section{Quantitative sudomotor axon reflex test}

In quantitative sudomotor axon reflex test (QSART), axons in the skin are activated locally through acetylcholine iontophoresis. Its exact mechanism is not fully understood. Antidromic transmission to an axon branching point may elicit action potentials that travel orthodromically to release acetylcholine from nerve terminals producing sweat. The sweat response is measured at the skin surface using a sudorometer to determine the sweat volume. ${ }^{7,73,74}$ In controls and diabetics, QSART appears to be sensitive, reproducible and only modestly time consuming. Sensitivity in SFN ranges from $59 \%$ to $80 \% .2,4,22,23,74$ A previous study has shown that patients with SFN may have abnomalities in both skin biopsy and QSART. ${ }^{22}$ However, abnormalities in these two lests do not always overlap. There are several abnormal QSART patterns. The response may be (1) normall, (2) reduced, (3) absent, (4) excessive, or (5) persistent. Pattern 5, consisting of persistent sweat response when the stimulus ceases, is often seen in patients with hyperalgesia such as SFN. ${ }^{B}$ However, special equipment is necessary and therefore this test is not widely available.

\section{Other tests of sudomotor function}

Other tests to assess sudomotor function include the thermoregulatory sweat test (TST) and the silastic skin imprint method. ${ }^{8}$ TST involves dusting a patient with an indicating powder (alizarin red, sodium carbonate and cornstarch) that turns purple when moist. The patient is placed in a hot enclosure and the pattern of the body surface covered by sweat is assessed semiquantitatively. Normal results show relatively uniform sweating over the entire body with characteristic areas of heavier or lighter sweating ${ }^{69}$ Sensitivity of the thermoregulatory sweat test appears to be high. It may be one of the most sensitive tests for SFN, showing sweat loss in the feet. ${ }^{69}$ Disadvantages of the test are that it is messy, semiquantative, time consuming and requires a sweat cabinet (air temperature $44-50^{\circ} \mathrm{C}$, relative humidity $35-45 \%$ ).

The silastic skin imprint method was described by Kennedy as a quantitative study of sweat droplet morphometry. ${ }^{75}$ Silastic material that hardens in a minute or two is applied to the skin. Iontophoresis of pilocarpine or acetylcholine are used to stimulate sweat. Sweat drops imprint in the silastic material and quantification is determined by measuring the number of activated sweat glands per square centimeter. Sensitivity of the silastic method has not been evaluated. ${ }^{75,76}$

\section{Skin vasomotor temperature testing}

In skin vasomotor testing surface skin temperature is measured using a non-contact, infrared thermometer on multiple sites bilaterally, including the lateral and medial thighs; 
legs, and feet. The distribution of skin temperature on the lower limbs is considered abnormal when site-to-site differences are $>1^{\circ} \mathrm{C}$ on at least three sites. ${ }^{14.77}$ The advantage of this method is that it is easily evaluated and may therefore be widely applied.

\section{Laser Doppler flowmetry}

Laser Doppler flowmetry (LDF) is a technology that makes use of the fact that red blood cells move through the capillaries of the skin. It is based on the Doppler effect. which occurs when laser light is directed into the skin and reflected back from moving red cells. A detailed description of the method and its applications is given by Shepherd and Öberg. ${ }^{78}$ Spatial differences in skin blood flow may markedly influence the values obtained. As laser Doppler imaging (LDI) evaluates larger skin areas in comparison with LDF, LDI may be more representative for the tissue evaluated than that measured by LDF. $^{79}$

The technique is often used to measure vasoconstrictor responses to stimuli such as cooling $^{80}$, arousal stimuli ${ }^{8 \%}$ and deep inspiration ${ }^{16}$ and vasodilator responses to heating ${ }^{80}$, and acetylcholine introduced electrophoresis. ${ }^{82}$ Heating, for example, causes a release of sympathetic vasoconstrictor tone. Accordingly, a lack of rise in blood flow during heating strongly argues for a defect in sympathetic nerve function. However, it is also important to remember that responses seem to decrease with age. ${ }^{80}$

\section{Cardiovascular reflex testing}

The sympathetic and parasympathetic nervous system are assessed by the Valsalva manoeuvre, by blood pressure response to standing or tilt, and by measuring the heart rate variation during deep breathing and during the Valsalva manoeuvre (Ewing tests). Cardiovascular reflex testing is widely available. However, sensitivity appears to be relatively low in SFN. ${ }^{2,1424}$

\section{Metaiodobenzylguanidine scintigraphy}

lodime-123 meta-iodobenzy/guanidine $\left({ }^{123}|-M| B G\right)$, an analogue of norepinephrine, is a tracer for the functioning of sympathetic neurons. ${ }^{12.3}$ I-MIBG is administered intravenously and cardiac sympathetic nerves take up ${ }^{123} \mathrm{H}-\mathrm{M} \mid \mathrm{BG}$, which radiolabel the vesicles in the terminals. This allows visualisation of the sympathetic innervation of the heart by scintigraphy, after the injection of ${ }^{123}-\mathrm{MIBG}^{84}$ An imbalance of the cardiac autonomic tone is considered to increase the propensity to develop fatal arrhythmias and ${ }^{123}$-MIBG appears to have prognostic value. ${ }^{85}$ Cardiovascular reflex testing (Ewing tests) provides indirect measures of sympathetic nervous system effects on the heart, and seems 
inherently less precise and sensitive than MBG. ${ }^{86}$ However, as there is no golden standard for cardiac denervation, sensitivity and specificity are unknown. MIBG myocardial scintigraphy can be performed safely and does not require special equipment. Therefore, MIBG myocardial scintigraphy may become widely available and utilized.

\section{Pathogenesis and etiology}

In some cases SFN is part of an underlying disease (table 3.2). However, no specific etiology is identified for the majority of SFN patients encountered in neurology practice. especially in the elderly (in up to $93 \%)^{22}$ Only case reports are published of most causes; therefore the frequencies of the different causes are not known. The neuropathology has remained largely unexplored. However, there is some support for a role of ischaemia, cytokines and oxidative stress:

Ischaemia: From an animal model using arterial infarction, there is some support that small nerve fibers are more vulnerable to ischaemia than are large diameter nerve fibers. ${ }^{\text {gt }}$ Ischaemia may be due to vasculitis. ${ }^{88}$

Cytokines: Suare ${ }^{89}$ postulated an immune mediated mechanism as the cause of Idiopathic autonomic neuropathy. Moreover, it is remarkable that SFN seems to be frequent in immune mediated diseases such as sarcoidosis ${ }^{24.90}$, Sjögren's disease ${ }^{91}$ and systemic lupus erythematosus (SLE) ${ }^{92}$, leading to the hypothesis that there might be a common pathway in immune mediated diseases resulting in SFN. Gorson and Ropper" suggested that an auto-immune mechanism causes idiopathic SFN, as three out of four of their patients improved on intravenous gamma globulin treatment. Further support for an immune mediated role is found in pharmacological and physiological studies suggesting that pro-inflammatory cytokines such as tumour necrosis factor alpha (TNF-a) are strongly involved in the generation and maintenance of neuropathic

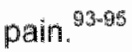

Oxidative stress: The role of oxidative stress also needs further exploration. A growing body of evidence suggests that oxidative stress is implicated in the pathogenesis of diabetic neuropathy. ${ }^{96-102}$ Furthemore, a decreased level of nicotinamide adenine dinucleotide phosphatase (NADPH) was found in the erythrocytes of sarcoidosis patients. ${ }^{103}$ As NADPH is a necessary factor in the defence against oxidative stress, this suggests a decreased anti-axidant defence capacity in sarcoidosis. It is tempting to speculate that oxidative stress might be the common pathway in different diseases causing SFN. 


\section{Natural course and prognosis}

Longitudinal natural history studies are not available to date. From follow-up, it is known that at least some patients evolve from a strict SFN to large fiber sensory neuropathy. ${ }^{22,104}$ in our experience, the progression of SFN seems to be slow, and aithough pain and autonomic dysfunction are troublesome symptoms, patients seem not to become physically disabled. Spontaneous remission sometimes occurs. Tobin et al. ${ }^{23}$ found that about one-third of their patients with idiopathic SFN experienced continuous symptoms, another third intermittent symptoms and that one-third had a monophasic course with resolution of symptoms after months to years.

involvement of cardiac sympathetic nerves might play a role in prognosis, as indices of autonomic cardiac dysfunction have been identified as strong predictors of cardiovascular morbidity and mortality. ${ }^{105-1133}$ However, this aspect needs further study.

Table 3.2 Causes of small fiber neuropathy

"diopathic"

Inherited

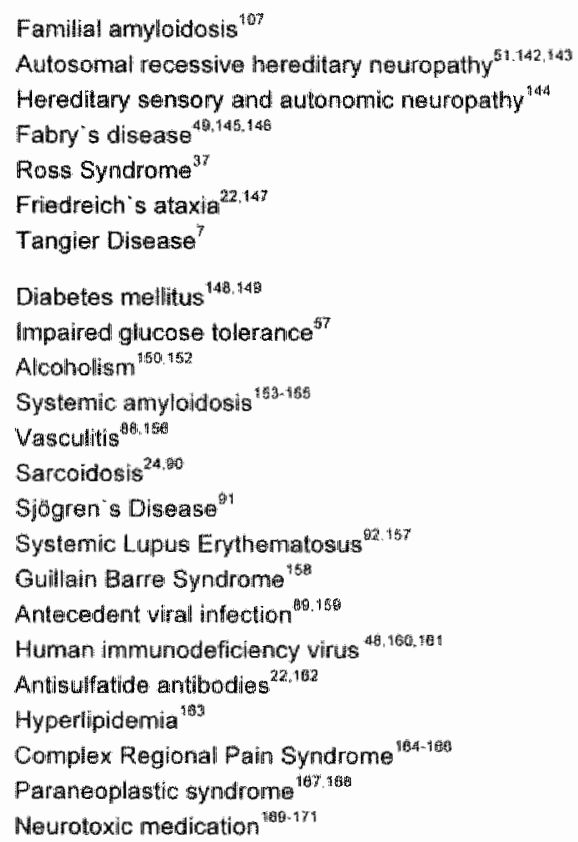




\section{Therapy}

Unless an identifiable treatable cause (table 3.2 ) is found, the management of SFN usually centers upon the treatment of neuropathic pain. ${ }^{7,114}$ Literature regarding painful neuropathies can be divided into three groups: diabetic neuropathies (the most extensively studied pathological condition), human immunodeficiency virus (HIV)-related neuropathies, and remaining neuropathies. There appears to be an important difference in HIV-related neuropathy on one hand, and diabetic and remaining neuropathies on the other hand; drugs that are efficacious in diabetic and other neuropathies have been proved in-efficacious in HIV-related neuropathy. As there appears to be no difference in treatment effect between diabetic and other neuropathy, one can most probably extrapolate the different diabetic studies to all painful neuropathies, excluding HIVrelated neuropathy.

Useful and frequently prescribed drug classes in painfull neuropathy, with the exclusion of HIV-related neuropatiny, include anticonvulsants ${ }^{\$ 15-117}$, tricyclic anti-depressants $^{1144_{1} 197,118}$, opiates ${ }^{116-119}$ and topical capsaicin cream ${ }^{120-122}$ (table 3.3).

Table 3.3. Commonly used treatment of painful sensory neuropathy

\begin{tabular}{|c|c|c|c|}
\hline Drug & Starting Dose and increase* & Usual Range of Doses & NNT \\
\hline \multicolumn{4}{|l|}{ Tricycilic } \\
\hline antidepressants & $10 \mathrm{mg} / \mathrm{day}$ : increase by $10 \mathrm{n} g /$ week & $75.100 \mathrm{mg} / \mathrm{day}$ & $2.6(2.2-3.3)$ \\
\hline Amitriptyline & $10 \mathrm{mg} / \mathrm{day}$ : increase by $10 \mathrm{mg} /$ week & $75.100 \mathrm{mg} / \mathrm{day}$ & \\
\hline \multicolumn{4}{|l|}{ Nortriptyllne } \\
\hline SSR' & $10 \mathrm{mg} / \mathrm{w}$ e ek increase by $10 \mathrm{mg}$ week & $20-60 \mathrm{mg} / \mathrm{day}$ & $6.7(3.4-435)$ \\
\hline Citalopran & $10 \mathrm{mg} /$ week increase by $110 \mathrm{mg}$ waek & $20-60 \mathrm{mg} / \mathrm{day}$ & \\
\hline \multicolumn{4}{|l|}{ Paroxetitin } \\
\hline \multicolumn{4}{|l|}{ Anticonvulsants a.k } \\
\hline Gabapentine & $300 \mathrm{mg} / \mathrm{day}$ increase by $300 \mathrm{mg} / \mathrm{week}$ & $1800-3600 \mathrm{mg} / \mathrm{day}$ & $3.7(2.4-8.3)^{3+2}$ \\
\hline Carbamazepir: & $200 \mathrm{mg} / \mathrm{d}$ as; inclease by $200 \mathrm{mg} /$ week & $800-1600 \mathrm{mg} / \mathrm{d}+\mathrm{y}$ & $3.3(2.0 \times 9.4)$ \\
\hline Oxcarbazep:n & $300 \mathrm{mg} / \mathrm{dlay}$; increas by 300 mg/week & $1200-2400 \mathrm{mg} / \mathrm{day}$ & $\mathrm{ND}$ \\
\hline Lamotriggin & 60. mg/day; increase by $100 \mathrm{mng}$ biwedkly & $200-600 \mathrm{~m}: \mathrm{g} d \mathrm{day}$ & ND \\
\hline Phenyton & $100 \mathrm{mg} / \mathrm{day}$ increase by $100 \mathrm{mg} /$ week & $300-500$ mgiday & $2 .(1.5-3.6)^{7}$ \\
\hline \multicolumn{4}{|l|}{ Opionds } \\
\hline Tramado! & $150 \mathrm{mg} / \mathrm{day}$; increase by $50 \mathrm{mg} /$ week & 200400 mgiday & $3.4(2.3 .6 .4)$ \\
\hline Morphine & $15-30$ nig every $8 \mathrm{hr}$ & $90.360 \mathrm{mg} / \mathrm{day}$ & NO \\
\hline Topical therapy & & Apply to painful area & \\
\hline Capsalicin crestry & $0.075 \%$ & 4 timesiday & $5.9(3.6-13)$ \\
\hline
\end{tabular}

SSRImselective serotonin reuptake inhbitor: NNT=numbers needed to treat ( $95 \% \mathrm{CH}$ ) to obtain one patient with more than $50 \%$ pain relief data according to Sindrup \& Jensen ${ }^{136,23}$ : ND=not done.

"data according to Mendell \& Sahenk ${ }^{114}$ " orkal" "It is important to note that a second placebo controlled study with phenytoin failed to demonstrate significant effect "At a dose of $3600 \mathrm{mg} / \mathrm{day}$. In a study with a much lower dose (900 mglday) no effect was found ${ }^{173}$

Treatment should be titrated until benefit is achieved to the maximum tolerable dose. Most of the drugs that are efficacious reduce pain intensity only $30-50 \%$, and such a 
reduction rarely meets patients expectations. ${ }^{1 / 4}$ In diabetics, the number needed to treat (NNT) values for most drugs is around 3 (table 3.3). This means that in neuropathic pain, 3 patients have to be treated in order to obtain one patient with more than $50 \%$ pain relief. Tricyclic antidepressants have been studied most extensively and may at the moment be the drugs of first choice; drugs such as gabapentin, carbamazepin, and tramadol may be tried if contraindications or tolerability problems are encountered with the tricyclics. ${ }^{123}$ It remains uncertain whether adequate pain relief can be achieved with a multi-drug strategy, particularly with the use of pharmacological agents targeted at more than one site in the pain pathway. ${ }^{114}$

Amitryptylin and capcaicin cream are not effective in treating HIV-related neuropathy. ${ }^{124-126}$ Data on the effect of lamotrigin in HIV-related painful neuropathy are contradictory. ${ }^{127.128}$ Possibly, there is some effect of lamotrigin in HIV patients who use neurotoxic antiretroviral therapy (ART). ${ }^{128}$

The efficacy of intravenous gammaglobulin in idiopathic SFN deserves further study. ${ }^{1}$ The older aldose reductase inhibitors do not reduce pain in diabetic neuropathy. ${ }^{120-131} \mathrm{~A}$ newer aldose reductase inhibitor, fidarestat, may be beneficial but further study needs to be done before this treatment can be recommended. ${ }^{132}$ Intensive diabetes therapy can also reduce painful diabetic neuropathy. ${ }^{133}$ One needs to aim at a stable metabolic situation and avoid hypoglycaemias as patients with autonomic neuropathy may not be aware of their hypoglycaemias.

As pro-inflammatory cytokines such as TNF- $\alpha$ contribute to the development of neuropathic pain ${ }^{93-95}$ one may hypothesize that anti-TNF-a therapy such as infliximab could be beneficial in SFN.

Finally, there has been therapeutic interest in nerve growth factor (NGF) ${ }^{\text {134 }}$ and lipoic acid. ${ }^{59,100}$ In several, although not all studies, intravenous administration of the antioxidant lipoic acid has been shown to ameliorate major neuropathic symptoms and also to improve heant rate variability in diabetics. ${ }^{99-102,135}$ However, oral administration of lipoic acid appears to be in-efficacious. ${ }^{102}$

NGF is trophic for small sensory neurons and stimulates the regeneration of damaged nerve fibers. ${ }^{136}$ NGF levels have been found to be reduced in sympathetic target tissue shortly after inducing diabetes in rats. ${ }^{137}$ On the other hand, recombinant human NGF improwed diabetic, chemotherapy-induced and HIV-related sensory neuropathies. ${ }^{138-140}$ It is not clear whether the benefits from NGF treatment is from its trophic effect or others like analgesic effect. NGF, anti-TNF-a, and antioxidants all deserve further study.

Nonpharmacological methods for pain management may also be helpful. Some patients find relief with cool soaks, heat, massage, elevation or lowering of the limbs. Shoes must not be tight and exercise may be beneficial as well. ${ }^{7}$ in the only controlled study of acupuncture for peripheral nerve pain related to HIV, there was no difference in effect 
when needles were placed in traditional sites rather than in sham sites. ${ }^{125}$ Transcutaneous electrotherapy (TENS) ameliorates pain and discomfort associated with diabetic neuropathy. ${ }^{411}$ Spinal cord stimulators and intrathecal morphine may be helpful in a select group of patients, but the long-term benefit is unknown. ${ }^{\text {? }}$

\section{Conclusions}

SFN is a relatively common disorder resulting in severe and troublesome symptoms, which may be difficult to control. Standard electrophysiological tests such as nerve conduction studies and EMG remain normal in SFN. Therefore, the syndrome may easily be overlooked. Whether patients with SFN are at risk for sudden life threatening arrhythmias when they develop cardiac denervation is unknown and needs further study. Future studies regarding pathophysiology and treatment are warranted as well. As SFN seems to be frequent in several immune mediated diseases such as sarcoidosis, SLE, Sjögrens's syndrome and vasculitis, there might be a common pathway in immune mediated diseases resulting in SFN. In this regard oxidative stress and proinflammatory cytokines such as TNF- $\alpha$ may be candidate and deserve further analysis. 


\section{References}

1. Gorson KC, Ropper AH. Idiopathic distal small fiber neuropathy. Acta Neurol Scand $1995 * 92: 376-82$.

2. Slewart JD, Low PA, Fealey RD. Distal small fiber neuropathy: results of tests of sweating and autonomic cardiovascular reflexes. Muscle Nerve 1992;15:661-5.

3. Jamal GA, Hansen $\mathrm{S}$, Weir $\mathrm{Al}$. Ballantyne JP. The neurophysiologic imvestigation of small fiber neuropathies. Muscle Nerve 1987, 10:537-45

4. Singer W, Spies JM, McArthur J, Low J, Griffin JW, Nickander KK, Gordon V, Low PA. Prospective evaluation of somatic and autonomic small fibers in selected autonomic neuropathies. Neurology 2004:62:612-8.

5. Winkler AS, Ejskjaer $N$, Edmonds $M_{4}$ Watkins PJ. Dissociated sensory loss in diabetic autonomic neuropathy. Diabet Med 2000;17:457-62.

6. Al-Shekhlee A, Chelimsky T, Preston D. Review: Small-fiber neuropathy. Neurologist 2002;8: 237-53.

7. Lacomis D. Small-fiber neuropathy. Muscle Nerve 2002;26:173-88.

8. Low P. Clinical Autonomic Disorders. Little, Brown \& Co, Boston 1997; 2nd adition.

9. Said G. Small fiber invalvement in peripheral neuropathies. Curr Opin Neurol 2003:16:601-2.

10. Polydefk is $M$, Allen RP, Hauer P. Earley $C J$, Griffin JW, McAtthur JC. Subclinical sensory neuropathy in late-onset restless legs syndrome. Neurology 2000;55:1115-21.

11. Dyck PJ. Chalk CH. The 10 P's: a mnemonic helpful in characterization and differential diagnosis of peripheral neuropathy. Neurology $1992 ; 42: 14-8$.

12. Hoitsma $E$, wan Santen-Hoefft M, Drent M. Impact of Pain in a Dutch Sarcoidosis Patient Population. Sarcoidosis Vasc Diffuse Lung Dis 2003;20:33-39.

13. Lacomis D, Tobin K. Guiliani M. Multifocal small fiber sensory neuropathy. I Clin Neuromusc Dis $1999 ; 1: 2-5$.

14. Novak V, Freimer ML, Kissel JT, Sahenk Z, Periquet IM, Nash SM, Collins MP, Mendell IR. Autonomic impairment in painful neuropathy. Neurology 2001;56:861-8.

15. Krarup C. An update on electrophysiological studies in neuropathy. Curr Opin Neurol 2003; 16:603-12.

16. Schuller $T B$, Hermann $K$, Baron $R$. Quantitative assessment and correlation of sympathetic, parasympathetic, and afferent small fiber function in peripheral neuropathy. J Neurol 2000; 247:267-72.

17. Dyck PJ, OBrien PC. Report of the Therapeutics and Technology Assessment Subcommittee of the American Academy of Neurology. Neurology 2003;61:1628.

18. Shy ME, Frohman EM, So YT, Arezzo JC, Comblath DR, Giuliani Mu, Kincald JC, Ochoa Jh. Parry GJ, Weimer $\mathrm{LH}$; Therapeutics and Technology Assessment Subcommittee of the American Academy of Neurology. Quantitative sensony testing: report of the Therapeutics and Technology Assessment Subcommittee of the American Academy of Neurology. Neurology 2003;60:898-904,

19. Dyck PJ. Larson TS, O'Brien PC Velosa JA. Patterns of quantitative sensation testing of hypoesthesia and hyperalgesia are predictive of diabetic polyneuropathy: a study of three cohorts. Nerve growth factor study group. Diabetes Care 2000;23:510-7.

20. Yarnitsky D. Quartitative sensory lesting. Muscle Nerve 1997;20:198-204.

21. Holland NR, Crawford TO, Hauer P. Comblath DR, Griffin JW. MCArthur JC. Small-fiber sensory neuropathies: clinical course and neuropathology of idiopathic cases. Ann Nourol $1998 ; 44: 47-59$.

22. Periquet Mi, Novak $V$, Collins MP. Nagaraja HN, Erdem $S$, Nash SM, Freimer ML, Sahenk $Z$. Kissel JT, Mendell JR. Painful sensory neuropathy: prospective evaluation using skin biopsy. Neurology 1999;53:1641-7:

23. Tobin $K$, Giuliani MJ, Lacomis D. Comparison of different modalities for detection of small fiber neuropathy. Chin Neurophysior 1999;110:1909-12. 
24. Hoitema E, Drent M, Verstraete E, Faber CG, Troost J, Spaans F, Reulen JPH. Abnomal warm and cold sensation thresholds suggestive of small-fibre neuropathy in sarcoidosis. Clin Neurophysiol $2003 ; 114,2326-33$.

25. Dyck Pu, Kennedy WR, Kesserwani H, Melanson M, Ochoa J, Shy M. Stevens JC. Suarez GA. OBrien PC. Limitations of quantitative sersory testing when patients are biased toward a bad outcome. Alurology 1998:50:1213.

28. Freeman $R$, Chase KP. Risk MR. Quantitative sensory lesting cannot differentiate simulated seresory loss from sensory neuropathy. Neurology $2003,60: 465-70$.

27. Yarnifsky D. Sprecher E. Thermal testing nomative data and repeatability for warious test aigorithms. J Neurol Scl 1994:125:3945.

28. Fieuten JPH, Lansbergen MD, Verstrate E. Spaans F. Comparison of themal threshold tests to assess small nerve fiber function: limits ws. levells. Clin Neurophysial 2003;1/4:556-63.

29. Technology review: the Neurometer Current Perception Thresthold (CPT). AAEM Equipment and Computer Committee. American Association of Electrodiagnostic Medicine. Musche Narve 1999:22:523-31.

30. Santiago S, Ferrer T. Espinosa ML. Neurophystological studies of thin myelinated (A delta) and unmyelinated (C) fibers: application to peripheral neuropathies. Neurophysiol Clin 2000: $30: 27-42$

31. Thompson RJ Doran JF, Jackson P. Dhillon AP. Rode J. PGP 9.5-a new marker for vertebrate neurons and neuroendocrime cells. Brain Res 1983:278:224-8.

32. Hilliges M. Wang L., Johansson 0 . Ultrastructural evidence for nerve fibers within all vital layers of the human epidemis. Invest Dermato 1995;104:134-7.

33. Wilson PO, Barber PC, Hamid QA, Power BF, Dhillon AP. Rode J, Day IN. Thompson RJ. Polak JM. The immunolocalization of protein gane product 9.5 using rabbit polyclonal and mouse monoclomal antibodies. Br J Exp Pathol 1988;69:91-104.

34. Doran JF. Jackson $P$, Kynoch PA, Thompson RJ. Isolation of PGP 9.5, a new human neurone-specific protein detected by highmresolution twomdimensional electrophoresis. $J \mathrm{New}$ rochem $1983 ; 40: 1542-7$.

35. Wikinson KD, Lee KM. Deshpande S, Duerksen-Hughes P, Boss JM, Pohl J. The meuronspecific protein PGP 9.5 is a thiquitin carboxyl-terminal thydrolase. Science 1989:246:670-3.

36. Arezzo JC. New developments in the diagnosis of diabetic neuropathy. Am $I M e d$ $1999 ; 107: 95-165$

37. Bergmann 1, Dauphin M. Naumann M, Flachenecker P. Mullges W, Koltzenburg M, Sommer C. Selective degeneration of sudomotor fibers in Ross syndrome and sulccessful treatment of compensatory hyperhidrosis with botulinum toxin. Muscie Nenve 1998:21:1790-3.

38. Guinard D. Usson Y. Guillemet C, Saxod R. PS.100 and NF 70-200 double immunalabeling for human digital skin meissiner corpuscle 3D imaging. I Histochem Cytochem 2000;48: $2915-302$

39. Herimamn DN, Griffin JW, Hauer P, Cornblath DR, McArthur JC. Epidermal nerve fiber density and sural nerve morphometry in peripheral neuropathies. Neurology 1999;53: $1634-40$

40. Holland NR, Stocks A. Hauer P. Comblath DR, Griffin JW, MoArthur JC. Intraepidermal nerve fiber density in patients with painful sensory neuropathy. Neurology 1997;48:708-11.

41. Hsieh ST, Chiang HY, Lin WM. Pathology of nerve terminal degeneration in the skin. I Neuropathol Exp Neurol 2000;59:297-307.

42. Kennedy WR, Wendelschafer-Crabb $G$. The innervation of human epidermis . A Neurol Sci $1993 ; 115: 184-90$.

43. Kennedy WR, Wendelschafer-Crabb $G$, Johnson T. Quantitation of epidermal nerves im diabetic neuropatiy. Neurology 1996;47:1042-8.

44. Kennedy WR, Nolano M, Wendelschafer-Crabb G, Johnson TL. Tamura E. A skin blister method to study epidermal nerves in peripheral nerve disease. Muscle Nenve 1999;22: $360-71$

45. Lauria G, MCArthur JC, Haver PE, Griffin JW, Comblath DR Neuropathological alterations in diabetic truncal neuropathy: evaluation by skin biopsy. \& Neurol Neurosurg Psychiatry 1998; $65: 762-6$ 
46. Lauria G, Holland N, Hauer P. Cornblath DR, Griffin JW, MCAnthur JC. Epidermal inmervation: changes with aging, topographic location, and in sensory neuropathy. J Neurol 501 1999: $164: 172-8$.

47. MoCarthy BG, Hsieh ST, Stocks A, Hauer P, Macko C, Cornblath DR, Grifin JW, McArthur JC. Cutaneous innervation in senson meuropathies; evaluation by skin biopsy. Newrology $1995 ; 45: 1848-55$.

48. Polydefkis $M$, Yiannoutsos $C T$, Cohen BA, Hollander $H$, Schifitto $G$, Cilfford DB, Simpson DM, Katzenstein D, Shriver S. Hauer P. Brown A, Haidich AB, Moo $\mathrm{L}$, McArthur JC. Reduced intraepidermal neve fiber density in HIV-associated sensory neuropathy. Neurology 2002: 58:115-9.

49. Scott LJ, Griffin JW, Luciano C. Barton NW, Banerjee T, Crawford T, MCArthur JC, Tournay A. Schiffmann R. Quantitative analysis of epidermal innervation in Fabry disease. Neurology $1999 ; 52: 1249-54$

50. Stocks EA, MCArthur JC, Griffen JW, Mouton PR. An unbiased method for estimation of total epidermal nerve fibre length. I Neurocytol 1996;25:637-44.

51. Verze L. Viglietti-Panzica $C$, Plumari L, Calcagni M. Stella M. Schrama LH. Panzica GC. Cutaneous innervation in hereditary sensory and autonomic neuropathy type IV. Nourology 2000:55:126-8.

52. Wakamoto $H$. Hirai $A$. Manabe $K$, Hayashi $M$. Idiopathic small-fiber sensory neuropathy in childhood: A diagnosis based on objective findings on punch skin biopsy specimens. J Pediatr 1999:135:257-60.

53. Weidner C, Schmelz M, Schmidt R. Hansson B, Handwerker HO, Torebjork HE. Functional attributes discriminating mechano-insensitive and mechano-responsive $\mathrm{C}$ nociceptors in human skin. J Neurosci 1999:19:10184-90.

54. Chien HF, Tseng TJ, Lin WM, Yang CC, Chang YC, Chen RC, Hsieh ST, Quantitative pathology of cutaneous nerve terminal degeneration in the human skin. Acta Neuropathol (Berl) 2001; 102:455-61.

55. McArthur JC, Stocks EA, Hauer P. Comblath DR, Griffin JW. Epidermal nerve fiber density: normative reference range and diagnostic efficiency. Arch Neurol 1998;55:1513-20.

56. Goransson LG, Mellgren SI, Lindal S, Omdal R. The effect of age and gender on epidermal nerve fiber density. Neurology 2004;62:774-7.

57. Smith $A G$, Ramachandram $P$. Tripp $S$, Singleton JR. Epidermal nerve innervation in impaired glucose tolerance and diabetes-associated neuropathy. Neurology 2001;57:1701-4.

58. Lauria G, Morbin M. Lombardi R, Borgna M, Mazzoleni G, Sghirlanzoni A, Pareyson D Axonal swellings predict the degeneration of epidermal nerve fibers in painfull neuropathies Neurology 2003;61:63:1-6.

59. Hermann DN, McDermott MP. Henderson D, Chen L. Akowuah K, Schifitto G. Epidermal nerve fiber density. axonal swellings and QST as predictors of HIV distal sensory neuropathy. Muscle Nerve 2004:29:420-7.

60. Bragard $D_{\text {, }}$ Chen $A C$. Plaghki L. Direct isolation of ultra-late ( $C$-fibre) evoked brain potentials by CO2 laser stimulation of tiny cutaneous surface areas in man. Nourosci Lett 1996;209. $81-4$

61. Mager W, Ali $Z$, Ellrich J, Meyer RA, Treede RD. C- and A delta-fiber components of heatevoked cerebral potentials in healthy human subjects Pain 1999;82:127-37.

62. Dotson RiM. Clinical neurophysiology laboratory tests to assess the nociceptive system in humans. J Clin Neurophysiol 1997;14:32 45.

63. Truini A. Cruccu G, Garcia-Larrea L. Painful sensiory neuropathy. $N$ Engl J Med 2003;349: $306-7$

54. Valeriani M, Le Pera D, Niddam D, Chen AC. Arendt-Nielsen L. Dipolar modelling of the scalp evoked potentials to painful contact heat stimulation of the human skin. Neurosci Lett 2002; 318:44-8.

65. Le Pera $D$, Valeriani $M$, Niddam $D$, Chen $A C$. Arendt-Nielsen $L$. Contact theat evoked potentials to painful and nonmpainful stimuli: effect of attention towards stimulus properties. Brain Topogr 2002;15:115-23. 
Chen AC, Niddam DM, Arendt-Nielsen L. Contact heat evoked potentials as a valid means to study nociceptive pathways in human subjects. Newrosci Lett 2001:316:79-82.

67. Jarnal GA, Hansen S. Weir Al, Ballantyne JP. Cerebral contical potentials to pure non-painful temperature stimulation: an objective technique for the assessment of small fibre pathway in man. I Neurol Neurosurg Psychiaty 1989;52:99-105.

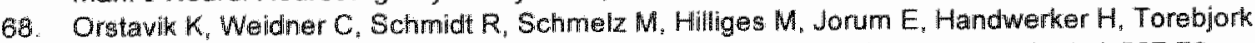
E. Pathological C-fibres in patients with a chronic painful condition. Brain 2003; 126:567-78

69. Low PA. Evaluation of sudomotor function. Clin Neurophysiol 2004:115:1506-13.

70. Shahani BT, Day $T$, Cros D. Khali $N_{1}$ Knerebone CS. RR interval variation and the sympathetic skin response in the assessment of autonomic function in peripheral neuropathy. Arch Nourol 1990:47:659-64.

71. Sandroni P, Low PA. Autonomic peripheral neuropathies: clinical presentation, diagnosis, and treatment, J Clin Nouromuscul Dis 2001;2:147-57

72. Maselli RA, Jaspan JB, Soliven BC, Green Ad, Spire JP, Arnason BG. Comparison of sympathetic skin response with quantitative sudomotor axon rellex fest in diabetic neuropathy. Muscle Nerve $1989 ; 12: 420-3$

73. Giuliani M. Tobin K. Low P. Small-fiber Neiropathy: Evaluation Recommendations. Nourology 1996;46:94.

74. Riedel A, Braune S, Kerum G, Schulte-Monting J, Lucking $\mathrm{CH}$. Quantitative sudomotor axon reflex test (QSART): new approach for testing distal sites. Muscie Nerwe 1999:22:1257-64.

75. Kennedy WR, Sakuta $M$. Sutherland $D$, Goetz FC. Quantitation of the sweating deficiency in diabetes mellitus. Ann Neurof 1984:15:482-8.

76. Ferrer T, Ramos MJ, Perez-Sales P, Perez-Jimenez A, Alvarez E. Sympathetic sudomotor function and aging. Muscle Nerve 1995:18:395-4011.

77. Low P. Evaluation of autonomic function. Curr Opin Neurol Neurosurg 1992,5:46:1-3.

78. Shepherd P, Oberg PA. Laser Doppler Blood Flowmetry. Boston: Kluwer 1990.

79. Bornmyr $S$, Svensson $H$, Lifia $B$, Sundkvist $G$. Cutaneaus vasomotor responses in young type I diabetic patients. J Diabetes Complications 1997;11:21-6.

80. Bornmyr $S$, Svensson $H_{n}$ Soderstrom T, Sundkvist $G$, Wollmer $P$. Finger skin blood flow in response to indirect cooling in normal subjects and in patients before and after sympathectomy, Clin Physiol 1998;18:103-7.

81. Hilz MJ, Hecht MJ, Berghoff M, Singer $W$, Neundoerfer $B$. Abnormal vasoreaction to arousal stimuli -an early sign of diabetic sympathetic neuropathy demonstrated by laser Doppler flowmetry. I Chin Neurophysiol 2000:17:419-25

82. Parkhouse $N$. Le Quesne PM. impaired neurogenie vascular response in patients with diabetes and neuropathic foot lesions. N Engl J Med 1988;318:4306-9.

83. Consensus statement: Report and recommendations of the San Antonio conference on diabetic neuropathy. American Diabetes Association American Academy of Neurology. Diabetes Care 1988:11:592-7.

84. Sisson JC, Shapiro B, Meyers L, Mallette S, Mangner TJ. Wieland DM, Glowniak MN. Sherman P, Beierwaltes WH. Metaiodobenzylquanidine to map scintigraphically the adrenergic nervous system in man. I Nucl Med 1987;28:1625-36.

85. Wakabayashi T. Nakata T. Hashimoto A, Yuda S, Tsuchihashi $K$, Travin MI, Shimamoto $K$ Assessment of underlying etiology and cardiac sympathetic innervation to identify patients at high risk of cardiac death. I Nucl Med 2001;42:1757-67.

86. Delahaye N, Dinanian S, Slama MS, Mzabi H, Samuel D, Adams D, Merlet P, Le Gulludec D. Cardiac sympathetic denervation in familial amyloid polyneuropathy assessed by iodine-123 metaiodobenzylguanidine scintigraphy and heart rate wariability. Eur $J$ Nucl Med 1999;26: 416-24.

87. Parry GJ, Brown MJ. Selective fiber vulnerability in acute ischemic neuropathy. Ann Neurol $1982 ; 11: 147 \% 54$

88. Lacomis D, Giuliani MJ. Steen V, Powell HC. Small fiber neuropathy and vasculitis. Arthritis Rheum 1997:40:1173-7.

89. Suarez GA, Fealey RD, Camilleri M, Low PA. Idiopathic autonomic neuropathy: clinical, neurophysiologic, and fallow- up studies on 27 patients. Neurology 1994;44:1675-82. 


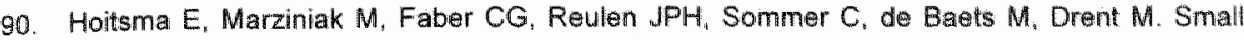
Fiber Neuropathy in Sarcoidosis. Lancet 2002;359:2085-6.

91. Kaplan JG. Rosenberg $R$. Reinitz $E$, Buchbinder $S$, Schatumburg HH. Invited review: peripheral neuropathy in Sjogren's syndrome. Muscle Nerve 1990;13:570-9.

92. Omdal R, Mellgren SI, Goransson L, Skjesol A. Lindal $S$, Koldingsnes $W$. Husby G. Small nerve fiber involvement in systemic lupus erythematosus: a controlled study. Arthritis Rheum 2002;46:1228i-32.

93. Sommer C, Schafers M. Painful mononeuropathy in C57BLNWld mice with delayed wallerian degeneration: differential effects of cytokine production and nerve regeneration on thermal and mechanical hypersensitivity. Brain Res 1998;784:154-62.

94. Sommer $C$. Marziniak $M$. Myers RR. The effect of thalidomide treatment on vascular pathology and hyperalgesia caused by chronic constriction injury of rat neve. Pain 1998: 74:83-91.

95. Schafers M, Geis C. Brors D, Yaksh TL. Sommer C. Anterograde transport of tumor necrosis factor-alpha in the intact and injured rat sciatic nerve. J Neurosoi 2002;22:536-45.

96. Manzella D, Barbieri M, Ragno E, Paolisso G. Chronic administration of pharmacologic doses of vitamin $E$ improves the cardiac autonomic nervous system in patients with type 2 diabetes. Am J Clin Nutr 2001;73:1052-7.

97. Feldman EL. Oxidative stress and diabetic neuropathy: a new understanding of an old problem. J Clin Invest 2003:111:431-3.

98. Low PA, Nickander $K K$, Tritschller HJ. The roles of oxidative stress and antioxidant treatment in experimental diabetic neuropathy. Diabetes $1997 ; 46: \$ 38-42$.

99. Biewenga $G$, Haenen $G R$, Bast $A$. The role of lipoic acid in the treatment of diabetic polyneuropathy. Drug Metab Rev 1997:29:1025-54.

100. Ziegler D, Gries FA. Alpha-lipoic acid in the treatment of diabetic peripheral and cardiac autonomic neuropathy. Diabetes 1997;46:S62-6.

101. Ziegler D, Schatz H, Conrad F, Gries FA, Uirich $H$. Reichel G. Effects of treatment with the antioxidant alpha-lipoic acid on cardiac autonomic meuropathy in NIDDM patients. A 4-month randomized controlled multicenter trial (DEKAN Study). Deutsche Kardiale Autonome Neuropathie. Diabetes Care 1997;20:369-73.

102. Ziegler D, Hanefeld M, Ruhnau KJ, Hasche H, Lobisch M, Schutte K, Kerum G, Malessa R. Treatment of symptomatic diabetic polyneuropathy with the antioxidant alpha-lipoic acid: a 7 month multicenter randomized controlled trial (ALADIN III Study). ALADIN III Study Group. Alpha-Lipoic Acid in Diabetic Neuropathy. Diabetes Care 1999:22:1296-301.

103. Rothkrantz-Kos S, Drent M, Vuil H, De Boer M. Bast A, Wouters EFM, Raos D, van Dieijen Visser MP. Decreased redox state in red blood cells from patients with sarcoidos is. Sarcoido sis Vasc Diffuse Lung Dis 2002;19:114-20.

104. Stewart JD. PAL. Clinical autonomic disorders: evaluation and management. Boston: Little, Brown 1993:653-66.

105. Ewing DJ, Boland O, Neilson JM, Cho CG, Clarke BF. Autonomic neuropathy, QT interval lengthening, and unexpected deaths in male diabetic patients. Diabetologia $1991 ; 34: 182-5$.

106. Bellavere $F$, Ferri $M$, Guarini $L_{n}$ Bax $G$, Piccoli $A$, Cardone $C$. Fedele D. Prolonged OT period in diabetic autonomic neuropathy: a possible role in sudden cardiac death? $\mathrm{Br}$ Heart $J 1988$ 59:379-83.

107. Kyle RA, Dyck PJ. Amyloidosis and neuropathy. Dyck PJ. Thomas PK, Griffin JW, et al, eds. Peripheral neuropathy. Philadelphia: WB Saunders 1993:1294-309.

108. Bergethon PR, Sabin TD, Lewis D, Simms RW, Cohen AS, Skinner M. Improvement in the polyneuropathy associated with familial amyloid polyneuropathy after liver transplantation. Neurology 1996:47:944-51.

109. Thomas PK. King RH. Peripheral nerve changes in amyloid neuropathy. Brain 1974,97 395-406

110. Ikeda $S$, Takei $Y$, Yanagisawa $N$, Matsunami $H$. Hashikura $Y$, Ikagami $T$, Kawasaki $S$ Peripheral nerves regenerated in familial amyloid polyneuropathy after liver transplantation. Ann Intern Med 1997:127:618-20. 
111. Krone $A$, Reuther $P$. Fuhrmeister U. Autonomic dysfunction in polyneuropathies: a report on 106 cases. J Neurof 1983:230:111-21.

112. Ewing DJ, Bellavere F, Espi F, Mckjbben BM, Buchanan KD. Riemersma RA, Clarke BF. Correlation of cardiovascular and neuroendocrine tests of autonomic function in diabetes. Metabohism 1988;35:349-53.

113. $Q$ Brien $D$, Johnson GC. Dysautonomia and autonomic neuropathies. Neuromuscular Diseases 2002;32:251-65.

114. Mendell JR, Sahenk Z. Clinical practice. Painful sensory neuropathy. N Engl J Med 2003;348: $1243 m 55$

115. McQuay $H$, Carroll D, Jadad AR, Wiffen P, Moore A. Anticonvulsant drugs for management of pain: a systematic review. Br Med $J 1995 ; 311: 1047-52$

116. Sindrup SH, Jensen TS. Efficacy of pharmacological treatments of neuropathic pain: an update and effect related to mechanism of drug action. Pain 1999:83:389-400.

117. Collins SL; Moore RA, McQuayHj, Wiffen P. Antidepressants and anticonvulsants for diabetic neuropathy and postherpetic neuralgia: a quantitative systematic review. I Pain Symptom Marnage $2000,20: 449-58$

118. McQuay HJ, Tramer M, Nye BA. Carroll D, Wiffen PJ, Moore RA. A systematic review of antidepressants in neuropathic pain. Pain 1996;68:217-27.

119. Gimbel JS. Richards P. Portenoy RK. Controlled-release oxycodone for pain in diabetic neuropathy: a randomized controlled trial. Neurology 2003;60:927-34.

120. Zhang WY, Li Wan Po A. The effectiveness of topically applied capsaicin. A metawanalysis. Eur J Clin Pharmacol 1994;46:517-22.

121. Treatment of painful diabetic neuropathy with topical capsaicin. A multicenter, double-blind, vehicle-controlled study. The Capsaicin Study Group. Arch intern Med 1991;151:2225-9.

122. Blesbroeck $R$, Bril $V$ "Hollander P, Kabadi U, Schwartz S, Singh SP. Ward WK, Bernstein JE A double-blind comparison of topical capsaicin and oral amitriptyline in painful diabetic neu. ropathy. Adw Ther 1995;12:111-20.

123. Sindrup $\mathrm{SH}_{0}$ Jensen TS. Pharmacologic treatment of pain in polyneuropathy. Neurology 2000:55:915-20.

124. Kieburtz K, Simpson D, Yiannoutsas C, Max MB, Hall CD, Ellis RJ, Marra CM, McKendall R, Singer E, Dal Pan G.J, Clifford DB, Tucker T, Cohen B. A randomized trial of amitriptyline and mexiletine for painful neuropathy in HIV infection. AlDS Clinical Trial Group 242 Protocol Team. Neurology 1998;51:1682-8.

125. Shlay JC, Chaloner $K$, Max MB, Flaws $B$, Reichelderfer $P$, Wentworth D, Hillman $S$, Brizz $B$, Cohn DL. Acupuncture and amitriptyline for pain due to HIV-related peripheral neuropathy: a randomized controlled trial. Terry Beirn Community Programs for Clinicial Research on AIDS. Jame 1998;280:1590-5.

126. Paice JA, Ferrans CE, Lashley FR, Shott $S$, Vizgirda V. Pitrak D. Topical capsaicin in the management of HIV-associated peripheral neuropathy. I Pain Symptom Manage 2000;19: 45-52.

127. Simpson DM, Olney $R$, MCArthur JC, Khan $A_{\text {. }}$ Godbold J, Ebel-Frommer K. A placebocontralled trial of lamotrigine for painful HIV-associated neuropathy. Neurology 2000;54: 2115.9

128. Simpson DM, MCArthur JC. Olney R, Clifford D, So Y, Ross D, Baird BJ, Barrett P, Hammer $A E$; Lamotrigine HIV Neuropathy Study Team. Lamotrigine for HIV-associated painful senw sory neuropathies: a placebo-controlled trial. Neurology 2003;60:1508-14.

129. Boulton AJ. Levin S, Comstock J. A multicentre trial of the aldose-reductase inhibitor. tolrestat, in patients with symptomatic diabetic neuropathy. Diabetologia 1990;33:431-7.

130. Ziegler $D$, Mayer P. Rathmiann W. Gries FA. One-year treatment with the aldose reductase inhibitor, ponalrestat, in diabetic neuropathy. Diabeles Res Chin Pract 1991;14:63-73.

131. Maclead AF, Boulton A.J, Owens DR, Van Rooy P, Van Gerven JM, Macrury S, Scarpello JH, Segers $O$, Heller SR, Van Der Veen EA. A multicentre trial of the aldose-reductase inhibitor tolrestat, in patients with symptomatic diabetic peripheral neuropathy. North European Tolrestat Study Group. Diabete Metab 1992;18:14-20. 
132. Hotta N, Toyota T, Matsuoka K, Shigeta $Y$, Kikkawa R, Kaneko T, Takahashi A, Sugimura $K_{n}$ Koike $Y$, Ishii J, Sakamoto $N_{\text {: }}$ SNK-860 Diabetic Neuropathy Study Group. Clinical efficacy of fidarestat, a novel aldose reductase inhibitor, for diabetic peripheral neuropathy: a 52-week multicenter placebo-controlled double-blind parallel group study. Diaberes Care 2001:24: $1776-82$.

133. The effect of intensive diabetes therapy on the development and progression of neuropathy. The Diabetes Control and Complications Trial Research Group. Ann Intern Med 1995:122: $561-8$.

134. Dyck PJ, Davies JL, Litchy WJ, O'Brien PC. Longitudinal assessment of diabetic polyneuropathy using a composite score in the Rochester Diabetic Neuropathy Study cohort. Neurology 1997;49:229-39.

135. Ziegler D, Hanefeld M, Ruhnau KJ, Meissner HP, Lobisch M, Schutte K, Gries FA. Treatment of symptomatic diabetic peripheral neuropathy with the anti-oxidant alpha-lipoic acid. A 3week multicentre randomized controlled trial (ALADIN Study). Diabetologia 1995;38:1425-33.

136. Levi-Montalcini $R$. The nerve growth factor 35 years later. Science 1987;237:1154-62.

137. Hellweg $R$, Hartung HD. Endogenous levels of nerwe growth factor (NGF) are altered in experimental diabetes mellitus: a possible role for NGF in the pathogenesis of diabetic neuropathy. INeurosci Res 1990;26:258-67.

138. MCArthur JC, Yiannoutsos C. Simpson DM. Adornato BT, Singer EJ. Hollander H, Marra C. Rubin $M$, Cohen BA, Tucker T, Navia BA, Schifitto $G$, Katzenstein D, Rask C, Zaborski L, Smith ME, Shriver S. Millar L, Clifford DB, Karalnik IJ. A phase II trial of nerve growth factor for sensory neuropathy associated with HIV infection. AIDS Clinical Trials Group Team 291. Neurology 2000;54:1080-8.

139. Aptel SC. Neurotrophic factors and diabetic peripheral neuropathy, Eur Neurol 199941: $27-34$

140. Apfel SC, Kessler JA, Adlomato BT, Litchy WJ, Sanders C, Rask CA. Recombinant human nerve growth factor in the treatment of diabetic polyneuropathy. NGF Study Group. Neurology" 1998;51:695-702.

141. Kumar D. Marshall HJ. Diabetic peripheral neuropathy: amelioration of pain with transcutaneous electrostimulation. Diabetes Care 1997:20:1702-5.

142. Dyck PJ. Neuronal atrophy and degeneration predominantly affecting peripheral sensory and autonomic neurons. Dyck. PJ, Thomas PK, Griffin JW, et al, eds. Peripheral neuropathy. Philadelphia: WB Saunders 1993:1065-93.

143. Hilz MJ, Stemper B, Axelrod FB. Sympathetic skin response differentiates hereditary sensory autonomic neuropathies $\mathrm{II}$ and IV. Neurology 1999;52:1652-7.

144. Goebel HH, Veit S, Dyck PJ. Confirmation of virtual unmyelinated fiber absence in hereditary sensory neuropathy type IV. I Neuropathol Exp Neurol 1980;39:670-5.

145. Ohnishi A, Dyck PJ. Loss of small peripheral sensory neurons in Fabry's disease. Arch Neurol 1974:31:120-127.

146. Dutsch $M$, Marthol $H$, Stemper $B$, Brys $M$, Haend $T$, Hilz MJ. Small fiber dysfunction predominates in Fabry neuropathy. J Cinn Neurophysiol 2002:19:575-86.

147. Nolano M. Provitera $V$, Crisci $C$, Saltalamacchia AM, Wendelschafer-Crabb G, Kennedy WR, Filla $A$, Santoro $L$. Caruso $G$. Small fibers involvement in Friedreich's ataxia. Ann Nourol 2001:50:17-25.

148. Said G. Slama G. Selva J. Progressive centripetal degeneration of axons in small fibre diabetic polyneuropathy. Brain 1983;106:791-807.

149. Brown MUl, Martin JR. Asbury AK. Painful diabetic neuropathy. A morphometric study. Arch Neurol 1976;33:164-71.

150. Holland $\mathrm{N}$. Idiopathic painful sensory neuropathy. $J$ Clin Neuromusc Dis 2001;2:211-20.

151. Hilz MJ, Zimmermann P, Claus D, Neundorfer $B$. Termal Threshold determination in alcoholic polyneuropathy: an improvement of diagnosis. Acta Neurol Scand 1995:91:389-93.

152. Koike $H_{\text {, Mori }} K_{r}, M i s u K$, et al. Painful alcoholic polyneuropathy with predominant small-fiber loss and normal thiamine status. Neurology 2001;56:1727-32.

153. Kelly $\mathrm{IJ} J \mathrm{Jr}$. Kyle RA, O'Brien PC, Dyck PJ. The natural history of peripheral neuropathy in primary systemic amyloidosis. Ann Neurol 1979:6:1-7. 
154. Verghese JP. Bradley WG, Nemni R. McAdam KP. Amyloid neuropathy in multiple myeloma and other plasma cell dyscrasias. A hypothesis of the pathogervesis of amyloid neuropathies. INeurol Sci $1983 ; 59: 237-46$.

155. Kissel JT. Mendell JR. Neuropathies associated with monoclonal gammopathies. Neuromuscul Disord 1996:6:3-18.

156. Zafrir $B$, Zimmerman $M$. Fellig $Y$, Naparstek $Y$, Reichman N. Flatau $E$. Small fiber neuropathy due to isolated vasculitis of the peripheral nervous system. Isr Med Assoc J 2004;6:183-4.

157. Omdal $\mathbb{R}_{\text {, }}$ Bekkelund St, Mellgren SI, Husby G. C-fibre function in systemic upus erythematosus. Lupus 1996:5:613-7

158. Seneviratne U. Gunasekera S. Acute small fibre sensory neuropathy: another variant of Guillain-Barre Syndrome? J Neurol Neurosurg Psychiatry 2002:72:540-2.

159. Kaida $K$, Kamakura $K$, Masaki $T$, Okano $M_{\text {: }}$ Nagata $N$, Inoue $K$. Pairful small-fibre multifocal mononeuropathy and local myositis following influenza B infection. J Neuraf Sol 1997;151: $103-6$.

160. Portegies $P$. Rosenberg NR. Sensory neuropathy in HN infection: pathogenesis and therapy. Med Tijdschr Geneeskd 2001;145:731-5.

161. Cornblath DR, MCArthur JC, Parry $G$. Griffin JW. Peripheral neuropathy in human immune deficiency virus infection. Dyck PJ, Thomas PK, Griffin JW, el al, eds. Peripheral neuropathy. Philadelphia: WB Saunders 1992.

162. Dabby $R$, Weimer $L H$. Hays $A P$, Olarte $M$, Latov $N$. Antisulfatide antibodies in neuropathy: clinical and electrophysiologic correlates. Neurology 2000,54:1448-52.

163. McManis PG. Windebank AJl, Kiziltan M. Neuropathy associated with hyperlipidemia. Neurology 1994;44:2185-6.

164. Kurvers HA, Jacobs MJ, Beuk RJ, van den Wildenberg FA, Kitslaar PJ, Slaaf DW, Reneman RS. The spinall component to skin blood flow abnormalities in reflex sympathetic dystrophy. Arch Neurol 1996;53:58-65.

165. Birklein F. Kunzel W, Sieweke N. Despite clinical similarities there are significant differences between acute limb trauma and complex regional pain syndrome I (CRPS I). Pain 2001; 93:165 71 .

166. Birklein F. Schmelz M, Schifter $S$, Weber $M$. The important rale of neuropeptides in complex regional pain syndrame. Neurology 2001;57:2179-84.

167. Howwich MS, Cho L Porro RS, Posner JB. Subacute sensory neuropathy: a remote effect of carcinoma. Ann Neurol 1977;2:7-19.

168. Chalk $C H$, Windebank AJ, Kimmel DW, McManis PG. The distinctive clinicall features of paraneoplastic sensory neuronopathy. Can J Neurol Sci 1992;19:346-51.

169. Blum AS, Dal Pan GJ, Feinberg J. Raines C, Mayjo K, Comblath DR, MCArthur JC. Low-dose zalcitabine-related toxic neuropathy: frequency, naturall history, and risk factors. Neurology 1996;46:899-1003.

170. Bradley WG, Karisson IJ, Rassol CG. Metronidazole neuropathy. Br Mod $/ 1977: 2: 610-1$.

171. Lo YL, Leoh TH, Loh LM, Tan CE. Statin therapy and small fibre neuropathy: a serial alectrophysiological study. J Neurol Sci 2003;208:105-8.

172. Saudek $\mathrm{CD}_{n}$ Werns $S$, Reidenberg MM. Phenytoin in the treatment of diabetic symmetrical polyneuropathy. Clin Phamacol Ther 1977;22:196-9.

173. Gorson KC, Schott C, Herman R, Ropper AH, Rand WM. Gabapentin in the treatment of painful diabetic neuropathy: a placebo controlled, double blind, crossover trial. I Neurol Neurosurg Psychiatry 1999;66:251-2. 


\section{Chapter 4}

Impact of pain in a Dutch sarcoidosis patient population

E Hoitsma, J De Vries, M van Santen-Hoeufft, CG Faber; M Drent

Sarcoidosis Vasc Diffuse Lung Dis 2003;20;33-9 


\section{Abstract}

\section{Bawground and aim}

Athough pain is prevalent in sarcoidosis, this has never been studied systematically. The aim of the present study was to evaluate the presence and impact of pain in sarcoidosis.

\section{Methods}

Members from the Dutch Sarcoidosis Society without co-morbidity $(n=821)$ participated in this study. The World Health Organisation Quality of Life assessment instrument (WHOQOL-100) was completed, as well as a symptom inventory questionnaire addressing the presence of various categories of pain, i.e. muscle pain, chest pain, abdominal pain, arthralgia, and/or headache.

\section{Resuls}

Pain was reported by 594 patients $(72.4 \%)$. Arthralgia was experienced most trequently $(53.8 \%)$, followed by muscle pain $(40.2 \%)$, headache $(28.0 \%)$ and chest pain $(26.9 \%)$. The number of types of pain a patient was suffering from (ranging from 0-5) was related to the WHOQOL-100 Pair and Discomfort scale $(r=0.49, p<0.001)$. Patients with more types of pain had lower quality of life (QOL). Im addition, the total amount of experienced pain categories was associated with the WHOQOL-100 domain Level of Independence $(r=-0.43, p<0.001)$, and the facet Energy and Fatigue $(r=-0.38, p<0.001)$. The number of types of pain was predicted by using analgesics, psychological/neurological medication, NSAIDs, being female "indicating to feel tired, more negative feelings and less energy $(F(7.635)=35.2, p<0.001 ; R 2=27.9 \%)$.

\section{Conclusion}

Pain appeared to be a major problem in sarcoidosis, especially arthralgia. Although negative feelings and fatigue were related to pain, it could not fully explain pain. Fulure studies are needed to address mechanisms of pain, pain behaviour, and the best therapeutic approach of pain ìn sarcoldosis. 


\section{Introduction}

Sarcoidosis is a disseminated granutomatous disease of unknown origin. ${ }^{~}$ Depending on the organs involved and the severity of granulomatous inflammation, patients suffer from a broad range of persistent physical symptoms. Besides respiratory symptoms such as coughing and dyspnoea on exertion, patients often suffer from systemic nonspecific symptoms such as fatigue and pain. ${ }^{2-5}$ Non-specific symptoms have an important impact on the quality of life of sarcoidosis patients. ${ }^{6.8}$ Assessment of quality of Bife (QOL) with the World Health Organisation Quality of Life assessment instrument (WHOQOL-100) appeared to be of additional value in the follow-up of sarcoidosis patients as well as patients suffering from meumatoid arthritis.

One of the non-specific symptoms in sarcoidosis is pain. Pain is considered to be a reflex response to underlying somatic pathology. However, pain is not a mere medical problem. There is growing evidence for the contribution of psychosocial variables in the prediction of pain and disability ${ }^{9.10}$ In the follow-up of sarcoidosis patients, results of routine tests to assess disease activity (including clinical investigation, chest radiography, ung function lesting, serum angiotensin converting enzyme (SACE) measurement, gallim-67 scamning, bronchoalveolar lavage parameters) do not measure paim. Therefore, these test results do not always correlate with the well-being of the patient. ${ }^{11}$ Consequently, the question arises if dysphoric symptoms are functional, i.e, based on psychogenic influences or are manifestations of the underlying organic disease. ${ }^{12}$ Anecdotal reports describe pain in sarcoidosis in relation to several organic disorders such as arthropathies, ${ }^{13-17}$ polyneuropathy, ${ }^{18-27}$ myopathy, ${ }^{20-34}$ chest pain, ${ }^{35-39}$ and headache. ${ }^{40-43}$ However, until now pain in sarcoidosis has never been studied systematically.

The aim of the present study was to evaluate the presence of various pain categories in sarcoidosis and the relationship between pain and quality of life assessed with the WHOQOL-100.

\section{Materials and methods}

\section{Study population}

All 1755 members of the Dutch Sarcoidosis Society (DSS) suffering from sarcoidosis were sent a test-booklet together with a letter from the DSS in which they were asked to participate in an in-depth study on quality of life and symptoms. All data including diagnosis, were recruited from the patients. Of the 1093 patients $(62.3 \%$ ) who responded, 1026 (58.5\% of the total group) completed the questionnaires. The remaining 
67 persons gave a number of reasons why they did not wish to participate in the study. The main reasons included (i) the innumerable list of questions, (ii) lack of time, (iii) the absence of symptoms, and (iv) the fact that the diagnosis was made quite some time ago. Eight persons returned the test-booklet without giving any reason. As we wanted to focus on pain related to sarcoidosis, only responders without co-morbidity $(n=821)$ were included in the present study and patients with relevant comorbidity were excluded. Comorbidity was defined as any medical problem not related to sarcoidosis. The control group consisted of persons who were recruited through a random digit dialling method $(n=178)$. For patient characteristics see table 4.1 .

Table 4.1 Characteristics of the sfudied sarcoidosis patien population $(n=824)$

\begin{tabular}{|c|c|c|}
\hline & $\begin{array}{l}\text { Number of casies } \\
\text { yes /no /missing }\end{array}$ & $\begin{array}{l}\text { Percentage of the total population } \\
\text { yes /no /missing }\end{array}$ \\
\hline Gender maleffermale/missing & $305 / 508 / 8$ & $37 / 62 / 1$ \\
\hline Current smoking status & $87 / 714 / 40$ & $8 / 87 / 5$ \\
\hline Age (years) & $46 \pm 12(16-74)$ & \\
\hline Wliness duration (years)" & $9 \pm 9(0-49)$ & \\
\hline Uness duration (> 2 years) & $625 / 133 / 63$ & $76 / 16 / 8$ \\
\hline Pulimonary irvolwemernt** & $606 / 69 / 119$ & $74 / 12 / 15$ \\
\hline Use of NSADS & $259 / 521 / 41$ & $32 / 64 / 5$ \\
\hline Use of analgesics & $268 / 512 / 41$ & $33 / 62 / 5$ \\
\hline Use of psychologicalneurological drugs & $100 / 680 / 41$ & $12 / 83 / 5$ \\
\hline Use of oral steroids & $469 / 311 / 41$ & $57 / 38 / 5$ \\
\hline Using oral steroids as well as NSAIDs. & $157 / 623 / 41$ & $19 / 76 / 5$ \\
\hline Fatigue: & $599 / 214 / 8$ & $73 / 26 / 1$ \\
\hline Ereathlessiness & $628 / 147 / 46$ & $77 / 18 / 6$ \\
\hline Paîn & $594 / 209 / 18$ & $72 / 26 / 2$ \\
\hline Muscle pain & $330 / 488 / 3$ & $40 / 59 / 0$ \\
\hline Chest pain & $221 / 598 / 2$ & $27 / 73 / 0$ \\
\hline Abdominal pain & $97 / 722 / 2$ & $12 / 88 / 0$ \\
\hline Arthralgiza & $442 / 377 / 2$ & $54 / 46 / 0$ \\
\hline Headache & $230 / 575 / 18$ & $28 / 70 / 2$ \\
\hline
\end{tabular}

Duter ane expesed as mean with standard deviation (SD) in parantheses.

- Meantostendard devilation with range in parentheses:

Presence of pulmonary involvament was based on the presence of cough and/or dyspnoea and/or dyspnoea on axertion; NSAIDs= non steroidal anti-inflammatory drugs

\section{Questionnaires}

\section{Symplom inventory questionaire}

The questionnaire consisted of 43 items including questions concerning sociodemographic and medical data such as medical history, family history, duration of disease, diagnostic procedures, treatment, and current symptoms. This questionnaire also included questions focussing on the presence of various categories of pain, 
including muscle pain, chest pain, abdominal pain, arthralgla, impaired mobily and/or headache. Most of the questions were multiple choice, sometimes giving the possibility to tick more than one answer. A number of questions were open-ended, allowing patients to give information concerning their personal situation. The questionnatre was not standardized or validated. It was pre-tested in a population of 10 sarcoidosis patients. ${ }^{2}$

\section{WHOOL-100}

All subjects and healthy controls completed the World Health Organization Quality of Life assessment instrument-100 (WHOQOL-100; Dutch version) ${ }^{11}$, a cross-culturally developed generic multidimensional QOL measure. It consists of 100 items assessing 24 facets of QOL within six domains (Physical health. Psychological health, Level of independence, Social relationships, Environment, and Spirituality/religion/personal beliefs) and a general evaluative facet (Overall quality of life and general health). Each facel is represented by four items. The response scale is a 5-point Likert scale. Scores on each facet and domain can range from 4 to 20. Higher scores indicate a better $Q O L$. with the exception of the facets Pain and discomfort. Negative feelings, and Dependence on medication or treatments, where low scores indicate higher $\mathrm{QOL}$. The reliability and validity of the instrument, which have also been tested in sarcoidosis, are good. ${ }^{11,44}$ The test-retest reliability is satisfactory. ${ }^{45}$

\section{Statistical analysis}

Frequencies were used for the descriptive information. Kruskal-Wallis tests were performed to establish possible differences in QOL between patients with pain $(\mathrm{n}=594$; group 11, patients without pain ( $n=209$; group 11), and the healthy control group $(n=178)$. A Chi-square analysis was used to examine the relationship between shortness of breath and chest pain. Pearson correlations were used to examine the relationship between the WHOQOL-100 and the number of types of pain. Mann-Whitney $U$ tesits were performed to further estabish the relationship between a type of pain and scores on the WHOQOL-100 facet Pain and Discomfort. A p-value below 0.01 was considered statistically significant. One multiple linear regression analysis (stepwise) and a series of logistic regression analyses were performed. Before the linear regression analysis was performed, the linear assumptions were tested. Normality was examined using histograms with kurtosis and skew ness. All variables should be normality distributed. Subsequently, linearity and homoscedasticity were tested using (partial) plots with standardized residuals and standardized predicted walues. In the present study, the linear assumptions were not violated and hence a linear regression analysis was allowed. Each regression analysis was done in block 1 with age. sex, and current 
smoking status. Block 2 consisted of the use of oral steroids, the use of analgesics, psychological/neurological medication, the use of non-steroidal anti-inflammatory drugs (NSAIDs) and illness duration. Finally, block 3 contained feeling tired (yes/no) and the WHOQOL-100 facets Energy and fatigue and Negative feelings. Pearson correlations were performed between illness duration and QOL. Due to the large sample size only correlations above 0.14 were considered statistically significant

\section{Results}

\section{Characteristics}

Characteristics of the studied sarcoidosis patient population are summarized in table 4.1 (females $61.9 \%$ ). The mean age was 46.3 years. Medication was used by $80.4 \%$ of the patients. The reported medication used included NSADS, analgesics, psychological or neurological medication, and oral steroids. Only one of the four mentioned types of drugs was used by $36.4 \%$ of the patients, whereas $44 \%$ of the patients used at least two types of drugs. The most frequently prescribed drugs were oral steroids $(57.1 \%)$, followed by analgesics $(32.6 \%)$. Regarding the location of sarcoid, there were 69 $(11.7 \%)$ patients without putmonary involvement and $606(73.8 \%)$ patients with pulmonary involvement and for $119(14.5 \%)$ patients these data were not available (pulmonary involvement was based on the presence of cough and/or dyspnoea and/or dyspnoea on exertion).

\section{Fatigue}

A large proportion of the patients reported to feel tired (73.0\%). The mean scores on the WHOQOL-100 facets Energy and Fatigue and Negative Feelings were 10.2 (SD=3.3; range $4-20)$ and $10.8(S D=3.2$; range $4-20)$, respectively. Sarcoidosis patients reported significantly more fatigue $(p<0.001 ; t=36.6)$ and negative feelings $(p<0.001 ; t=12.5)$ than healthy controls.

\section{Pain}

The majority of the patients (72.4\%) reported at least one type of pain. Arthralgia was experienced most frequently $(53.8 \%)$ followed by muscle pain $(40.2 \%)$, headache $(28.0 \%)$. chest pain $(26.9 \%)$ and abdominal pain $(11.8 \%)$. In the age group up to 45 years $196(48.8 \%)$ patients suffered from arthralgia and $206(51.2 \%)$ did not, whereas in the age group above 45 years $246(58.7 \%)$ patients suffered from arthralgia, 171 $(40.8 \%)$ did not have arthralgia and $2(0.5 \%)$ were missing. Two hundred and eleven 
(25.7\%) patients suffered from only one type of pain, mainly arthralgia $(54.5 \%)$ or headache $(21.3 \%)$. Patients with breathlessness often also reported chest pain (Chi-square $=34.7 ; p<0.001$ ). Having more types of pain (possible range $0=$ no pain to 5 = all types of pain) was associated with all WHOQOL-100 domains and facets except the facet Body Image and Appearance and the domain Spirituality. The correlations were strongest for the domains Physical Health $(r=-0.48)$ and Level of Independence $(r=-0.43)$ and the facets Pain and Discomfort $(r=0.49)$. Activities of Daily Living $(r=-0.42)$, Energy and Fatigue $(r=-0.38)$, Mobility $(r=-0.38)$, and Working Capacily $(r=-0.37$; all $p$ s $<0.001$ ). In figure 4.1 WHOQOL-100 scores per domain for sarcoidosis patients with pain $(n=594)$, sarcoidosis patients without pain $(n=209)$ and healthy controls $(n=178)$ are shown. QOL scores of all domains except spirituality were significantly lower in patients with (any type of) pain compared with patients without pain. Sarcoidosis patients who indicated not to suffer from pain had the same score on the facet Pain and discomfort as the control group (mean 9.7 and 9.5 , respectively).

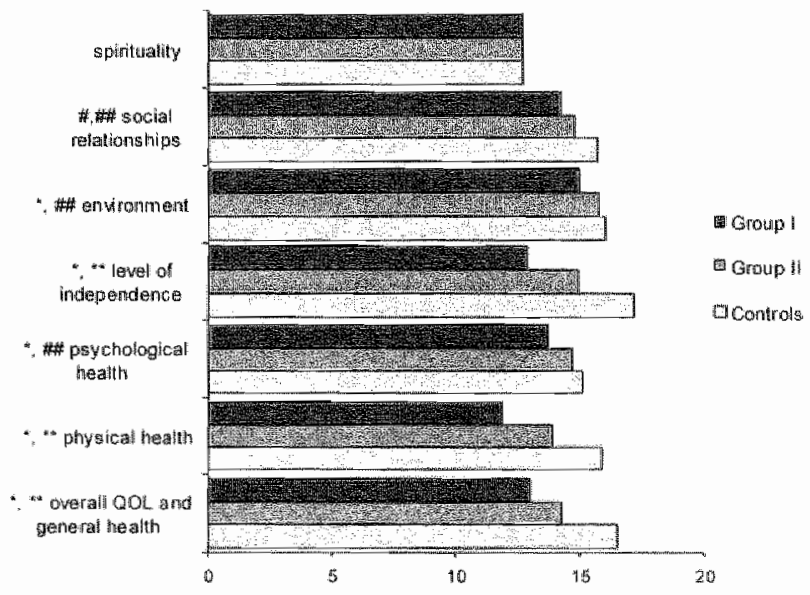

Figure 4. 1 WHOQOL-100 scores in sarcoidosis patients with pain (group 1): sarcoidosis palients without pain

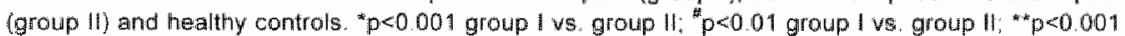
both group I and group |ll vs. controls: p<0.001 group 1 ws. controls.

Spirituality; Social Relationships: Personal relationships, Social support, Sewual artivity; Enwironment: Physical safety and security. Home environment, Finaricial resources. Haalth and social care. New information and skills. Recreationileisure. Physical environment, Transpon; Level of Independ ence: Mobility. Activities of daily living, Medication/traatment Working capacity; Psychological Health: Positive feelings, Cognitive functions, Self estem, Body image, Negative feelings; Physical Mealth: Pain and discomfort, Energy and fatigue, Sleep and rest

Subsequently, a multiple regression analysis with the number of pain categories that a patient was suffering from (ranging from 0 to 5 ) as dependent variable was performed. Being female, using analgesics, psychological / neurological drugs and NSAIDs, 
indicating to feel tired, scoring low on the WHOQOL-100 facel Energy and Fatigue, and scoring high on the facet Negative feelings together explained $27.9 \%$ of the variance of the number of pains $(F(7.635)=35.2, p<0.001)$.

The results from the logistic regression analyses are presented in table 4.2 .

Table 4.2 Relation betwen the different types of pain and sex medication, fatigue and megative feelings

\begin{tabular}{|c|c|c|c|}
\hline Yariables & & Odds Ratio & Confidence interval \\
\hline \multirow[t]{6}{*}{ Pain } & $-S e x($ malle $)$ & 0.54 & $0.37-0.80^{2}$ \\
\hline & - NSAIDS & 1.70 & $1.05-2.74^{1}$ \\
\hline & Analgesics & 2.44 & $1.48-4.05^{2}$ \\
\hline & Feeling tired & 1.59 & $1.00-2.54$ \\
\hline & WHOQOL - 100 facel Energy and Fatigue & 0.90 & $0.840 .97^{2}$ \\
\hline & - WHOQOL-100 facet Negativa Feelings & 1.10 & $1.02-1.18^{1}$ \\
\hline \multirow[t]{9}{*}{ Muscle pain } & - Sex (male) & 0.75 & $0.52-1.08$ \\
\hline & - Iliness duration: $\quad 1-4.9$ years & 1.89 & $1.12-3.19^{4}$ \\
\hline & $5-9.9$ years & 2.07 & $1.15-3.71^{1}$ \\
\hline & $\geq 10$ years & 2.68 & $1.56-4.62^{3}$ \\
\hline & - NSALDs & 1.45 & 0.992 .12 \\
\hline & - Oral steroids & 0.62 & $0.43-0.89^{2}$ \\
\hline & - Analgesics & 2.40 & $1.64-3.51^{3}$ \\
\hline & - Psychologicalineurological drugs & 1.40 & $0.83-2.34$ \\
\hline & - WHOQOL-100 facet Energy and Fatigue & 0.86 & $0.01-0.914^{3}$ \\
\hline \multirow[t]{6}{*}{ Chest pain } & - Sex (malle) & 0.55 & $0.36-0.82^{2}$ \\
\hline & - Analgesics & 1.81 & $1.23-2.65^{2}$ \\
\hline & . Psychologicallineurological arugs & 1.27 & $0.75-2.15$ \\
\hline & - Feeling tired & 196 & $1.11 .3 .46^{1}$ \\
\hline & - WHOQOL-100 facel Energy and Fatigue & 0.86 & $0.80-0.93^{3}$ \\
\hline & - WHOQOL-100 facel Negative Feelings & 1.09 & $1.02-1.17^{1}$ \\
\hline \multirow[t]{4}{*}{ Abdominal pain } & Sex (male) & 0.44 & $0.24-0.81^{2}$ \\
\hline & - Psychological/neurological drugs & 1.38 & $0.73-2.61$ \\
\hline & - WHOQOL 100 face Energy and Fatigue & 0.87 & $0.79-0.96^{2}$ \\
\hline & - WHOQOL... 00 facel Negative felings & 1.10 & $1.00-1.20^{1}$ \\
\hline \multirow[t]{8}{*}{ Arthralgia } & - Sex (male) & 0.65 & $0.46-0.92$ \\
\hline & - Hllness duration: $11-4.9$ years & 1.54 & $0.95-2.512$ \\
\hline & $5-9.9$ years & 220 & $1.25-3.35^{2}$ \\
\hline & $\approx 10$ years & 1.99 & $1.19-3.33^{2}$ \\
\hline & - NSAIDS & 1.68 & $9.15-2.47^{2}$ \\
\hline & - Oral steroids & 0.59 & $0.42-0.85^{2}$ \\
\hline & Analgesics & 2.64 & $1.78-3.91^{3}$ \\
\hline & - Feoling tired & 2.77 & $1.87-4.09^{3}$ \\
\hline \multirow[t]{4}{*}{ Headactho } & - Sext (male) & 0.74 & $0.50-1.09$ \\
\hline & Analgesics & 2.12 & $1.45 \cdot 3.08^{3}$ \\
\hline & - WHOQOL-100 facet Energy and Fratigue & 0.92 & $0.96 .0 .98^{\circ}$ \\
\hline & - WHOQOL"100 facet Negative Feelings & 1.15 & $1.08-1.23^{3}$ \\
\hline
\end{tabular}

Note: "p<0.05; ${ }^{2}$ p<0.01; ; $p<0.001$ : NSADS: non siteroidal anti-inflammatory drugs; WHOQOL-1001: World Hoalth Organisation Quality of Life assessment instrument 
Having pain was predicted by being male, using analgesics and NSAIDs, indicating to feel tired, scoring low on the WHOQOL-100 facet Energy and Fatigue and high on the WHOQOL-100 facet Negative Feelings. Looking at the type of pain reported, it appeared that the use of analgesics was related to all types of pain except abdominal pain. From the other drugs, psychological/ neurological drugs were related to chest pain, muscle pain, and abdominal pain, while the Use of NSAIDs as well as not using oral steroids appeared to be related to muscle pain and arthralgia.

lliness duration played a role in muscle pain and arthralgia: patients with chronic sarcoidosis (illness duration more than 2 years) reported more often muscle pain (chim square $=5.50, p<0.05$ ) and arthralgia (chi-square $=6.97, p<0.01$ ). Lower scores on the WHOQOL-100 facet Energy and Fatigue predicted muscle pain, chest pain, abdominal pain, and headache, while answering yes on the single item indicating to feel tired predicted chest pain and arthralgia. A high score on the facet Negative Feelings was related to chest pain, abdominal pain, and headache (table 4.2).

No relation was found between illness duration and $Q O L$.

\section{Discussion}

Pain was frequent in the studied sarcoidosis population $(n=821): 72.4 \%$ reported at least one type of pain. Furthermore, sarcoidosis patients with pain appeared to have significantly lower quality of life scores than sarcoidosis patients without pain. Pain in our sarcoidosis population involves mainly arthralgia, which seems to have a predilection for the knees, followed by ankles and shoulders. The second most prevalent pain reported appeared to be muscle pain, mostly reported in the lower limbs. A large proportion of the patients reported to feel tired and reported negative feelings. Further more, these feelings were related to pain. However, no indication was found that the pain was merely the result of psychogenic influences. Although negative feelings and fatigue were related to pain, they can only explain a part of the pain. Regarding the impact of gender on pain, females reported more different types of pain whereas male gender was a predictor for having one particular type of pain. Other factors involved in pain in sarcoidosis need to be explored.

Though arthralgia as well as myalgia were frequent in our sarcoidosis population, which consists mainly of Caucasians, arthritis as well as myositis and dactylitis in relation to sarcoidosis are very rare in Caucasians. Therefore, the cause of arthralgia and myalgia often remains unclear. We have the impression that the pain mostly is of noninflammatory character: without morning- or starting stiffness and worse after exertion in comparison to the pain at rest. Furthermore, although prostaglandin $E_{2}$ is a very potent stimulator of peripheral pain receptors and hyperalgia ${ }^{46}$, in most cases NSAIDs fail to 
relieve pain sufficiently. This gives rise to the hypothesis that the pathophysiology is not merely prostaglandin related. In a group of sarcoidosis patients referred to our hospital we found some patients reported paraesthesias and symptoms of autonomic dysfunction along with their pain in a pattern that was highly suggestive for small fiber neuropathy. Recently, the presence of small fiber neuropathy in this subset of sarcoidosis patients was confirmed. ${ }^{47}$ A more precise characterisation of different pain categories in different situations in sarcoidosis is needed to better understand the pathophysiology and underlying mechanisms leading to pain in sarcoidosis.

In treating the sarcoidosis patient with pain, symptomatic (neuropathic) pain treatment such as gabapentine or amitryptilin is indicated in case of small fiber neuropathy. ${ }^{47}$ However, optimal treatment should be beneficial in both the inflammation process and the subjective symptoms such as fatigue and pain. It was suggested that in sarcoidosis. as in other immune mediated disorders, constitutional symptoms, especially fatigue and pain, may be caused by circulating cytokines such as TNF- $\alpha$ and interleukin (IL)-1., 9,48 Several effective treatment regimens for sarcoidosis such as steroids and more recently infliximab, suppress TNF-a production or release. ${ }^{49.50}$ Therefore, these might be beneficial in reducing disease activity as well as in reducing pain and fatigue.

Using patient organisations provides the opportunity to gather information concerning a large number of patients in a short time span. However, critics point out that it is not known whether members of a certain patient organisation are representative of the particular patient population at large. Previously, it was demonstrated that members of the sarcoidosis patient organisation had lower QOL than non-members. ${ }^{44}$ However, after correction for the presence of symptoms, most differences disappeared. Another problem might be the fact that members of a patient organisation more often suffer from chronic disease and QOL may vary with disease chronicity. However, we found no relation between illness duration and $\mathrm{QOL}$. In the present study $76.1 \%$ of the cases suffered from chronic disease (time since onset two or more years) whereas $16.2 \%$ suffered from a disease history of less than two years $(7.7 \%$ missing) (table 4.1$)$. The chronic cases reported more arthralgia and muscle pain compared to those with a shorter disease history. Although the members of the DSS members are not completely representative of sarcoidosis patients in general, in the large group of patients studied (821 patients), which might be representative for chronic sarcoidosis patients, pain appeared to be a substantial problem. Another limitation of the study might be the acquisition of pain by the symptom inventory questionnaire. This questionnaire is nat a validated or standardized tool. However, this questionnaire was used to make a pain inventory. Now that pain appears a major problem in sarcoidosis more detailed pain studies with in-depth pain questionnaires are needed. Furthermore, there might be a lack of specificity in this study, i.e. it cannot be excluded that arthralgia was partly due to coexistent degenerative joint disease. Similarly, abdominal discomfort could be 
medication induced. However, sarcoidosis patients with any lype of co-morbidity were excluded from the study. This approach ensures that existing co-morbidity interferes with pain as reported in the present study. Besides, in our experience degenerative joint disease is extremely rare in sarcoidosis. Moreover, $44.3 \%$ of all patients suffering from arthralgia are under 45 years of age. Arthrosis is highly unlikely at this age. Therefore. we consider it unlikely that degenerative joint disease causes arthralgia in a large proportion of our sarcoidosis patients. Regarding the relation between aboominal pain and medication, abdominal pain was in contrast to other types of pain not related to the use of analgesics or NSAIDs. Therefore, abdominal discomfort due to medication also appears unlikely.

Generally, the management of a sarcoidosis patient is coordinated by a pulmonologist. However, sarcoidosis is a multisystem disorder in which many other organ systerns may be involved. Extrapulmonary symptoms appeared to be a common problem in chronic sarcoidosis and do not always correlate with pulmonary symptoms. Moreover, lack of an objective system for assessment of sarcoidosis to evaluate disease course and effectiveness of therapy is a major problem. ${ }^{5.52}$ Therefore, in the evaluation of the efficacy of treatment, extrapulmonary parameters such as pain and fatigue need more attention, including sufficient questionnaires to add to the regular investigations. More knowledge is warranted to better understand the impact of extrapulimonary symptoms.

\section{Conclusions}

Pain is a major problem in sarcoidosis, especially arthralgia. Although negative feelings and faligue are rellated to pain, they cannot fully explain the pain. Future studies are needed to address the precise characteristics and the underlying mechanisms of pain, pain behaviour and coping, and the most appropriate therapeutic approach in sarcoidosis. As pain is a substantial problem in sarcoidosis, appropriate questionnaires gaining information about pain might be helpful. The simultaneously use of these question. naires, lung function tests, imaging procedures and other clinical markers of disease activity and severity may provide a framework for understanding how to correctly manage the intriguing disease sarcoidlosis. 


\section{References}

1. Hunninghake GW, Costabel U, Ando M. Baughman RP, Cordier JF, du Bois RM, Eklund $A_{\text {, }}$ Kitaichi M. Lynch J. Rizzato $G$, Rose $C$. Selroos $O$. Semenzato $G$, Shama OP. ATS/ERSNNASOG statement on sarcoidosis. American Thoracic Society/European Respiratory Society/World Association of Sarcoidosis and other Granulomatous Disorders. Sarcoidosis Vasc Diffuse Lung Dis 1999;16:149-73.

2. Wirnsberger RM, De Vries $J$, Wouters EFM. Orent $M$. Clinical presentation of sarcoidosis in The Netherlands an epidemiological study. Neth J Med 1998:53:53-60

3. Sharma OP. Fatigue and sarcoidosis. Eur Respir J 1999;13:713-4.

4. James DG. Complications of sarcoidosis. Chronic fatigue syndrome. Sarcoidosis 1993:10: $1-3$

5. Newman LS, Rose CS, Maier LA. Sarcoidosis. N Engl Med 1997;336:1224-34

6. Wirnsberger RM, De Vries J, Jansen TLThA, van Heck GL, Wouters EFM, Drent M. Impairment of quality of life: rheumatoid arthritis versus sarcoidosis. Neth $\mathcal{I}$ Med 1999;54: 86-95.

7. De Vries J, wan Heck GL, Drent M. Gender differences in sarcoidosis: symptoms, quality of life, and medical consumption. Women Health 1999;30:99-114.

8. Chang B. Steimel $J$, Moller DR, Baughman RP, Judson MA, Yeager $H J$ r, Teirstein AS, Rossman MD, Rand CS. Depression in sarcoidosis. Am J Respir Crit Care Med 2001;163: 329-34.

9. Crombez G, Vlaeyn JW. Heuts PH, Lysens R. Pain-related fear is more disabling than pain itself: evidence on the role of pain-related fear in chronic back pain disability. Pain 1999; $80: 329-39$

10. Sullivan MJ, Neish $\mathrm{N}$. The effects of disclosure on pain during dental hygiene treatment: the moderating role of catastrophizing. Pain 1999;79:155-63.

11. Wirnsberger RM, De Vries J, Breteler MHM, van Heck $G L$, Wouters EFM, Drent $M$. Evaluation of quality of life in sarcoidosis patients. Respir Med 1998;92:750-6.

12. DeRemee RD. Dysphoria and Sarcoidosis. Sarcoidosis Vaso Diffuse Lung Dis 1998;15:21.

13. Pierson DJ, Willett ES. Sarcoidosis presenting with finger pain. Jama 1978,239:2023-4.

14. Shaw RA, Holt PA, Stevens MB. Heel pain in sarcoidosis. Ann Intern Med 1988;109:675-7.

15. West SG, Gilbreath GE, Lawless OJ. Painful clubbing and sarcoidosis. Jama 1981;246: 1338-9.

16. Lichniak. JE. The heel in systemic disease. Clin Podiatr Med Surg 1990;7:225-41

17. Case records of the Massachusetts General Hospital. Weekly clinicopathological exercises Case 4-2001. A 26-year-old man with pain, erythema, and swelling of the legs. N Engf J Med $2001 ; 344: 443-9$.

18. Gainsborough N, Hall SM, Hughes RA, Leibowitz S. Sarcoid neuropathy. J Neurol 1991;238. $177-80$

19. Galassi G. Gilbertoni M. Mancini A, Nemni R, Volpi G, Merelli E, Vacca G. Sarcoidosis of the peripheral nerve: clinical, electrophysiological and histological study of two cases. Eur Neurol $1984: 23: 459-65$

20. Matthews WB. Sarcoid neuropathy. In: Dyck PJ. Thomas PK, Lambert EH. Bunge R, editors. Peripheral neuropathy. 2nd ed. Philadelphia: W.B. Saunders, 1984:2018-26.

21. Miller RN, Sheron N. Semple S. Sarcoidosis presenting with an acute Guillain-Barre syndrome. Postgrad Med J 1989;65:765-7.

22. Oh SJ. Sarcoid polyneuropathy: a histologically proved case. Ann Neurol 1980;7:178-81.

23. Dierkes-Globisch $A$, Schneiderhan W. Mohr $H$. Akutes Nierenversagen auf dem boen einer hyperkalzaemie und periphere plyneuropathie- seltene manifestationen Sarcoidose. Medizinische Klinik 2000;95:583-6.

24. Sharma OP. Neurosarcoidosis: a personal perspective based on the study of 37 patients. Chest 1997:112:220-8. 
25. Nemni $R$, Galassi $G$, Cohen $M$. Hays AP, Gould $R$, Singh $N$, Bressman $S$, Gamboa $E T$. Symmetric sarcoid polyneuropathy: analysis of a sural nerve biopsy. Neurology 1981:31: $1217-23$

26. Allen RK, Merory 4 . Intravenous pulse methyl prednisoione in the successfull treatment of severe sarcoid polyneuropathy with pulmonary involvement. Aust $N Z$ v Med 1985:15:45-6.

27. Scott TS, Brillman J. Gross JA. Sarcoidosis of the peripheral nervous system. Neurol Res 1993:15:389-90.

28. Gemignani $F$, Bellanova MF, Salih S, Margarito FP, Marbini A Sarcoid neuromyopathy with selective involvement of the intramuscular nerves. Acta Neuropathol (Berl) 1998;95:437-41

29. Otake S. Sarcoildosis involving skeletal muscle: imaging findings and relative value of imaging procedures. Am J Roentgenol 1994;162:369-75.

30. Scola RH, Werneck LC, Prevedelio DM, Greboge P. Iwamoto FM. Symptomatic muscle involvement in neurosarcoidosis: a clinicopathological study of 5 cases. Arq Neuropsiquiatr 2001:59:347-52.

31. Reichmann $H$, Schalke $B$. Seibel $P$, Naumann $M$, Toyka KV. Sarcoid myopathy and mitochondrial respiratory chain defects: clinicopathological, biochemical and molecular biological analyses. Neuromuscul Disord 1995;5:277-83.

32. Uddenfeldt $P$, Bjelle $A$, Olsson $T$, Stjernberg $N$, Thunell $M$. Musculo-skeletal symptoms in early sarcoidosis. Twenty-four newly diagnosed patients and a two-year follow-up. Acta Med Scand $1983: 214: 279-84$.

33. Ost D, Yeldandi A, Cugell D. Acute sarcoid myositis with respiratory muscle involvement. Case report and review of the literature. Chest $1995 ; 107: 879-82$.

34 Rossi GA, Battistini $E$, Celle ME, Lamba LD, Pessagno A, Gambini $C$, Veneselli E. Longlasting myopathy as a major clinical feature of sarcoidosis in a child: case report with a 7-year follow-up. Sarcoidosis Vasc Diffuse Lung Dis 2001;18:196-200

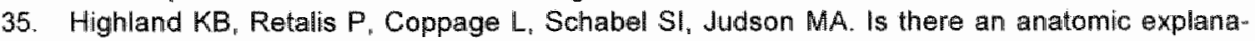
tion for chest pain in patients with pulmonary sarcoidosis? South Med J 1997:90: 911 w4.

36. Hendrick DJ, Blackwood RA, Black JM. Chest pain in the presentation of sarcoidosis. Br J Dis Chest 1976:70:206-10.

37. Wait JL, Movahed A. Anginal chest pain in sarcoidosis. Thorax 1989;44:39:-5.

38. Anderson A. The Concept of Mediastinal Pain. BrMed J 1957:1490 4.

39. van Esser JW, van Belle AF, Lamers RJS, Thunnissen FBJM, Wesseling GJ, Wouters EFM. A young woman with cough and chest pain. Eur Respir J 1995;8:664-6.

40. LeWitt PA. Neurosarcoidiosis and headache. South Med $\int 1984: 77: 272-3$.

41. Christoforidis GA, Spickler EM, Recio MV, Mehta BM. MR of CNS sarcoidosis: correlation of imaging features to clinical symptoms and response to treatment. Am INeuroradiof 1999; 20:655-69

42. Strickland-Marmol LB, Fessler RG, Rojilani AM. Necrotizing sarcoid granulomatosis mimicking an intracranial neoplasm: clinicopathologic features and review of the literature. Mod Pathol 2000;13:909-13.

43. Norwood CW Kelly DL. Intracerebral sarcoidosis acting as a mass lesion. Surg Neurol 1974 2:367-72

44. De Vries J, Drent $M$, van Heck $G L$, Wouters EFM. Quality of life in sarcoidosis: a comparison between members of a patient orglanisation and a random sample. Sarcoidosis Vasc Diffuse Lung Dis 1998;15:183-8.

45. De Vries J. Beyond Health status: Construction and Validation of the Dutch WHO Quality of Life assessment instrument (dissertation). Tilburg, Tilburg Universily, 1996

46. Baracos $V$, Rodemarn HP, Dinarello CA. Goldberg AL. Stimulation of muscle protein degradation and prostaglandin E2 release by leukocytic pyrogen (interleukin-1). A mechanism for the increased degradation of muscle proteins during fever. $N$ Engl $/$ Med $1983 ; 308$ : 553-8.

47. Hoitsma E, Marziniak M, Faber CG. Reulen JPH, Sommer C, De Baets M. Drent M. Small Fiber Neuropathy in Sarcoidosis. Lancel 2002; 359:2085-6.

48. Baughman RP, Lower EE. Infliximab for refractory sarcoidosis. Sarcoidosis Vasc Diffuse Lung Dis 2001;18:70-4. 
49. Baughman RP, Ohmichi M. Lower EE. Combination therapy for sarcoidosis. Sarcoidosis Vasc Diffuse Lung Dis 2001;18:133-7

50. Agostini C. Cytokine and chemokine blockade as immunointervention strategy for the treatment of diffuse lung diseases. Sarcoidosis Vasc Diffuse Lung Dis 2001;18:18-22

51. Sharma OP, Alam S. Diagnosis, pathogenesis, and treatment of sarcoidosis. Curr Opin Pulm Med 1995; 1:392-400.

52. Baughman RP. Lower EE. New treatment for sarcoidosis: where's the proof? Eur Respir $J$ 1999;14:1000-1. 


\section{Chapter 5}

Sleep disturbances associated with periodic leg movements in chronic sarcoidosis

J Verbraecken, E Hoitsma, CPM van der Grinten. NAM Cobben, EFM Wouters, M Drent 


\section{Abstract}

\section{Background and aim}

Many sarcoidosis patients suffer from fatigue and sleep disturbances. Recently, it was demonstrated that obstructive sleep apnoea (OSA) is rather common in sarcoidosis. Moreover, sheet intolerance and painful legs are frequently reported in sarcoidosis patients. These symptoms might interfere with sleep quality.

\section{Methods}

In order to determine the relationship between objective and subjective sleep disturbance full polysomnography, including leg electromyography (EMG) analysis, was performed in 46 chronic sarcoidosis patients indicating awakening unrefreshed in the morning.

\section{Resuls}

in $20(44 \%)$ patients OSA activity [60\% with PLM $(n=12) .40 \%$ without $(n=8)$ ] was demonstrated, while in 7 patients (15\%) significant periodic leg movement (PLM) without OSA were found. In 19 patients (42\%) no OSA or PLM activity was present. Moreover, restless legs (RLS) were reported by $52 \%$ of the patients ( $45 \%$ in OSA: $71 \%$ in PLM: $47 \%$ in others). Distribution of steep stages and sleep fragmentation was comparable in all groups. In a healthy snoring control group $(\mathrm{n}=102)$ a prevalence of PLM was found in $13.7 \%(17.8 \%$ in men; $3.4 \%$ in women), while RLS were only reported by $1.4 \%$ (men) and $6.9 \%$ (women).

\section{Conclusions}

Sleep disturbance (OSA and/or PLM) and RLS were demonstrated in more than half of the studied sarcoidosis patients. A high prevalence of RLS or PLM (primary and secondary) has not been reported before in sarcoidosis. Further studies are needed to establish whether RLS, OSA and/or PLM might contribute to fatigue and whether fatigue complaints improve after treatment of RLLSIPLM/OSA. 


\section{Introduction}

Sarcoidosis is a multiorgan inflammatory disorder of unknown origin, characterized by T-lymphocyte and mononuclear phagocyte infiltration in the affected organs, granuloma formation, and distortion of the normal micro-architecture, which is probably antigendriven. "The clinical manifestations of sarcoidosis are largely nonspecific, dependent on the intensity of the inflammation and organ systems affected, of which the lung is the most prominent.

Asymptomatic muscle involvement appears to be quite common, whereas symptomatic muscle inwolvement is rare. 2,3 Patients with sarcoidosis generally present with symptoms directly related to chest involvement such as coughing, dyspnoea, particularly with exertion, and chest pain. Furthermore, they may suffer from nonspecific constitutional

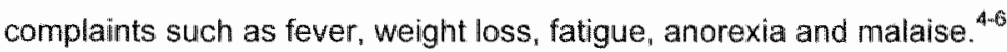

Fatigue appears to be the most frequently reported symptom. ${ }^{6.7}$ When features of disease activity, for example radiological abnormalities, lung function impairment and serum angiotensin converting enzyme (SACE) levels become normal "less specific and otherwise difficult to objectify symptoms, such as fatigue, may persist. Besides fatigue many sarcoidosis patients suffer from sleep disturbances. ${ }^{8.9}$ Recently, it was demonstrated that obstructive sleep apnoea (OSA) is frequent in sarcoiclosis. ${ }^{10}$ Prolonged corticoid use could lead to weight gain and myopathy involving the pharyngeal musculature, while severity of the disease, with pronounced muscle involvement is another possible factor. ${ }^{11-94}$ Moreover, sheet intolerance and painful legs are frequently reported in sarcoidosis patients. ${ }^{15}$ Small fiber neuropathy has been found to be present in sarcoidosis. ${ }^{15.16}$ Symptoms of small fiber neuropathy consist of peripheral pain, paraesthesias, intolerance for bedclothes, hyperhidrosis, hypohidrosis, sicca syndrome. facial flushing, diarrhoea, constipation, micturation disturbances and male sexual dysfunction. ${ }^{17}$ Polydefkis et al. found that small fiber neuropathy was also frequently present in patients with late-onset restless legs syndrome. ${ }^{18}$ Since restless legs syndrome is frequently associated with periodic leg movement disorder (PLMD), we hypothesized that PlLMD is also present in sarcoidosis. No data are known, however, about the frequency of periodic leg movements in sarcoidosis patients. The aim of the present study was to evaluate the relationship between objective and subjective sleep disturbance with emphasis on the occurrence of periodic leg movements (PLM) in sarcoidosis. 


\section{Materials and methods}

\section{Subjects}

Forty-six out-patients suffering from sarcoidosis, who attended the University Hospital Maastricht, were enrolled in this study. All patients suffered from fatigue and indicated awakening unrefreshed in the morning. The diagnosis of sarcoidosis was based on the international guidelines. ${ }^{1}$ Subjects with any significant medical history or co-morbidity were excluded from the present study. When polysomnography was performed, 30 patients had been treated with corticosteroids for at least three months, e.g. prednisone orally (initial dose $40 \mathrm{mg}$ daily. decreased by $10 \mathrm{mg}$ a month). Sixteen patients had not been treated during the previous 3 months. 15 patients $(33 \%)$ were still using oral corticosteroids at the time of the polysomnography. Only 2 of the studied cases were current smokers. The number of pack years for the whole group was 9 (17) years. The diagnosis of sarcoidosis was confirmed 5.2 (5.9) years ago. Clinical characteristics of the patients are summarized in table 5.1 .

\section{Prevalence of PLM and restless legs in a normal population}

In order to evaluate the prevalence of PLM and restless legs (RLS) in a normal population we screened the files of 2200 patients evaluated in our sleep lab between 1999 and August 2003 for sleep disordered breathing. Patients with evidence of a serious medical or psychiatric disorder, patients with a history of drug abuse or dependency, including alcohol, patients requiring psychoactive medication or any other drug that might interfere with the goals of a control group were excluded. Minimal criteria for RLS as defined by the International Classification of Sleep Disorders ${ }^{* 9}$ were: a) a complaint of unpleasant sensation in the legs at night; b) Disagreeable sensations of "creeping" inside the calves, often associated with general aches and pains in the $\|$ legs; $c$ ) the discomfort is relieved by movement of the limbs. Patients were assessed if any form of PLM (mild, moderate or severe) appeared to be present. In this period 124 asymptomatic primary snorers (no subjective sleep complaints and a AHI <5) were identified. Finally, 102 patients between $30-50$ years of age (mean age $43 \pm 7 \mathrm{y}$; BMl $26 \pm 4$ ) were studied. Notably, due to financial considerations it was not possible to evaluate sleep in a series of completely normal, asymptomatic and non-snoring subjects.

\section{Lung function tests}

Lung function measurements included forced expiratory volume in one second (FEVi) " inspiratory vital capacity (WC) and the diffusing capacity for carbon monoxide (DLCO) 
by the single-breath method (Masterlab; Jaeger, Wurzburg. Germany). ${ }^{20}$ Inspiratory and expiratory muscle strength were assessed by measuring maximal respiratory mouth pressures using the method of Black and Hyatt. ${ }^{21}$ Maximal inspiratory mouth pressure (PiMax) was measured at residual volume (RV), whilst maximal expiratory mouth pressure (PeMax) was measured at total lung capacity (TLC) (MP 45.30; Validyne Engineering Corp., Northridge, CA, USA).

Table 5.1 Patient characteristics of the sarcoidosis population

\begin{tabular}{|c|c|c|c|c|}
\hline & Overall & Group 1 & Group II & Group 111 \\
\hline Number & 46 & $19(41 \%)$ & $20(44 \%)$ & $7(15 \%)$ \\
\hline Age, years (SD ramge) & $45(11-28-66)$ & $40(7: 28-52)$ & $50(13: 28-66)^{6}$ & $42(0: 28-51\}$ \\
\hline Sex male/fentale: & $26 / 20$ & $10: 9$ & $12 / 8$ & $4 / 3$ \\
\hline $\mathrm{BH} /: \mathrm{kg} / \mathrm{m} 2$ & $29(6)$ & $27(6)$ & $32(5)$ & $27(5)+$ \\
\hline \multicolumn{5}{|l|}{ Chest X-ray } \\
\hline Stage 0 & $8 \cdot(17 \%)$ & $3(16 \%)$ & $4(20 \%)$ & $1(14 \%)$ \\
\hline Stage I & $5(11 \%)$ & $2(10 \%)$ & $3(15 \%)$ & $0(0 \%)$ \\
\hline Stage II & $12(26 \%)$ & $4(21 \%)$ & $5(25 \%)$ & $3(43 \%)$ \\
\hline Stage III & $17(37 \%)$ & $7(37 \%)$ & $7(35 \%)$ & $3(43 \%)$ \\
\hline Stage IV & $4(9 \%)$ & $3(16 \%)$ & $1(5 \%)$ & $010 \%)$ \\
\hline \multicolumn{5}{|l|}{ Laboratory } \\
\hline SACE UA $(9-25)^{1.4}$ & $21.8(7.8)$ & $19.4(7.3)$ & $22.0(10.0)$ & $23.9(7.3)$ \\
\hline G-reactive protein mg/l $(2-9)^{\text {" }}$ & $14.7(13.1)$ & $16.9(18.9)$ & $14.8(13.7)$ & $4.0(5.4)$ \\
\hline Callum mmold $(2.10-2.60)$ " & $2.40(0.09)$ & $2.41(0.07)$ & $2.40(0.07)$ & $2.37(0.09)$ \\
\hline \multicolumn{5}{|l|}{ Lung function } \\
\hline PaCOZ kPa & $5.3(0.5)$ & $5.3(0.3)$ & $5.3(0.5)$ & $5.3(0.6)$ \\
\hline $\mathrm{PaO} 2 \mathrm{kPa}$ & $10.6(2.0)$ & $11.1(1.7)$ & $9.6(2.3)$ & $11.2(1.3)$ \\
\hline FEV1 \% Pred & $82(20)$ & $78(24)$ & $85(15)$ & $86(23)$ \\
\hline Kco & $82(18)$ & $83(2 \pi)$ & $82(19)$ & $82(11)$ \\
\hline PUMax: cm H2O & $-84(30)$ & $-85(35)$ & $-77(24)$ & $-107(17)$ \\
\hline PeMax ch $\mathrm{H} 2 \mathrm{O}$ & $89(32)$ & $79(27)$ & $90(34)$ & $119(20)^{4}$ \\
\hline
\end{tabular}

Group I cases without OSA and withonit PLM; Group II cases with OSA with or without PLM; and Group III cases with PLM only. Data are expressed as mean with standard deviation (SD) in parentheses. If appropriate iange or percentage of the total number is given. BMil = body mass index; FEVt forced expiratory wolume in one second; $\mathrm{KCO}=$ iransfer coefficient of the Lung for $\mathrm{CO}$; PiMax = maximal inspiratory muscle pressiure; Poumax meximal expiratory muscle pressure: PLM = periodic leg movements; $5 A C E=$ serum angiotensin convesting enzym:

"Reference ranges of laboratory values in parentheses; "p 0.05 compared with Group 1; ${ }^{*}<0.05$ compared with Group II, Mansn-Whitney U-test.

\section{Polysomnography}

Polysomnography during the night was performed, using EEG, EOG and EMG measurements (Brainlab" ${ }^{R}$, OSG, Reet, Belgium). Sleep stages were scored according to the classic Rechtschaffen and Kales criteria. ${ }^{22}$ This allowed determination of total sleep time (TST) defined as the totall sleep period minus periods awake during this period, sleep efficiency index (SEI) defined as the ratio of TST/SPT, sleep latency (SL) 
and relative duration of steep stages all expressed as percentage of sleep period time (SPT). Ribcage and abdominal movements were monitored with respiratory inductance plethysmography (Respitrace? ${ }^{\text {? }}$; Ambulatory Monitoring. Ardsley, NY), which uses two transducers wrapped around the rib cage and abdomen. ${ }^{23,24}$ The sum of these two movements represients the flow. This device also allows differentiation of obstructive from central apnoeas on the basis of out of phase movement of the ribcage and abdominal components from the Respitrace signal.

Analysis for upper airway resistance syndrome was not performed, since no Respitrace software was avallable. Central and obstructive apnoeas and hypopnoea were defined according to classic criteria. ${ }^{19}$ Central sleep apnoea was only considered when visibly detectable deflections in flow and thoracic and abdominal movements were completely absent. Hypopnoea was defined as a reduction in airflow with at least $50 \%$ and a $4 \%$ drop in oxygen saturation. Oxygen saturation ( $\mathrm{SaO}_{2}$ ) was measured by pulse oximetry. Microarousals were scored according to criteria of the American Sleep Disorders Association (ASDA) ${ }^{25}$ A computer analysis was performed into the origin of the arousals (from leg movement or respiratory events). A respiratory arousal index was calculated based on the number of respiratory arousals per hour of sleep, occurring within a range of $(-5 s$ to $+5 s)$ of end of the respiratory event.

\section{Leg movements}

Leg activity was recorded from both anterior tibialis muscles as described by Coleman. ${ }^{26}$ Leg movements were scored using Coleman's criteria. ${ }^{26}$ Movements during awakenings or wakefulness were not taken into consideration and only those movements occurring after a minimum of $10 \mathrm{~s}$ of continuous sleep were accepted as part of a PLM episode. Movements were scored irrespective of whether they occurred in one or both legs.

PLMS were scored in any stage of sleep when the following criteria were fulfilled: 1) The movements occurred as part of a series of four separate movements that were separated by at least 5 but no more than 90 s. 2) The duration of the movements was between 0.5 and 5 s. 3) An end of PLM episode was caused by a greater than 90-s interval without movements.

All movements were evaluated for the presence or absence of an accompanying arousal ${ }^{27}$, defined as a change in EEG pattern to alpha waves, withim 5 s before or after the start of leg EMG activity. Leg movements occurring simultaneously with or immediatelly after a respiratory event (apnoea or hypopnoea) were also scored. The following variables were derived: 1) LMI (Leg Movement Index: total number of leg movements per hour of sleep), overall and during NREM and REM sleep. 2) PLMI (Pericdic Leg Movement Index: number of periodic leg movements per hour of sleep), overall and during NREM and REM sleep. 3) LMAI (Leg Movement Arousal index: the number of leg movements leading to an EEG arousal per hour of sleep). 4) PLMAI 
(Periodic Leg Movement Arousall Index: the number of periodic leg movements leading to an EEG arousal ( $>3$ s) per hour of sleep). 5) The number of PLM sequences of at least 4 periodic leg movements. 6) Moreover, total duration of PLM (the cumulative duration of all PLM-sequences), the average length of a PLM sequence, the average length of one single periodic leg movement and the mean PLM-interval (mean interval between two periodic leg movements) were evaluated. A PLMI greater than 5 is considered pathological.

\section{Study design}

Patients were only evaluated once with full polysomnography (Dept of Respiratory Medicine, University Hospital Maastricht). Criterion for obstructive sleep apnoea (OSA) was an apnoea hypopnoea index $(\mathrm{AHI})>5$, while criterion for a periodic leg movement disorder was a periodic leg movement index (PLMI) $>5$. Patients were divided into three groups: Group I: AHI $<5$ and PLMI $<5$ (no OSA, no PLM), Group II: AHIl $>5$ (OSA, with or without PLM) and Group III: AHI $<5$ and PLMI $>5$ (only PLM).

\section{Analysis of data}

The parameters obtained from each patient were analysed statistically using KruskalWallis ANOVA and Mann-Whitney U-test (post-hoc analysis). All analyses were performed using the CSS Statistica ${ }^{\mathrm{R}}$ packagle from Statsoft, USA. Spearman correlation analysis was also performed.

\section{Results}

Patient characteristics are shown in table 5.1. In 19 patients (41\%) no OSA or PLM was present (Group 1). In 20 (44\%) of the cases OSA was demonstrated [(60\% with PLM $(n=12), 40 \%$ without $(n=8)$, Group II]. Group II consisted of 12 males and 8 females and PLM occurred in $7 / 12(58 \%)$ of the males and in $5 / 8(62 \%)$ of the females. Six of the eight female OSA patients ( $75 \%$ ) were postmenopausal ( 250 years old). In 7 patients $(15 \%)$ significant PLM without OSA was found [Group II) $4 / 26(15 \%)$ of the males and $3 / 20(15 \%)$ of the females]. This means that $42 \%(11 / 26)$ of our male sarcoidosis patients and $40 \%(8 / 20)$ of our female sarcoidosis patients demonstrated a primary or secondary form of PLM.

Based on our clinical sleep questionnaire $52 \%$ of the studied patients reported the presence of restlless legs syndrome (RLS)(46\% of men and $60 \%$ of women). The prevalence of RLS in the subgroups was $47 \%(9 / 19)$ in Group $1(40 \%$ im men, $56 \%$ in women), $45 \%(9 / 20)$ in Group $\| 1$ (42\% in men, $63 \%$ in women) and $71 \%(5 / 7)$ in Group III $(75 \%$ in men, $67 \%$ in women). In our healthy control group the overall prevalence of 
PLM was $13.7 \%$ (14/102). In male patients the PLM prevalence was $17.8 \%(13 / 73)$. while in female patients it appeared to be only $3.4 \%$ (1/29). To date, RLS were reported less frequently by $1.4 \%(1 / 73)$ of the control men and in $6.9 \%(2 / 29)$ of the control women. The lowest transfer coefficient of the lungs (Kco) was $59 \%$ predicted.

Oral corticosteroids were used by $21 \%$ (4/19) (Group 1), 45\% (9/20) (Group II) and $28 \%$ (2/7) (Group III) of the patients at the time of the polysomnography. In tables 5.2 and 5.3 the results of the breathing pattern and sleep structure are summarized, respectively.

Group II had, due to the definition, a significantly higher respiratory disturbance compared with Group I and Group III. This was also reflected in some of the oxygen saturation parameters. In Group II men and women showed comparable respiratory disturbance (AHI $20 \pm 18$ ws. $17 \pm 11, p=0.67$ ), while women were more obese (BMI $30 \pm 4$ vs. $35 \pm 5, p=0.02$ ).

No differences in sleep quality and in distribution of sleep stages (REM-latency and delta-latency) could be found (table 5.3). Subanalysis of sleep characteristics according to sex in Group II showed more Stage 4 sleep in females suffering from OSA compared with males with OSA $(8 \pm 5$ vs. $3 \pm 1, p=0.02)$.

Table 5.2 Nocturnal breathing patterm of the sarcoidosis population studied: Group I cases without OS.A and without PLM; Group II cases with OSA with or without PLM; and Group Ill cases with PLM only

\begin{tabular}{|c|c|c|c|}
\hline & Group I & Group II & Group III \\
\hline$O A: n / h$ & $0(0)$ & $3(4)^{k}$ & $0(0)^{+}$ \\
\hline $\mathrm{CAl} ; \mathrm{n} / \mathrm{h}$ & $0(0)$ & $2(3)^{k / k}$ & $0(0)^{*}$ \\
\hline Hill m/h & $1(1)$ & $14(13)^{\star}$ & $1(1)^{*}$ \\
\hline 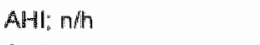 & $1(1)$ & $19(16)^{*}$ & $1 \pm 1^{2}$ \\
\hline $\mathrm{SaO}_{2}<90 \% ; \% \mathrm{TIB}$ & $16(28)$ & $24(20)$ & $8(7)$ \\
\hline $\mathrm{SaO}_{2} \mathrm{Min}_{\%} \%$ & $82(11)$ & $80(6)$ & $86(5)^{*}$ \\
\hline Time $\mathrm{SaO}_{2}<8 \mathrm{Bg}$ \%, min & $17(48)$ & $15(22)^{*}$ & $1(2)^{\star}$ \\
\hline Mearm $\mathrm{SaO}_{2}$ 筒 & $92(3)$ & $92(2)$ & $93(2)$ \\
\hline
\end{tabular}

Data are axpressed as mean with starndard deviation (SD) in parentheses.

PLM= periodic leg movements: OAI obstuctive apnoea index; CAl= central apnoes index: HI= hypopnoea

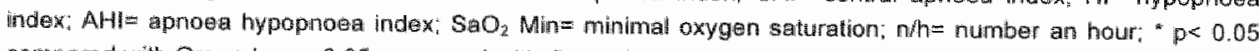
comparied with Group 1: * pe0.05 compared with Group II. Mann-Whitney U-test.

Distribution of the AHI according to gender showed a male/female ratio of 6/5 for AHI 5-15. 4/2 for $\mathrm{AHI} 15-30$ and $2 / 1$ for $\mathrm{AHI}>30$, respectively. The two premenopausal women showed only mill OSA (10 \pm 1$)$. In 6 male OSA and in 3 female OSA patients CPAP therapy was indicated (AHI $\geq 15$. CPAP criterion for the Netherlands). Sleep fragmentation (arousal index) was comparable in all groups. High LMI was present in all groups (LMI >5). which was periodic in 46.7\% (Group II) and in $81.7 \%$ (Group III). respectively (table 5.4). Statistically higher values for LMI and PLMI (by definition) were found in Groups $\|$ and 111 , with the highest PLM\| found in Group \|\|$(p<0.01)$. An 
evaluation of the distribution of (periodic) leg movements showed relatively higher indices throughout NREM/REM sleep (LMI-NREM, LMI-REM, PLMI-NREM, PLMI-REM), compared with the indices based on total sleep time (TST), in all groups. There was only a (non-significant) trend towards higher PLMI/LMI in NREM. LMI-NREM appeared to be significantly higher than LMI-REM in Group II only $(p=0.03)$. PLMI-NREM was significantly higher in Group III compared with Group II, while PLMI-REM was unchanged. No sex differences were found. The arousal indices for (periodic) leg movements (LMAI, PLMAI) were small, but substantially contributed to overall arousal index (table 5.5) in Group II [PLMAI $31 \%$ of arousal index, LMAI $46 \%$ of total arousal index, Respiratory arousal index $31 \%$ of arousal index] as well as in Group III [PLMAI 8\% of arousal index, LMAI 50\% of total arousal index, Respiratory arousal index $8 \%$ of arousal index], thus explaining 33\% (in Group 1), $77 \%$ (in Group II) and $58 \%$ (in Group III) of all detected arousals. In Group III female patients tended to have a

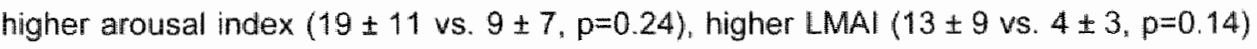
and higher PLMAI $(10 \pm 8$ vs. $4 \pm 3, p=0.30)$, but without statistical significance. Nonparametric Spearman correlation analysis in the whole group showed only a weak correlation between LMI and $\mathrm{AHI}(\mathrm{r}=0.30, \mathrm{p}=0.03)$, while no correlations were found with daytime or nocturnal oxygen parameters.

Daytime SaO2 correlated only with $\mathrm{SaO} 2<90 \%(r=-0.44, p=0.03)$. No other daytime parameters correlated with the level of nocturnal hypoxaemia, not even KCO. PiMax or PeMax. Correlation analysis between leg parameters and nocturnal sleep parameters showed a significant positive correlation between leg movement interval and arousal index $(r=0.38, p<0.01)$. No correlation was found between leg parameters and REM sleep latency or slow wave sleep latency.

Tabie 5.3 Sleep characteristics of the sarcoidosis populiation studied: Group I cases without os $\mathrm{A}$ and without PLM; Group II cases with OSA with or without PLM; and Group Ill cases with PLM only

\begin{tabular}{|c|c|c|c|}
\hline & Group I & Group II & 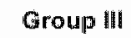 \\
\hline TST: min & $405(100)$ & $371(93)$ & $383(91)$ \\
\hline SEI:\%TST/SPT & $83(11)$ & $76(13)$ & $83(12)$ \\
\hline REM: \%PT & $16(4)$ & $12(7)$ & $15(4)$ \\
\hline REM-SL; min & $111(58)$ & $119(93)$ & $96(34)$ \\
\hline DeltamsL: min & $27(28)$ & $53(74)$ & $28(18)$ \\
\hline Stage 1; ${ }_{j}$ SPT & 8. $(4.1)$ & $10.2(7.6)$ & $6.5(4.0)$ \\
\hline Stage 2; \%SPT & $41.6(11.9)$ & $40.2(15.8)$ & $46.0(11.4)$ \\
\hline Stage $3 ; \%$ GPT & $9.9(6.6)$ & $8.3(7.7)$ & $123(7.8)$ \\
\hline Stage 4; \% $5 P T$ & $7.9(6.6)$ & $5.2(4.8)$ & $3.6(5.0)$ \\
\hline Delta: & $18(10)$ & $13(1)$ & $10(9)$ \\
\hline Arousal Index & $10(6)$ & $13(15)$ & $12(9)$ \\
\hline
\end{tabular}

Data are expressed as mean with standad deviation (SD) in parentheses.

$P L M=$ periodic leg movements; $T S T=$ total sleep time; SE = sleep efficiency index; $S P T=$ sledp parrod time; SL= sleep latency; REM = rapid eye movement sleep; Stage 1 and 2: light sleep; Stage 3 and 4: deep sleep (Delta), * p 0.05 compared with Group l: + p $<0.05$ compared with Group II: Mann-Whitney U-test. 
Presence of lag movements in warcoidosis population studied Group i cases without OSA and

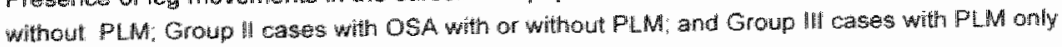

\begin{tabular}{|c|c|c|c|}
\hline & Group I & Group II & Group III \\
\hline \multicolumn{4}{|l|}{ All Leg Hovements } \\
\hline 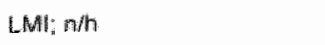 & $6(4 ; 0-16)$ & $21(16 ; 1061)^{*}$ & $52(26 ; 15-206)^{t}$ \\
\hline WLANREM: $n / \mathrm{h}$ & $\theta(3,1-14)$ & $21(18 ; 1-74)$ & $50(72: 17-212)^{*}$ \\
\hline LUMWREM; NMW & $11(10.0-34)$ & $11(9,0-33)$ & $56(70 ; 6-175)$ \\
\hline RMA & $2(2 ; 0-8)$ & $6(9 ; 1-42)$ & $6(6 ; 2-6)+$ \\
\hline \multicolumn{4}{|l|}{ Periodic Lag hoventents } \\
\hline PLMU: nith & $1(2: 0.5)$ & $10(13 \cdot 0-45)^{*}$ & $30(32 ; 7.98)^{*}$ \\
\hline PLMINAREM; WIT & $2(3 ; 0-14)$ & $16(22: 0-88)^{*}$ & $47(73: 8-210)^{4}$ \\
\hline 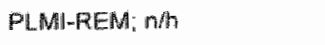 & $1(3 ; 0-12)$ & $B(28 ; 0-126)$ & $33(67 ; 0-180)$ \\
\hline PLMAI; ; n/h & $9(1 ; 0-2)$ & $4(8 ; 0-28)^{*}$ & $6(5 ;-16)^{*}$ \\
\hline PLM-sequences: $n$ & $1(2 ; 0-6)$ & $7(7 ; 0-24)^{2}$ & $15(7 ; 8-25)^{4+}$ \\
\hline Total duration of PM $M(m$ (mon) & $5(6 ; 0.20)$ & $32(36 ; 0-126)$ & $77(56 ; 32-194)^{m-2}$ \\
\hline Mean length PLM series (s) & $122(143 ; 0-486)$ & $191(143 ; 0-527)^{11}$ & $359(134 ; 193-521)^{4}$ \\
\hline Mean duration one $P(M M(s)$ & $1.5(1,4 ; 0,0,3)$ & $1.5(0,9 ; 0-3.1)$ & $1.9(0,4: 1,4-2.7)$ \\
\hline PuM-interval (s) & $25(25 ; 0-80)$ & $30(17: 0.52)$ & $35(11 ; 17-49)$ \\
\hline
\end{tabular}

Data are expressed mesn with stardard deviation (SD) and range in patentheses

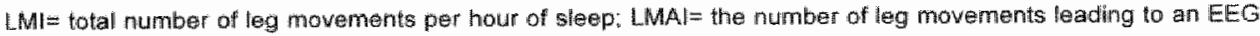
arousal per hour of slegp: PLMII= periodic leg movement PER OUR OF SLEEP; nreme nin raoid eye movement steep; rem rapid eye mowement slleep,PLMAl the number of periodic lag movements leading to an EEG arousa per hour of stex; n/h= number an hour: total duration of PLM: cumulative duration of all PLM-sequences; PLMinterval: mean interval between two periodic leg movements." $p<0.05$ compared with Group $1 ;+p<0.05$ compared with Group II, Mann-Whitiney U-test.

\section{Discussion}

In this study OSA was frequently found, while PLM and restless legs were also common. Surprisingly, in all groups the LMI was high. Arousal indices were found to be high in all groups. The high number of arousals did not influence the sleep efficiency index (SEl) in our patients. However, SEl is mainly a parameter for the macrostructure of sleep, rather than expressing the microstructure of sleep. Our studied sarcoidosis patients reported the presence of RLS very often (approximately $50 \%$ ) compared with our snoring control group and also compared with prevalence rates reported by others. Saletu et al reported a prevalence of $22 \%$ in women vs. $12 \%$ in men among 1000 Austrians of all age groups. ${ }^{28}$ Ohayon et al. reported an even lower prevalence of restless legs of $4.1 \%$ in a general population study in the age range $30-50$ years old. ${ }^{29}$ This latter observation was more or less in accordance with our observation in our used control group.

The reported prevalence of PLM in a general population of the same age range is $3.7 \%$, which is much lower than the prevalence we found in our patients. ${ }^{29}$ The latter authors also reported that the odds ratio for loud snoring to get PLM was 1.06, supporting our 
choice for heavy snorers as healthy controls. Some authors reported limited contribution of PLM to the arousal indices (IOW PLMAI between $19 \%$ and $42 \%$ of PLMI) $30-33$ "but most studies do not define the interval between PLM and arousal. In PLM we also found that PLMAI was $20 \%$ of PLMI. Only Eisensehr et al. ${ }^{31}$ found higher rates $(42 \%)$. When we looked at OSA patients in Group II, however, also high rates (40\%) were found. The LMAI could even explain 50\% of arousals in OSA as well as in PLM.

Although the presence of OSA in patients with interstitial lung disease is rare ${ }^{34}$, we found OSA highly prevalent in sarcoidosis, as was also reported by others recently. ${ }^{\text {in }}$ The high prevalence of RLS and (periodic) leg movements in (male and female) sarcoidosis patients is a new finding. which is not yet described or explained up to the present. Recently. Hoitsma et al. ${ }^{15,35}$ described the presence of small fiber neuropathy in sarcoidosis, based on temperature threshold testing and a decreased density of intraepidermal nerve fiber. Moreover, Polydefkis et al. reported an association between small fiber neuropathy and restless legs syndrome. ${ }^{13}$ We also found high rates for restless legs in our study population, which was even more pronounced than for PLM. Whether the presence of small fiber neuropathy contributes to the development of RLS and/or PLM in sarcoidosis has to be explored.

Several other reasons may explain the development of OSA and PLM in sarcoidosis. like pronounced muscle involvement and infiltration of the upper airway by sarcoidosis before treatment with corticosteroids. ${ }^{12}$ Moreover, myopathy as well as an increase of fat deposition in the neck and upper part of the body are well-known side-effects of corticosteroids $^{36}$ and could justify the high prevalence of the disorder in a relatively young female population. Sarcoidosis patients with OSA also demonstrated the highest body mass index. So, weight gain together with myopathy involving the pharyngeal musculature could contribute to the development of sleep apnoea. An argument against muscle weakness to explain the presence of OSA is the relatively preserved PiMax and PeMax in this study. Moreover upper aiway strength in OSA has been shown to be preserved or even increased, as was shown for the genioglossus and tensor palatini muscle. ${ }^{37.38}$ The number of patients treated with corticosteraids was also comparable in all groups, arguing against an important influence of drug treatment. The intake of corticosteroids can however influence the levels of catecholamines, leading to motor excitation and increase in (P)LM.

Myopathy involving the peripheral musculature could also contribute to the development of PLM. Asymptomatic granulomatous muscle involvement in sarcoidosis has been reported with a prevalence of $80 \%$, whereas symptomatic muscle involvement is much less common $(1.4-2.3 \%)^{36}$ The symptomatic involvement that has been described varies from a palpable nodular type to an acute myositis, and chronic myopathy lype. Usually, patients present with pain, weakness, fatigue, muscle atrophy including respiratory muscles and sometimes fever. Recently. Wirnsberger et al. demonstrated 
reduced respiratory muscle strength and endurance time in sarcoidosis patients with nomal lung function. ${ }^{39}$ Moreover, the respiratory muscle function seemed to quantify and characterize the functional impairment in patients with sarcoidosis and reflected symptoms, such as fatigue and general weakness. We found however relatively preserved PiMax and PeMax in this study, which may also argue against myopathy to explain the presence of PLM. No arguments could be found to explain the presence of PLM due to the appearance of nocturnal hypoxaemia, as shown in patients with COPD. ${ }^{40,4}$ The highest degree of hypoxaemia was found in both group I and group II. Subanalysis of OSA patients with or without PLM did also not show any difference in the oxygen desaturation time. No difference in $\mathrm{CO}_{2}$ level was found and could thus not be used to explain differences in PLM activity.

Tabie 5.5 Arousal indices related to leg mowements and respiratory events in the sarcoidosis population studied: Group I cases without OSA and without PLM: Group II cases with OSA with or without PMiL and Group lit cases with PLM only

\begin{tabular}{lccc} 
& Group I & Group II & Group III \\
Arousal Index; $n$ h & $10(6 ; 0-21)$ & $13(15 ; 0.73)$ & $12(9 ; 1-27)$ \\
Leg Movement Arousial Indlex; $n / h$ & $2(2 ; 0-8)$ & $6(9 ; 1-42)^{*}$ & $6(6 ; 1-20)^{*}$ \\
Respiratory Arousal Index; $n / h$ & $1(1 ; 0.1)$ & $4(9 ; 0-36)^{*}$ & $1(1 ; 0-1)+$ \\
\hline
\end{tabular}

Data are expressed as meam with standard devation (SD) in parentheses.

" $p<0.05$ compared with Growp 1. Mann-Whitney U-test; $4 p<0.05$ compared with Group 1I, Marn-Whitney U-iest

The influence of sleep stages on (P)LM distribution was also less pronounced in sarcoidosis. Previous studies have demonstrated that PLM were found to be most frequent during NREM sleep and almost absent during REM-sleep. ${ }^{42,43}$ The presence of a significant number of (P)LM during REM sleep suggests that REM sleep suppression of spinal motoneurons is not complete throughout the REM sleep period in sarcoidosis patients. Notably, leg movements during wakefulness were not scored due to the Coleman criteria. Moreover, there is confusion about the criteria to be used to identify (periodic) leg movements during wakefulness.

The high prevalence of OSA in our female patients might be explained by the slightly higher disease rate of sarcoidosis for women. In the only population based incidence study of sarcoidosis in the United States, rates were 5.9 per 100,000 personyears for men and 6.3 per 100,000 person-years for women [44], which results in a male/female ratio of $0.9 / 1$. In the ACCESS study $34 \%$ mate and $66 \%$ female sarcoidosis patients were included. ${ }^{45,46}$ Based on a questionnaire study among the members of the Dutch Sarcoidosis Society $37 \%$ are men and $63 \%$ are female $(n=1026 \text {, age } 47(12) y)^{47}$, confirming the ACCESS data from the USA. The ratio of men to women with OSA (without sarcoidosis) in clinical and community studies appeared to be considerably higher (approximately 5 to $8 / 1$ and 2 to $3 / 1$, respectively). Increased complaints of 
insomnia, fatigue, headache, and dissatisfaction with life could lead primary care and specialist physicians to under or mis-diagnose OSA in women. ${ }^{48}$ We found that female OSA patients were more obese than male OSA patients. However post-menopausal women with OSA ( $n=6)$ and age-matched male OSA $(n=7)$ had approximately equivalent body mass indices (32 (4) and 36 (5) respectively, $p=0.19$ ), paralleling observations in OSA without sarcoidosis.

When clinically relevant OSA is present, CPAP application can be considered, since this device is the golden standard for OSA treatment. In patients demonstrating a decrease of PLM during CPAP therapy, movements could be considered as a consequence of OSA. Starting CPAP has to be performed carefully, since PLM can be unmasked during CPAP therapy, causing persistent complaints of diurnal symptoms. ${ }^{49}$ This has to be studied in detail in the sarcoidosis population. In our series 9 patients used chronic CPAP therapy, but follow-up polysomnographies were not yet performed. The most suitable drug treatment for PLM is also not yet determined. Since pain is sometimes involved in the presence of PLM or neuropathy, it is possible that PLM in sarcoidosis is most adequately treated with drugs as gabapentine, whereas clonazepam or dopamine agonists are other possibilities. This needs further evaluation.

Sleep disorders are a substantial problem in chronic sarcoidosis. To date, the greatest impact on quality of life in sarcoidosis, as seen in the clinical practice, seems to be caused by symptoms such as fatigue and sleep disorders. Drent et al. evaluated health status and quality of life of sarcoidosis patients with the Sickness Impact Profile and found high scores for the item Sleep and Rest ${ }^{8}$ compared with a control group and compared with sarcoidosis patients without complaints. Sleeping problems appeared to be associated most with the Beck Depression Inventory and the Cognitive Depression Index, those with sleeping problems being more depressed $(r=0.63)^{*}$ With the WHOQOL-100 an association between fatigue and physical health (facet sleep and rest) was also demonstrated, but not with depression (although lower scores were found in sarcoidosis) It was concluded that sarcoidosis patients developed depressive symptoms as an expression of exhaustion by the disease. Although a normal REMsleep latency was present in the present series, this does not exclude the existence of a depressed mood state in these patients ${ }^{50,51}$ Possibly, an improvement in the experienced stress level can be obtained with CPAP, decreasing sympathetic activity. ${ }^{52}$

Direct measurement of the sleep and breathing pattern by polysomnography seems necessary to assess sleep and fatigue objectively and to evaluate whether intervention strategies in this group of patients are of benefit (CPAP, drugs, cognitive behavioural therapy), since neither the $\mathrm{FEV}_{1}$, nor the SACE level in patients suffering from sarcoidosis accounted for a significant variation in the AHI or PLMI. Moreover, no relation with radiographic stage or respiratory muscle strength was found. Also, no correlation between daytime $\mathrm{PaO} 2$ and nocturnal hypoxaemia (time $<88 \%$ ) was demonstrated. 
Therefore, overnight monitoring of gas exchange needs to be considered in patients with fatigue, even in the absence of clinical suspicion of OSA.

Alhough sleep disorders appeared to be a substantial problem in chronic sarcoidosis. the contribution of PLM to fatigue and sleepiness is controversial.

A recent study found that arousals recorded with PLM more often precede rather than follow the movements. ${ }^{30}$ These authors however used an interval of $10 \mathrm{~s}$ before or after PLM, what seems too long an interval to us. Therefore we preferred to use an intervall of $5 \mathrm{~s}$. Shorter intervals have the disadvantage that an event-arousal relationship can be underestimated. Chervin ef al. concluded that incidental PLM during sleep are not associated with excessive daytime sleepiness in a clinical series of 1124 adult patients. ${ }^{53}$ Montplaisir et al. concluded that the validity of PLM disorders as a distinct entity is highly questionable, since PLM are not more prevalent in patients with insomnia or hypersomnia than in control subjects. ${ }^{54}$ Mendelson et al found no relationship between PLMAI and reporting subjective bad sleep. ${ }^{55}$ In contrast, other authors have found a relationghip between PLM and sleepiness. ${ }^{56}$ In the present study an important number of arousals could be explained by OSA and PLM (77\% and $58 \%$ in each group). However, this relationship was not found when using a shorter interval (2 s). Moreover. as many studies do not report the event-arousal interval duration comparisons are impossible. Therefore, a firm conclusion about a causal relationship between PLM and non-restorative sleep is not yet possible. Other arousal disorders could also be involved, like an upper airway resistance syndrome (UARS), by pharyngeal infiltration of the upper airway by sarcoidosis, leading to flow limitation. ${ }^{57}$ Pharyngoesophageal pressure measurements have to be performed to prove this hypothesis. ${ }^{58}$ It has also been shown that PLM are associated with autonomic (subcortical) arousals, which can lead to tachycardia, rises in blood pressure, vasoconstriction and decreased periphera! pulses. 59,00 These types of arousal can lead to daytime sleepiness too. However, these types of arousals have not been evaluated in this study. The likellihood of UARS is less clear, since only $42 \%$ (Group I) and $57 \%$ (Group III) of the patients reported snoring. Another reason for arousals could be the presence of pain stimuli during sleep, resulting in EEG arousall responses. Recently it was reported that many sarcoidosis patients hawe pain complaints $(72 \%$ of the 821 studied patients, mostly arthralgia and muscle pain), which may also play a role in movements and/or arousals. ${ }^{61}$

Although this study contains an interesting message, it also has some limitations. Firstly, we used a low cut-off point for the selection of PLM patients (PLMI $>5$ ). It should be questioned whether this criterion is abnormal. since it has been chosen arbitrarily (historically), without documented clinical correlation. Secondly, we also did not measure the multiple sleep latency test (MSLT), to evaluate daytime sleepiness. Third, autonomic arousals measurements were not performed. Fourth, we have not taken into account whether arousals recorded with PLM more often precede rather than follow the 
movements, as was reported by Karadeniz ${ }^{30}$ (based on a 10 s interval). Fifth, although we used a Respitrace signal for monitoring ventilation, an analysis for upper airway resistance syndrome was not performed, since no software for automatic analysis of small phase angle changes was available. It was however showr that respiratory inductance plethysmography is the least sensitive non-invasive indicator of flow limitation. ${ }^{62}$ Last but not least, it has to be underlined that high arousal indices can occur in mormal subjects when evaluated by a 1-night polysomnography. ${ }^{63}$ This latter could indicate that the technical equipment could influence the arousal pattern or that high arousal indices are nol linked with daytime sleepiness.

\section{Conclusions}

RLS, OSA and PLM frequently occur in sarcoidosis patients suffering from awakening unrefreshed in the morning. The exact extent of the presence of RLS, OSA and PLM to the complaints of sarcoidosis patients remains still controversial, however. Application of CPAP therapy in OSA is self-evident, while the most suitable drug treatment for PLM has not yet been studied. Further studies, also including asymptomatic sarcoidosis, should focus on the presence of RLS, PLM and OSA in relation to fatigue in sarcoidosis. Also studies assessing intervention strategies are needed to evaluate the impact of these disturbances. 


\section{References}

1. Hunninghak GW, Costabel U, Ando M, Baughman RP, Cordier JF, du Bois RM, Eklund A, Kitaichi M, Lynch J. Rizzato $G$, Rose $C$. Selroos $O$. Semenzato $G$, Sharma OP. ATSIERSMASOG statement on sarcoidosis. American Thoracic Society/European Respiratory Society/World Association of Sarcoidosis and other Granulomatous Disorders. Sarcoidosis Vasc Diffusie Lung Dis 1999:16:149-73.

2. Agbogu BN, Sterm B., Sewell $C$, Yang $G$. Therapeutic considerations in patients with refractory neurosarcoidosis. Arch Neurol 1995;52:875-9.

3. Silverstein A, Siltzbach LE. Muscle involvement in sarcoidosis. Arch Neurol 1969;21:235-41.

4. Costabel U. Hunninghake GW. ATS/ERSNWASOG statement on sarcoidosis. Eur Respir $y$ $1999 ; 14: 735-7$.

5. Costabel U. Sarcoidosis; clinical update. Eur Respir $\downarrow$ 2001:18:56s-68s.

6. Drent M, Wirnsberger RM, De Vries J, wan Dieijen-Visser MP, Wouters EFM, Schols AMW Association of fatigue with an acute phase response in sarcoidosis. Eur Respor of $1999 ; 13: 718-22$.

7. Sharma OP. Fatigue and sarcoidosis. Eur Respir J 1999:13:713-4.

8. Drent M, Wirnsberger RM, Breteler MHM, Kock LMM, De Vries. J. Wouters EFM. Quality of life and depressive symptoms in patients suffering from sarcoidosis. Sarcoidosis Vasc Diffuse Lung Dis 1998;15:59m66.

9. Wirnsberger RM, De Vries J, Breteler MHM, Van Heck GL, Wouters EFM, Drent M Evaluation of quality of life in sarcoidosis patients. Respir Med 1998;92:750-6.

10. Turner GA, Lower EE, Corser BC. Gunther KL, Baughman RP. Sleep apnea in sarcoidosis Sarcoidosis Vasc Diffuse Lung Dis 1997;14:61-4.

11. Drent M, Verbraecken $J$ van der Grinten CPM, Wouters EFM. Fatigue associated with obstructive sleep apnea in a patient with sarcoidosis. Respiration 2000;67:337-40.

12. Shah RNH, Mills PR, George PJM, Wedzicha JA. Upper airways sarcoidosis presenting as obstructive sleep apnoea. Thorax 1998;53:232-3.

13. Allen RK, Sellars RE, Sandstrom PA. Aprospective study of 32 patients with neurosarcoidosis. Sarcoidosis Vasc Diffuse Lung Dis 2003;20:118-25

14. Torralba KD, Quismorio FP Jr. Sarcoid arthritis: a review of clinical features, pathology and therapy. Sarcoidosis Vasc Diffuse Lung Dis 2003;20:95-103.

15. Hoitsma $E$, Marzimiak M, Faber $C G$, Reulen JPH, Sommer $C$, De Baets M, Drent M. Small fiber neuropathy in sarcoidosis. Lancet 2002;359:2085-6.

16. Kidd D. Beynon HL. The neurological complications of systemic sarcoidosis Sarcoidosis Vasc Diffuse Lung Dis 2003;20:85-94.

17. Lacomis D. Small-fiber meuropathy. Muscle Nerve 2002;26:173-88.

18. Polydefkis M. Allen RP. Hauer P. Earley CJ, Griffin JW. McArthur JC. Subclinical sensony neuropathy in fate-onset restless legs syndrome. Neurology 2000;55:1115-21.

19. Diagnastic Classification Steering Committee. International Classification of Sleep Disorders: Diagnostic and Coding Manual. Rochester: Aimerican Sleep Disorders Association, 1990.

20. Quanjer PH, Tammeling GJ, Cotes JE, Pedersen OF, Peslin $R$, Yemault JC. Lung volumes and forced ventilatory flows. Report working party standardization of lung function tests European Community for Steel and Coal. Eur Respir J 1993:6:5-40.

21. Black LF. Hyatt RE. Maximal respiratory pressures: normal values and relationship to age and sex. Am Rev Respir Dis 1969:99:696-702.

22. Rechtschaffen A, Kales A. A manual of standardised terminology, techniques and scoring for sleep stages of human subjects. Los Angeles: Brain Information Service/Brain Research Institute. University of California, UCLA, 1968

23. Chadha TS, Watson H. Birch S, Jenouri GA, Schneider AW. Cohn MA, Sackner MA Validation of respiratory inductance plethysmography using different calibration procedures. Am Rev Respir Dis 1982:125:644-9. 
24. Hyland RH, Hutcheon MA, Perl A, Bowes G, Anthonisen NR, Zamel N, Phillipson EA. Upper airway occlusion induced by diaphragm pacing for primary alveolar hypoventilation: implications for the pathogenesis of obstructive sleep apnea. Am Rev Respir Dis 1981:124:180-5.

25. American Sleep Disorders Association. EEG arousals: scoring rules and examples. A preliminary report from the sleep disorders atlas task force of the American Sleep Disorders Association. Sleep 1992:15:173-84.

26. Coleman RM, Pollack CP. Weitzman ED. Periodic movements in sleep (nocturnal myoclonus): relation to sleep disorders. Ann Neurol 1980;8:416-21.

27. ASDA. Atlas Task Force. Recording and scoring leg movements. Sleep 1993;16:748-59.

28. Saletu $B$, Anderer $P$. Saletu M, et al. Restless Legs Syndrome (RLS) - newe schlafmedizinische Erkenntnisse in Diagnose und Therapie. In: Dezsy $J$ (ed): Medizin 2001 - aus Forschung und Praxis. Vienna: Dr. Peter Muller Verllag 2001:263-80.

29. Ohayon $M M_{1}$ Roth $T$. Prevalence of restless legs syndrome and periodic limb movement disorder in the general population. I Psychosomatic Research 2002;53:547-554.

30. Karadeniz D. Ondze B. Besset A, Billiard M. EEG arousals and awakenings in relation with periodic leg movements during sleep. J Sleep Res 2000;9:273-7.

31. Eisensehr $\mathrm{I}$, Ehrenberg $\mathrm{BL}$. Noachtar $\mathrm{S}$. Different sleep characteristics in restless legs syndrome and periodic limb movement disorder. Sleep Med 2003;4:147-52.

32. Gann $H$, Feige B, Fasihi S, van Calker D, Voderholzer U, Riemann D. Periodic limb movements during sleep in alcohol dependent patients. Eur Arch Psychiatry Clin Neurosci 2002;252:124:9.

33. Hanly PJ. Zuberi-Khokhar N. Periodic leg movements during sleep in patients with congestive heart fallure. Chest 1996; 109: 1497-502.

34. Perez-Padilla $R$, West $P$, Lertzman $M$, Kryger MH. Breathing during sleep in patients with interstitiall lung disease. Am Rev Respir Dis 1985;132:224-9.

35. Hoitsma $E$, Drent M, Verstraete E, Faber CG, Troost J, Spaans F, Reulen JPH. Abnormal warm and cold sensation thresholds suggestive of small fiber neuropathy in sarcoidosis. Clin Neurophysiol 2003;114:2326-33.

36. Ost $D$, Yeldani $A$, Cugell $D$. Acute sarcoid myositis with respiratory muscle involvement, case report and review of the literature. Chest 1995;107:879-82.

37. Mezzanotte WS, Tangel D., White DP. Waking genioglossal EMG in sleep apnea patients versus normal controls (a neuromuscular compensatory mechanism). J Clin Invest $1992 ; 89: 1571-9$

38. Mezzanotte WS, Tangel DJ, White DP. Influence of sleep onset on upper-ainway muscle activity in apnea patients versus normal controls. An I Respir Crit Care Med 1996, $153: 1880-7$

39. Wirnsberger RM, Drent M, Hekelaar N, Breteler MHM. Drent S, Wouters EFM, Dekhulizen PNR. Relationship between respiratory muscle function and quality of life in sarcoidosis. Eur Respir J 1997;10:1450-5

40. Spillane JD. Restless legs syndrome in chronic puhmonary disease. BMN 1970;4:796-8.

41. Narayan M, Ferranti $R$. Nerve conduction impairment in patients with respiratory insufficiency and severe chronic hypoxemia. Arch Phys Med Rehabl 1978;59:188-92.

42. Nicolas $A$, Michaud $M$, Lavigne $G$, Montplaisir $J$. The influence of sex, age and sleep/wake state on characteristics of periodic leg movements in restless legs syndrome patients. Clin Neurophysiol 1999:110:1168-74.

43. Pollmacher $T$, Schultz $H$. Feriodic leg movements (PLM): their relationship to steep stages. Sleep 1993;16:572-7.

44. Henke CE. Henke G. Elveback LR, Beard CM, Ballard DJ, Kurland LT. The epidemiology of sarcoidosis in Rochester, Minnesota: a population-based study of incidence and survival. Am J Epidemiol 1986; 123:840-5.

45. Baughman RP. Bresnitz E, Lannuzzi M, et al. Design of a case contral atiologic study of sarcoidosis (ACCESS). \& Clin Epidemiol 1999;52:1173-86.

46. Baughman RP, Teirstein AS, Judson MA, Rossman MD, Yeager H Jr, Bresnitz EA, DePalo L, Hunninghake $G$, lannuzzi MC, Johns $C$ s McLennan $G$, Moller DR Newmar $L S$, Rabin DL. Rose C, Rybicki B, Weinberger SE, Terrin ML, Knattend GL, Cherniak R, Case Controt Etio- 
logic Study of Sarcoidosis (ACCESS) research group. Clinical characteristics of patients in a case control study of sarcoidosis: Am I Respir Crit Care Med 2001:164:1885-9.

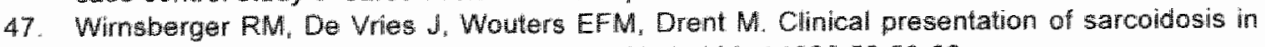
the Nethertands. An epidemiological situdy. Neth J Med 1998:53:53-60.

48. Jordan AS, McEwoy RO. Gender differences in sieep apnea: epidemiology, clinical presentation and pathogenic mechanisms. Sleep Med Rev 2003;7:377-89.

49. Kotterba $S$, Clarenbach $P$, Bornmel $W$, Rasche $K$. Periodic leg movements in patients with obstructive sleep apnea syndrome during nCPAP therapy. Somnologie 2000:4:93-5.

50. Benca RM. Mood disorders. In: Kryger $M_{1}$. Roth $T$. Dement WC (eds): Principles and practice af sleep medicine. Philadelphia: W.B.Saunders Company 1994:899-913.

51. Roschke d, Mann K. The sleep EEG"s micrastructure in depression: alterations of the phase relations between EEG rhythms during REM and NREM sleep. Sleep Medicine 2002;3:501-5.

52. Hedner J, Darpo B. Ejnell $H$. Calson J. Caidahl $K$. Reduction in sympathetic activity after long-term CPAP treatment in sleep apnoea: cardiovascular implications. Eur Respir I $1995 ; 8: 222-9$.

53. Chervin RD. Periodic leg movements and sleepiness in patients evaluated for sleepdisordered breathing. Am I Respir Crit Care Med 2001;164:1454-8.

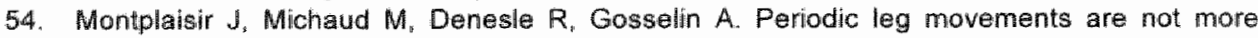
prevalent in insomnia or hypersomnia but are specifically associated with sleep disorders involving a dopaminergic impairment. Sleep Med 2000,1:163-7.

55. Mendelson WB. Are periodic leg movements associated with clinical sleep disturbance? Sleop 1996;19:219-23.

56. Bastuji H, Garcia-Larrea L. Sleeptwake abnormalities in patients with periodic leg movements during sleep: factor analysis on data from 24-h ambulatory polygraphy. I Sleep Res $1999 ; 8: 217-23$.

57. Exar EN, Collop NA. The assaciation of upper airway resistance with periodic limb movements. Sleep 2001;24:188-92.

58. American Academy of Sleep Medicine Task Force: Sleep-related breathing disorders in adults: recommendations for syndrome definition and measurement techniques in clinical research. Sloep 1999;22:667-89.

59. Sforza E, Nicolas $A_{1}$ Lavigne $G$, Gosselin $A_{n}$ Petit $D$, Montplaisir J. EEG and cardiac activation during periodic leg movements in sleep. Support for a hierarchy of arousal responses. Neurology 1999;52:786-91

60. Ali NJ, Davies. RJ, Fleetham JA, Stradling JR. Periodic movements of the legs during sleep associated with rises in system blood pressure. Sleep 1991;14:163-5.

61. Hoitsma E, De Vries J, van Santen-Hoeuff M, Faber CG, Drent M. Impact of pain in a Dutch sarcoidosis patient population. Sarcoidosis Vasc Diffuse Lung Dis 2003;20:33-9.

62. Clark SS. Wilson CR, Satoh M. Pegelow D. Dempsey JA. Assessment of inspiratory flow limitation invasively and noninvasively during sleep. Am $\&$ Respir Crit Care Med $1998: 158: 713-22$.

63. Mathur $\mathrm{R}$, Douglas NJ. Frequency of EEG arousals from nocturnal sleep in normal subjects. Slow $1995 ; 18: 330-3$. 


\section{Chapter 6}

Abnormal warm and cold sensation thresholds suggestive of small fiber neuropathy in sarcoidosis

E Hoitsma, M Drent, E Verstraete, CG Faber, $J$ Troost, F Spaans, JPH Reulen: 


\section{Abstract}

\section{Earkground wand wh}

A substantial number of sarcoidosis patients report apparently non-specific symptoms such as pain, for which no organic substrate has yet been found. Recently we observed symptoms suggestive of small fiber neuropathy in a group of sarcoidosis patients. The aim of the present study was to verify this observation using various electrophysiological tests.

Wethots

In 74 sarcoidosis patients complaining of symptoms suggestive of small fiber neuropathy, thresholds tor warm (WS) and cold sensation (CS) as well as for heal pain were determined at the thenar eminence and the foot dorsum. Furthermore, sympathetic skin responses (SSR), nerve conduction studies and concentric needle electromyography were performed. in 31 patients cardiovascular autonomic testing was carried out.

\section{Results}

Themal threshold testing (TTT) revealed abnormalities in 51 of the 74 patients. Abnormalities showed an asymmetrical distribution. WS was affected more often than CS and feet more often than hands. Nerve conduction studies in the legs showed slightly abnormal results in 6 patients; all of these had abnormal TTT results. The SSR was absent at the foot in 7 patients. Cardiovascular autonomic testing was abnomal in only a single patient.

\section{Conclusions}

In a subgroup of sarcoidosis patients we found $T T T$ abnormalities suggestive of small fiber neuropathy. SSR and cardiowascular autonomic testing appeared to be of little diagnostic value. Small fiber netropathy may be the cause of a number of hitherto unexplained symptoms in sarcoidosis. 


\section{Introduction}

Sarcoidosis is a multi-organ disorder of unknown origin, characterized by granuloma formation, which is probably antigen driven. The disease occurs throughout the world, although prevalence varies among ethnic and racial groups. Prevalence ranges from 10 to 40 per 100000 population, mostly young adults of either gender. "The clinical manifestation of sarcoidosis is highly variable, depending on the intensity of the inflammation and the organ systems affected. Sarcoidosis occurs most frequently in the lungs or lymph nodes, although it can appear in other organs. Spontaneous recovery may occur, but the disease can also become chronic or have a progressive course. Apart from pulmonary symptoms such as dyspnoea and coughing, patients often complain of symptoms such as fatigue, pain and sweating. ${ }^{2-5}$ So far, no organic substrate has been found for these symptoms. Treatment of sarcoidosis consists largely of immunosuppressive drugs such as steroids, methotrexate, cyclosporin and, more recently, infliximab. ${ }^{6}$ When features of disease activity, for example radiological abnormalities and lung function impairment, resolve during treatment, fatigue and pain may persist. Therefore, objective test results such as chest $X$-ray and laboratory parameters do not always correlate with the well-being of the patient. ${ }^{3}$ Consequently, the question arises whether these symptoms are psychogenic or manifestations of the underlying organic disease.

Recently, we observed a pattern of symptoms suggestive of small fiber neuropathy with autonomic involvement in a subset of sarcoidosis patients. ${ }^{7}$

Small fiber neuropathy is a generalized peripheral neuropathy selectively involving Ad and $C$ fibers. When the somatic small afferent fibers are affected, symptoms typically consist of pain, dysaesthesias and disturbed temperature sensitivity. Furthermore, autonomic fibers may be involved, causing autonomic dysfunction. Standard nerve conduction tests evaluate only large nerve fiber function. Quantitative techniques for the assessment of small nerve fibers are not routinely applied. Therefore, the diagnosis of small fiber neuropathy can easily be missed.

Quantitative sensory testing has become an important tool in assessing small and large sensory fiber functions. Small-calibre sensory fibers are assessed by temperature threshoid testing (TTT) and large-calibre fibers by vibratory threshold testing. TTT quantifies thresholds for warm and cold perception. ${ }^{8-11}$ It is a non-invasive method easy to perform, and mostly not painful. Furthermore, the testing does not require highly trained personnel.

Autonomic neuropathy can be assessed by cardiovascular autonomic reflex testing on the basis of heart rate variability and blood pressure investigations. ${ }^{12}$ Small fiber sudomotor function can be assessed, among other functions, by the sympathetic skin 
response (SSR). Although the diagnostic value of SSR is limited, it is widely available and inexpensive. Quantitative sudomotor axon reflex testing (QSART) is a more sensitive technique for sudomotor assessment, but it requires special equipment which is available in only a few centers.

The aim of the present study was to investigate small fiber sensory function by determining TTT, EMG, SSR and cardiovascular autonomic tests in a subset of sarcoidosis patients.

\section{Patients and methods}

\section{Patients}

From August 2000 to July 2002, 125 patients with sarcoidosis, confirmed according to international guidelines ${ }^{13}$ were referred to the Maastricht Sarcoidosis Management Center, which serves as a tertiary referral center for sarcoidosis patients in the Netherlands. A group of 74 patients ( 41 men, 33 women) were included in the present study. To be included, patients had to recall symptoms suggestive af small fiber neuropathy (a combination of two or more of the following symptoms: peripheral pain. paraesthesias, intolerance of bedclothes, hyperhidrosis, hypohidrosis, sicca syndrome, facial flushing, diarrhoea, constipation, micturition disturbances, and male sexual dysfunction). Patients with diabetes, alcohol abuse, or renal insufficiency were excluded. Patient characteristics are summarized in table 6.1.

Table 6.1. Summary of the characteristics of the 74 sarcoidosis patients with symploms suggestive of smalt fiber newropathy.

\begin{tabular}{|c|c|c|}
\hline & TT normal $(n=23)$ & TT abnormal $(n=51)$ \\
\hline Malovfomalo $(n)$ & 9114 & $32 / 19^{*}$ \\
\hline Age, (yerars) & $42.9 \pm 11.7(25-65)$ & $45.3 \pm 11.7(19-80)^{*}$ \\
\hline Time since diagnosis (vears) & $3.8 \pm 4.0(0.5-12)$ & $5.7 \pm 0.8(0.5-17)$ \\
\hline CXR 0 /1/U/III/IV (N) & $5 / 1 / 7 / 7 / 3$ & $11 / 7 / 10 / 48 / 5^{*}$ \\
\hline ACE (U/1)* & $20.9 \pm 11.1$ & $24.1: 4.4 .6^{*}$ \\
\hline Snoking notyes (n) & $19 / 4$ & $45 / 6^{4}$ \\
\hline Prednison notyes $(n)$ & $11 / 12$ & $24 / 27^{*}$ \\
\hline $\begin{array}{l}\text { Other inmmunosuppressive therapy (prednisonet. } \\
M T X \text { ) nolyes (n) }\end{array}$ & $18 / 5$ & $37 / 14^{*}$ \\
\hline
\end{tabular}

TTT=thermal threshold testing; $n=n u m b e r$ of cases; CXR=hest radiographs graded according to DeRemee

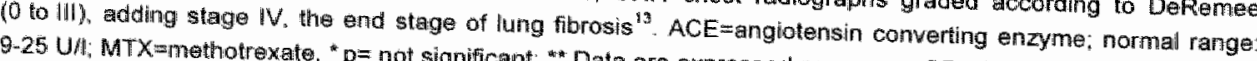
9-25 U/7, MT: $X$ methotrexate. " $p=$ not significant; "Data are expressed as mean \pm SD with range in parentheses 
The 51 patients not enrolled in the study consisted of 31 males and 20 females, age $43.2 \pm 11.1$ and time since diagnosis in this group was $5.1 \pm 6.4$ years. All included patients underwent TTT. EMG and SSR. In the furst 31 patients cardiovascular autonomic testing was performed.

\section{Thermal threshold testing}

\section{Equipment}

All tests were performed using a TSA 2001 (Medoc, Ramat Yishai, Israel), which operates on the Peltier principle. A rectangular stimulator thermode with a surface of $3.2 \times 3.2 \mathrm{~cm}$ was used for culaneous stimulation. Thermode baseline temperature was $32^{\circ} \mathrm{C}$. In order to prevent thermal injury and to protect the Peltier element the high temperature limit was $50^{\circ} \mathrm{C}$ and the lower limit $0^{\circ} \mathrm{C}$.

\section{Test aloonhms}

The method of levels (MLE) and method of limits (MLI) were used. 11,14,15

\section{Method of levels}

Subjects were asked to press YES on a switch held in the free hand if a thermal sensation was perceived and NO if this was not the case. For warmth there was an initial temperature step of $2^{\circ} \mathrm{C}$ with the temperature returning to baseline immediately upon stimulus termination. After the first YES response the stimulus decreased by onehalf of the initial step until a NO was given. Subsequently the step was halved for each successive stimulus and the direction changed according to the response: increase for NO, decrease for $Y E S$. The procedure was continued until the step size reached $0.1^{\circ} \mathrm{C}$. For cold an initial temperature step of $1{ }^{\circ} \mathrm{C}$ was given, this being the only difference compared with the procedure to assess the warm perception threshold. To optimise alertness, an auditory cue was given at stimulus onset. At random no change of temperature occurred (dummy stimulus) after an acoustic alert.

\section{Method of limis}

The test was performed with a rate of temperature change of $1^{\circ} \mathrm{C} / \mathrm{s}$. Subjects were asked to press a switch held in the free hand immediately upon thermal sensation. Five readings at each recording site were obtained for each thermal sensation, and the results were averaged to obtain a single threshold score. An auditory cue al stimulus onset was given to optimise alertness. Patients were told in advance whether a cold or warm temperature stimulus was to be given and were instructed not to react until an obvious thermal sensation was perceived. 


\section{Hsat pain}

The procedure was the same as for MLI warm sensation. Subjects were asked to react immediately upon pain sensation. The order of tests was in all cases as follows: MLI for warm sensation (WS), MLI for cold sensation (CS), MLE for WS, MLE for CS, MLE for heat pain. The tests were performed in a draught-free, soundproof room at a room temperature of $20^{\circ} \mathrm{C}$. The patient relaxed on a recliner without visual access to the display screen.

\section{Tost siles}

Thresholds were assessed at the foot dorsum and thenar eminence on both sides. The thermode was attached to the skin by means of elastic Velcro tape. Care was taken to minimize the variation of the thermode application pressure. Duration of the examination ranged from 40 to $60 \mathrm{~min}$.

\section{Sympathetic skin response}

At irregular intervals of between 4 and 10 s the median nerve was stimulated at the wrist with pulses of $0.2 \mathrm{~ms}$ and amplitudes between 20 and $50 \mathrm{~mA}$. Skin responses were recorded from the contralateral hand and foot. Room temperature was between 22 and $25^{\circ} \mathrm{C}$ and skin temperature was at least $32^{\circ} \mathrm{C}$. For recording $\mathrm{Ag}$-AgCl electrodes were used. The active electrodes were on the palm of the hand and the sole of the foot, respectively, and the reference electrodes on the dorsal side of the hand and the foot. Filter settings were $2 \mathrm{~Hz}$ and $2 \mathrm{kHz}$. The patient was lying supine on the examination table. From each hand and foot 3 or 4 responses were recorded. Only absence of response was considered abnormal.

\section{Cardiovascular autonomic function testing}

Cardiovascular autonomic function was assessed using 5 tests recommended by the San Antonio Consensus Meeting. ${ }^{16}$ Heart rate variability (HRV) and blood pressure were measured while the patient rested in a supine position for about $10 \mathrm{~min}$, while the patient remained standing for about $5 \mathrm{~min}$, during deep respiration (respiratory sinus arrhythmia) with a frequency of $0.1 \mathrm{~Hz}$, during a Valsalva manoeuvre (forced expiration against $40 \mathrm{~mm} \mathrm{Hg}$ during $15 \mathrm{~s}$ ) and while rapidly changing posture from supine to upright. HRV was measured using a computerized system for automatic ECG QRScomplex detection and interval analysis. The following time and frequency parameters were determined for the different tests and compared with age-corrected reference values. ${ }^{17}$ Lying supine and standing: coefficient of variation $\mathrm{CV}(\mathrm{CV}=$ standard deviation $\times 100 \%$ mean), the quotient of maximal and minimal heart rate, the spectral peak 
frequency in the mid-frequency range $0.5-0.15 \mathrm{~Hz}$, and the difference in mean heart rate between standing and lying; Valsalva test: Valsalva ratio; respiration test: successive maximal expiration-inspiration difference; lying-to-standing: initial change in heart rate, 30/15-ratio and with 1 min interval manually measured sphygmomanometric systolic and diastolic blood pressure. Cardiovascular autonomic function was classiffied abnormal if at least 2 of the 5 tests were abnormal.

\section{Nerve conduction studies and EMG}

In all patients motor nerve conduction of the peroneal nerve, sensory conduction of the sural nerve, as well as the soleus. $H$ reflex were measured on both sides. In 6 of them, with TTT abnormalities limited to the hands, sensory conduction of the median and ulnar nerves was measured over the wrist-ring fingler segment. All nerve conduction studies were performed with surface electrodes using standard techniques. For the H reflex, values were taken from. ${ }^{18}$ For peripheral motor and sensory nerve conduction studies, normal values of the own clinical neurophysiology department were used. Needle-EMG was perfiormed an both tibialis and gastrocnemius muscles in all patients.

\section{Calculations and statistical analysis}

Age and sex related reference values for WS and CS thresholds were taken from. ${ }^{10}$ These authors used the same apparatus, thermode size, and stimulation protocol as we did in the present study. Classification of abnormality was based on $Z$ value statistics. The $Z$ value indicates how far and in what direction the measured value deviates from the mean of the reference distribution, expressed in units of the reference distribution's standard deviation. A measurement was considered abnormal when its $Z$ value exceedled 2.5. For a sensation at an extremity to be classified as abnomal, results of both MLI and MLE testing had to be abnormal.

The relation between MLE and corresponding MLI Z values was established by simple linear regression analysis. Differences in median values of absolute right minus left $Z$ values were compared using Mann-Whitney $U$ test.

\section{Results}

\section{Temperalure theshold testing}

TIT results at any measured site were considered abnormal only if both MLE and MLI were abnormal. This was the case in 51 of the 74 patients with symptoms suggestive of small fiber neuropathy (69\%). Of these 51 patients 28,7 and 16 showed only WS, only 
CS, and both WS and CS abnormalities, respectively (table 6.2). TTT findings were more often abnormal in the feet than the hands ( 54 vs. $38 \%$ ). However, a combination of abnormal temperature sensation in the hands and normal temperature sensation in the feet occurred in 11 patients $(15 \%)$. Foot WS was more often abnormal in men than in women (23 males ws. 5 females: maleffemale ratio $=3.3$ ). Other abnomalities were equally distributed among males and females. Allodynia was found in 5 cases $(7 \%)$ and always found in combination with other TTT abnormalities.

Table 6.2 Themath theshold testing (TT) results for warm seinsation and cold sensation in 74 sarcoidosis patients with clinical symptoms suggestive of small fiber neturopathy.

\begin{tabular}{lccc} 
& $\begin{array}{c}\text { Normal cold sensation } \\
\mathbf{n}(\%)\end{array}$ & $\begin{array}{c}\text { Abnormal cold sensation } \\
\mathbf{n}(\%)\end{array}$ & $\begin{array}{c}\text { Total } \\
\mathbf{n}(\%)\end{array}$ \\
\hline Normal warm sensation: & $23(31.1)$ & $7(9.5)$ & $30(40.6)$ \\
Abnormal warm sensation & $28(37.8)$ & $16(21.6)$ & $44(59.4)$ \\
Total & $51(68.9)$ & $23(31.1)$ & $74(100.0)$ \\
\hline
\end{tabular}

The distribution of abnormalities is shown in Table 6.3. TT abnormalities were bilateral in 19 patients and unilateral in 22 patients. In 10 patients a combination of unilateral and bilateral abnormalities was found. Both for unilateral and bilateral TT abnormalities the absolute value of the side difference in $Z$ value $(\Delta Z)$ was calculated for WS and CS in both the hand and the foot. Absolute values were calculated in order to classify right-left and leftright differences in a comparable way. Median values and their interquartile ranges were computed per extremity and modality for umilateral abnormalities, bilateral abnormalities and normal thermal thresholds (table 6.4). The median value of the side difference was significantly larger in unilateral abnormalities than the corresponding value in normal TTT results. This holds for thenar and foot WS and foot CS. Except for thenar WS, $\triangle Z$ was also significantly greater in bilateral abnormalities than in normal TTT results. Only for WS in the fook was $\triangle Z$ significantly lower for bilateral than for unilateral abnormal TTT values. 
Table 6.3 Distribution of themal threshold testing (TIT) nesults over the extremities in 74 santowosis. patients with symptoms suggestive of small fiber neuropathy.

\begin{tabular}{|c|c|c|c|c|c|}
\hline & $\begin{array}{c}\text { mo abnormalities } \\
n(\%)\end{array}$ & $\begin{array}{c}\text { one hand } \\
\text { n }(\%)\end{array}$ & $\begin{array}{c}\text { both hands } \\
n|\%\rangle\end{array}$ & $\begin{array}{c}\text { one foot } \\
n(\%)\end{array}$ & $\begin{array}{c}\text { both feet } \\
\text { n }(\%)\end{array}$ \\
\hline no abnomalities & $23(31.1)$ & - & - & 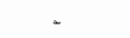 & . \\
\hline one hand & - & $7(9.4)$ & - & $2(2.7)$ & $5(6.8)$ \\
\hline both hands & - & - & $4(5.4)$ & $5(6.8)$ & $5(6.8)$ \\
\hline one toot & - & $2(2.7)$ & $5(6.8)$ & $13(176)$ &. \\
\hline \multirow[t]{2}{*}{ both feet } & - & $5(6.8)$ & $5(6.8)$ & - & $10(13.5)$ \\
\hline & $23(31.1)$ & $14(18.9)$ & $14(18.9)$ & $20(27.0)$ & $20(27.0)$ \\
\hline
\end{tabular}

Table 6.4 Comparison of median walues of absolute right minus left Zxvalue differences in normal thermal threshold testing (TTT) results (A), bilateral TT abnormalities (B) and asymmetrical TT abnormalities (C), in 74 sarcoidosis patients with symptoms suggestiwe of small fiber neuropathy.

\begin{tabular}{|c|c|c|c|c|c|}
\hline & & \multicolumn{4}{|c|}{ Madian* (IQR) } \\
\hline & & Thenar warm & Thenar coldd & Foot warm & Foot cold \\
\hline \multicolumn{2}{|c|}{ A: TTT normal } & $0.88(0.7)$ & $0.51(0.6)$ & $0.80(0.7)$ & $1.05(1.2)$ \\
\hline \multicolumn{2}{|c|}{ B: TTT bilaterally abnormal } & $4.61(4.5)$ & $5.20(3.2)$ & $0.60(0.6)$ & $3.20(2.6)$ \\
\hline \multicolumn{2}{|c|}{ Q: TTI unitaterally abnormal } & $4.12(1.4)$ & np & $2.49(0.7)$ & $3.54(0.8)$ \\
\hline \multirow[t]{3}{*}{$p$-value } & $A$ ws. B & $<0,0001$ & 0.001 & 0.22 & 0.002 \\
\hline & $\mathrm{B}$ ws. C & 0.85 & & $<0.0001$ & 0.21 \\
\hline & Aws. C & $<0.0 .001$ & & $<0.0001$ & $<0.0001$ \\
\hline
\end{tabular}

* Median of absolute differences in Zvalue between right and left side; "Mann-Whitrey U test $\mid Q R$ : interquartile range; $n p=$ not present

Two different measuring methods, MLE and MLl, were applied. The correspondence between the results of both methods at a single recording site was illustrated and quantified by plotting for every patient the $M L I Z$ value as a function of the MLE $Z$ value. This scatter plot of MLI vS. MLE Z values for WS in the right foot is illustrated in figure 6.1. Obviously there is a significant linear correlation $(r=0: 89, p<0: 001)$ between MLI and MLE $Z$ values. Similar linear correlation values were found for the other sites and modalities (mean r=0:81, range 0.58-0.89). Regarding abnormality, both methods may be complementary to each other or may give supplementary information. Four areas in the MLI VS. MLE scatter plot can be distinguished (table 6.5), namely: area I (MLI $Z \leq 2: 5$ and $M L E Z \leq 2: 5$ ), area $\| I$ ( $M L I Z \leq 2: 5$ and $M L E Z>2: 5$ ), area $\|$ II (MLI $Z>2: 5$ and $M L E Z \leq 2.5)$ and area $I V(M L I Z>2: 5$ and $M L E Z>2: 5)$. In table 6.5 the percentages as distributed over the different areas are summarized. Overall correspondence between the results of both tests was found to be $83.5 \%$ (range $78-89 \%$ ). No consistent pattern was found in cases of disagreement. For WS in the thands $(9.3 \mathrm{vs} .9 .2 \%)$ there was no difference, whereas for WS in the foot (18 vs. $4 \%$ ) and CS in the hand $(7.3 \mathrm{vs}$. $3.7 \%$ ) MLE resulted in more abnormalities than MLI. Finally, for foot CS, MLI showed more abnormalities than MLE (10.8 vs. $2.5 \%$ ). 


\section{Sympathetic skin response}

In 7 of the 74 patients suspected of small fiber neuropathy, the SSR could not be recorded in the foot. TTT results were normal in 3 of these patients; WS in the hand was abnormal in 1 patient; CS in the foot was abnormal in 1 patient; and in 2 patients both WS and CS in the foot were abnormal.

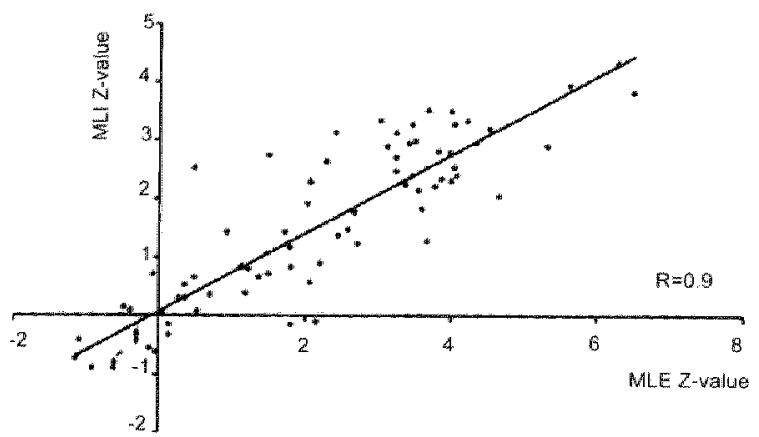

Figure 6.1 Method of limits (MLI) Z value as a function of method of levels (MLE) $Z$ value in a group of 74 sarcoidosis patients with clinical symptoms suggestive of small fiber neuropathy. Data are for warm sensation in the right foot. Linear correlation coefficient ir $=0.9(p<0.001)$.

Table 6.5. Comparison of results by method of limits (MLI) and method of levels (MLE) in 74 patients with symptoms suggestive of small fiber neuropathy. Numbers I through IV denote the four areas of the MLE-MLI scatter plot.

\begin{tabular}{|c|c|c|c|}
\hline & 1 and iv & II & 槅 \\
\hline Warm therenar & 81.5 & 9.2 & 9.3 \\
\hline Warm foot & 78.0 & 18.0 & 4.0 \\
\hline Cold therver & 89.0 & 7.3 & 3.7 \\
\hline Cold foot & 85.5 & 2.5 & 10.8 \\
\hline Mean (range) & $83.5(78.0 \cdot 89.0)$ & $9.5(2.5-18.0)$ & $7.0(3.7-10.8)$ \\
\hline
\end{tabular}

Results per test site were divided into 3 groups: MLE and MLI both momal (I) or both abnormal (WW): MLE abnormal whereas MLI is normal (II): MLI abnormal whereas MLE is normal (III).

Abnormal: $Z>2.5$. Parcentages per group are shown for each modality and test site.

\section{EMG and nerve conduction studies}

EMG of lower leg muscles did not reveal any abnormality. Nerve conduction studies showed an absent soleus $H$ reflex in 3 patients $(4 \%)$. Slightly decreased nerve 
conduction welocities were found in 3 other patients. These 6 patients all had abnormal TTT results. In 6 of the 11 patients with isolated TTT abnormalities in the hands, median nerve conduction in the wrist was normal.

\section{Cardiovascular autonomic reflex tests}

Of the first consecutive 31 patients, only a single patient showed abnormality of heart rate variability indicative of cardiovascular autonomic dysfunction. Therefore, and because autonomic tests are relatively time consuming we decided not to perform autonomic tests in the following 43 patients.

\section{Discussion}

To the best of our knowledge we are the first to report TTT abnormalities suggestive of small fiber neuropathy in sarcoidosis, possibly explaining symptoms which so far have often been considered to be 'non-specific." Fifty-one out of 74 patients with symptoms suggestive of small fiber neuropathy had abnormal TTT results.

WS was more often affected than CS (59 vs. $31 \%$ ). CS abnormalities in combination with normal WS were present in 7 of the 74 cases. Thus, unmyelinated $C$ fibers seemed to be more involved than Ad fibers. However, as reported before in idiopathic small fiber neuropathy " sometimes. Ad fibers seem to be selectively involved. Disturbed temperature sensation occurred more frequently in the feet than in the hands. This finding might be due to a greater vulnerability of the longest fibers. Length dependent axonal degeneration has indeed been reported in small fiber neuropathy. ${ }^{19-21}$ However, in 11 cases $(15 \%)$ temperature sensation was normal in the feet but abnormal in the hands. A possible explanation could have been compression of the median nerve in the wrist, which ${ }^{22}$ found to be common in sarcoidosis. Furthermore, Goadsby and Burke ${ }^{23}$ found that abnormal thermal thresholds occurred in up to $25 \%$ of patients with CTS, remarkably both in the median and ulnar nerve supply areas. However, in the present study, median nerve conduction across the wrist was measured in 6 of the 11 above mentioned cases and was found to be normal in all. Apparently, in a minority of sarcoidosis patients with small fiber neuropathy, hands are more or possibly even exclusively involved.

No sex differences were found in earlier studies on small fiber neuropathy. ${ }^{20}$ However, in the present study, males showed more WS abnormalities in the feet than did females. Heat pain abnormalities were rare in our population and always occurred in combination with other abnormalities. Thus, for the diagnosis of small fiber neuropathy, assessment 
of heat pain, a time consuming and unpleasant method, seems to provide no additional information.

In 22 cases we found unilateral TT abnormalities (table 6.3). Reference values for side differences are not yet available. However, when unilateral abnormalities were found, side differences were significantly greater than in those cases with normal TTT results. This was also true for bilateral TTT abnormalities, except for WS in the foot (table 6.4). Thus, these measurements are highly suggestive of an asymmetrical distribution of the neuropathy. In sarcoid large fiber neuropathy, pathological studies have shown asymmetrical involvement of nerve fascicles. ${ }^{24}$ Idiopathic small fiber neuropathy is mostly distal and symmetrically distributed, but a 'multifocal' nonlength-dependent variant has been described. ${ }^{25-27}$ Furthermore, asymmetric presentation of small fiber dysfunction has been described in Sjögren's syndrome ${ }^{28}$ Similarly, a specific subset of nerve fibers can be affected in the peripheral autonomic nervous system, while another subset can be preserved. ${ }^{29.30}$

The SSR was always obtained from the hand and was absent in the foot in only 7 of the 74 patients with symptoms of small fiber neuropathy. Amplitude and shape of the SSR show habituation and great variability. Furthermore, sympathetic postganglionic fibers in peripheral neuropathy conduct with normal velocities or they do not conduct at all. Therefore, only an absent response should be considered abnormal. ${ }^{34}$ Former studies report that the sensitivity of SSR is probably low. Evans et al. ${ }^{32}$ found that only $10 \%$ of 54 patients with suspected small fiber neuropathy had an abnomal skin response. The specificity of SSR for small fiber neuropathy is also considered to be low. ${ }^{27}$ Although widely available and inexpensive, SSR does not seem to be a valuable diagnostic tool in small fiber neuropathy.

In a study on idiopathic small fiber neuropathy, cardiovascular autonomic tests were found to be abnormal in $28 \%$ of the patients. ${ }^{33}$ Despite the accurrence of clinical signs of autonomic dysfunction in some of our 31 investigated patients, cardiovascular autonomic testing was found to be abnormal in only a single case. This suggests a different pattern of involvement of the autonomic nervous system in sarcoidosis patients.

A disadvantage of TTT is that it is a psychophysical method. Consequently, the patient must be alert "concentrated, and not biased to a certain test outcome. ${ }^{11,34}$ The population studied consisted of relatively young adults (mean age 44 years, range 19-70). All subjects were cooperative and performed the testing without any problems. To improve outcome reliability, we used a $99 \%$ instead of $95 \%$ confidence interval and two instead of a single testing method. Moreover, the correlation between MLE and MLI was highly significant. Finally, as diagnoses should ideally not be based on a single test result, skin biopsy was performed in a subgroup of 7 consecutive patients with symptoms suggestive of small fiber neuropathy: hyperhidrosis $n=5$, diarrhoea $n=4$, 
Sicca syndrome $n=3$, impotence $n=2$, peripheral pain $n=7$, paraesthesias $n=5$, intolerance of bedcloth $n=5$, micturition disturbances $n=4$. TT in these patients showed abnormalities in both hands and feet in 3 patients. WS was abnormal at both feet in two patients, CS was abnormal at one foot in one patient and warm sensation was abnormal at both hands in one patient. The presence of small fiber neuropathy was confirmed by skin biopsies in all 7 patients. ${ }^{7}$ The quantification of epidermal nerves in skin biopsy appears to be an objective and valuable method for detecting small fiber neuropathy. ${ }^{19,21}$ Indeed, skin biopsy seems to be more sensitive than $T T^{20}$. However, the technique is availlable in only a few centers. ${ }^{27}$

Large fiber neuropathy is considered to be rare in sarcoidosis ${ }^{35,36}$ The pattern of large fiber neuropathy reported in sarcoidosis includes multiple mononeuropathies, polyradiculopathy, Guillain-Barre' syndrome, and symmetric distal polyneuropathy, which may be sensorimotor, pure sensory, or pure motor. ${ }^{24,35,37-48}$ Apparently, there is a wide clinical and pathological spectrum of sarcoid neuropathy. The pathophysiology of small fiber neuropathy may be immune mediated. We found unilateral abnormal TTT results in a subset of the investigated patients. Furthermore, in patients with bilateral TT abnormalities, right-left differences were also significantly greater than they were in patients with normal $\pi T$ results. Large fiber neuropathies with an asymmetrical distribution are predominantly immunologically determined, such as multiple mononeuropathies in vasculitis ${ }^{49}$ and multifocal motor neuropathy. ${ }^{50}$ Recently, small fiber neuropathy has been described in other immune mediated diseases, including systemic lupus erythematodes and Sjögren's syndrome. ${ }^{28,51}$ Some authors believe that a distal small fiber neuropathy may even be the most common form of neuropathy in Sjögren's syndrome. ${ }^{27}$ Whether this may also be the case for sarcoidosis needs further study. Presumably, in some immune mediated diseases, there is a common pathway causing neuron damage, for which small fibers are more or even selectively vulnerable. In immune mediated diseases, prednisone is the most commonly used treatment. However, prednisone might also play a role in the pathogenesis as it may cause hyperglycaemia. Hyperglycaemia can cause small fiber neuropathy. However, in the number of cases treated with prednisone we found no differences between patients with and without abnormal TTT results in sarcoidosis (table 6.1).

\section{Conclusions}

The present study suggests that patients with sarcoidosis may develop small fiber neuropathy. Thermal threshold testing showed abnormalities in a majority of patients in whom this diagnosis was suspected on clinical grounds. Moreover, these tests revealed indications of an asymmetrical involvement of both $A \delta$ and $C$ fibers. 


\section{References}

1. Newman LS, Rose CS, Maier LA. Sarcoidosis. N Engl Med 1997;336:1224-34.

2. James DG. Complications of sarcoidosis. Chronic fatigue syndrome. Sarcoidosis $1993 ; 10$ $1-3$.

3. Wirnsberger RM, De Vries J, Breteler MHM van Heck GL, Wouters EFM, Drent M. Evaluation of quality of life in sarcoidosis patients. Respir Med 1998;92:750-6.

4. Sharma OP. Fatigue and sarcoidosis. Eur Respir J 1999;13:713-4.

5. Hoitsma E. De Vries d, Faber CG, van Santen-Hoeufft M, Drent M. Chronic pain in a Dutch sarcoidosis population. Sarcoidosis Vasc Diffuse Lung Dis 2003;20:33-9

B. Baughman RP, Lower EE. Infliximab for refractory sarcoidosis. Sarcoidosis Vasc Diffuse Lung Dis 2001:18:70-4.

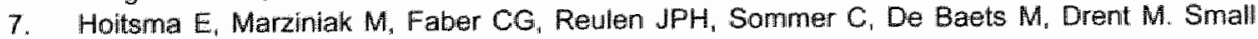
Fiber Neuropathy in Sarcoidosis. Lancet 2002;359:2085-6.

8. Fruhstorfer $\mathrm{H}$. Lindblom U, Schmidt WC. Method for quantitative estimation of thermal thresholds in patients. J Neurol Neurosurg Psychiatry 1976;39:1071-5.

9. Jamal GA, Hansen S, Weir Al, Ballantyne JP. The neurophysiologic investigation of small fiber neuropathies. Muscle Nerve 1987:10:537-45.

10. Yamitsky $D$. Sprecher $E$. Thermal testing: normative data and repealability for various test algorithms. J Neurol Sci 1994;125:39-45.

11. Reulen JPH, Lansbergen MDI, Verstraete E, Spaans F. Comparison of thermal threshald tests to assess small nerve fiber function: limits ws. levels. Clin Neurophysiol 2003;114: $556-63$

12. Ewing DJ, Clarke BF. Diagnosis and management of diabetic autonomic neuropathy. BMJ (Clin Res Ed) 1982;285:916-8.

13. Humninghake GW, Costabel U, Ando M. Baughman RP, Cordier JF, du Bois RM, Eklund $A$ Kataichi $M_{n}$ Lynch J, Rizzato $G$, Rose $C$, Selroos O, Semenzato $G$, Sharma OP. ATS/ERSWASOG statement on sarcoidosis. American Thoracic Society/European Respiratory Society/World Association of Sarcoidosis and other Granulomatous Disorders. Sarcoidosis Wasc Diffuse Lung Dis 1999;16:149-73.

14. Claus DM, Hilz J. Neundorfer B. Thermal discrimination threshalds: a comparison of different methods. Acta Neurol Scand 1990;81:533-40.

15. Kemler MA, Reulen JPH, van Kleef M, Barendse GA, vanden Wildenberg FA, Spaans $F$ Thermal thresholds in complex regional pain syndrome type i: sensitivity and repeatability of the methods of limits and levels. Clin Neurophysiol 2000;111:1561-8.

16. American Diabetes Association, American Academy of Neurology: Report and recommendations of the San Antonio Conference on Diabetic Neuropathy (Consensus Statement). Diatates Care 1988:11:592-7.

17. Lanting P. Aspects of autonomic neuropathy in diabetes mellitus. Thesis, VU publishers, Amsterdam 1990; ISBN 90-6256-894-7.

18. Visser SL, Zonneveldt A, de Rijke W, Don JA, Martens El, Stam D. Normal Hofimann reflex latencies (H-M interval) in relation to age and body length. Clin Neurol Neurosurg 1983;85-91.

19. McCarthy BG, Hsieh ST, Stocks A. Hauer P. Macko C, Cornblath DR, Griffin JC, McArthur JC. Cutaneous innervation in sensory neuropathies: evaluation by skin biopsy. Neurology 1995; $45: 1848-55$.

20. MCArthur JC, Stocks EA, Haver P, Cornblath DR, Griffin JW, MCArthur JC. Epidermal nerve fiber density: normative reference range and cliagnostic efficiency. Arch Neurol 1998:55: $1513-20$

21. Lauria G, Holland $N$, Hauer $P$, Comblath DR, Griffin JW, McArthur JC. Epidermal innervation: changes with aging, topographic location, and in sensory neurapathy. J Neurol Sol 1999:164: $172-8$.

22. Niemer $G W$. Bolster MB, Buxbaum $L$, Judson MA. Carpal tunnel syndrome in sarcoidosis. Sarcoidosis Vasc Diffuse Lung Dis 2001;18:296-300. 
23. Goadsby PJ, Burke D. Deficits in the function of smatl and large afferent fibers in confirmed cases of carpal tunnel syndrome. Muscle Nerve 1994;17:614-22.

24. Said G, Lacroix C. Plante-Bordeneuve W. La Page L. Pico F. Presles O, Senant J, Reny P. Rondepierre $P$. Mallecourt $\downarrow$. Nerve granulomas and vasculitis in sarcoid peripheral neuropathy: a clinicopathological study of 11 patients. Brain 2002;125:264-75.

25. Lacomis D. Tobin K, Guiliani MJ. Nultifocal small fiber sensory neuropathy. J Clin Neuromusc Dis 1999:1:2-5.

26. Holland N. Idiopathic painful sensory neuropathy. J Clim Neuromusc Dis 2001:2:211-20.

27. Lacomis D. Small-fiber neuropathy. Muscle Nerve 2002;26:173-88.

28. Denislic $M$, Meh D. Early asymmetric neuropathy in primary Sjogren's Syndrome. I Neurol $1997 ; 244: 383-7$

29. Rydler RE, Hardisty CA. Which battery of cardiovascular autonomic function tests? Diabetologia 1990;33:177-9

30. Hanson $P$, Schumacker $P$, Debugne $T$, Clerin $M$. Evaluation of somatic and autonomic small fibers neuropathy in diabetes. Am J Phys Med Rehabil 1992;71:44-7.

31. Gutrecht JA. Sympathetic skin response. J Clin Neurophysiol 1994;11:519-24

32. Evans BA, Lussky $D$, Knezevic $W$. The peripheral autonomic surface potential in suspected small fiber neuropathy. Muscle Nerve 198:8;1:982.

33. Stewart JD, Low PA, Fealey RD. Distal small fiber neuropathy: results of tests of sweating and autonomic cardiovascular reflexes. Muscle Nerve 1992;15:661-5.

34. Dyck PJ, Kennedy WR, Kesserwani $H_{1}$ Melanson $M$, Ochoa J, Shy $M$, Stevens $J C$, Suarez GA, O'Brien PC. Limitations of quantitative sensory testing when patients are blased toward a bad outcome. Neurology 1998:50:1213.

35. Miller $R$, Sheron N, Semple S. Sarcoidasis presenting with an acute Guillain-Barre syndrome. Postgrad Med J 1989;65:765-7.

36. Gaimsborough $N_{1}$ Hall $S M$, Hughes RA, Leibonitz S. Sarcoid neuropathy. J Neurol 1991;238: $177-80$.

37. Strickland GT. Moser Jr, Moser KM. Sarcoidosis with a Landry-Guillain-Barre syndrome and clinical response to corticosteroids. Am J Med 1967;43:131-5.

38. On SJ. Sarcoid polyneuropathy: a histologically proved case. Ann Neurol 1980;7:178-81.

39. Nemni R, Galassi $G$, Cohen $M$. Hays AP, Gould R, Singh N, Bressman $S$, Gamboa ET. Symmetric sarcoid polyneuropathy: analysis of a sural nerve biopsy. Neurology 1981;31: 1217-23.

40. Vital C. Aubertin J, Ragnault JM, Amigues $H$, Mouton L, Bellance R. Sarcoidosis of the peripheral nerve: a histological and ultrastructural study of two cases. Acta Neuropathol 1982; $58: 111-4$

41. Challenor, YB, Felton CP, Brust JC. Peripheral nerve involvement in sarcoidesis: an electrodiagnostic study. I Neurol Neurosurg Psychiatry 1984:47:1219-22.

42. Galassi $G$, Gibertoni M, Mancini $A_{n}$ Nemni R, Volpi $G$, Merelli $E$, Vacca $G$. Sarcoidosis of the peripheral nerve: clinical, electrophysiological and histological sludy of two cases Eur Nourol $1984: 23: 459-65$.

43. Elkin $R$, Willcox PA. Neurosarcoidosis. A report of 5 cases. S Afr Med $J 1985 ; 67: 943-6$.

44. Oksanen $V$. Neurosarcoldosis: clinical presentations and course in 50 patients. Acta Neurol Scand 1986;73:283-90.

45. Baron $B$, Goldberg $A L$, Rothfus WE ${ }_{n}$ Scherman RL. CT features of sarcoid infiltration of a lumbosacrall nerve root. I Comput Assist Tomogr 1989;13:364-5.

46. Matthews WB. Sarcoid neuropathy. In: Dyck PJ, Thomas PK, Lambert EH, Bunge R, editors. Peripheral Neuropathy. $2^{\text {nd }}$ ed. Philadelphia. W.B. Saunders; 1984:2018-26.

47. Scott TS, Brillman J, Gross JA. Sarcoidosis of the peripheral mervous system. Neurol Res 1993; 15:389-90.

48. Koffman $\mathrm{B}$, Junck L, Elias SB, Feit HW, Levine SR. Polyradiculopathy in sarcoidosis. Muscle Nerve 1999:22:608-13.

49. Said G. Vasculitis neuropathies. Im: Latow $N_{\sharp}$ Wokke JHH, Kelly Jd Jr, editors. Immunological and infectious diseases of the peripheral nerves. Cambridge University Press 1998, Cambridge. 
50. Van den Berg-Vos RM. Franssen $H$, Wokke JHJ, wan Es HW, van den Berg LH. Multifocal motor neuropathy: Diagnostic criteria that predict the response to immunoglobuin treatment. Ann Neurol 2000; 48:919-26.

51. Omdal $\mathbb{R}$, Mellgren SI, Goransson L, Sikjesol A, Lidal $S$, Koldingsnes $W$, Husby $G$. Small nerve fiber involwement in systemic lupus erythematosus: a controlled study. Arthritis Rheum $2002 ; 46: 1228-32$ 


\section{Chapter 7}

\section{Small fiber neuropathy in sarcoidosis}

EHoitsma, MMariniak, CG Faber, JPHReulen, CSommer, M De Baets, M Drent 


\section{Abstract}

\section{Background and aim}

Some patients with sarcoidosis have unexplained pain and dysaesthesia.

\section{Methods}

We did quantitative sensory testing in 31 sarcoidosis patients with pain or autonomic dysfunction. 25 patients had reduced warmth sensitivity, cold sensitivity, or both. Intraepidermal nerve fiber density (IENFD) was measured in punch biopsy skin samples in seven consecutive patients.

Results

All seven patients had reduced IENFD compared with controls, which confirmed the presence of small fiber neuropathy in these patients.

\section{Conclusions}

Some patients with sarcoidosis may have small fiber neuropathy with autonomic involvement. 


\section{Introduction}

Sarcoidosils is a disseminated granulomatous disease whose cause is unknown. Estimates of prevalence range from 1-40 per 100000 population, varying among ethnic and racial groups. 'The clinical course of sarcoidosis is highly variable, and practically every organ can be involved. Spontaneous recovery may occur, but the disease is chronic and progressive, in about $25 \%$ of cases. About $5 \%$ of patients will die from sarcoidosis. Most cases $(90 \%)$ have respiratory symptoms, abnormal chest radiographs, or both when first diagnosed. In addition, many sarcoidosis patients report nonspecific symptoms such as fatigue and pain. These nonspecific symptoms are disabling for the patient and can become chronic. Although some groups have investigated possible causes of fatigue, the exact mechanism is still unknown. ${ }^{2}$ By contrast, pain in sarcoidosis has received little attention.

Small fiber neuropathy is a generalized peripheral neuropathy that selectively involves the small thinly myelinated ( $A^{\mathrm{rm}}$ ) and unmyelinated (C) nerve fibers. Typically, symptoms consist of pain and dysaesthesias and a disturbed temperature sensitivity. Furthermore, autonomic fibers may be involved causing autonomic dysfunction.

However, few objective measures are available for the assessment of small nerve fibers. Routine neurological examination and standard electro-physiological tests evaluate only the large fibers. Therefore, small fiber neuropathy is often difficult to diagnose. A functional measure to evaluate the small fibers is quantitative sensory testing, in which thresholds for warmth and cold perception are determined. ${ }^{3}$

Quantification of epidermal nerves in skin biopsies is an objective and valuable method to detect small fiber neuropathy. Reduced intraepidermal nerve fiber density (IENFD) may be the first and only detectable abnormality in patients with painful neuropathy. ${ }^{4}$

\section{Patients and methods}

From August, 2000, to February, 2001, 70 patients with chronic severe sarcoidosis (diagnosed with a bronchoalveolar lavage or biopsy according to international guidelines) $)^{5}$ were referred to the Sarcoidosis Knowledge and Treatment Center of the University Hospital Maastricht, Netherlands, for a second opinion. Of these patients " 31 (44\%) had peripheral pain and paraesthesias, symptoms related to autonomic dysfunction, or both. They were all seen by the same neurologist (EH). The study group consisted of 16 men ( $53 \%$ ) and 15 women (47\%), the median age was 45 (range 20-64) years. Duration of sarcoidosis ranged from 0.5 to 25 years (median 4.0 years). None of the patients had diabetes. 


\section{Results}

The following symptoms were present: peripheral pain $(n=24,77 \%)$, paraesthesias $(20$, $65 \%$ ), sheet intolerance $(14,45 \%)$, hyperhidrosis $(14,45 \%)$, hypohidrosis (two, $6 \%$ ), sicca syndrome $(16,52 \%)$, facial flushing $(16,52 \%)$, orthostatic intolerance (five, $16 \%$ ), diarrhoea $(11,35 \%)$, constipation (one. $3 \%$ ), micturition disturbances $(12,39 \%)$, and male sexual dysfunction (ten, $32 \%$ ).

Nerve conduction studies and concentric needle examinations (measuring only large peripheral nerve fiber function), were within normal limits in all patients. Quantitative sensory testing was done with a Medoc TSA-2001 device (Medoc, Ramat Yishai, israel). Thresholds for warmth and cold sensation were determined on the hand and dorsum of the foot using the levels and the limits method; normative data according to Yarnitskys were used. Reduced temperature sensitivity was found in 25 of 31 patients $(81 \%)$

In order to further quantify small fiber neuropathy, a $4 \mathrm{~mm}$ punch biopsy sample of the skin was taken $10 \mathrm{~cm}$ above the lateral malleolus of the last seven consecutive patients (median age 36 years [30-51], six men [86\%]) and of six healthy controls (median age 35 years $[29-50]$, three men $[50 \%])$. Of these patients, three had severe abnormalities in quantitative sensory testing and four had only minor abnormalities. Two patients had been treated with corticosteroids in the past whereas the other five patients were never treated with corticosteroids or any other immunotherapy. After fixation and freezing, $50 \mu \mathrm{m}$ sections were cut and stained with polyclonal antihuman protein gene product (PGP) 9.5 (UltraClone Limited, Isle of Wight, UK). For each biopsy sample the average number of separate intraepidermal nerve fibers per $\mathrm{mm}$ length of epidermis was derived. A-prioril counting rules were established to count only fibers that traverse the basal membrane. The analysis was done by two observers blinded to the allocation of the specimen (MM and CS). Statistical analysis used the non-parametric Mann-Whitney $U$ test (two tailed). Median IENFD values were $5.4(3.9-6.7$, IQR 2.1) and 13.2 (7.6 to $15.6,4.6)$ in patients and controls, respectively. Figures 7.1 and 7.2 show the IENFD in patients and controls, revealing a significant reduction in IENFD in sarcoidosis patients $(p=0.003)$. 


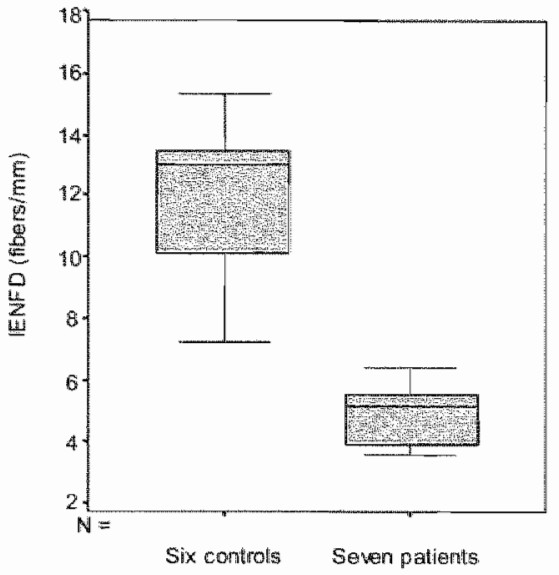

Figure 7.1 Intraepidemal nerve fiber idensity (UENFD) in sarcoidosis patients and heallhy controls. Boxplots show medians, IQRs and ranges $(p=0.003)$
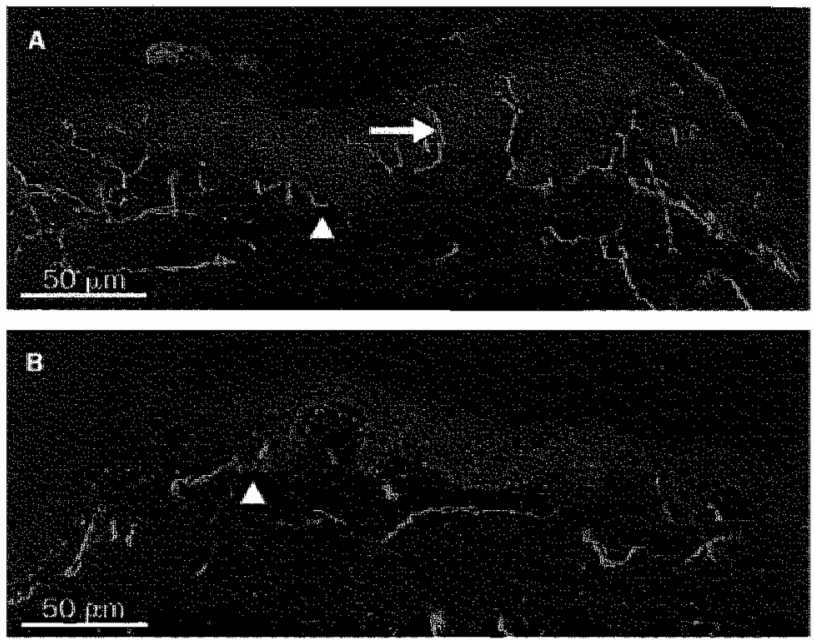

Figure 7.2 Skin biopsy samples showing intraepidermal nerve fiber density (IENFD). Magnification $200 x$. Top panel shows punch skin biopsy sample from a healthy control with nomal intraepidermal nerve fiber density. Lower panel shows pufich skin biopsy sample from a sarcoidosis patient with a severe loss in intraepidermal nerve fibers. Arrow=intraepidermal nerve fiber. Arrowhead=basal rnembrame (the epidermis is sthown above the basal membrane, under the basal membrame the dermis is shown with some nerve fibers). 


\section{Discussion}

Based on our clinical observations, quantitative sensory testing results, and skin biopsy data, small fiber neuropathy may occur in sarcoidosis, possibly related to pain and autonomic dysfunction. We wish to alert physicians who take care of sarcoidosis patients to this diagnosis, in particular pulmonologists, general practitioners, and neurologists. Since sarcoidosis patients are usually referred to non-neurologists, and onlly few objective measures are available for assessment of small nerve fibers, the diagnosis can be easily missed. The recognition of an organic basis of peripheral pain and autonomic symptoms in chronic sarcoidosis patients is important since patients report benefit from knowing the cause of their complaints. Symptomatic treatment of neuropathic pain with drugs such as amitriptyline, gabapentin, or carbamazepine should be considered. Moreover, autonomic dysfunction linked to small fiber neuropathy might cause life threatening events. Occasionally, sudden death of unknown cause occurs in sarcoidosis. Indeed, as seen in diabetes mellitus and in Guillain-Barrë-syndrome, sudden death in sarcoidosis might be due to autonomic dysfunction.

\section{Conclusion}

Future studies should address the pathophysiology and methods of treatment of this hitherto unrecognised feature of sarcoidosis. 


\section{References}

1. Newman LS, Rose CS, Maier LA. Sarcoidosis. N Engl I Med 1997:336:1224-34.

2. Sharma OP. Fatigue and sarcoidosis. Eur Respir $J 1999 ; 13: 713-14$.

3. Yarnitsky $D$. Sprecher $E$. Thermal testing: normative data and repeatability for warious test algarithms. I Neurol Sci 1994;125:39-45.

4. Kennedy WR, Said $G$. Sensory nerves in skin: answers about painful feet? Neurology 1999; 53:1614-15.

5. Hunninghake GW, Costabel U, Ando M, Baughman RP, Cordier JF, du Bois RM Eklund $A_{\text {; }}$ Kitaichi $M$, Lynch J, Rizzato $G$, Rose $C$, Selroos $O$, Semenzato $G$, Sharma OP. ATS/ERSWASOG stattement on sarcoidosis. American Thoracic Society/European Respiratory Society/World Association of Sarcaidosis and other Granulomatous Disorders. Sarcoidosis Vasc Difflise Lung Dis 1999;16:149-73. 
$12 \mathrm{a}$ 


\section{Chapter 8}

The Small Fiber Neuropathy Screening List: Construction and cross-validation in sarcoidosis 


\section{Abstract}

\section{Bakground and am}

Small fiber neuropathy (SFN) appears to be relatively common in sarcoidosis patients. However. there is no golden standard to establish SFN and diagnostic tests for SFN are not widely available. There is a need for an easily to administer SFN screening instrument for clinical assessment research or therapeutic trials. The aim of the present study was to develop a screening list to identify sarcoidosis patients with SFN.

\section{Mohode}

We studied 139 sarcoidosis patients. The first consecutive 84 patients (Group 1) underwent temperature threshold testing (TIT) and completed an extensive SFN-symptoms-questionnaire. Based on data from Group 1 and using distribution measures and discriminant analyses, a screening list for SFN in sarcoidosis consisting of 21 questions was constructed: the Small Fiber Neuropathy Screening List (SFNSL). Subsequently, this SFNSL was crossvalidated in the next 55 consecutive patients (Group 2).

\section{Results}

The same cut-off scores as found for Group 1 were appropriate in Group 2. The SFNSL was found to have high levels of internal consistency (Cronbach's alpha 0.90) and exploratory factor analysis showed that it measures only one underlying factor. Convergent walidity seems good.

\section{Conclusions}

We developed a brief and easy to administer screening list to assess SFN in sarcoidosis. The results of the present study support the idea that SFN is a relatively uniform disorder. Future studies in patient populations suffering from SFN associated with other causes are needed to establish the broad usefulness of this SFN screening list and expand knowledge on the psychometric properties. 


\section{Introduction}

Sarcoidosis is a disseminated granulomatous disease of unknown origin. "Depending on the organs involved and the severity of granulomatous inflammation, patients suffer from a broad range of persistent physical symptoms. Besides respiratory symptoms such as coughing and dyspnoea on exertion, patients often suffer from systemic nonspecific symptoms such as fatigue and pain. ${ }^{2-6}$

Pain is considered to be a reflex response to underlying somatic pathology. In a previous study we found that many sarcoidosis patients with peripheral pain appeared to suffer from small fiber neuropathy (SFN) with involvernent of autonomic nerve fibers. ${ }^{7.8}$ SFN is a generalised peripheral neuropathy selectively involving $A \delta$ and $C$ fibers. When the somatic small afferent fibers are affected, symptoms typically consist of neuropathic pain. Furthermore, autonomic fibers may be involved, causing autonomic dysfunction.

Routinely applied nerve conduction tests as well as tendon reflexes evaluate only large nerve fiber function and consequently remain normal in isolated SFN. Besides, symptoms of autonomic dysfunction are not always sufficiently severe to be mentioned spontaneously by the patient. Furthermore, sarcoidosis patients are generally seen by physicians, such as internists and pulmonologists, who may not be familiar with SFN. Therefore, the diagnosis of SFN can easily be missed. Tests for assessment of small nerve fibers include temperature threshold testing (TTT), quantitative sudomotor axon reflex testing (QSART), intraepidermal nerve fiber density assessment in skin biopsy and laser evoked potentials. ${ }^{9}$ These tests are not widely available , however.

There is a need for adequate means of assessing the presence of SFN, both for clinical management and also for guidance of the development of further therapies. Assessment of SFN may also be useful in epidemiological and pathophysiological studies. The aim of the present study was to develop a short and easy to administer questionnaire that screens for the presence of SFN in sarcoidosis patients.

\section{Patients and methods}

\section{Participants}

From 2001 to 2004,139 (82 males and 57 females) sarcoidosis patients who visited the outpatient clinic of the University Hospital Maastricht, a referral centre for sarcoidosis, participated in the present study. Patients were diagnosed with sarcoidosis based on consistent clinical features and bronchoalveolar lavage (BAL) fiuid analysis or biopsy 
results, according to the WASOG guidelines. Informed consent was obtained from all participating patients. Relevant co-morbidity only included diabetes mellitus $(n=7)$

The first consecutive 84 patients seen before august 2003 (49 males and 35 females; mean age 44.2411 .1 ) were evaluated with an extensive pilot questionnaire (Group 1). Based on these data and using distribution measures and discriminant analyses, a shorter screening list was constructed (see below). Patients seen after august 2003 (Group 2) were used tor cross validation of this screening list. This group consisted of 55 patients ( 34 males and 21 females; mean age $45.5 \pm 10.7$ ). Patient characteristics are summarized in table 8.1 .

Finally, 15 healthy controls (mean age $33.3 \pm 9.8 ; 8$ males, 7 females) were evaluated.

Table 8.1 Summary of the most relewant characteristics of the studied sarcoidosis population,

\begin{tabular}{|c|c|c|c|c|}
\hline & \multicolumn{2}{|c|}{$\begin{array}{c}\text { Group } 1 \\
(n=84)\end{array}$} & \multicolumn{2}{|c|}{$\begin{array}{c}\text { Group } 2 \\
(n=55)\end{array}$} \\
\hline & TrT normal & TाT albnormal & TT normal & TT abnormal \\
\hline Number of patients & 31 & 53 & 19 & 36 \\
\hline Ange (years) & $37.3 \pm 9.8$ & $47.3 \pm 10.7^{*}$ & $38.1 \pm 8.9$ & $45.1 \pm 9.6$ \\
\hline Sex (males / temales) & $12 / 19$ & $34 / 19$ & $9 / 10$ & $25 / 11$ \\
\hline Diables (yes / no) & $1 / 30$ & $2 / 51$ & 4178 & $3 / 33$ \\
\hline Titure since diagnosis (years) & $2.5 \pm 3.9$ & $5.8 \pm 8.2^{*}$ & $2.4 \pm 2.6$ & $5.9 \pm 6.6^{*}$ \\
\hline Chest $X$-ray stage (omilmin/W) & $6 / 4 / 6 / 12 / 3$ & $8 / 9 / 18 / 13 / 5$ & $3 / 2 / 4 / 4 / 6$ & $6 / 8 / 12 / 8 / 2$ \\
\hline Prednison (yes / no) & $14 / 17$ & $20 / 33$ & $8 / 11$ & $18 / 19$ \\
\hline
\end{tabular}

TTr: temperature threshold testing. Data are expressed as absolute numbers and, if appropriate, mean \pm stanclard dewiation. No statistical differences were found between group 1 and 2 , pro 05 between the subgroups witll a normal TIT or an abnormal TT.

\section{Pilot questionnaire of the small fiber neuropathy screening list (SFNSL)}

Based on clinical experience and existing neuropathy questionnaires, ${ }^{10-19}$ a pilot questionnaire consisting of 93 questions, covering some 30 different complaints, was constructed. It had three parts: questions in part I (35 questions) concerned presence or absence of complaints; questions in part 11 (29 questions) were aimed at the frequency of complaints; and part III (29 questions) concerned the severity of the complaints. The response scale for part II ranged from 0 Never to 4 Always and for part III the scale went from 0 Never to 4 Severe. The patients in Group 1 who reported pain also completed the Neuropathic Pain Scale. ${ }^{20}$ 


\section{Temperature threshold testing (TTT)}

TT was used to assess function of small calibre sensory fibers by measuring temperature sensation thresholds. TT was done with a Medoc TSA-2001 device Medoc, Ramat Yishai, Israel). Thresholds for warm and cold sensation were determined on the hand and dorsum of the foot on both sides using the method of levels (MLE) and the method of limits (MLI) as described previously. Nomative data according to Yamitsky were used. ${ }^{21}$ Temperature sensation was considered abnormal if at least on one side both MLE and MLI testing resulted in $Z$ values exceeding 2.5 (above the $99^{\mathrm{th}}$ percentille)

\section{Statistical procedure and construction steps of the SFNSL}

Frequencies were used for the characteristics of the patient groups. A number of steps were performed using Group 1 to develop the SFNSL by reducing the number of questions of the pilot questionnaire. First missing values were examined to identify questions with a percentage of missing values above $10 \%$. Second remarks from patients concerning the questionnaire were recorded. Furthermore, three series of discriminant analyses were performed starting with (i) the questions from Part 11 and (ii) the questions from Part III of the pilot questionnaire, and (iii) the remaining questions from Part II and III together. The criteria for the discriminant analyses were the size of the discriminant function, the percentage predicted in the correct category, and reducing the number of questions as much as possible. This resulted in the SFNSL. Subse. quently, exploratory factor analysis (principle axis factoring) was performed using the screetest criterion ${ }^{22}$ to establish the number of underlying factors measured by the questionnaire and Cronbach's alpha was employed to measure internal consistency. ${ }^{23}$ We used a criterion of $0.70-0.80$ to indicate adequate internal consistency. ${ }^{23-25}$ In addition. Pearson correlations and t-tests were performed between the SFNSL and the neuropathic pain scale (NPS), depending on the questions of the latter questionnaire, to provide some preliminary information on construct or convergent validity. It is usually accepted that correlations above 0.40 indicate acceptable convergent validity. ${ }^{20}$ The SFNSL was than completed by Group 2. The percentage of missing values was checked. Again, exploratory factor analysis (principle axis factoring) was performed and internal consistency was examined. The cut-off scores found in Group 1 were examined on applicability in Group 2. Statistical analyses were performed using the SPSS11.0 for Windows (SPSS, Chicago, IL, USA). 


\section{Results}

\section{Development of SFNSL in Group 1}

The examination of the answers to the questions of the first consecutive 84 patients (Group 1) revealed that seven questions had more than $10 \%$ missing values. One question concerned the partner and whether he/she informed the patient about frequent leg movement at night and the other questions concerned sexual intercourse related questions. Therefore, we decided to remove these questions from further analyses.

The remaining remarks from the patients concerned part I of the questionnaire. Patients indicated to find it difficult to answer these questions because of the yes/no response category. They were not comfortable with it because of lack of sophistication (not detailed enough). They frequently commented that they wanted to answer 'sometimes' and felt that yes was too strong and no was also not good. For this reason, all questions in part I were left out of the subsequent analyses. Thus, for the statistical analyses 51 questions (25 part II and 26 part III) were used.

Subsequently, three series of discriminant analyses were performed to find out which questions can correctly distinguish patients with normal and abnormal TTT results. These specific questions were selected. In the first series of analyses the questions from Part $I I$, were used. The number of questions was reduced to 10 . In the second series of analyses, the same was done for the questions from Part III of the pilat questionnaire. This resulted in 15 questions. In the final series, the remaining questions from parts II and III together (25 questions) were used to group patients according to their SFN status based on their THT scores. This analysis showed that $83.9 \%$ of cases could be correctly classified as having SFN using the discriminant coefficients (Chi-square $=38.93, p=0.037$ ). Finally, we reduced the number of questions to 21 keeping the percentage correctly classified as having SFN at $83.9 \%$ (Chi-square $=40.94$, $p=0.006$ ). This resulted in the Small Fiber Neuropathy Screening List (SFNSL) questionnaire (see Appendix). Subsequently, a total score was made for the SFNSL by summing the scores of the 21 questions. It appeared that a cut-off score of $<11(25.8 \%$ of patients) indicated only patients with normal TTT and a cut-off score of $>48(18.9 \%$ of patients) indicated only patients with abnormal TTT. A score range from 11 to 48 indicated a group of patients in which $33 \%$ had normal TTT and $67 \%$ had abnormal TTT (Figure 8.1). 


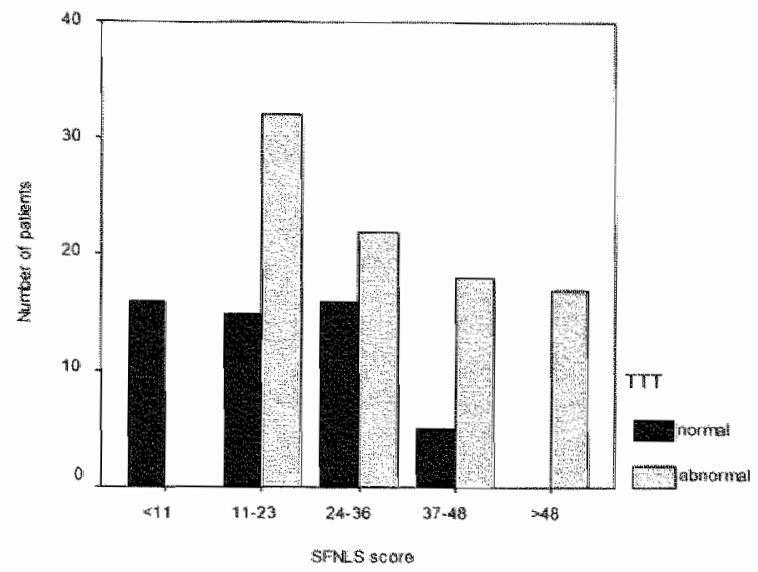

Figure 8.1 Temperature threshold testing (TTT) results in a group of sarcoidasis paltients with a small fiber neuropathy screening list (SFNSL) score bellow 11 , in a group of sarcoidosis patients with a SFNSL score from 11 to 23 , from 24 to 36 , from 37 to 48 and in a group of sarcoidosis patients with a SFNSL score above 48.

\section{Reliability and validity in Group 1}

Exploratory factor analysis was employed to examine content validity. Herewith the number of underlying factors measured by the questionnaire can be determined using the screetest. The screetest criterion clearly showed that the SFNSL consisted of only one underlying factor.

Furthermore, construct validity of the SFNSL was assessed. Construct validity is the extent to which the SFNSL actually assesses what it is intended to assess. ${ }^{28}$ This is. examined by assessing the relationship of this questionnaire with other questionnaires. For this purpose the relationship with the neuropathic pain scale (NPS) was examined. Compared with patients without pain (mean SFNSL score=18.4, SD=12.1), patients who indicated to have pain (mean SFNSL Score $=29.8, S D=15.4$ ) scored significantly higher on the SFNSL $(t=-2.58, p=0.012)$. Furthermore, in patients with pain, the correlation between pain at this moment (question of the NPS) and the total SFNSL score was 0.49 $(p<0.001)$.

internal consistency (Cronbach's aipha) was assessed to find oul to what extent the different questions of the SFNSL were related with each other. The Cronbach's alpha was 0.89 . Correlations between individual items (questions 1 through 21) and the total 
score of the questionmaire (minus that item) were aways significant and positive. The item-total correlations ranged from 0.25 to 0.70 .

\section{Cross validation of the SFNSL in Group 2}

The SFNSL was then completed by the following consecutive 55 patients (Group 2). There were no missing values. The cutwoff scores provided by Group $\mathbb{1}$ were also useful in Group 2. Now, $19.4 \%$ of the patients had an SFNSL above 48 . They all had an abnormal TT. The percentage of patients with a SFNSL score below 11 was $38.1 \%$. They all had a normal TT.

Again exploratory factor analysis showed that the SFNSL measured one construct. since the screetest clearly showed one factor. The Cronbach's alpha was 0.90 and the item-tatal correlations ranged from 0.29 10 0.72 .

\section{Total group}

Cronbach's alpha for the total scale was 0.90 and item-total correlations ranged from $0.32-0.67$. Based on TTT results, serisitivity and specificity of the SFNSL was $100 \%$ and $31 \%$, respectively, when a cut off score of 11 is used and $19 \%$ and $100 \%$, respectively. when a cut off score of 48 is used (figure 8.1 ).

\section{Healthy controls}

A All the 15 tested healthy controls had a normal TTT. Moreover, the SFNSL scores of all of them were below 11 .

\section{Discussion}

We have developed a short and easy to administer questionnaire to screen for small fiber neuropathy (SFN) in sarcoidosis patients. The questionnaire was cross-validated in an other sarcoidosis patient group. Cut-off scores of below 11 for certainly no SFN and above 48 for certainly SFN were established based on temperature threshold testing (TIT) results. The reliability and validity analyses revealed results that exceeded minimum quality standards for an instrument of this kind. Internal consistency revealed that this scale was highly unified, a conclusion supported by content validity assessment that revealed that the SFNSL measured only one underlying factor. These results strongly argue that SFN is a unified condition and they argue against a psychogenetic component to the symptoms of SFN. 
Strict TIT criteria were used to diagnose SFN. Both MLE and MLI test results had to exceed the $99 \%$ value of a normal population to score TT results as abnormal. These sharp cut-off scores were used as we preferred a high specificity of TTT in order to be relatively certain which patients do have SFN. Consequently, based on the present results patients with a SFNSL score above 48 can almost certainly be suspected of suffering from SFN. We strived to develop a screening list with the highest possible sensitivity because SFN is a disorder that probably develops over time with increasing symptom severity. Since a strict criterion for SFN was defined using $T T$, it is possible that a considerable number of patients are suffering from SFN-related symptoms, but do not yet meet the TTT criteria. With these strict cut-off values it is possible to indicate which patients certainly have no SFN (SFNSL score below 11) and diefinitive do have SFN (SFNSL score above 48). In the intermediate group of patients $33 \%$ had normal TT and $67 \%$ had abnormal TT. These patients should be carefully monitored and tested for the presence of SFN. All 15 tested healthy controls had normal TTT results and SFNSL scores were all below 11. Thus, based on the results in healthy controls and the results in both groups sarcoidosis patients a SFNSL score below 11 seems to exclude the presence of SFN.

One of the limitations that this and other studies have to face is that unfortunately a proper gold standard to diagnose SFN is still lacking. SFN is clinically defined by paresthesias (abnormal sensations), pain, and sometimes numbness, in combination with normal strength and normal nerve conduction studies. ${ }^{\circ}$ A number of investigative tools are now available for confirming the diagnosis. TTT reaches sensitivity of $60-85 \%$, and the test is validated and standardized. ${ }^{31.32}$ Epidermal nerve fiber density analysis has been used extensively by several groups, and sensitivities of $74.0-87.5 \%$ are reported. ${ }^{32}$ This latter method, however, is technically difficult and not widely available. The sparse availability of diagnostic tests for SFN urges for an easy to administer screening instrument. In the present study we used TT to diagnose SFN, which, as already mentioned, does not reach 100 percent sensitivity. Therefore, the diagnostic value and cut-off scores of the SFNSL should be examined further in future studies, using also other clinical tests that can be used to diagnose SFN, such as intraepidermal nerve fiber density assessment in skim biopsy, QSART, laser evoked potentials and cardiovascular autonomic function testing.

In the present study only sarcoidosis patients participated. Presumably, the SFNSL is also useful in idiopathic SFN or those due to other causes. However, this assumption has to be examined.

As SFN has only recently gained more attention, exact data on prognosis, clinical course and treatment efficacy are lacking. Furthermore, the condition may be easily missed as symptoms of autonomic dysfunction may not always be recalled spontaneously by the patient. Moreover, even if reported, symptoms such as diarrhoea, 
micturation disturbances and sweating may not always be recognised as such. In this respect, recognition of SFN is important because it may prevent extensive investigations such as colonoscopy in the case of diarhoea or urodynamic investigation in case of micturation disturbances. And finally, tests for assessment of SFN are not widely available while routinely applied nerve conduction studies and EMG remain nomal in SFN patients. Moreover, the SFNSL can be easily used by physicians including pulmonologists who often are involved in the follow-up of sarcoidosis patients and are not so familiar with the clinical picture of SFN. Especially, the SFNSL might be helpful to distinguish those patients without SFN from those with probably or highly likely SFN. Therefore, the SFNSL is recommended as first screenings tool for various disciplines seeing patients with possible SFN.

\section{Conclusion}

In conclusion, the SFNSL is aimed to be a practical tool in screening for the presence of SFN. It is brief and offers the possibility of ready use in clinical practice, in epidemiological and pathophysiological research, and in clinical trials. 


\section{References}

1. Hunninghake GW, Costabel $U$, Ando M, Baughman RP, Cordier JF, du Bois RM, Eklund $A_{\text {, }}$ Kitaichi M, Lynch J, Rizzato $G$, Rose $C$. Selroas $O$, Semenzato $G$, Sharma $O P$. ATS/ERSMASOG statement on sarcoidosis. American Thoracic Society/European Respiratory Society/World Association of Sarcoidosis and ather Granulomatous Disorders. Sarcoidosis Vasc Diffuse Lung Dis 1999;16:149.73.

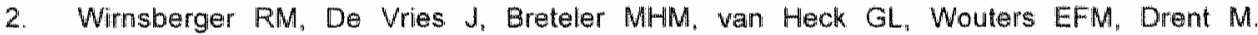
Evaluation of quality of life in sarcoidosis patients. Respir Med 1998;92:750-6.

3. Sharma OP. Fatigue and sarcoidosis. Eur Respir J 1999:43:713-4.

4. James. DG. Complications of sarcoidosis. Chronic fatigue syndrome. Sarcoidosis 1993;10: $1-3$.

5. Newman LS, Rose CS, Maier LA. Sarcoidiosis. N Engl J Med 1997;336:1224-34.

6. Hoitsma E. De Vries J, van Santen-Hoeuff M, Faber CG, Drent M. Impact of pain in a Dutch sarcoidosis patient population. Sarcoidosis Vasc Diffuse Lung Dis 2003;20:33-9.

7. Hoitsina E, Marziniak M, Faber CG, Reulen JPH, Sommer $C$, de Baets M, Drent, M. Small Fiber Neuropathy in Sarcoidosis. Lancet 2002;359:2085-6.

8. Hoitsma E, Drent M, Verstraete E, Faber CG. Troost J, Spaans F, Reulen JPH. Abnormal warm and cold sensation thresholds suggestive of small-fibre neuropathy in sarcoidosis. Clin Neurophysiol 2003:414:2326-33.

9. Hoitsma E, Reulen JPH, de Baets M, Drent M, Spaans F, Faber CG. Small fiber neuropathy: a common and important clinical disorder. IN Neurol Sci 2004;15;227:119.30.

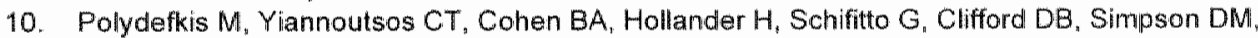
Katzenstein $D$, Shriver $S$, Hauer $P$. Brown A, Haidich AB, Moo L, McArthur JC. Reduced intraepidermal nerve fiber density in HIV-associated sensory neuropathy. Neurology 2002; $58: 115-9$

11. Novak V. Freimer ML, Kissel JT, Sahenk Z, Periquet IM, Nash SM, Collins MP, Mendell JR. Autonomic impairment in painful neuropathy. Neurology 2001;56:861-8

12. Grootenthuis PA, Snoek FJ. Heine RJ, Bouter LM. Development of a type 2 diabetes symptom checklist: a measure of symptom severity. Diabet Med 1994,11:253-61.

13. Dyck PJ, Davies JL, Litchy WJ, O'Brien PC. Longitudinal assessment of diabetic polyneuropathy using a composite score in the Rochester Diabetic Neuropathy Study cohort. Neurology $1997,49: 229-39$

14. Dyck Pu, Kames JL, O'Brien PC. Litchy WJ, Low PA, Melton LJ. The Rochester Diabetic Neuropathy Study: reassessment of tests and criteria for diagnosis and staged severity. Neurology $1992 ; 42: 1164 \% 70$.

15. Dyck PJ, Litchy WJ, Lehman KA, Hokanson $\mathrm{JL}$, Low $\mathrm{PA}, \mathrm{O}^{\prime}$ Brien PC. Variables influencing neuropathic endpoints: the Rochester Diabetic Neuropathy Study of Healthy Subjects. Nourology 1995; $45: 1115-21$.

16. Dyck PJ, Kratz KM, Lehman KA, Kames $\mathrm{JL}$, Melton LJ 3rd, O'Brien PC, Litchy WJ, Windebank AJ, Smith BE, Low PA, et al. The Rochester Diabetic Neuropathy Study: design, criteria for types of neuropathy, selection bias, and reproducibility of neuropathic tests. Neum rology 1991;41:799-80\%.

17. Dyck PJ. Detection, characterization, and staging of polyneuropathy: assessed in diabetics. Muscle Nerve 1988:11:21-32.

18. Dyck PJ, Karnes J, O'Brien PC, Swanson CJ. Neuropathy Symptom Profille in mealth, motor neuron disease, diabetic neuropathy, and amyloidosis. Neurology 1986;36:1300-8.

19. Bril V. NIS-LL: the primary measurement scale for clinical trial endpoints in diabetic peripheral neuropathy. Eur Neurol 1999:41(\$1): 8-13.

20. Galer BS, Jensen MP. Development and preliminary validation of a pain measure specific to neuropathic pain the Neuropathic Pain Scale. Neurology 1997,48:332-8. 
21. Yarnitsky $D$, Sprecher $E$. Thermal testing: nomative data and repeatability for various test algorithms. I Newrol Soi 1994;125:39-45.

22. Cattell R.B. The scree test for the number of factors. Multivariate Behavioral Research 1966;1: $140-61$

23. Cronbach LPJ. Coefficient alpha and the internal structure of tests. Psychometrika 1951,16: $297-334$

24. Tabachnik BG. Fidell LS. Using multivariate statistics. Now York, Harper Collins, 1996.

25. Grass-Forney L., Watkins MP. Foundations of clinical research: Applications to practice. Upper Saddle River, NJ, Prentice Hall, 2000.

26. Campbell DT. Fiske DW. Convergent and discriminant validation by the mulititrait-multimethod matrix. Psychol Bull 1959;56:81-105.

27. Zechmeister JS. Zechmeister EB. Shaughnessy dl. Essentials of Research Methods in Psychology. Now York: MeGraw-Hill 2001:118-21.

28. Jamal $G A$, Hansen $S$, Weir $A$, Ballantyne JP. The neurophysiologic inwestigation of small fiber neuropathies. Muscle Nerve 1987;10:537-45.

29. Holland NR, Crawford TO, Hauer P, Cormblath DR, Griffin JW, McArthur JC. Small-fiber sensory neuropathies: clinical course and neuropathology of idiopathic cases. Ann Neurol $1998 ; 44: 47-59$.

30. Periquet MI, Novak V, Collins MP, Nagaraja HN, Erdem S, Nash SM, Freimer ML, Sahenk Z, Kissel JT. Mendell JR. Painfull sensory neurropathy: prospective evaluation using skin biopsy [see comments]. Meurology 1999;53:1641-7.

31. Tobin $K$, Giuliani MJ, Lacomis D. Comparison of different modalities for detection of small fiber neuropathy. Clin Neurophysiol 1999;110:1909-12.

32. Lacomis D. Small-fiber neuropathy. Muscle Nerve 2002; 26: 173-88. 


\section{Chapter 9}

\section{Association of small fiber neuropathy with cardiac sympathetic dysfunction in sarcoidosis}

E Hoitsma, CG Faber, MJPG van Kroonenburgh, APM Gorgels, SGEA Halders, GAK Heidendal, AGH Kessels, JPH Reulen, M Drent

Sarcoidosis Vasc Diffuse Lung Dis 2005; accepted for publication 


\section{Abstract}

\section{Background and am}

Recently we found that small fiber neuropathy (SFN) occurs frequently in sarcoidosis. Autonomic dysfunction may be a feature of SFN. Since cardiac autonomic dysfunction has been identified as a strong predictor of morbidity and mortality, recognition of cardiac autonomic involvement is of clinical relevance. It was hypothesised that SFN might be related to cardiac sympathetic denervation in sarcoidosis.

\section{Mahodg}

In the present study 45 consecutive sarcoidosis patients (13 without SFN assessed by thermal threshold testing (TTT), 32 with SFN (abnormal TTT) were enrolled. To rule out bias dive to myocardial ischemia cases with abnormal Thallium ${ }^{201} \mathrm{TI}$ ) perfusion scintigraphy were excluded $(n=2)$. Cardiovascular autonomic function testing (Ewing tests) and ${ }^{123}$ - $M$ MIBG (metaiodobenzylguanidine) scintigraphy were used to assess cardiac autonomic function. Further cardiac diagnostic work-up included ECG. Holter recording and echo Doppler cardiography.

\section{Results}

Mild to moderate heterogeneity of ${ }^{123}$-MIBG uptake regional in the myocardium was demonstrated in a substantial number of the studied sarcoidosis population, especially in those with SFN (abnormal TTT). Mean inferior-anterior ratios were $0.85 \pm 0.17$ (SFN) and $1.0 \pm 0.17$ (no SFN: $p=0.003$ ), respectively. Four out of the 14 cases with abnormall MIBG scintigraphy and SFN showed an abnormal Ewing test.

\section{Conclusion}

Cardiac sympathetic dysfunction assessed by use of ${ }^{123} \mathrm{~m} \mathrm{M} / \mathrm{B} / \mathrm{BG}$ myocardial scanning appeared to be heterogeneous in sarcoidosis patients and dependent on the priesence or absence of SFN. MIBG scintigraphy may be of additional value in de management and follow-up of sarcoidosis patients. Future study is warranted to explore possible prognostic and therapeutic implications of these findings in sarcoidosis. 


\section{Introduction}

Sarcoidosis is a disseminated granulomatous disease of unknown origin. Estimates of prevalence range from $1-40$ per 100,000 population "varying among ethnic and racial groups. "The clinical course of sarcoidosis is highly variable. Spontaneous recovery may occur, but the disease can also be chronic or progressive. Depending on the organs involved and the severity of granulomatous inflammation, patients suffer from a broad range of persistent physical symptoms. Besides respiratory symptoms such as coughing and dyspnoea on exertion, patients often suffer from apparently nom-specific symptoms such as fatigue and pain, including atypical chest pain. ${ }^{2-5}$ In most sarcoidosis patients suffering from recurring chest pain. palpitations and collapses, routine examination revealed no evidence of cardiac involvement.

Cardiac sarcoidosis is a challenging entity. ${ }^{6}$ The extent of which the heart is involved in sarcoidosis has long been a matter of controversy. ${ }^{7}$ Reports on incidence of clinically evident sarcoidosis involving the heart is rather uncommon, affecting 2 to $7 \%$ of patients with sarcoidosis. However, occult involvement is much higher $(>20 \%){ }^{6}$ In general, Japanese studies show more often cardiac involvement than those in other ethnic backgrounds. 6 .7 Moreover, the incidence is higher when specific cardiac tests are performed in unselected patents with sarcoidosis, e.g. echocardiography and radionuclide scans. ${ }^{6}$

Optimal strategies to diagnose cardiac involvement have not yet been clarified. Thallium $^{201}$ scintigraphy has been most extensively studied. Echocardiography may have a complementary role but it is less sensitive. Clinical features of cardiac involvement include supra-ventricular arrhythmias and conduction disturbances. ${ }^{8,9}$ It has been suggested that these cardiac manifestations reflect granulomatous infiltration within the conduction system or ventricular wall. ${ }^{6}$ Sudden death without a premonitory sign seems to be relatively frequent and selecting patients at risk is one of the major obstacles facing clinicians. ${ }^{10}$ Therefore, given the often life-threatening nature of cardiac involvement an appropriate diagnostic approach is warranted. ${ }^{1,2}$ Making the diagnosis early and promplly initiating appropriate treatment can be life-saving."

Recently, we demonstrated the presence of small fiber neuropathy (SFN) in sarcoidosis patients. ${ }^{11,12}$ Small nerve fibers carry sensory functions (pain and temperature sensation) and autonomic functions. As a result, SFN may cause peripheral pain, paraesthesias, intolerance of bedclothes, hyperhidrosis, hypohidrosis, sicca syndrome, facial flushing, diarrhoea, constipation, micturation disturbances, sexual dysfunction and/or orthostatic intolerance. It is important to recognize that pain can be due to impairment of small sensory fibers as well as autonomic C-fibers. ${ }^{13}$ 
Autonomic dysfunction has been identified as a strong predictor of cardiovascular morbidity and mortally. ${ }^{14-17}$ Therefore, recognition and evaluation of autonomic dysfunction is very umportant. Different methods have been proposed to study the myocardial sympathetic nervous system, including measurement of plasma noradrenaIne concentration, baroreflex-sensitivity, heart rate variability and noradrenaline spillover, ${ }^{19}$ lodine-123 meta-iodobenzylguanidine ( ${ }^{123}$-MIBG), an analogue of norepinephrine, is a tracer for the functioning of sympathetic neurons. Cardiac sympathetic nerves take up ${ }^{123}$ IMIBG, which radiolabel the vesicles in the terminals. This allows visualisation of the sympathetic innervation of the heart by scintigraphy after injection of ${ }^{123}$ I-MIBG. MIBG imaging seems an interesting tool for the quantitative assessment of presynaptic sympathetic nerve terminal disturbances. Moreover, an imbalance of the sympathetic tone is considered to increase the propensity to develop ventricular arrhythmias in various cardiac diseases and conditions. ${ }^{19}$

The aim of the present study was to test the hypothesis that myocardial sympathelic innervation might be impaired and variable according to the presence or absence of small fiber neuropathy. Therefore, we examined 32 sarcoidosis patients with and 13 patients without SFN by use of ${ }^{123}$ I-MIBG single photon emission computed tomography as a non-invasive screening test to cardiac sympathetic function. Myocardial perfusion scintigrams (Thallium ${ }^{201}$ ) were used to rulle out deficiencies of MIBG uptake due to myocardial ischemia.

\section{Patients and methods}

\section{Patients}

Forty-seven consecutive sarcoidosis patients (18 female, 29 male; mean age $45 \pm 11$ years) from the Maastricht Sarcoidosis Management Center, which serves as a tertiary referral center for sarcoidosis patients in the Netherlands, were included in the present study. Diagnosis of sarcoidosis was based on the international criteria. ${ }^{2}$ None of the patients included had a history of alcohol abuse, renal insufficiency, diabetes or involvement of the central nervous system and none of them were receiving medication that could affect ${ }^{123} 1-\mathrm{MIBG}$ uptake and metabolism. Sensory symptoms such as peripheral pain, paraesthesias, hypoesthesia, hyperesthesia, and/or intolerance for bed cloths and autonomic symptoms such as hyperhidrosis, hypohidrosis, sicca syndrome, facial flushing, diarrhoea, constipation, micturation disturbances, sexual dysfunction and/or orthostatic intolerance were regarded as SFN symptoms. Paipitations were regarded as cardiac symptoms. To rule out deficiencies of MIBG uptake due to 
myocardial ischemia cases with abnormal myocardial perfusion scintigrams were excluded from further analyses.

\section{MIBG scintigraphy}

All subjects received an oral dose of potassium perchlorate to block the thyroid uptake. After an intravenous injection of $185 \mathrm{MBq}{ }^{123}$ l.MBG, an early (30 minutes) and a late (240 minutes) planar image was obtained of the thorax and upper abdominal region using a dual detector gamma camera (Siemens Multispect-2). Immediately after image collecting sessions a SPECT study was performed, with data collection of 30 frames per camera head for 60 seconds per frame. Reconstruction was performed to produce short axis, vertical and horizontal longl axis tomograms.

\section{Thallium scintigraphy}

A dose of $110 \mathrm{MBq}$ of ${ }^{201}$ thalliumchloride was administered intravenously. Both rest and stress studies were performed. The stress study was performed following dymamic exercise on a treadmill with a ${ }^{201} \mathrm{TI}$ injection at the peak of exercise. A triple-detector gamma camera (Siemens, Multispect-3) was used for the SPECT imaging. A noncircular body contour tracking $360^{\circ}$ acquisition was performed to obtain 60 projection images of 45 seconds each. Short-axis, vertical and horizontal long axis tomograms were produced.

MIBG and thallium scintigraphy were performed with a minimum delay of two days between the two studies. Visual assessment was based on regional heterogeneity in ${ }^{123}$ I-MIBG and ${ }^{201}$ TI uptake. Scans were considered abnormal if obvious heterogeneity was present. The images were examined independently and blindly two experienced nuclear physicians (G.H. and M.V.K.). Both observers scored all images wice for assessment of intra- and inter-observer variability.

Quantitative ${ }^{123}$ H-MBG uptake assessment was based on the count ratio of the heart and mediastinum $(H / M)$, of the inferior and anterior wall of the left ventricle $(/ / A)$ and the cardiac wash-out rate (percentage of [early counts - delayed counts]/early counts).

\section{Temperature threshold testing}

Temperature threshold testing (TTT) was used to assess small sensory fiber functioning by measuring temperature sensation thresholds using a Medoc TSA-2001 device (Medoc, Ramat Yishai, Israel). Thresholds for warm and cold sensation were determined on the hand and on the dorsum of the foot on both sides using the method of levels (MLE) and the method of limits (MLI) as described previously. ${ }^{12,20}$ Normative 
data according to Yarnitsiky and Sprecher were used. ${ }^{23}$ Temperature sensation was considered abnormal if at least on one side both MLE and MLI testing resulted in $Z$ values exceeding 2.5 (above the $99^{\text {ift }}$ percentile) ${ }^{12}$

\section{Cardiovascular autonomic function test}

Cardiovascular autonomic function was assessed using 5 tests (Ewing tests) recommended by the San Antonio Consensus Meeting. ${ }^{22}$ Heart rate variability and blood pressure were measured while the patient rested in a supine position for about 10 minutes, while the patient remained standing for about 5 minutes, during deep respiration (respiratory sinus arrhythmia) with a frequency of $0.1 \mathrm{~Hz}$, during a Valsalva manoeuvre (forced expiration against $40 \mathrm{~mm} \mathrm{Hg}$ during 15 seconds) and while rapidly changing posture from supine to upright. Various time and frequency domain measures of heart rate variability (HRV) and manually measured sphygmomanometric systolic and diastolic blood pressure were determined. Cardiovascular autonomic function test (CAFT) was classified abnormal if at least two of the five tests were abnormal.

\section{Cardiac assessment}

Standard 12 lead electrocardiograms (ECGs) were obtained by the MAC VU electrocardiograph (GE Medical Systems, Milwaukee, USA), using a frequency range of $0.01-150$ $\mathrm{Hz}$.

Twenty-four hours of continuous electrocardiograms were recorded using analogue 3-channel Holter recordings with amplitude modulation and a speed of $1 \mathrm{~mm}$ per second (GE Medical Systems). Tapes were analysed on a digital system (Marquette 8000).

Echocardiograms were recorded using a Hewlett-Packard (Sonos 2500 with a $2.5 \mathrm{MHz}$ transducer) echocardiograph. Parasternal long and short axis and apical views were obtained. LV end-diastolic and end-systolic volumes were computed using the disc summation method (modified Simpson's rule), according to the recommendations of the American Sociely of Echocardiography (cut-off values for left ventricular mass index of $110 \mathrm{~g} / \mathrm{m} 2$ or greater for women and $134 \mathrm{~g} / \mathrm{m} 2$ or greater for men). ${ }^{23}$

\section{Statistical analysis}

The Mann Whitney-U test and $X^{2}$ - test (or Fisher exact test if appropriate) were used for comparisons between groups. Probability values of less than 0.05 were considered significant. To assess intraobserver agreement and for interobserver agreement kappa statistics were used. A K-value less than 0.20 indicates poor agreement, between 0.21 and 0.40 moderate, between 0.41 and 0.60 fiair, between 0.61 and 0.80 good and between 0.81 and 1.00 excellent agreement. 


\section{Results}

\section{Cardiac assessment}

In only two patients a perfusion defect was found using a Thallium scintigraphy. Those wo cases both had abnormal MIBG scintigraphy and abnormal TTT results. However, to rule out that the deficiencies of MBBG uptake might be due to myocardial ischemia these two cases were excluded from further analyses. Therefore, 45 cases were included in this study.

\section{Themal threshold testing}

TTT was abnormal in 32 of $45(71.1 \%$ ) cases (table 9.1 ). Symptoms of SFN were significantly more frequent in patients with abnormal TTा than in patients with normal TTT $(p<0.0001)$. Cardiac symptoms, age, sex, or the use of prednison did not differ significantly between the two groups.

Table 9.1 Summary of characteristics of the studied sarcoidosis patients without small fiber neuropathy ("temperature threshold testing (TTT) normal: group i) and with small fiber netropathy (TTा abruarmal; group 2)

\begin{tabular}{|c|c|c|c|}
\hline & $\begin{array}{c}\text { Group } 1 \\
(n=13)\end{array}$ & $\begin{array}{c}\text { Group } 2 \\
(n=32)\end{array}$ & $\begin{array}{l}\text { Total population } \\
\qquad(n=45)\end{array}$ \\
\hline Age (years) & $40.9 \pm 8.7(30-56)$ & $45.9 \pm 10.7(32-70)$ & $44.5 \pm 10.3(30-70)$ \\
\hline Sex (maleffemale) & $11 / 2$ & $17 / 15$ & $28 / 17$ \\
\hline Smoking (yes/na) & 310 & $4 / 28$ & $7 / 28$ \\
\hline Time since diagnosis (years) & $4(1-7)$ & $4(1-6)$ & $4(1-7)$ \\
\hline Prednison (yes/no) & $6 \pi$ & $19 / 13$ & $25 / 20$ \\
\hline \multicolumn{4}{|l|}{ SFN symptoms (Yes/no) } \\
\hline Sensory symptoms & $4 / 9$ & $31 / 1$ & 35410 \\
\hline A utonamic sylmptoms & $4 / 9$ & $2557^{\prime \prime}$ & 2911 \\
\hline Cardiac symptoms (yesfno) & $8 / 5$ & $25 \pi$ & 3312 \\
\hline CXF (OH/HHWM) & $3 / 1 / 3 / 3 / 3$ & $2 / 56 / 13 / 4$ & $56 / 11 / 16 / 7$ \\
\hline ACE (U/H) & $24.4 \pm 14.3$ & $22.3 \pm 10.7$ & $230+11.7$ \\
\hline
\end{tabular}

Date are expressed as absolute number and mean $t$ standard davilion with range in parentheses if appropriate.

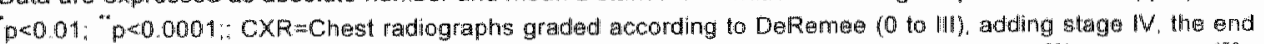

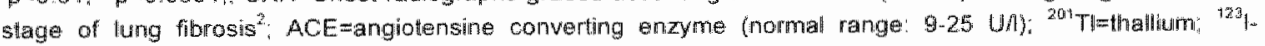
MBG=lodine-123 meta-iodobenzylguanidine; CAFT=cardiowascular autoncmic function testing; SFN= small fiber neuropathy 


\section{Cardiovascular autonomic function tests}

CAFT were performed in 45 patients and were abnormal in $4(8.9 \%)$ of them. The 4 cases ( 2 males) with abnormal CAFT all had cardiac and SFN symploms, abnormal TTT results and abnormal MBG-scintigraphy.

\section{MBG scintigraphy}

As a measure of internal consistency and reliability, we assessed intra- and interobserver variability. K-walues for intra-observer variability were excellent for observer 1 and good for observer $2(0.87$ and 0.71 , respectively). Inter-observer variability k-values (calculated for all possible matches) varied from fair $(0.56)$ to good $(0.62,0.67$ and 0.71 ). The MIBG results of both scores of observer 1 and 2 are presented in table 9.2 . A significant reduction of ${ }^{123}$ 1-M $M B G$ uptake regional in the myocardium was demonstrated in a substantial number of the studied sarcoidosis population (varying from 24.5 to 37.8 percent depending on which score was used) with various distribution patterns of myocardial ${ }^{123}$ I-MIBG accumulation (figure 9.1). Observer 1, the observer with the most optimal intra-observer wariability, scored $35.6 \%$ and $37.8 \%$ of MIBGs as abnormal. Both scores achieved statistical significant difference between sarcoidosis patient with or without SFN, respectively. The first scores of observer 1 were used for further analysis because of optimal intra-observer variability.

In 7 cases an apical defect was found, in 2 cases an anterior defect, in 12 cases an inferior defect, in 6 cases a lateral defect and in 1 case a septal defect. Eleven patients showed more than one defect. There was a significant difference between MIBG results in patients with abnormal TTT and normal TTT ( $p=0.007$; table 9.2).

\section{MBG scintigraphy, quantitative assessment}

The inferior-anterior ratios (IAR) were significantly decreased in patients with SFN $(p=0.003)$. No significant gender difference was found. IAR was significantly lower in patients with abnormal CAFT and abnormal MIBG scans than in patients with normal results ( $p=0.02$ and $p=0.001$, respectively).

H/M was significantly lower in patients with abnormal CAFT than in patients with norma! CAFT ( $p=0.007)$.

Myocardial MIBG wash=oul was significantly higher in patients with abnormal MIBG scans and abnormal CAFT compared with patients with normal MIBG scans and CAFT $(p=0.01$ and $p=0.03$, respectively $)$. 

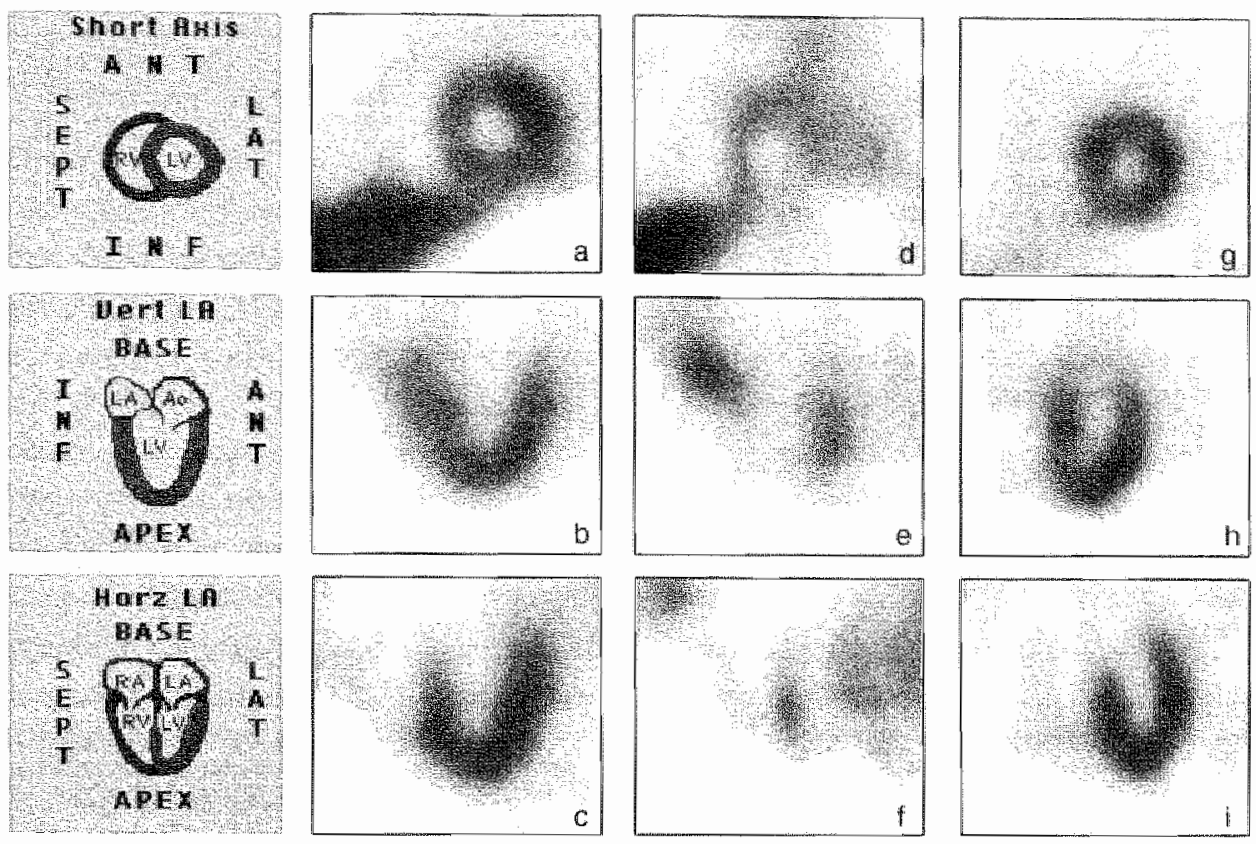

Figure $9.1 \quad a, b, c$ : Tomogiraphic images of the heart performed a sarcoidosis pathent (male; 50 years) with normal ${ }^{123}-M M B G$ uptake" $d_{i} e_{n}, g, h$, i: Tomographic images of the heart in a sarcoldosis patient (male; 4 years) with infero-apical defects of: ${ }^{42}$ H-MIBG uptake, with extension to the lateral wail (d. e, f), but with normal ${ }^{201}$ Thallium uptake $(g, h, i)$.

Echocardiography was performed in 40 patients. Left ventricular hypertrophy was found in 1 out of 14 patients with an abnormal MIBG scan and in 1 out of 26 with a normal MBG scan. Right ventricular hypertrophy was found in 1 out of 14 patients with an abnormal MIBG scan. There were no signs of cardiac granulomas, fibrosis or valve abnormalities. All Holter recordings were normal. ECG findings revealed non-specific abnormalities including low voltage and non-specific ST segment abnormalities in 5 out of 17 with MIBG abnormalities and in 8 of the 28 cases with normal MIBG scans, respectively (not significant). Abnormalities that could be related to sarcoidosis, including conduction disturbances and right ventricular hypertrophy, were found in 3 out of 17 cases with MIBG abnormalities and 2 out of 28 patients with normal MIBG scans. respectively (not significant). 
Table 92 Cardiac and scinfigraphy characteristics of sarcoidiosis patients without small fiber neuropathy

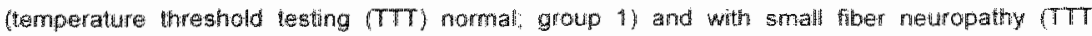
abromal: group 23

\begin{tabular}{|c|c|c|c|}
\hline & $\begin{array}{l}\text { Group } 1 \\
(n=13)\end{array}$ & $\begin{array}{l}\text { Group } 2 \\
(n=32)\end{array}$ & $\begin{array}{l}\text { Total population } \\
\qquad(n=45)\end{array}$ \\
\hline \multicolumn{4}{|l|}{ 123 } \\
\hline obserwer 1 , frst scome & $\{2\} 1$ & $16 / 16$ & $28 / 17$ \\
\hline observer 1 , seconid score & $11 / 2$ & $18 / 14 *$ & $29 / 16$ \\
\hline obserwer 2. first score & $12 / 1$ & $21 / 11$ & $33 / 12$ \\
\hline obserwer 2 , second score & $12 / 1$ & $22 / 10$ & $34 / 11$ \\
\hline CAFT (nomalabnormalmissing) & $13 / 0 / 0$ & $27: 4: 1$ & $40 / 4 / 1$ \\
\hline \multicolumn{4}{|l|}{ TTE (nolyes/missing) } \\
\hline Left ventricular hypertrophy & $11 / 1 / 1$ & $2217 / 3$ & $33 / 8 / 4$ \\
\hline Right wentricular hypertrophy & $1210 / 4$ & $27 / 2 / 3$ & $29 / 2 / 4$ \\
\hline Holter (normal/abnomal) & $13 / 10$ & $32: 0$ & 4510 \\
\hline ECG (now malmors-specific tabnomallis) & $11 / 1 / 1$ & $24 / 5 / 3$ & $25 / 6 / 4$ \\
\hline \multirow[t]{2}{*}{ HAM } & $3.02 \pm 0.56$ & $3.19 \pm 0.41$ & $3.14 \pm 0.46$ \\
\hline & $290 \pm 0.60$ & $3.10 \pm 0.56$ & $3.011 \pm 0.58$ \\
\hline IAR & $1.03 \pm 0.17$ & $0.85 \pm 0.17^{\text {kw }}$ & $0.91 \pm 0.19$ \\
\hline Washout percentage & $24.9 \pm 6.9$ & $20.6+9.2^{*}$ & $21.8 \pm 9.3$ \\
\hline
\end{tabular}

Data are expressed in absolute number or as mean t standard deviation if approprate. $p<0.05 ;{ }^{*} p=0.003$; "Including low voltage ECG and non-specific ST-segment abnomallites; Anciuding conduction disturbences and vight wentricular hypertrophy; ${ }^{201} \mathrm{Tl}=$ thallium; ${ }^{123}$ L-MIBG=lodine-123 meta-iodobenzylguandine: CAFT $=$ cardiovascular autonomic function lesting: $S F N=$ small fiber neuropatty: HM=heart-mediastincum ratio; IAP=inferior-anterior ratio: TTE=trans thoraicic echocardiagraphy.

\section{Discussion}

This is the first study assessing myocardial sympathetic integrity by use of qualitative and quantitative ${ }^{123} 1-M \mid B G-5 c i n t i g r a p h y$ in sarcoidosis patients with and without SFN. A significant reduction of ${ }^{123}$-MIBG uptake regional in the myocardium was demonstrated in a substantial number of the studied sarcoidosis population (varying from 24.5 to 37.8 percent depending on which score was used). In our study, the inferior/anterior ratio and myocardial washout ratio of MIBG were significantly decreased in patients with SFN compared to sarcoidosis patients without signs of SFN assessed by TTT. Moreover, patients with SFN demonstrated striking differences in the visual qualitative scintigraphic scores of both observers. Sarcoidosis patients with SFN exhibit prominent myocardial adrenergic denervation with normal or impaired sympathetic neural function of the heart. In contrast to ${ }^{12} 1-\mathrm{MIBG}$ scintigraphy and frequently presented symptoms of autonomic dysfunction, the frequency of CAFT (Ewing tests) abnormalities was relatively low in our patients. This is in line with previous results in sarcoidosis, diabetes and idiapathic SFN. ${ }^{12.24,25}$ CAFT provides indirect measures of sympathetic nervous system effects on the heart and seems inherently less sensitive than MIBG. The only direct and precise method is the determination of heart norepinephrine spillover ${ }^{26.27}$, which is however an 
invasive procedure requiring heart catheterisation. An advantage of MIBG myocardial scintigraphy is that it can be performed safely and does not require special equipment.

\section{Potential mechanisms of MBG heterogeneity in sarcoidosis}

Defects on MIBG scans in sarcoidosis have been reported before ${ }^{28-30}$, but so far the underlying mechanism has remained unclear. One possible explanation postulated was that local ischemia or myocardial inflammation may play an important role. In the present study, myocardial MIBG abnormalities due to myocardial hypoperfusion were excluded as a mechanism of in the present study, as cases with an abnormal myocardial perfusion ${ }^{20.1} \mathrm{Tl}$-scintigraphy $(n=2)$ were excluded. Moreover, none of the studied cardiac parameters appeared to be rellated to the cardiac denervation. Furthermore, there were no signs of granulomatous cardiac involvement or fibrotic lesions related to sarcoidosis in the studied sarcoidosis population. Sympathetic neuronal damage measured by MIBG scintigraphy may be related to the area of inflammation, since neuronal damage is highly sensitive to inflammation compared with myocardial cells. ${ }^{20}$

Experimental studies have shown that cytokine production by the heart may be regulated by sympathetic nervous system stimulation of cardiac beta-adrenergic receptors. Moreover, neuronal damage may be induced by the involvement of cytokines including tumour necrosis factor-alpha or interleukin-10 which are involved in the inflammatory process in sarcoidosis as well. ${ }^{31,32}$ Parthenakis et al. demonstrated that reduced cardiac sympathetic innervation in heart failure is associated with elevated levels of inflammatory cytokines, suggesting that it has a potential inflammatory effect via modulation of the cardiac production of these cytokines. "It is tempting to speculate that the observed autonomic dysfunction and SFN is related to the ongoing inflammatory process and cytokine production in sarcoidosis.

\section{Implications / relevance}

In general, the assessment of cardiac involvement is focussing on the presence of cardiac granulomatous lesions. So far, search for abnormal sympathetic innervation is less common in sarcoidosis. The results of this study stress the importance of including search for cardiac neuronal dysfunction in the management of sarcoidosis patients even in asymptomatic cases. Autonomic dysregulation might contribute to fatal arrhythmias and unexplained sudden death in diabetes mellitus, amyloidosis, epilepsy and Guillain Barre syndrome. It is known from patients with neuropathy that the involvement of small autonomic nerve fibers is a predictor of cardiovascular mortality. ${ }^{34.35}$ Suidden death is a rare but dramatic complication. In case of sarcoidosis it is thought to be due mostly to cardiac involvement. Active granulomatous infiltration and resulting myocardial fibrosis are considered to be the substrate. Because of the potential danger of malignant 
arrhythmias, intensive screening is indicated when cardiac sarcoidosis is suspected. Another explanation could be autonomic involvement due to SFN. Until now, sympathetic innervation has not been evaluated systematically. Moreover "adequate and sensitive techniques to assess patients at risk for life threatening arrhythmias are lacking and better diagnostic tools are needed.

In line with our observations, it is recommended that the possibility of autonomic cardiac dysfunction should be considered in the management of sarcoidosis patients. Moreover: careful follow-up is mandatory to evaluate the prognostic implications. Whether there might be a relation with conduction disturbances and implantation of an intracardial defibrillator (ICD) should be recommended needs future study. The proper and adequate treatment of SFN is currently unknown. Although there is common consensus that corticosteroids are beneficial in granulomatous cardiac involvement in sarcoidosis, this is not known for SFN related to sarcoidosis. Whether other therapeutics such as anti-TNFa or lipoic acid are beneficial also deserves further study. ${ }^{36,37}$

\section{Limitations of the study}

In normal subjects, regional MIBG uptake may be non-homogeneous and apparently lower in the inferior and septal wall than in the anterior wall, especially in older males. $38-40$ However, in our study MIBG results and IAR did not differ significantly between males and females. Furthermore, our population was of relatively young age. Finally, cardiac ${ }^{123}$ I-MIBG markers that have been used include not only regional uptake heterogeneity but also global myocardial uptake (H/M ratio) and wash-out kinetics. However, H/M ratios and wash-out measurements are highly influenced by the placement of the regions of interest (ROI), by varying background ${ }^{123}$ I-MIBG uptake in the mediastinum, over projecting breasts and subcutaneous fat ${ }^{41}$ Therefore, in line with others $^{19.42}$, we rely on quantifying regional rather than global uptake and ratios

Although we did not have the opportunity to include healthy subjects in our study, the difference between both studied patients subgroups was obvious. The myocardial uptake and turnover of MIBG in patients with sarcoidosis are heterogeneous and dependent on the presence or absence of SFN.

\section{Conclusion}

The results of our study provide evidence of the presence of abnormal sympathetic myocardial innervation in sarcoidosis patients, more prominent in those with SFN.

${ }^{123}$ I-MIBG SPECT seems a feasible relatively non-invasive approach investigating cardiac adrenergic innervation and localizes the territories of reduced sympathetic 
innervation. Moreover, "123/-MBG scintigraphy is more sensitive in detecting inflammatory induced myocardial sympathetic neuronal damage in sarcoidosis than myocardial perfuision Thallium ${ }^{201}$ scintigraphy and therefore of additional value in the workup of cardiac inwolvement related to sarcoidosis. The intriguing hypothesis that small fiber neuropathy might explain - at least in part - the hitherto unexplained but frequently presented symptoms of myocardial autonomic dysfunction in sarcoidosis needs prospective studies. The results of such studies may not only provide new insight in the pathophysiology of arrythmogenesis in sarcoidosis but also have future therapeutic implications, because pharmacological interventions resulting in a normalization of autonomic imbalance may reduce arthythmias in sarcoidosis. Future studies are needed to evaluate its clinical implications and therapeutic options. Moreover, the important question of whether SFN with or without cardiac innervation impairment is reversible or mot should be explored. 


\section{References}

1 Newman LS, Rose CS, Maier LA. Sarcoidosis. N Engl J Med 1997;336:1224-34.

2 Hunninghake GW, Costabel $U$. Ando $M$ Baughman RP. Cordier JF, du Bois RM, Eklund $A$. Kitaichi M. Lynch J. Rizzato $G$. Rose $c$. Selroos $O$, Semenzato $G$, Sharma OP. ATSIERSNNASOG statement on sarcoidosis. American Thoracic Saciety/European Respiratory Society World Association of Sarcoidosis and other Granulomatous Disorders. Sarcoidosis Vasc Diffuse Lung Dis 1999:16:149-73.

3 James DG. Complications of sarcoidosis. Chronic fatigue syndrome. Sarcoidosis 1993;10: $1+3$.

4 Wirnsberger RM. De Vries $J$, Wouters EFM. Drent $M$. Clinical presentation of sarcoidosis in The Netherlands an epidemiological study. Neth J Med 1998; 53: 53-60.

5 Hoitsma E, De Vries J, van Santen-Hoeuff M. Faber CG, Drent M. Impact of pain in a Dutch sarcoidosis patient population. Sarcoidosis Vasc Diffuse Lung Dis 2003;20;33-9.

6 Deng JC and Baughman RB. Cardiac involvement in sarcoidosis. Semin Respir Crit Care Med 2002:23:51328.

7 Larsen F, Pehrsson SK, Hammar N, Skold CM, Izumi T, Nagai S, Shigematsu M. Eklund A. ECG-abnormalities in Japanese and Swedish patients with sarcoidosis. A comparison. Sarcoidosis Vasc Diffuse Lung Dis 2001;18:284-8.

8 Mitchell DN, du Bois RM, Oldershaw PJ. Cardiac sarcoidosis. BMJ 1997:314:320-1.

9 Virmani $\mathbb{R}$, Bures $J C$. Roberts WC. Cardiac sarcoidosis; a major cause of sudden death in young individuals. Chest 1980;77:423-8.

10 Case records of the Massachusetts General Hospital. Weekly clinicopathological exercises. Case 34-1996. A 50-year-old woman with cardiac disease, an electronic pacemaker, and cardiac arrest in ventricular fibrillation. $N$ Engf $J$ Med 1996;335:1378-86.

11 Hoitsma E, Marziniak M, Faber CG, Reulen JPH. Sommer $C$. de Baets M, Drent M. Small Fiber Neuropathy in Sarcoidosis. Lancet 2002;359:2085-6.

12 Hoitsma E, Drent M, Verstraete E, Faber CG, Troost J Spaans F, Reulen JPH. Abnormal warm and cold sensation thresholds suggestive of small-fibre neuropathy in sarcoidosis. Clin Neurophysiol 2003;114:2326-33.

13 Novak V, Freimer ML, Kissel JT, Sahenk Z, Periquet IM, Nash SM, Collins MP, Mendell JR. Autonomic impairment in painful neuropathy. Neurology 2001;56:861-8.

14 Ewing DJ, Boland O. Neilson JM, Cho CG, Clarke BF. Autonomic neuropathy, QT interval lengthening, and unexpected deaths in male diabetic patients. Diabetologia 1991:34:182-5.

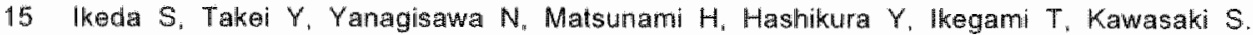
Peripheral nerves regenerated in familial amyloid polyneuropathy after liver transplantation. Ann Intern Med 1997;127:618-20.

16 Krone A. Reuther P. Fuhrmeister U. Autonomic dysfunction in polyneuropathies: a report on 106 cases. J Nourol 1983;230:111-21.

17 O'Brien GM, Baughman RP, Broderick JP, Arnold L, Lower EE. Paranoid psychosis due to neurosarcoidosis. Sarcoidosis 1994:11:34-6.

18 Goldstein DS, Robertson D. Ester M. Straus SE. Eisenhofer G. Dysautonomias: clinical disorders of the autonomic nervous system. Ann intern Med 2002;137:753-63.

19 Wichter T, Matheja P. Eckardt $L$, et al. Myocardial iodine-123-metaiodobenzylguanidine (123H-MIBG) imaging in Brugada syndrome. Circulation 2002: 106: e59-60.

20 Reulen JPH, Lansbergen MD, Verstraete E, Spaans F. Comparison of thermal threshold tests to assess small nerve fiber function: limits ws. levels. Clin Neurophysiol 2003;114:556-63.

21 Yarnitsky D. Sprecher E. Thermal testing: normative data and repeatability for various test algorithms. J Neurol Sci 1994:125:39-45.

22 Consensus statement: Report and recommendations of the San Antonio conference on diabetic neuropathy. American Diabetes Association American Academy of Neurology. Diaw betes Care 1988:11:592-7. 
23 Hammond IW. Devereux RB, Alderman MH, Lutas EM, Spitzer MC, Crowley JS, Laragh JH. The prevalience and correlates of echocardiographic left wentricular hypertrophy among employed patients with uncomplicated hypertension. I Am Coll Cardiol 1986;7:639-50.

24 Stewart JD. Low PA. Fealey RD. Distal small fiber neuropathy: results of tests of sweating and autonomic cardiovascular reflexes. Muscle Nerve 1992;15:661-5.

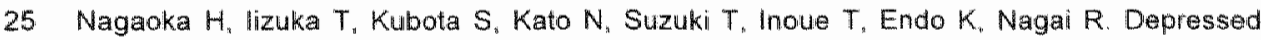
contractile response to exercise in diabetic patients in the absence of cardiovascular disease: relationship to adrenergic cardiac dysinnervation. Nucl Med Commun 1997;18:761-70.

26 Esler M. Assessment of sympathetic nervous function in humans from moradrenaline plasma kinetics. Clin Sci (Lond) 1982;62: 247-54.

27 Schafers $M$, Schober $\mathrm{O}$, Lerch $\mathrm{H}$. Cardiac sympathetic neurotransmission scintigrapluy. Eur J Nucl Med 1998;25:435-41.

28 Misumi I, Kimura $Y$, Hokamura $Y$, Honda $Y$, Yasunaga $T$, Nakashima $K$, Takemura $N$, Asoshina M. Uranaka N. Takenaka S, Shima K. Scintigraphic detection of regional disruption of the adrenergic nervous system in sarcoid heart disease. Jpn Circ J 1996;60:774-8.

29 Matsuo S, Nakamura $Y$, Matsui T. Matsumoto T, Kinoshita M. Detection of denervated but viable myocardium in cardiac sarcoidosis with $1-123$ MIBG and TI-201 SPECT imaging. Ann Nucl Med 2001:15:373-5.

30 Imai E, Kaminaga T, Takada K, Kutomi K, Furui S. Radioactive defect on Im123 MiBG myocardial SPECT imaging in a patient with cardiac sarcoidosis. Clin NuCl Med 2002,27: 729-30.

31 Takashige $N$. Naruse TK, Matsumori $A$, Hara M, Nagai $S$, Morimota $S$, Hiramitsu $S$, Sasayama $S$, inoko $H$. Genetic polymorphisms at the tumour necrosis factor loci (TNFA and TNFB) in cardiac sarcoidosis. Tissue Antigens 1999:54:191/3.

32 Baughman RP, Lower EE, du Bois RM. Sarcoidosis. Lancet 2003,361:1111-8.

33 Parthenakis FI, Patrianakos A, Prassopoulos V, Papadimitriou E, Nikitovic D, Karkavitsas NS. Vardas PE. Relation of cardiac sympathetic innervation to proinflammatory cytokine levels in patients with heart failure secondary to idiopathic dilated cardiomyopathy. Am J Cardiol 2003" 91:1190-4.

34 Tuck RR, Mcleod JG. Autonomic dysfunction in Guilain-Barre syndrome. I Neurol Neurosurg Psychiatry 1981;44:983-90.

35 Ewing D.J, Campbell IW. Clarke BF. Assessment of cardiovascular effects in diabetic autonomic neuropathy and prognostic implications. Ann Intern Med 1980;92:308 11 .

36 Yee AM, Pochapin MB. Treatment of complicated sarcoidosis with infliximab anti-tumor necrosis factor-alpha therapy. Ann Intern Med 2001:135:27-31.

37 Ziegler $D$. Schatz $H$, Conrad F, Gries FA, Ulrich $H$, Reichel $G$. Effects of treatment witth the antioxidant alpha-lipoic acid on cardiac autonomic neuropathy in NIDDM patients. A 4-month randomized controlled multicenter trial (OEKAN Study). Deutsche Kardiale Autonome Neurow pathie. Diabetes Care 1997:20:369-73.

38 Tsuchimochi S, Tamaki $N$. Tadamura E, Kawamoto M, Fujita T, Yonekura Y, Konishi \&. Agle and gender differences in normal myocardial adrenergic neuronal function evaluated by iodine-123-MIBG imaging. I Nucl Med 1995,36:969-74

39 Gill JS. Hunter GJ. Gane J. Ward DE Camm AJ. Asymmetry of cardiac [1231] meta. iodobenzyl-guanidine scans in patients with ventricular tachycardia and a "clinically normal" heart. Br Heart $J 1993 ; 69: 6-13$.

40 Nakata $T$. Nagao K, Tsuchihashi $K$, Hashimoto A, Tanaka S, limura O. Regional cardiac sympathetic nerve dysfunction and the diagnostic efficacy of metaiodobenzylguanidine tomography in stable coronary artery disease. Am J Cardiol 1996,78:292-7.

41 Wichter $T$, Hindricks $G$, Lerch $H$. Bartenstein $P$, Borggrefe $M$. Sichober $O$. Breithardi $G$. Regional myocardial sympathetic dysinnervation in arrhythmogenic right ventricular cardiomyopathy. An analysis using 1231 -meta-iodobenzylguanidine scintigraphy. Circulation $1994 ; 89: 667 \times 83$.

42. Wichter $T$, Matheja $P$, Eckardt L, Kies $P$, Schafers $K$, Schulze-Bahr $E$, Haverkamp $W$, Borggrefe $M$, Schober $O$, Breithardt $G$, Schafers $M$. Cardiac autonomic dysfunction in Brugada syndrome. Circulation 2002; 105:702-6. 
${ }_{156} \mid$ 


\section{Chapter 10}

Association of HLA DQB $1{ }^{\star} 0602$ in sarcoidosis patients with small fiber neuropathy

CEM Voonter, M Drent, E Hoitsma, CG Faber, $\mathrm{PM}$ van den Berg-Loonen

Sarcoidosis Vasc Diffuse Lung Dis 2005: accepted for publication 


\section{Abstract}

\section{Background and am}

Sarcoidosis has been reported to be associated with the HLA genes, in particular DQB1.

\section{Mothods}

High resolution DQB1 of 103 sarcoidosis patients was obtained by sequence-based typing. Iow resolution HLA-A/B/DRB1 typing was performed by serologicall and molecular methods. Small fiber neuropathy (SFN) was established by thermal threshold testing.

\section{Results}

Sixty-seven patients suffered from SFN (SFN-), in 36 patients SFN was absent (SFN-). Comparing HLA DQB1 typings of SFN+ patients, SFN-patients and control individuals revealed a significant increase of the allele DQB1*0602 in SFN+ patients compared to controls.

\section{Conctusion}

This association might be correlated with a severe course of the disease. 


\section{Introduction}

Sarcoidosis is a multiorgan inflammatory disorder of unknown origin, characterized by T-lymphocyte and mononuclear phagocyte infiltration in the affected organs, granuloma formation, and distortion of the normal micro-architecture, which is probably antigendriven. 'The clinical manifestations of sarcoidosis are largely nonspecific, dependent on the intensity of the inflammation and organ systems affected. of which the lung is the most prominent. Sarcoidosis patients may suffer from a great variety of symptoms. A substantial number of sarcoidosis patients report apparently non-specific symptoms such as pain, for which no organic substrate has yet been established. ${ }^{2}$ Recently, we and others found that small fiber neuropathy is rather common in sarcoidosis patients. ${ }^{3-5}$ Several studies have suggested that the clinical outcome of sarcoidosis is affected by clinicall phenotype, race, gender and age of onset. A genetic component for sarcoidosis is suspected based on familiar clustering and different prevalence of the disease in various ethnic groups. The genes in the $M H C$ have been investigated and recently the strongest association was shown for the HLA gene DQB1. ${ }^{7.6}$ The aim of this study was to evaluate whether there is a difference between sarcoidosis patients with or without small fiber neuropathy and healthy controls regarding their HLA association.

\section{Patients and methods}

From January 2002 to February 2004, 103 Caucasian sarcoidosis patients from the Sarcoidosis Management Center - a tertiary referral center in the Netherlands - of the University Hospital Maastricht were studied. The diagnosis sarcoidosis was made according to the World Association of Sarcoidosis and Other Granulomatous disease (WASOG) guidelines. ${ }^{9}$ Informed consent was obtained from all participating patients. The clinical records were reviewed (MD) and patients were divided into 2 groups based on their clinical status at least three years after initial diagnosis (table 10.1).

Temperature threshold testing (TTT) was performed to assess the presence of SFN with a Medoc TSA-2001 device (Medoc, Ramat Yishai, Israel). Thresholds for warmth and cold sensation were determined on the hand and dorsum of the foot using the method of levels (MLE) and limits (MLI). Normative data according to Yarnitsky were used. ${ }^{3.4} \mathrm{~A}$ patient was considered to suffer from SFN (SFN+) when his temperature sensation threshold for both MLE and MLl exceeded the $99 \%$ interval of a healthy population. ${ }^{10}$ 
Tabil 10.1 Summary of most refevan cinical clata of the shudied Caucasian sarcoidosis poputation with or without small fiber neuropathy $(S F N-(n=36)$ or $S F N+(n=67)$

\begin{tabular}{|c|c|c|c|}
\hline & no small fiber neuropathy & \multicolumn{2}{|c|}{ small fiber neuropathy } \\
\hline Age at diagnosis, years " & $35.7 \pm 10.3$ & \multicolumn{2}{|c|}{$41.5 \pm 9.9$} \\
\hline \multirow[t]{2}{*}{ Time since diagnosis: yrs } & $4.4 \pm 3.9$ & \multicolumn{2}{|c|}{$4.3 \pm 5.9$} \\
\hline & $\%$ & $n$ & $\%$ \\
\hline \multicolumn{4}{|l|}{ Gender " } \\
\hline male & 38.9 & 45 & 67.2 \\
\hline female & 61.1 & 22 & 32.8 \\
\hline \multicolumn{4}{|l|}{ Chest $X$-ray stage af presentation } \\
\hline \& & 25.0 & 17 & 25.4 \\
\hline ॥ & 33.3 & 26 & 38.8 \\
\hline III & 36.1 & 98 & 26.9 \\
\hline N & 5.6 & 6 & 9.0 \\
\hline \multicolumn{4}{|l|}{ Treatment } \\
\hline never & 36.1 & 19 & 28.4 \\
\hline predinison & 47.2 & 34 & 50.7 \\
\hline prednisonet methotrexate & 16.7 & 12 & 17.9 \\
\hline anti TNF alpha & 0 & 2 & 3.0 \\
\hline \multicolumn{4}{|l|}{ Prograssion of disease " } \\
\hline milld disease & 33.3 & 40 & 14.9 \\
\hline moderate to savere disease ${ }^{2}$ & 66.7 & 57 & 85.1 \\
\hline
\end{tabular}

Data are expessed as number of cases (n) and percentages or mean with $5 \mathrm{D}$, as appropriate. "p<0.05

"mild disease inciuded: - resolved, never treated or no therapy $>12$ months

- minimal disease newer treated or no therapy $>12$ months

${ }^{2}$ moclerate to severe disease included: - persistent disease, never treated or no therapy $>\| 2$ morths

- persistent disease on therapy (asymptomatic, stabie, worsening)

From all individuals genomic DNA was isolated by using QIA-AMP Kits following the suppliers protocol (Qiagem, Westburg, Leusden, NL). Concentration and purity of DNA samples were measured at $260 \mathrm{~nm}$ and $260 / 280 \mathrm{~nm}$. All patients were typed for HLA-DQB1 to the allele level by sequence-based typing as previously described ${ }^{\text {t1.12, }}$, sequence data were processed automatically and evaluated manually. HLA-DRB 1 was typed at the low resolution level by PCR-SSP, HLA-A and -B were detected by serological techniques. ${ }^{13.14}$ The control groups for high resolution DQB1 consisted of 418 healthy Caucasian individuals, for low resolution DRB1 624 and AB 720. HLA phenotype frequencies were determined for patients and controls. Frequencies were compared by $x^{2}$-testing, $p$ values were calculated and corrected for the number of alleles tested. 
Tabile 10.2

DQB I and DRB1 phenowpe frequencies in Duton sarcoidesis patients with or without small fiber meuropathy (SFN+, n=67 vs $5 F N-n=36$ ) compared to control individuals (for high resolution $\mathrm{DQB}$ : $r=418$; for low resolution $\mathrm{DFB}$, $\mathrm{n}=624 \mathrm{l}$

\begin{tabular}{|c|c|c|c|c|c|c|c|c|}
\hline \multirow[b]{2}{*}{ allele } & \multicolumn{2}{|c|}{ no small fiber neuropathy } & \multicolumn{2}{|c|}{ small fiber neuropattry } & \multicolumn{2}{|c|}{ controls } & \multirow[t]{2}{*}{$p$} & \multirow[t]{2}{*}{ poonir } \\
\hline & $n$ & $\%$ & $n$ & 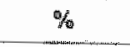 & $n$ & $\%$ & & \\
\hline DOBI:0201 & 7 & 19,4 & 95 & 22.4 & 99 & 23.7 & & \\
\hline $\mathrm{DOB}+0202$ & 7 & 19,4 & 5 & 7,5 & 73 & 17,5 & & \\
\hline DQB $1 * 0301$ & 16 & $4,4,4$ & 22 & $32, B$ & 128 & 30,6 & & \\
\hline DQB11*0302 & 4 & 11,1 & 12 & 17.9 & 57 & 13,6 & & \\
\hline DQBH 0303 & 2 & 5,6 & 6 & 9,0 & 45 & 10.8 & & \\
\hline DQB1 19304 & 0 & 0,0 & 0 & 0,0 & 2 & 0,5 & & \\
\hline $\mathrm{DQB1} 1 * 0305$ & 0 & 0.0 & 0 & 0.0 & 1 & 0,2 & & \\
\hline OQB $1 * 0401$ & 0 & 0,0 & 0 & 0,0 & 0 & 0.0 & & \\
\hline $\mathrm{DQB}: 0402$ & 3 & 8,3 & 5 & $7: 5$ & $\|$ & 2.6 & & \\
\hline DOB 0501 & 5 & 13,9 & 9 & 43,4 & 84 & 20.1 & & \\
\hline DQB1*0502 & 1 & 2,8 & 2 & 3,0 & 23 & 5,5 & & \\
\hline $00 B 1 \times 0503$ & 3 & $B_{13} 3$ & $\overrightarrow{7}$ & 10,4 & 32 & 7.7 & & \\
\hline$D Q B 11^{\circ} 0504$ & 0 & 0,0 & 0 & 0,0 & 2 & 0,5 & & \\
\hline DQB1.0601 & 0 & 0,0 & 0 & 0,0 & 91 & 26 & & \\
\hline DOB 0602 & 9 & 25,0 & 25 & $37,3^{34}$ & 76 & 18,2 & 0,0006 & $0,012^{*}$ \\
\hline 000110603 & 5 & 13,9 & 11 & 16.4 & 88 & 21,1 & & \\
\hline $\mathrm{DOB} 1 * 0604$ & 5 & 13,9 & 7 & 10,4 & 46 & 11,0 & & \\
\hline DQB. 0605 & 0 & 0,0 & 0 & 0,0 & $a$ & 0,0 & & \\
\hline DOB1*0607 & 0 & 0,0 & 0 & 0,0 & $y$ & 0,2 & & \\
\hline $\mathrm{DQB} 1 * 0609$ & 0 & 0,0 & 2 & 3.0 & 14 & 3,3 & & \\
\hline $\mathrm{DQB} 1 \times 0614$ & 0 & 0,0 & 0 & 0,0 & 0 & 0,0 & & \\
\hline DRB 1"011 & 4 & 91,1 & 6 & $9,0^{\text {wix }}$ & 142 & 22,8 & $0,0139^{\text {nink }}$ & \\
\hline DRB $1 * 15$ & 9 & 25,0 & 27 & $40,3^{* \pi *}$ & 143 & 22,9 & $0,0028^{* * x}$ & $0,0336^{.4 *}$ \\
\hline DRB: 16 & 1 & 2,8 & 1 & 1,5 & 25 & 4,0 & & \\
\hline $\mathrm{DRB}+\|^{\star 03}$ & 8 & 22,2 & 15 & 22,4 & 149 & 23,9 & & \\
\hline DRB $\| 04$ & 5 & 13.9 & 14 & 20,9 & 146 & 23,4 & & \\
\hline $\mathrm{DRB} \|^{* 11}$ & 12 & 33,3 & 16 & 23.9 & 121 & 19.4 & & \\
\hline DRB1.12 & 2 & 5,6 & 1 & 1,5 & 39 & 6.1 & & \\
\hline DERE'13 & 10 & 27,8 & 27 & 31,3 & 147 & 23,6 & & \\
\hline $\mathrm{ORB} \cdot 14$ & 3 & 8.3 & 7 & $10 n_{n} 4$ & 54 & 8.2 & & \\
\hline $\mathrm{DPB} \|^{\circ} \mathrm{O}$ & $a$ & 22.2 & 7 & $10,4^{k}$ & 155 & 24.6 & $0,0127^{7}$ & \\
\hline ORB1"OB & 4 & 11,1 & 6 & 9,0 & 36 & 5.8 & & \\
\hline ORB1"09 & $y$ & 2.8 & 3 & $4 ; 5$ & 13 & 2,1 & & \\
\hline DRB*10 & 1 & 2,8 & 2 & 3,0 & 9 & 1.4 & & \\
\hline
\end{tabular}

${ }^{*} \mathrm{P}_{\mathrm{cor}}=\mathrm{p}$ value corrected for the number of alleles tested; ** SFN* VS. controls

\section{Results}

When the clinical features of SFN+ patients were compared with SFN- patients statistically significant differences were found for age at diagnosis, gender and disease progression (table 10.1 , all $p$ values $<0.05$ ). Concerning the HLA results an increase of DQB1*0602 was shown for the SFN+ group compared to healthy conitrols (37.3 vs. 
$\left.18.2 \%, p_{c o r r}=0.012\right)$. which remained statistically significant also after correction for the number of alleles tested. For DRB1 an increase for DRB1 15 was also found in the $S F N *$ group compared to the controls $(40.3 \mathrm{ws} .22 .9 \%$, porr $=0.036)$. The increase of both alleles is consistent with the well known HLA linkage disequilibrium between the DQB1 and DRB1 genes, since DRB1*15 and DQB1*0602 are tightly linked in Caucasian individuals. Furthermore, a decrease of DRB1*01 and DRB1*07 in the SFN+ group was seen, as well as an increase of B7 in the SFN- group compared to controls. However, these differences were no longler statistically significant after correction for the number of alleles tested. All deviating frequencies for DRB1 and DQB1 are shown in table 10.2 .

\section{Discussion}

HLA class II antigens have been reported to be associated with sarcoidosis in different ethnic populations, and recently DQB1 and not DRB1 was indicated to play an important role in sarcoidosis susceptibility. ${ }^{7,8,15}$ Although DQB1*0602 was previlously mentioned to be associated with sarcoidosis, it was never the most prominent associated DQB1 allele. However, within the SFN+ patients the most prominent HLA DQB1 association is found with DQB1*0602, and this is consistent with our finding of DQB1*0602 as the most prominent DQB1 association with sarcoidosis in a group of 149 Dutch Caucasian patients. The strongest association with DQB1*0602 was detected in patients with severe pulmonary sarcoidosis, according to their chest $X$-ray stage at presentation. In the present study no differences were detected in the distribution of $X$-ray stages between SFN- and SFN+ patients. However, regarding clinicall progression of the disease significant differences were found. Within the SFN+ group a higher percentage of patients suffered from moderate to severe disease compared to the SFN-group in which mild disease was more frequent $(p=0.03)$.

\section{Conclusion}

In conclusion, this implicates that both the presence of $D Q B 1{ }^{*} 0602$ and the occurrence of small fiber neuropathy in sarcoidosis patients are associated and might be correlated with a more severe course of the disease. Typing for HLA might be helpful to recagnize sarcoidosis patients with a suspected severe course in conjunction with development of small fiber neuropathy. 


\section{References}

1. Baughman RP, Lower EE, du Bois RM. Sarcoidosis. Lancet 2003:361:1111-8.

2. Hoitsma $E$, De Vries J, Santen-Hoeuff $M$, Faber $C G$, Drent $M$. Impact of pain in a Dutch sarcoidosis patient population. Sarcoidosis Vasc Diffuse Lung Dis 2003:20:33-9.

3. Hoitsma E, Marziniak M, Faber CG Reulen JPH, Sammer C, de Baets M, Drent M. Small fibre neuropathy in sarcoidosis. Lancet 2002:359:2085-6.

4. Hoitsma $E$, Drent $M$, Verstraete $E$. Abnornal warm and cold sensation thresholds suggestiwe of smalt-fibre neuropathy in sarcoidosis. Clin Neurophysiol 2003:114:2326-33.

5. Allen RK, Sellars RE, Sandstrom PA. A prospective study of 32 patients with neurosarcoidosis. Sarcoidosis Vasc Diffuse Lung Dis 2003:20:118-25.

6. Kidd D. Beynon HL. The neurological complications of systemic sarcoidosis. Sarcoidosis Vasc Diffuse Lung Dis 2003:20:85-94.

7. Sato $H_{2}$ Grutters JC. Pantelidis P. Mizzon AN, Ahmad T, Van Houte A.J, Lammers J-Wu, van den Bosch JMM, Weish Kl, du Bois RM. HLA-DQB1*0201: A marker for good prognosis in British and Dutch patients with sarcoidosis. Am J Raspir Cell Mol Biol 2002:27:406-12.

8. Rybicki BA, Maliarik MJ, Poisson LM, Sheffer R, Chen KM, Major M. Chase GA, Lannuzzi MC. The major histocompatibility complex gene region and sarcoidosis susceptibility in African Americans. Am J Respir Crit Care Med 2003:167:444-9.

9. Hunninghake GW, Costabel U, Ando M, Baughman RP, Cordier JF, du Bois RM, Eklund A. Kitaichi $M$, Lynch J, Rizzato $G$, Rose $C$, Selroos $O$. Semenzato $G$. Sharma OP. ATS/ERSMASOG statement on sarcoidosis. American Thoracic Society/European Respiratory SiacietyNorld Association of Sarcoidosis and other Granulomatous Disorders. Sarcoidosis Vasc Diffuse Lung Dis 1999,16:149-73.

10. Hoitsma $E$, Reulen JPH, de Baets M, Drent M, Spaans F. Faber CG. Small fiber neuropathy: a common and important clinical disorder. J Neurol Sci 2004:227:119-30.

11. Voorter CEM, Kik MC, van den Berg-Loonen EM. High-resolution HLA typing for the DQB1 gene by sequence-based typing. Tissue Antigens 1998:51:80-7.

12. Voorter CEM, KiK MC, van den Berg-Loonen EM. Sequence-based typing for HLA-DQB: Strategy for the ALF express. Chapter 12-B. In: HWWG technical manual genomic analysis of the human MHC, DNA-based typing for HLA alleles and linked polymorphisms 2000: Publication of the 13 th International Histocompatibivity Working Group. Tilanus MGJ. Hansen JH. Hunlley $\mathrm{CK}_{n}$ eds. Publisher: Fred Hutchinson Cancer Research Center, Seattle USA. ISBN \#0945278-02-0.

13. Voorter CEM, Rozemuller EH, de Bruyn-Geraets D, van der Zwan AW, Tilanus MGJ, wan den Berg-Loonen EM. Comparison of DRB sequence-based typing using different strategies. Tissue Antigens 1997:49:471-6.

14. Woorter CEM, wan der Vies S, Kik M, van den Berg-Loonen EM. Unexpected Bw4 and Bw6 reactivity patterns in new alleles. Tissue Antigens 2000:56:363-70.

15. Grunewald $J$, Eklund $A$, Olerup $O$. Human leukocyte antigen class I alleles and the disease course in sarcoidosis patients. Am I Respir Crit Care Med 2004:169:696-702. 
164 
Chapter 11

Spectacular improvement of small fiber neuropathy in a sarcoidosis patient after treatment with infliximab

E Hoitsma, CG Faber, M Drent

Submitted for publication 
168 chaphen 11 


\section{Introduction}

Sarcoidosis is a multi-organ inflammatory disorder of unknown origin, characterized by T-lymphocyte and mononuclear phagocyte infiltration in the affected organs, granuloma formation, and distortion of the normal micro-architecture, which is probably antigen. driven." The inflammatory process may be accelerated by the release of tumour necrosis factor- $\alpha$ (TNF-a) from resident macrophages, resulting in further recruitment of inflammatory cells. ${ }^{2}$ The clinical manifestations of sarcoidosis are largely non-specific, dependent on the intensity of the inflammation and organ systems affected, of which the lung is the most prominent. Besides pulmonary symptoms many patients suffer from fatigue, pain and vegetative symptoms. ${ }^{3-5}$ Recently, we found that small fiber neuropathy (SFN) is rather common in sarcoidosis patients. ${ }^{.6}$

While treatment of systemic sarcoidosis usually includes corticasteroids or other immunosuppressants such as methotrexate, treatment of SFN is unknown so far. In our experience corticosteroids and methotrexate are not beneficial in SFN related to sarcoidosis. ${ }^{7}$ Therefore, symptoms of SFN become usually chronic, devastating and one of the major problems in sarcoidosis.

Infliximab is a chimeric $\lg G$ monoclonal antibody directed against TNF- $\alpha$ which binds both the soluble and transmembrane form of TNF- $a .^{8}$ It has proved usieful in treating active rheumatoid arthritis and Crohn's disease., 90 Because TNF- a may be a crucial cylokine in sarcoidosis, and infliximab has proved successful in treating other chronic inflammatory diseases " there is a rationale for treating refractory sarcoidosis with infliximab too. 8 "11 We describe a case of multi-organ sarcoidosis with severe SFN who improved spectacularly after treatment with infliximab.

\section{Case report}

In May 2001, this 39 year-old Caucasian man was suffering from dysprioea and wheezing. A chest $X$ wray demonstrated hilar lymph adenopathy suggestive of sarcoidosis without pulmonary infiltrates. His medical history revealed hypertension, hypercholesterolemia and morbid obesitas since 1985 treated with perindopril and orlistat. Since May 2000 he was known with diabetes type II, for which he was successfully treated with metformine and glimepiride. Up to now his glycaemic controls remained perfectly stable (HBA $1 \mathrm{C}$ between 6.3 and $6.9 \%$ ) and he did not develop retinopathy. At that time no additional medical treatment was initiated for his pulmonary symptoms. However, in December 2001 his fatigue and dyspnoea increased and he complained of progressive burning sensations in both feet and hands, accompanied by profuse sweating, diarrhoea, erectile dysfunction, dizziness while upright, and sicca syndrome, all 
suggestive of SFN with autonomic involvement. He also reported sleeplessness and a depressive mood. Furthermore, he suffered from arthralgia in shoulders and knees and developed subcutaneous nodules of 1 to $2 \mathrm{~cm}$ diameter located on his lower arms and legs. Due to his clinical deterioration he was unable to work. Physical examination revealed dyspnoea and distall dysesthesia with loss of temperature sensation, and red, wet palms and soles. Further physical and neurological examination including reflexes remained normal, besides the subcutaneous nodules. Chest $X$-ray again showed mediastinal and hilar lymph adenopathy. Biopsies of a mediastinal lymph node and subcutaneous nodule were performed, showing non-caseating granulomas consistent with the diagnosis of sarcoidosis. For assessment of polyneuropathy and central proprioceptive sensory pathways he underwent electromyography (EMG), nerve conduction studies and somatosensory evoked potentials (SSEP), which were all narmal. Evaluation of small nerve fiber function was performed by temperature threshold testing (TTT), using the method of levels and method of limitis. ${ }^{4,12}$ Severely abnormal warm and cold sensation thresholds were found in both hands and feet compatible with severe small fiber neuropathy (table 11.1). The results of TTT revealed in most cases a warm sensation threshold exceeding $50^{\circ} \mathrm{C}$ and a cold sensation threshold below $0^{\circ} \mathrm{C}\left(50^{\circ} \mathrm{C}\right.$ and $0^{\circ} \mathrm{C}$ being the maximal and minimal temperature limit of our equipment). Cardiovascular autonomic function was assessed using the tests recommended by the San Antonio Consensus Meeting ${ }^{13}$ which showed three tests out of five that were abnormal, indicating autonomic dysfunction (table 11.1 and figure 11.1). By the end of December 2001 he started with prednison $40 \mathrm{mg}$ daily, which was without benefit however and tapered. Glycaemic controls remained stable during therapy. In February 2002 methotrexate $7.5 \mathrm{mg}$ weekly was added to the $10 \mathrm{mg}$ prednison daily. As this appeared to be ineffective, the dose of methotrexate was increased up to $20 \mathrm{mg}$ weekly. Despite this, his fatigue, neuropathic pain, autonomic dysfunction, and arthralgia deteriorated and the subcutameous noduli enlarged. Initiated reuropathic pain treatment with gabapentin, opioids, carbamazepin and amitryptilin achieved no improvement. At the end of 2002 he was admitted to a dermatologist because of severe skin lesions on both hands (figure 11.2). The lesions were diagnosed as burns due to insensitivity for heat. This insensitivity was attributable to the SFN. Therefore, to avoid these burning lesions in the future, thermostats at the warm water taps were advised.

In May 2003 infliximab was started. A dosage of $3 \mathrm{mg} / \mathrm{kg}$ of infliximab (500 $\mathrm{mg}$ ) was given and repeated at week 2,6 and 12 with spectacular reduction of his symptoms. Remarkably, in a schedule of therapy every 6 weeks symptoms reoccurred after 4 weeks and he demonstrated a 'rebound' reaction. To try to avoid this reaction the dosage interval was shortened in once every 4 weeks and the dosage tapered to 
$400 \mathrm{mg}$. This appeared to be successful. First his arthralgias, fatigue and lung function tests as well as inflammatory parameters improved (table 11.1).

Tabie 11.1 Temperafure threshold lesting (TTT) and cardiowascular autonomic function tests (CAFT) before and after one year treatment with infiximab

\section{Before treatment After treatment Nomative value \\ (c)}

$(\mathrm{C})$

(c)

TIT

\begin{tabular}{|c|c|c|c|}
\hline \multirow[t]{4}{*}{ Warm sensation } & $R$ hand MLE / MLI & $48.4 / 49.0$ & $35.1 / 35.8$ \\
\hline & $L$ hand MLE / MLI & $>50 \mid>50$ & $35.1 / 32.5$ \\
\hline & R foot MLE MLI & $47.8 />50$ & $43.8 / 45.5$ \\
\hline & 1 foot MLE/MLI & $48.6 />50$ & $40.3 / 46.2$ \\
\hline \multirow[t]{4}{*}{ Cold sersation } & Fi hand MLE / MLI & $<0 /<0$ & $30.4 / 29.0$ \\
\hline & L hand MLE / MLI & $9.7 /<0$ & $31.5 / 30.9$ \\
\hline & R foot MLE MLL & $<0 /<0$ & $26.5 / 26.2$ \\
\hline & $L$ foot MLE / MLI & $3.5 /<0$ & $23.0 / 20.6$ \\
\hline
\end{tabular}

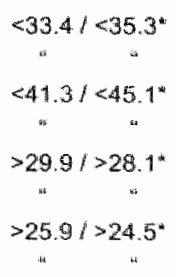

in rest, supine

Mean HR (beats/minute) CV $(\%)$

lin rest, upright

\section{Mean HR (beats/minute)} CV (\%)

From supine to uptight

Deita HR (beats)

$30 / 15$ ratio

Deep breathing I-E (beats)

Valsalva maneuvre $H R_{\text {niax }} / H R_{\text {min }}$

\section{Laboratory tests}

SACE (Ui))

SilL $2 R(\mathrm{KU} / \mathrm{H})$

\section{Lung function tests}

FEV1. \% of praclicted

FVC, $\%$ of predicted

\section{Symptom scores}

FAS (fatigue)
WHOQOL-100 (quality of life)
SFNSL-Score

$\begin{array}{ll}78 & 7.4 \\ 1.9 & 2.6\end{array}$

\begin{tabular}{lcc}
13.9 & 20.2 & $>16.3$ \\
1.05 & 1.13 & $>1.12$ \\
14.8 & 11.8 & $>10.5$ \\
1.1 & 1.3 & $>1.5$ \\
22 & 9 & 9.25 \\
725 & 325 & $21.4-846$ \\
66 & 82 & $>180 \%$ \\
74 & 86 & $>80 \%$ \\
45 & 20 & $<22$ \\
4 & 16 & $>15.9$ \\
77 & 311 & $<48$ \\
\hline
\end{tabular}

Abnormall data are presented bold; "9g\% cut off value according to Yarnitsky and Sprecher ${ }^{2}$. TTT $=$ temperature threshold testing (data are presented in " $\mathrm{C}$, starting temperature in all tegis $32^{\circ} \mathrm{C}$ ) MLE method of lavels; MLI $=$ method of limits; CAFT = cardiowascular autonomic function testing: HR = heart rate; $C V=$ couffictent of variation; Della $\mathrm{HR}=$ intitial maximal increase in heart rate after standing upright; $30 \% 5$ ratio = heart rate 30 seconds after standing upright divided by heart rate 15 seconds after standing upright: $1-E$ w succesive maximum inspiration minus mimimum expiration heart rate while desep breathing; $s A C E=$ senum angiotensin converting enzyme; $s \mid L 2 R$ = soluble interlaukin-2-receptor; $\mathrm{FEW} 4=$ forced expiratory volume in one second; FV/C = forced vilal capacity:

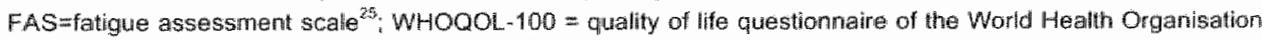
(overall quality of life and general heaith facet); SFWSL= small fiber neuropathy screening list 
Thereafter, his subcutaneous noduli disappeared and at last, after almost half a year, the neuropathic pain symptoms, as well as symptoms of autonomic dysfunction disappeared. Temperature threshold testing and cardiovascular autonomic function testing were repeated in July 2004. Both showed spectacular improvement (figure 11.1 and table 11.1). Although cardiovascular autonomic function testing was still judged abnormal ( 2 two out of the 5 tests were abnormal), the degree of abnormality was remarkably reduced. After therapy both systolic and diastolic blood pressure showed a more flat response after rising from supine to an upright position and he reported no dizziness anymore. At present he is stable on infliximab once every 4.5 weeks. His quality of life improved substantially, his fatigule became within normal limits (table 11.1). he is enjoying life again and even restarted working successfully.

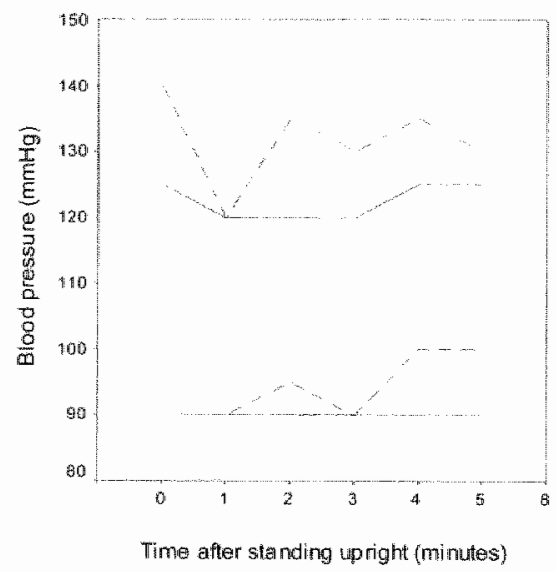

Figuire 11.1 Blood pressure rasponse affer standing in upright position before and after one year infliximab

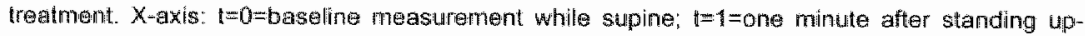
right; $t=2=$ two minutes after standing upright; otc. Scattered line: systolic and diastolic blood pressure before treatment with infiximab. Patient reported dizziness after standing upright. Bold lime: systolic and diastolic blood pressure after treatment with infiximab. No dizziness was reported after standing upright 


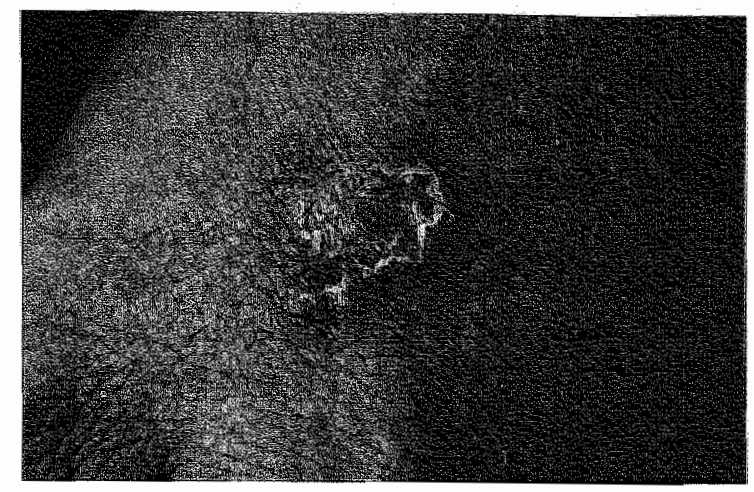

Figure 11.2 Burns on the hand of the sarcoidosis patient with severe small fiber neuropathy.

\section{Discussion}

Our patient suffered from diabetes type 11 and multi-organ sarcoidosis with severe small fiber neuropathy. The intriguing question whether the SFN in this case was related to sarcoidosis together with diabetes or one of these disorders alone will stay unanswered. In our opinion the facts that glucose levells were stable in our patient despite severe SFN, other organ damage due to diabetes such as retinopathy or nephropathy were absent and the reversibility of SFN that went parallel with reversibility of sarcoidosis symptoms, make sarcoidosis a rather more likely cause of SFN than diabeles in this case.

SFN is a neuropathy selectively involving small diameter myelinated and unmyelinated nerve fibers ${ }^{45}$ Interest in this disorder has considerably increased during the past few years. Patients typically present with peripheral pain and/or symptoms of autonomic dysfunction. Diagnosis is made on the basis of the clinical features, normal nerve conduction studies, and abnormal specialized tests of small nerve fibers. Among others, these tests include TTT for sensory fibers and cardiovascular autonomic testing for autonomic fibers. ${ }^{14}$ The pathophysiology of SFN is unknown. However, it appears to be frequent in several immune mediated diseases such as Guillain-Barré syndrome. Sjögren's disease, vasculitis, SLE, rheumaloid arthritis and sarcoidosis. "14.15 The latter relation has been appreciated just recently. ${ }^{6}$ Furthermore, SFN is frequent in diabetes. ${ }^{16}$ So far, no proper treatment for SFN is available. Treatment is usually directed towards 
alleviation of neuropathic pain and often stays problematic. ${ }^{14}$ Prognostic studies are lacking, but in our experience SFN in sarcoidosis is usually chronic and devastating. In diabetes patients SFN is usually progressive, with eventually involvement of large nerve fibers. ${ }^{16}$

Infliximab was an attractive therapeutic option in our patient for several reasons. Treatment with corticosteroids and methotrexate had not been successful. Moreover, corticosteroids caused severe side-effects and were not well tolerated. He still was severely disabled. Furthermore, increasing evidence has demonstrated that TNF-a is a crucial cytokine in the pathogenesis of sarcoidosis and recently, refractory sarcoidosis has been treated successfully with Infliximab. ${ }^{8.11}$ However, at present no data are available of the effect of anti-TNF-a therapy on SFN, while in our patient SFN was the most devastating problem. Remarkably "severe SFN appeared to be reversible after treatment with Infliximab in this case.

Theoretical support for the effect of anti-TNF-a therapy on SFN may be found in the following. First, it has been appreciated recently that proinflammatory cytokines including TNF-C contribute to the development of inflammatory and neuropathic pain as well as hyperalgesia. ${ }^{17}$ Second, TNF-a plays an important role in neuropathies such as Guillain-Barré syndrome and in Guillain-Barré syndrome small nerve fibers are also involved. Elevated serum concentration of TNF-a shows a positive correlation with neuropathy severity in patients with Guillain-Barré syndrome. ${ }^{18.19}$ Furthermore, the decrease in serum TNF-a and increase in serum soluble TNF receptors shows a positive correlation with neuropathy recovery following treatment in those patients. Finally, the presence of SFN in several immune mediated diseases suggests a common final pathway in the pathogenesis of the disorder that may be related to the ongoing inflammatory process. Similarity might be related to cytokine release in immune mediated diseases. Support for the hypothesis that SFN in immune mediated diseases is related to cytokine release is found in pharmacological and physiological studies. These studies report that pro-inflammatory cytokines such as TNF-a are strongly involved in the generation and maintenance of neuropathic pain. ${ }^{17,20-24}$ Therefore, it is tempting to speculate that anti-TNF-a therapy might be beneficiall in SFN.

\section{Conclusion}

This case once again stresses that infliximab might be considered as a promising alternative in the treatment of refractory multi-organ sarcoidosis. The case presented suffering from sarcoidosis, diabetes and SFN responded very successful. Our patient reveals two new and important issues. First, severe SFN appeared to be reversible in this case. Second, TNF-a may be a crucial cytokine in the pathogenesis of SFN related 
to sarcoidosis and possibly in other immune mediated inflammatory diseases and diabetes as well. The successful reaction to anti-TNF-a therapy is very promising and this observation opens a window for new therapeutic and pathogenetic studies. 


\section{References}

1. Baughman RP, Lower EE, du Bois RM. Sarcoidosis. Lancet 2003;361:1111-8.

2. Zlegentiagen MW. Benner UK, Zissel $G$, Zabel $P$, Schlaak $M$, Muller-Quernheim J. Sarcoidosis: TNF-alpha release from alveolar macrophages and serum level of slL-2R are prognostic markers. Am J Respir Crit Care Med 1997;156:1586-92.

3. Hollsma E, Die Vries J, van Santen-Hoeufft M. Faber CG. Drent M. Impact of pain in a Dutch sarcoidosis patient population. Sarcoidosis Vasc Diffuse Lung Dis 2003,20:33-9.

4. Hoitsma $E$, Drent M, Verstraete $E$, Faber CG. Troost J. Spaans F, Reulen JPH. Abnormal warm and cold sensation thresholds suggestive of small-fibre neuropathy in sarcoidosis. Chin Neurophysiol 2003;114:2326-33.

5. Wirnsberger RM, De Vries J, Breteler MHM, van Heck GL, Wouters EFM, Drent $M$. Evaluation of quality of life in sarcoidosis patients. Respir Med 1998;92:750-6.

6. Hoitsma E, Marziniak M, Faber $C_{G}$, Reulen JPH, Sommer $C$, de Baets M, Drent M. M. Small Fiber Neuropathy in Sarcolidosis. Lancet 2002;359:2085-6.

7. Hoitsma E, Faber $C_{G}$ Drent M, Sharma OP. Neurosarcoidosis: a clinical dilemma. Lancet Neurol 2004;3:397-407.

8. Baughman RP, Lower EE. Infliximab for refractory sarcoidosis. Sarcoidosis Vasc Diffuse Lung Dis 2001:18:70-4.

9. Maini R, St Clair EW, Breedveld F, Furst D, Kalden J, Weisman M, Smolen J, Emery P. Harriman $G$. Feldmann M, Lipsky P. Infliximab (chimeric anti-tumour necrosis factor alpha monoclonal antibody) versus placebo in rheumatoid arthritis patients receiving concomitant methotrexate: a randomised phase III trial. ATTRACT Study Group. Lancet 1999;354:1932-9.

10. Heller $T_{i}$ James SP, Drachenberg $C$. Hernandez $C$, Darwin PE. Treatment of severe esophageal Crohn's disease with infliximab. Inflamm Bowel Dis 1999;5:279-82.

11. Yee AM, Pochapin MB. Treatment of complicated sarcoidosis with infliximab anti-tumor necrosis factor-alpha therapy. Arm intern Med 2001:135:27-31.

12. Yarnitsky $D$, Sprecher $E$. Thermal testing: normative dala and repeatability for various test algorithms. J Neurol Sci 1994:125:39-45.

13. Consensus statement: Report and recommendations of the San Antonio conference on diabetic neuropathy. American Diabetes Association American Academy of Neurology. Diabetes Care 1988; 11:592-7.

14. Hoitsma E, Reulen JPH, de Baets M "Drent M, Spaans. F, Faber CG. Small fiber neuropathy: a common and important clinical disorder. J Neurol Sci 2004:227:119-30.

15. Lacomis D. Small-fiber neuropathy. Muscle Nerve 2002;26:173-88.

16. Simmons Z, Feldman EL. Update on diabetic neuropathy. Curr Opin Newrol 2002;15:595-603.

17. Opree $A$, Kress $M$. Involvement of the proinflammatory cytokines tumor necrasis factor-alpha, IL-1 beta, and IL-6 but not IL-8 in the development of heat hyperalgesia: effects on heat evoked calcitonin gene-related peptide release from rat skin. J Neurosci 2000;20:6289-93.

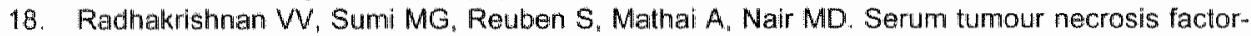
alpha and soluble tumour necrosis factor receptors levels in patients with Guillain-Barre syndrome. Acta Neurol Scand 2004:109:71-4.

19. Creange $A$, Belec $L$, Clair $B$, Raphael JC, Gherardi RK. Circulating tumor necrosis factor (TNF)-alpha and soluble TNF-alpha receptors in patients with Guillain-Barre syndrome. $J$ Neuroimmunol 1996;68:95-9.

20. Sommer $C$, Marziniak $M$, Myers RR. The effect of thalidomide treatment on vascular pathology and hyperalgesia caused by chronic constriction injury of rat nerve. Pain 1998;74: $83-91$.

21. Sommer $\mathrm{C}$. Schafers M. Painful mononeuropathy in C57BL/Wid mice with delayed wailerian degeneration: differential effects of cytokine production and nerve regeneration on thermal and mechanical hypersensitivity. Brain Res 1998;784:154-62.

22. Schafers $M$, Geis $C$, Brors $D$, Yaksh TL, Sommer $C$. Anterograde transport of tumor necrosis factor-alpha in the intact and injured rat sciatic nerve. J Neurosci 2002;22:536-45. 
23. Empl M, Renaud $S$, Erne $B$, et al. TNF-alpha expression in painful and nonpaimful neuropathies. Neurology 2001;56:1371-7.

24. Cunha $F Q$. Poole $S$, Lorenzetti BB, Ferreira SH. The pivotal rolle of tumour necrosis, factor alpha in the development of inflammatory hyperalgesia. Br J Pharmacol 1992;107:660-4.

25. De Vries J, Rothkrantz-Kos $S$, van Dieijen-Visser MP, Drent $M$. The relationship between fatigue and clinical parameters in pulmonary sarcoidosis. Sarcoidosis Vasc Diffuse Lung Dis $2004: 21: 127-36$ 
176 
Chapter 12

Summary, general discussion and directions for future studies 
178 maptw 


\section{Summary}

Sarcoidosis patients exhibit a broad variety of clinical features. Besides pulmonary symptoms which generally reflect disease activity many patients present with symp. toms suclr as pain, fatigue and autonomic dysfunction. So far "these symptoms have had little attention in the sarcoidosis literature, and have remained an enigma to physicians. We found that many of these apparently nonwspecific symptoms could be related to small fiber neuropathy (SFN) with autonomic involvement. This observation was the motive for this thesis.

First a literature search was performed. In chapter 2 the existing literature regarding neurosarcoidosis was reviewed to provide an overview of the present knowledge and dilemmas clinicians are faced with in the diagnostic work-up and treatment of patients suffering from this complicated disease. In this chapter an approach for the diagnosis of neurosarcoidosis as well as treatment strategies are proposed. Furthermore, our novel observation SFN in sarcoidosis was added to the list of neurological complications attributable to this disease.

Chaprer 3 reviews the literature regarding what is known about SFN. SFN is a neuropathy selectively involving small diameter myelinated and unmyelinated nerve fibers. Interest in this disorder has considerably increased during the past few years. Clinical presentation consists of peripheral pain and/or symptoms of autonomic dysfunction. Routine electrodiagnostic studies, which primarily test large myelinated fiber function, are generally normal in these patients. Therefore, the disorder SFN has been an enigma to practitioners because of the unexplained contrast between severe pain in the extremities and a paucity of neurological and electrophysiological findings. Diagnosis is achieved based on clinical features, normal nerve conduction studies, and abnormal specialized tests of small nerve fibers. Among others, these tests include assessment of epidermal nerve fiber density in skin biopsy, temperature sensation tests for sensory fibers and sudomotor and cardiovascular function testing (CAFT) for autonomic fibers. Untess an underlying disease is identified, treatment usually is symptomatic and directed towards alleviation of neuropathic pain.

SFN is often idiopathic, however, it occurs relatively frequently in several immune mediated diseases such as vasculitis, ${ }^{12}$ Sjögren's disease, ${ }^{3}$ systemic lupus erythematosus (SLE), ${ }^{4.5}$ Guillain-Barré syndrome ${ }^{6: 7}$ and to our own experience SFN occurs also in Wegener's disease, and rheumatoid arthritis. Accordingly, it was hypothesized that in immune mediated diseases there might be a common pathway causing SFN. In sarcoidosis, SFN related symptoms not always occur parallel with disease activity assessed by general used diagnostic procedures and it does nof seem to respond to 
conticosteroids. In line with this, it is reasonable to assume that SFN in sarcoidosis is not directly caused by granuloma lormation. Finally we discussed candidate mechanisms involved in the pathogenesis of SFN including tumour necrosis factor (TNF)-a and oxidative stress.

Although pain is prevalent in sarcoidosis, this has never been studied systematically. The study described in chapter 4 was aimed to evaluate the presence and impact of pain in sarcoidosis. Members of the Dutch Sarcoidlosis Society without co-morbidity $(n=821)$ participated in this study. The World Health Organisation Quality of Life assessment instrument (WHOQOL-100; see appendix) was completed, as well as a symptom inventory questionnaire addressing the presence of various categories of pain. Pain appeared to be a major problem in sarcoidosis, occurring in up to $72 \%$ of the studied sarcoidosis patients. Although negative feelings and fatigue were found to be related to pain, it could not fully explain painn.

Besides pain, many sarcoidosis patients suffer from fatigue ${ }^{8.9}$ and sleep disturbances. Recently, it was demonstrated that obstructive sleep apnea (OSA) is rather common in sarcoidosis. ${ }^{10}$ Moreover, sheet intolerance, painful legs and restless legs are frequently reported in sarcoidosis patients. Remarkably, restless legs syndrome (RLS) may be an early feature of SFN. ${ }^{11,12}$ These symptoms might interfere with sleep quality. In order to determine the relationship between objective and subjective sleep disturbance in chapter 5 full polysomnography, including leg EMG analysis, was performed in 46 chronic sarcoidosis patients indicating awakening unrefreshed in the morning. Both sleep disturbance (OSA and/or periodic leg movement (PLM)) and RLS were found in more than half of the studied sarcoidlosis patients. Its relation with SFN and fatigue needs further exploration.

After we discovered a frequent occurring symptom pattern, consisting of peripheral pain accompanied by symptoms of autonomic dysfunction, suggestive of SFN, we established the presence of SFN using various types of testing.

In chapter 6 various electrophysiological tests were used to assess the presence of SFN. Seventy-four sarcoildosis patients complaining of symptoms suggestive of SFN undenwent temperature threshold testing (TTT) to assess thresholds for warm and cold sensation as well as for heat pain, sympathetic skin responses (SSR), nerve conduction studies and concentric needle electromyography. Furthermore, in 31 patients, CAFT was carried out. TTT revealed abnormalities in 51 of the 74 patients $(69 \%)$, consistent with our clinical observation. This obsemation was in accordance with former studies that have also found sensitivity rates of TT varying form 60 to $85 \%$. ${ }^{13-17}$ Nerve conduction studies in the legs showed slightly abnormal results in 6 of the 74 patients, 
all of these had abnormal $\pi T$ resuits. The SSR was absent at the foot in 7 of the 74 patients. CAFT was abnormal in only a single case of the 31 tested patients, which is in accordance with data from others reporting low sensitivity of CAFT in SFN. 14,18

In conclusion, we found in a subgroup of sarcoidosis patients TT abnormalities suggestive of SFN. SSR and cardiovascular autonomic testing appeared to be of little diagnostic walue.

In chapter 7 the presence of SFN was further explored by obtaining skin biopsy specimens. Quantification of epidermal nerves in skin biopsies is an objective and valuable method to detect SFN. Reduced intraepidermal nerve fiber density (IENFD) can be the first and only detectable abnormality in patients with painful neuropathy. In 7 consecultive sarcoldosis patients and 6 age matched healthy controls IENFD in punch biopsies of the skin was determined. Reduced IENFD was found in all 7 patients compared to 6 healthy controls, consistent with the presence of SFN in these patients.

In clinical practice there is a need for an easily administered instrument to assess SFN which can be applied to all patients with suspicion of the disorder. In chapter 8 we describe the development and validation of a questionnaire to screen for the presence of SFN. Such a questionnaire is aimed to be useful in clinical assessment, for research assessing prevalence and natural course and in therapeutic trials. We developed and validated a questionnaire in a group of 84 sarcoidosis patients that was short and easy to administer, the SFN-screening list (SFNSL). Cut-off scores were determined based on TTT results. Thereafter, in another group of 55 sarcoidosis patients the SFNSL was cross-validated. The same cut-off scores were found appropriate. Internal consistency assessment revealed that the different questions of the SFNSL were strongly related to each other (Cronbach's alpha 0.90). Furthermore, exploratory factor analysis showed that the SFNSL measures only one underlying factor. These results support the idea that SFN is a uniform disease and makes a psychogenetic component explaining for the symptoms of SFN highly unlikely.

Besides fatigue and peripheral pain many sarcoidosis patients report symptoms related to cardiac autonomic dysfunction such as orthostatic intolerance with dizziness, collapses in the shower, or pain in coat hanger area selectively in an upright position. However, as described in chapter 5 and by others, CAFT remain normal in most of them. Recognition of cardiac autonomic involvement is of clinical importance as cardiac autonomic dysfunction has been identified as a strong predictor of morbidity and mortality as this may cause sudden cardiac arrythmias. In chapter 9 we describe the assessment of cardiac sympathetic innervation using ${ }^{123}$ 1-MIBG (metaiodobenzylguanidine) cardiac scintigraphy in sarcoidosis patients. Cardiac sympathetic 
dysfunction was present and appeared to be related to SFN. The possible prognostic and therapeutic implications of cardiac sympathetic dysfunction need further study.

There is little doubt that genetic factors piay an important role in the genesis of sarcoildosis and an association with the human leucocyte antigen (HLA) was found, in particular the DQB1 gene. In chapter 10 we explored the association between HLA and SFN in sarcoidosis. Low resolution HLA typing was performed for 103 sarcoidosis patients by serological and molecular methods, high resolution DQB1 was obtained by sequence-based typing. SFN was established by TTT. Sixty-seven patients had abnormal TTT (SFN+), 36 patients had normal TTT (SFN-). Comparing HLA typings of SFN+ patients, SFN- patients and control individuals revealed a significant increase of the HLA class 11 allele DQB1 0602 in SFN+ patients compared to controls. Differences were found in progression of disease. Within the SFN+ group a higher percentage of patients suffered from persistent or current disease compared to the SFN-group. This implicates that both the presence of DQB1*0602 and the occurrence of SFN in sarcoidosis patients might be correlated with a more severe course of the disease.

Although patients report benefit from finally knowing the cause of their symptoms, SFN remains a major problem as therapy has been disappointing so far. Corticosteroids and methotrexate, the mainstay of therapy in sarcoidosis, did not appear to be beneficial in SFN (own obserwation). Therefore, so far, therapy is mainly symptomatic and directed towards alleviation of neuropathic pain. However, most of the drugs that are efficacious reduce pain intensity only in 30-50\%, and such a reduction rarely meets patients expectations. Furthermore, adequate therapy for autonomic dysfunction is lacking. In chapter 11 we describe a patient with severe SFN with autonomic involvement, who was experimentally treated with infliximab, an anti-TNF-a therapy. His symptoms completely resolved, and his TTT as well as cardiovascular autonomic function test improved substantially after therapy.

This patient reveals two important issues. First, it shows that SFN seems not an irreversible disorder, even in severe cases. Second. TNF-a may be a crucial cytokine in the pathogenesis of SFN in sarcoidosis and presumably also in other immune mediated inflammatory diseases. The logic for the latter is that TNF has been found important in the development of neuropathic pain and has been related to disease activity in neuropathy in Guillain-Barre syndrome. Furthermore. SFN appears to occur frequent in several other immune mediated diseases. Thus, it is tempting to speculate that there might be a final common pathway in these immune mediated diseases resulting in SFN. Hypothetically, this similarity might be cytokine release related. 
In conclusion; this thesis describes the spectrum of neurological involvement in sarcoidosis and moreover added and explored a new finding related to sarcoidosis: small fiber neuropathy. SFN appeared to explain some of the so lar baffling symptoms in sarcoidosis. The recognition of SFN is important as patients report benefit form knowing the cause of their symptoms, and it may also have implications for health insurances in this group of relatively young patients. Different aspects of SFN in sarcoidosis are discussed including pain, sleep disturbances, and autonomic cardiac dysfunction which eventually may have prognostic implications. The latter needs further study in longitudinal "prognostic studies. A SFN screening list was developed and validated. This list is easily applicable and not time consuming. In a clinical setting this list is recommended as a screening tool. Moreover, it can be used in future studies. HLA typing revealed that the presence of HLA-DQB1*0602 was related to the presence of TTT abnormalities and ta a more severe course of sarcoidosis. Finally, we found in one of our patients that severe SFN completely resolved after anti-TNF-a therapy. This opens many directions for further study. 


\section{General discussion}

The major conclusion of the current thesis is that SFN is a frequent and novell finding in sarcoidosis. Patients with SFN present a wide spectrum of symptoms such as neuropathic pain, symptoms of autonomic dysfunction such as diarrhoea, sweating. heat intolerance, sexual dysfunction, hot flushes, orthostatic intolerance and sicca syndrome. Moreover, restless legs may be a presenting feature of SFN. "Remarkably, SFN and especially symptoms of autonomic dysfunction frequently remain unrecognised. This may be due to the fact that neurologists do not focus on symptoms such as diarrhoea, sweating, flushes and sicca syndrome, and pulmonary and internal physicians are not farniliar with the underlying neurological syndromes. Especially those cases without all features of the disorder, just some of them, often remain unrecognised. Moreover, techniques to diagnose SFN are not widely available.

\section{Small fber neuropathy assessment}

TTT appeared to be a useful tool for measuring small fiber sensory impairment. ${ }^{19}$ However, TTT is a psychophysical method and therefore requires the cooperation of the patient. This means that this test is liable to loss of attention, especially in older subjects, and to malingering. ${ }^{49-21}$. However, our patient population consists of relatively young patients. Furthermore, by using two types of testing as a control, the method of levels and the method of limits, false positive results may be reduced. ${ }^{22.23}$ Moreover. TTT is a test of small nerve fiber function, and does not asses structural pathollogy.

The assessment of IENFD counting in skin biopsy provides an objective tool for SFN assessment and does assess structural pathology. The technique appears to be promising and deserves further exploration, especially because pathophysiology of SFN may herewith be explored at the site of the symptoms, the small nerve fibers in the skin. However, IENFD assessment is a relatively difficult technique only available in few centers. Normative values appear to vary considerably and before implementing in a clinical setting a subset of healthy controls need to be investigated to determine normative values in every laboratory. Moreover, it has to be explored whether SFN is caused by a reduction of the number of fibers (quantitative effect) or might be caused, at least in part, by impaired function (qualitative effect).

To enable the diagnosis of SFN there is a need for an easily administered instrument, which can be applied to screen for the presence of SFN. For this purpose we established the SFNSL. The SFNSL proved to measure only one underlying factor and supports our clinical observation that the wide spectrum of different symptoms of autonomic dysfunction and neuropathic pain are the result of one underlying condition, small nerve fiber dysfunction. These results strongly argue that SFN is a unified 
condition and they argue against a psychogenetic component to the symptoms of SFN. The SFNSL is aimed to be a practical tool in clinical assessment. Furthemore, this list can be used for purposes of research, epidemiological and pathophysiological studies, and to guide the development of further therapy.

\section{Cardiac denenation}

We found that cardiac sympathetic denervation occurs in sarcoidosis (chapter 9), and according to our hypothesis, it seems to be related to SFN. ${ }^{123}$-MIIBG SPECT appeared a feasible, relatively non-invasive, approach investigating cardiac adrenergic innervation and localizes the territories of reduced sympathetic innervation. An imbalance of the autonomic tone is considered to increase the propensity to develop fatal arrhythmias. It is known from patients with neuropathy in diabetes mellitus, amyloidosis and GuillainBarré syndrome that the involvement of small autonomic nerve fibers is a predictor of cardiovascular mortality. ${ }^{724}$ Sudden death in sarcoidosis is a rare but dramatic complication and is thought to be due mostly to cardiac involvement. However, selecting patients at risk is one of the major obstacles facing clinicians. ${ }^{25}$ Until now, sympathetic innervation has not been evaluated systematically. In line with our observations, it is recommended that the possibility of autonomic cardiac dysfunction should be considered in the management of sarcoidosis patients. Moreover, carefull follow-up is mandatory to evaluate the prognosis. The results of such studies may not only provide new insight in the pathophysiology of arrythmogenesis in sarcoidosis but also have important therapeutic implications, because (pharmacological) interventions or implantation of an intracardial defibrillator (ICD) may reduce arrhythmias in sarcoidosis and presumably also in patients with SFN with involvement of cardiac denervation due to other causes.

\section{Pathogenesis and treatment}

The observation that SFN is rather common in sarcoidosis raised a lot of questions, including what the pathogenesis could be and which treatment might be beneficial?

It is remarkable that SFN seems to be frequent in several immune mediated diseases. This leads to the hypothesis that there might be a common pathway in immune mediated diseases resulting in SFN. The idea of an immune mediated mechanism as the cause of SFN has also been reported by others. ${ }^{26,27}$ The pathogenetic role of oxidative stress, inflammatory cytokines such as TNF-a and neuropeptides such as substance P (SP) are interesting to explore as a common final pathway in several immune mediated inflammatory diseases. 


\section{Tumor nochosis beword}

The benefit of TNF - a inhibitor treatment in sarcoidosis supports the fact that sarcoidosis is a TNF mediated disease. ${ }^{23-33}$ The patient described in chapter 11 with severe SFN showed spectacular improvement after treatment with anti-TNF-a (Infliximab). This case supports the idea that TNF-a may be a crucial cytokine in the pathogenesis of SFN related to sarcoidosis and in SFN related to other immune mediated inflammatory diseases as well. Theoretical support for the effect of anti-TNF-a therapy on SFN may be found in the following. First. TNF-a plays an important role in immune-mediated neuropathies such as Guillain-Barre syndrome, in which small nerve fibers are also involved. ${ }^{34.35}$ Elevated serum concentration of TNF-a shows a positive correlation with neuropathy severity in patients with Guillain-Barré syndrome. ${ }^{34.35}$ Furthermore, the decrease in serum TNF-a and increase in serum soluble TNF receptors shows a positive correlation with neuropathy recovery following ireatment in those patients. Second, pharmacological and physiological studies report that pro-inflammatory cytokines such as TNF $\alpha$ are strongly involved in the generation and maintenance of neuropathic pain. ${ }^{36-41}$

\section{Substance P}

SP is a is a proinflammatory neuropeptide that is secreted by nerves and inflammatory cells such as macrophages, eosinophils, lymphocytes, and dendritic cells. ${ }^{42} \mathrm{SP}$ acts by binding to the neurokinin-1 receptor (NK-1R) and increases secretion of TNF- $\alpha$ in many cell types. SP is involved in transmission of pain and causes rapid contractions of the gastrointestinal smooth muscle, and modulates inflammatory and immune responses. It has pro-inflammatory effects in inflammatory diseases. In bronchoalveolar lavage fluid obtained from sarcoidosis patients increased SP levels and upregulated NK-1R expression are found. ${ }^{43-46}$

As shown in figure 1.2 of chapter 1 persistent antigenic stimulation together with tumour growth factor (TGF) $\beta$ may result in chronic inflammation and fibrosis in sarcoidosis. In the inflammatory process some T-cells produce soluble "immunoproteins" that bind specifically to non-processed antigen (TABM). TABM may function by antigen-specific "targeting" of cytokines, particularly TGF- $\beta$. TGF- $\beta$ associated with TABM will induce the secretion of SP and will amplify the effect of SP on sensory neurons. ${ }^{47}$ In figure 12.1 the mechanism is shown by which TABM-TGF- $\beta$ bind the antigen and thereby activate TGF- $\beta$, which increases on one hand SP production by sensory neurons resulting in pain and muscle contraction and on the other hand the production of TNF- $\alpha$ by monocytes. Thus, one may conclude that the neuropeptide SP might - among others have a role in SFN related to inflammatory diseases. 
In the discussion of the pathogenesis of SFN the role of oxidative stress also needs further exploration. A growing body of evidence suggests that oxidative stress is implicated in the pathogenesis of diabetic neuropathy. ${ }^{48-54}$ Furthemore, a decreased level of nicotinamide adenine dinucleotide phosphatase (NADPH) was found in the erythrocytes of sarcoidosis patients. ${ }^{55}$ As NADPH is a necessary factor in the defence against oxidative stress, this suggests a decreased anti-oxidant defence capacity in sarcoidosis. Moreover, sarcoidosis is suggested to trigger an oxidative stress response. which is indicated by an increased activation of nuclear regulatory factor kappa-B (NFKB). ${ }^{56-58}$ The possibility exists that in patients with inflammatory disorders in general a decrease of the redox-steate contributes to meuronal changes.

In figure 12.2 treatment strategies for sarcoidosis are presented. As discussed above the possible role of TNF-a and SP may guide new therapeutic approaches and initiate trials. At present it appears interesting to initiate a study of anti-TNF-a therapy in SFN related to sarcoidosis.

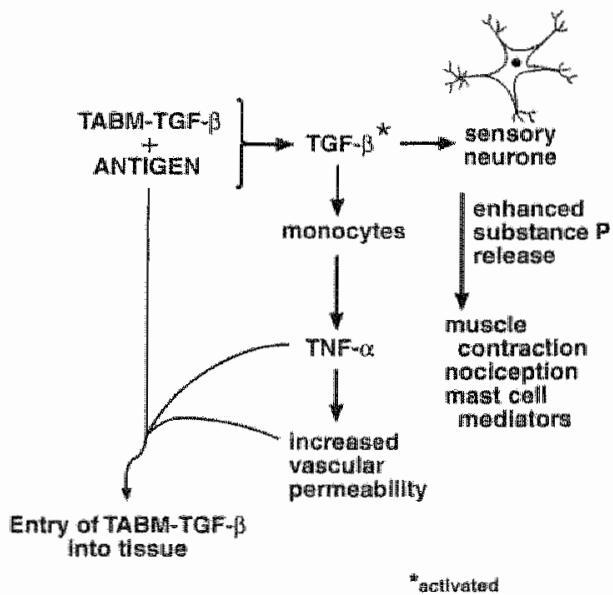

Figure 2:1 A model for the effect of TABM (soluble "immunoproteins" that bind specifically to nonprocessed antigen) antigen interaction on sensory neurons through TABM-associated iumour girowth factor (TGF)-B. TABHA-TGF-fs produced by $T$ cells binds specifically to antigen and TABM-ASSociated TGF- $B$ is thereby activated. The activated TGF $B$ increases the production of substance $P$ by sensony neurons and induces the production of TNH-ch by monocyles that increases the entry of TABMt into lissue by increasing vascular permeability (Adapted from Cone et al.)." 


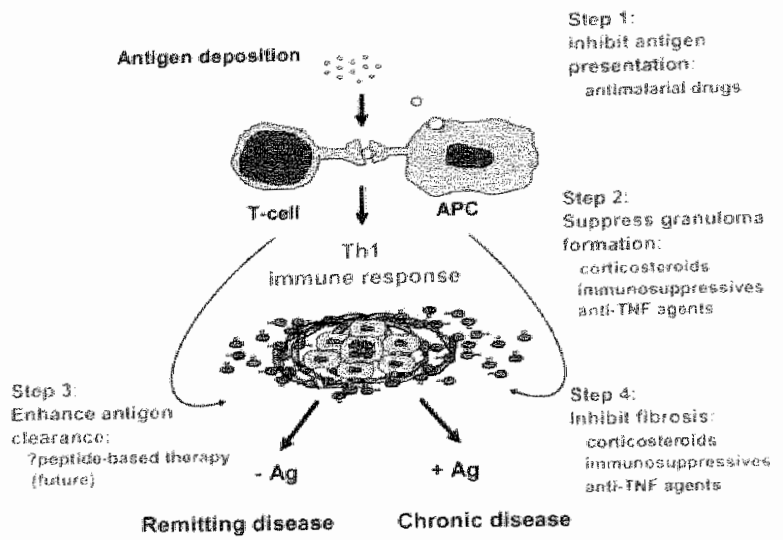

Figure 12.2 Schematic diagram of strategies for treatment of sarooidosis based on stages of granulomatous intlammation in the disease. Step 1 involves inthibiting pathogenic antigen processing and presentation by antigen-presenting celis (APC) fo CO4. T celis with antimallaria! drugs. Suppression of granuloma formation involves the use of corticosteroids. immunosuppressive drugs and antw TNF agents. Future peptide-based therapies can be envisioned to enhance or suppress relevant $T$-ceil mediated immune responses that may accelerate disease remission. Finally, reducing hbrosis may be accomplished by suppressirng granulomatous inflammation and accompanying tissue injury fadapted with permisson from Moller).

There is little doubt that genetic factors play an important role in the genesis of sarcoidosis. ${ }^{59,60}$ Newly developed molecular genotyping techniques are now being applied to explore genetic aspects of the disease. It has been found that HLA-DR alleles have prognostic value for the course of sarcoidosis. There is a strong HLA class II association with the development of a persistent disease (HLA-DRB1"15 and HLA-DQB4*0602) or to resolution of the disease (DRB1*03 and DQB1*0201). chapter 10 we describe that HLA-DQB $1 * 062$ and the occurrence of SFN in sarcoidosis patients are associated. Funthermore, it appeared that both might be correlated with a more severe course of the disease. Typing for HLA might prove to be helpful to recognize sarcoidosis patients with suspected severe course in conjunction with development of SFN. 


\section{Directions for future studies}

Answers to scientific problems are born pregnant with new questions. Several questions that have arisen as a result of the present thesis seem interesting enough for further exploration. What is the most practical and reliable way to diagnose SFN? What are the prognostic implications of the presence of SFN? What is the natural course? Is fatigue related to SFN? What is the pathophysiology? Can we treat SFN and how?

For instance, future studies may further validate the SFNSL. Other tests to aSsess SFN may be used to validate the SFNSL, such as IENFD in skin biopsy, quantitative sympathetic axon reflex testing (QSART), and eventually newer techniques such as contact-heat evoked potential (CHEPS). This may lead to a higher sensitivity and specificity of the SFNSL. Subsequently, with the SFNSL the presence and prevalence of SFN in other immune mediated diseases may be evaluated.

Furthermore, future studies focussing on the role of cardiac denervation on prognosis and sudden death should be performed. Additionally, longitudinal studies to depict patients that are at risk of developing cardiac conduction disturbances are mandatory. In this regard, it is also of great clinical relevance to explore the preventive efficacy of implantation of an intracardial defibrillator (ICD).

It has been found that different HLA-DR and $\triangle D Q$ alleles have prognostic value regarding the course of sarcoidosis. ${ }^{\text {.1.63 }}$. The results described in chapter 10 revealed that there is a difference between sarcoidosis patients with SFN and healthy controls regarding their HLA association. Thus, there might be a genetic predisposition to develop SFN in sarcoidosis. This needs to be explored in larger studies.

TNF-a polymorphism has also been found to have prognostic value for the course of the disease. ${ }^{65}$ The TNF family consists of at least 15 cytokines that play an important role in inflammation and immune response and TNF polymorphism may influence the course of sarcoidosis. It is tempting to speculate that TNF polymorphism may influence the development of SFN in sarcoidosis. Thereofore, exploring the relationship of certain polymorphisms with the severity of sarcoidosis and the presence of SFN might guide the development of new therapeutic strategies.

As mentioned before fatigue is a major problem in sarcoidosis and deserves more attention. Up till now no disease activity marker has been found to depict fatigue. Moreover, fatigue may persist even after all parameters assessing disease activity have become within normal limits. However, it has been found that autonomic dysfunction is frequently accompanied by fatigue. ${ }^{86}$ Therefore, the correlation of SFN and fatigue 
appears interesting to explore, for which the SFNSL (see appendix) and fatigue assessment scale (FAS; appendix) may be helpful. As fatigue is present in many chronic diseases, among which also Guillain-Barré syndrome ${ }^{67}$, in this regard the role of cylokines e.g. TNF-a and neuropeptides such as SP on fatigue also appear interesting to explore.

Finally, as RLS is some cases a first sign of SFN ${ }^{14}$ and RLS and periodic leg movement disordier (PLMD) are related, the association between SFN and fatigue on one hand and RLSIPLM on the other hand is also interesting to explore.

Answers to these questions may lead to better understanding of the intriguing disorder SFN and sarcoidosis. This may guide more appropriate management of patients. Information can be focussed more to what patients might expect and to better treatment of thase suffering from this devastating disorder. 


\section{References}

1. Zafrir $B$, Zimmerman $M$, Fellig $Y$, Naparstek $Y$, Reichman $N$, Flatau $E$. Small fiber neuropathy due to isolated vasculitis of the peripheral nervous system. Isr Med Assoc J 2004;6:183-4.

2. Lacomis D, Giuliani MJ Steen V. Powell HC. Small fiber neuropathy and wasculitis. Arthritis Rheum 1997:40:1173-7.

3. Kaplan JG, Rosenberg R, Reinitz E, Buchbinder $S$, Schaumburg HH. Invited review peripheral neuropathy in Sjogren's syndrome. Muscle Newe 1990;13:570-9.

4. Omdal $\mathrm{R}$, Bekkelund $\mathrm{SI}$. Mellgren SI. Husby $\mathrm{G}$. C-fibre function in systemic lupus erythematosus. Lupus 1996;5:613-7.

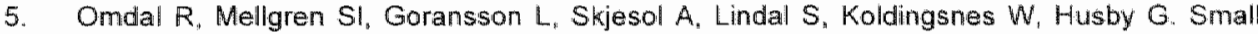
nerve fiber involvement in systemic lupus erythematosus: a controlled study. Arthritis Rheum $2002 ; 46: 1228-32$.

6. Seneviratne U. Gunasekera S. Acute small fibre sensory neuropathy: another variant of Guillain-Barre Syndrome? I neurol neurosurg psychiatry 2002;72:540-542.

7. Tuck RR, McLeod JG. Autonomic dysfunction in Guillain-Barre syndrome. J Neurof Neurosurg Psychiatry 1981:44:983-90.

8. Wirnsberger RM, De Vries J, Wouters EFM, Drent M. Clinical presentation of sarcoidosis in The Netherlands an epidemiological study. Neth J Mod 1998;53:53-60.

9. De Vries $J_{d}$ Rothkrantz-Kos $S$, van Dieijen-Visser MP. Drent M. The relationship between fatigue and clinical parameters in pulmonary sarcoidosis. Sarcoidosis Vasc Diffuse Lung Dis 2004:21:127-36.

10. Turner GA, Lower EE, Corser BC. Gunther KL, Baughman RP. Sleep apnea in sarcoidosis. Sarcoidosis Vasc Diffuse Lung Dis 1997:14:61-4.

11. Polydefkis M. Allen RP, Hauer P, Earley CJ, Griffin JW, McArthur JC. Subdinical sensory neuropathy in late-onset restiess legs syndrome [1n Process Citation]. Neurology 2000;55: 1115-21.

12. Schattschneider $J$, Bode $A$, Wasner $G$, Binder $A$, Deuschl $G$, Baron $\mathbb{R}$. Idiopathic restless legs syndrome: abmormalities in central somatosensory processing. \& Neurol 2004:251:977-82.

13. Jamal GA, Hansen $\mathrm{S}$, Weir Al, Ballantyne JP. The neurophysiologic investigation of small fiber neuropathies. Muscle Nerve 1987;10:537-45.

14. Novak V, Freimer ML, Kissel JT, Sahenk Z, Periquet IM, Nash SM, Collins MP, Mendell JR. Autonomic impairment in painful neuropathy. Neurology 2001;56:861-8.

15. Holland NR, Crawford TO, Hauer P, Cornblath DR, Griffim JW, McArthur JC. Small-fiber sensory neuropathies: clinical course and neuropathology of idiopathic cases. Ann Neurol $1998: 44: 47-59$

16. Periquet MI, Novak $V$, Collins MP, Nagaraja HN, Erdem $S$, Nash SM, Freimer ML, Sahenk $Z$, Kissel JT, Mendell JR. Painful sensory neuropathy: prospective evaluation using skin biopsy [see comments]. Nourology 1999;53:1641-7.

17. Tobin K, Giuliani MJ, Lacomis D. Comparison of different modalities for detection of small fiber neuropathy. Clin Neurophysiol 1999;110:1909-12.

18. Stewart WD . Low PA. Fealey RD. Distal small fiber neuropathy: results of tests of sweating and autonomic cardiovascular reflexes. Muscle Nerve 1992;15:661-5.

19. Shy ME, Frohman EM, So YT, Arezzo JC, Cornblath DR, Giuliani MJ, Kincaid JC, Ochoa JL, Parry GJ. Weimer LH; Therapeutics and Technology Assessment Subcommittee of the American Academy of Neurology. Quantitative sensory testing: report of the Therapeutics and Technology Assessment Subcommittee of the American Acaderny of Neurology. Neurology 2003;60:898-904.

20. Dyck PJ, Kennedy WR, Kesserwani $H$. Kesserwani $H$, Melanson M, Ochoa J, Shy M, Stevens JC Suarez GA, O'Brien PC. Limitations of quantitative sensory testing when patients are biased loward a bad outcome [see comments]. Neurology 1998;50:1213.

21. Freeman R, Chase KP. Risk MR. Quantitative sensory testing cannot differentiate simulated sensory loss from sensory neuropathy. Neurology 2003;60:465-70 
22. Reulen JPH, Lansbergen MD, Verstraete E, Spaans F. Comparison of thermal threshold tests to assess small merve fiber function: limits vs. leveis. Clin Neurophysiof 2003;114:556-63.

23. Yarnitsky $D$, Sprecher $E$. Thermal testing: normative dala and repeatability for various test algorithms. J Nourol Sci 1994;125:39-45.

24. Exwing DJ. Campbell IW, Clarke BF. Assessment of cardiovascular effects in diabetic autonomic neuropathy and prognostic implications. Ann intern Med 1980;92:308-11.

25. Case records of the Massachusetts General Hospital. Weekly clinicopathological exercises. Case 34-1996. A 50-year-old woman with cardiac disease, an electronic pacemaker, and cardiac arrest in ventricular fibrillation. N Engl J Mod 1996;335:1378-86.

26. Suarez GA, Fealey RD, Camilleri M. Low PA. Idiopathic autonomic neuropathy: clinical, neurophysiologic, and follow up studies on 27 patients. Neurology 1994:44:1675-82.

27. Gorson KC, Ropper A.H. Idiopathic distal small fiber neuropathy. Acta Neurol Scand 1995; $92: 376-82$.

28. Morcos Z. Refractory meurosarcoidosis responding to infliximab. Neurology 2003;60:1220-1; author reply 1220-1.

29. Pettersen JA, Zochodne DW, Bell RB, Martin $L$. Hill MD. Refractory neurosarcoidosís responding to infliximab. Neurology 2002;59:1660-4

30. Yee $A M$, Pochapin $M B$. Treatment of complicated sarcoidosis with infliximab anti-tumor necrosis factor-alpha therapy. Ann Intern Med 2001:135:27-31.

31. Zabel P. Entzian P. Dahoff K. Schlaak M. Pentoxifylline in treatment of sarcoidosis. Am J Respir Crit Care Med 1997; 155:1665-9.

32. Baughman RP, Lower EE, du Bois RM. Sarcoidosis. Lancel 2003;361:1111-8.

33. Meyerle $\mathrm{JH}$, Shorr A. The use of infliximab in cutaneous sarcoidosis. J' Drugs Dermatol 2003; 2:413-4.

34. Radhakrishnan $W V$, Sumi MG, Reuben $S$, Mathai $A_{1}$ Nair MD. Serum tumour necrosis factoralpha and soluble tumour mecrosis factor receptors levels in patients with Guillain-Barre syndrome. Acta Nourol Scand 2004;109:71-4.

35. Creange $A$, Belec L, Clair B, Raphael JC, Gherardi RK Circulating tumor necrosis factor (TNF)-alpha and soluble TNF-alpha receptors in patients with Guillain-Barre syndrome. I Neunoimmunol 1996;68:95-9.

36. Sommer $C_{*}$ Marziniak M, Myers RR. The effect of thalidomide treatment on vascular pathology and hyperalgesia caused by chronic constriction injury of rat nerve. Pain 1998;74: $83-91$.

37. Sommer C, Schafers M. Painful mononeuropathy in C57BL/WId mice with delayed wallerian degeneration: differential effects of cytokine production and nerve regeneration on thermal and mechanical hypersensitivity. Brain Res 1998:784:154-62.

38. Schafers M, Geis C, Brors D. Yaksh TL. Sommer C. Anterograde transport of tumor necrosis factor-alpha in the intact and injured rat sciatic nerve. I Neurosci 2002;22:536-45.

39. Opree A, Kress M. Involvement of the proinflanmatory cylokines tumor mecrosis factor-alpha, $\| \mathrm{L}-1$ beta, and $\mathrm{L}-6$ but not $\mathrm{L}-8$ in the development of heat hyperalgesia: effects on healevoked calcitonin gene-related peptide release from rat skin. J Neurosci 2000;20:6289-93.

40. Empl M, Renaud S, Eme B, Fuhr P, Straube A, Schaeren-Wiemers N. Steck AJ. TNF-alpha expression in painful and nonpainful neuropathies. Nourology 2001:56:1371-7.

41. Cunha FQ. Poole S, Lorenzetti BB. Ferreira SH. The pivotall rolle of tumour necrosis factor alpha in the devellopment of inflammatory hyperalgesia. BrJ Pharmacol 1992;107:660-4.

42. O'Connor TM. O'Connell J, O'Brien DI, Goode T. Bredir CP. Shanahan $F$. The rolle of substance $P$ in inflammatory disease. $/$ Cell Physiol 2004;201:167-80.

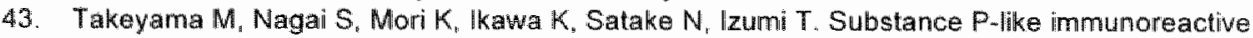
substance in bronchoalveolar lavage fluids from patients with idiopathic pulmonary fibrosis and pulmonary sarcoidosis. Sarcoidosis Vasc Diffuse Lung Dis 1996;13:33-7.

44. Brunelleschi S, Nicali $R$, Lavagno L, Viano :, Pozzi E, Gagliardi L, Ghio P, Albera $C$ Tachykinin activation of human monocytes from patients with interstitial lung disease, healthy smokers or healthy volunteers. Neuropeptides $2000 ; 34: 45-50$ 
45. Brumelleschi S, Guidotto S, Vano 1, Fantozzi R. Pozzi E, Ghio P. Albera C. Tachykinin activation of human alveolar macrophages in tobacco smoke and sarcoidosis: a phenotypical and functional study. Neuropeptides 1996:30:456-64.

46. O'Connor TM, O'Connell J, O'Brien DI, Bennett MW, Goode T. Burke $L$, Bredin CP. Shanahan $F$. Upregulation of neurokinin-11 receptor expression in the lungs of patients with sarcoidosis. J Clim Immunol 2003:23:425-35.

47. Cone RE, Georgiou $G M$, Little $\mathrm{CH}$. Soluble T-lymphocyte antigen-specific immunoproteins: a progress report. Exp Biol Med (Maywood) 2002;227:438-444.

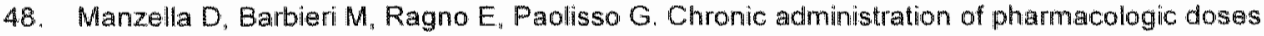
of vitamin $E$ improves the cardiac autonomic nervous system in patients with type 2 diabetes. Am J Clin Nutr 2001;73:1052-7.

49. Feldman EL. Oxidative stress and diabetic neuropathy: a new understanding of an old problem. J Clin Invest 2003;111:431-3.

50. Low PA. Nickander KK. Tritschler HJ. The roles of oxidative stress and antioxidant treatment in experimental diabetic neuropathy. Diabetes 1997;46 Suppl 2:S38-42.

51. Ziegler D, Gries. FA. Alpha-lipoic acid in the treatment of diabetic peripheral and cardiac autonomic neuropathy. Diabetes 1997;46 Suppl 2:S62-6.

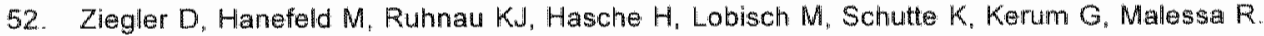
Treatment of symptomatic diabetic polyneuropathy with the antioxidant alpha-lipoic acid: a 7 month multicenter randomized controlled trial (ALADIN III Study). ALADIN III Study Group. Alpha-Lipoic Acid in Diabetic Neuropathy. Diabetes Care 1999;22:1296-301.

53. Ziegler D. Hanefeld M, Ruhnau KJ, Meissner HP, Lobisch M, Schutte K, Gries FA. Treatment of symptomatic diabetic peripheral neuropathy with the anti-oxidant alpha-lipoic acid. A 3week multicentre randomized controlled trial (ALADIN Study). Diabetologia 1995;38:1425-33.

54. Biewenga $G$, Haenen GRMM, Bast $A$. The role of lipoic acid in the treatment of diabetic polyne:uropathy. Drug Metab Rev 1997;29:1025-54. .

55. Rothkrantz-Kos $S$, Drent $M$, Vuil $H$, De Boer M, Bast $A_{n}$ Wouters EFM, Roos $D$, van DiejenVisser MP. Decreased redox state in red blood cells from patients with sarcoidosis. Sarcoidosis Vasc Diffuse Lung Dis 2002;19:114-20.

56. Culver DA, Barna BP, Raychaudhuri B, Bonfield TL, Abraham S, Malluir A, Farver CF, Kavuru MS, Thomassen MJ. Peroxisome proliferator-activated receptor gamma activity is deficient in alveolar macrophages in pulmonary sarcoidosis. Am J Respir Cell Mol Biol 2004;30:1-5.

57. Drent $M$, wan den Berg $R$, Haenen GRMM, van den Berg $H$, Wouters EFM, Bast A. NFkappaB, activation in sarcoidosis. Sarcoidosis Vasc Diffuse Lung Dis 2001;18:50-6.

58. van den Berg R. Haenen GRMM, van den Berg H, Bast A. Transcription factor NF-kappaB as a potential biomarker for oxidative stress. Br J Nuitr 2001;86 Suppl 1:S121-7.

59. Sharma OP. Tumor necrosis factor polymorphism in sarcoidosis. Chest 2001:119:678-9.

60 . Yamaguchi $E$. Itoh $A$. Hizawa $N$, Kawakami $Y$. The gene polymorptism of tumor necrosis factor-beta, but not that of tumor necrosis factor-alpha, is associated with the prognosis of sarcoidosis. Chest 2001:119:753-61.

61. Grunewald J. Eklund $A$, Olerup $O$. Human leukocyte antigen class I alleles and the disease course in sarcoidosis patients. Am J Respir Crit Care Mod 2004:169:696-702.

62. Berlin M, Fogdell-Hahn A, Olerup O. Eklund A, Grunewald J HLA-DR predicts the prognosis in Scandinavian patients with pulmonary sarcoidosis. Am J Respir Crit Care Med 1997;156. $1601-5$

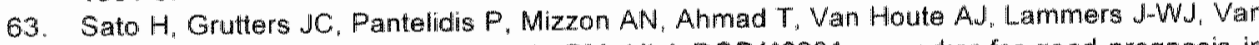
Den Bosch JMM, Welsh KI, du Bois RM. HLA.DQB1"0201: a marker for good prognosis in British and Dutch patients with sarcoidosis. Am J Respir Cell Mol Biol 2002;27:406-12.

64. Moller DR. Treatment of sarcoidosis - from a basic science point of view. I Intem Mod 2003; 253:31-40.

65. Swider C. Schnittger L. Bogunia-Kubik K, Gerdes J, Flad H, Lange A, Seitzer U. TNF-alpha and HLA-DR genotyping as potential prognostic markers in pulmonary sarcoidosis. Eur Cytokine Netw 1999;10:143-6.

66. Goldstein DS, Robertson D. Esler M. Straus SE, Eisenholer G. Dysautonomias: clinical disorders of the autonomic nervous system. Ann Intern Med 2002;137:753-63 
67. Merkies IS, Schmitz PI. Samijn JP, van der Meche FG, van Doom PA. Fatigue in immunemediated polyneuropathies. European inflammatory Neuropathy Cause and Treatment (INCAT) Group. Neurology $1999 ; 53: 1648-54$ 
Samenvatting 
196 


\section{Samenvatting}

Sarcoidose is een granulomateuze multi-systeemaandoening. waarvan de oorzaak niet bekend is. Patiënten met sarcoïdose kunnen een grote verscheidenheid aan klachten en klinische verschijnselen vertonen. Het merendeel van de patiènten (meer dan $90 \%$ ) heeft longklachten, zoals kortademigheid, hoesten en benauwdheid. Naast longklachten hebben veel patiënten ogenschijnlijk atypische klachten zoals pijn, vermoeidheid en vegetatieve klachten. Deze atypische klachten hebben tot duswerre weinig aandacht gehad in de medische literatuur, en in wele gevallen lopen deze klachten niet parallel met objectieve tekenen van ziekte-activiteit. Als bijvoorbeeld de longklachten en afwijkingen op de longloto afgenomen zijn, kunnen klachten van pijn, vermoeidheid en vegetatieve disfunctie persisteren. Onduidelijkheid over de oorzaak van deze klachten leidt vaak tot onbegrip bil arts, patiènt en omgeving.

Wiij vonden bij een groot deel van onze sarcoïdosepopulatie een steeds terugkerend klachtenpatroon bestaande uit neuropathische pijn, vermoeidheid en vegetatieve klachten zoals diarree, mictiestoornissen, heftig zweten, erectiestoornissen, droge ogen en mond, wissellend wazig zien en duizeligheid bij overeind komen. Dit klachtenpatroon zou goed kunnen passen bij een dunne vezell neuropathie (small fiber neuropathy, SFN), zodat de hypothese gevormd werd dat SFN een veel voorkomende en tot nog toe niet herkende complicatie van sarcoïdose zou kunnen zijn. Deze hypothese vormde de basis van het in dit proefschrift beschreven onderzoek.

Hoofdstuk 2 geeft een literatuuroverzicht van de neurologische complicaties van sarcoildose. Tevens worden mogelijke dilemma's waarmee medici geconfronteerd kunnen worden bij de behandeling van neurosarcoildose beschreven. Daarnaast worden schema's gepresenteerd, die in de praktijk kunnen worden gebruikt bij de diagnostiek en behandeling van deze gecompliceerde ziekte. Tenslatte is SFN toegevoegd aan de lijst van neurologische complicaties.

In hoofdstuk 3 wordt een overzicht van de literatuur van SFN gegeven. SFN is een neuropathie welke selectief de dunne gemyeliniseerde en niet-gemyeliniseerde zenuwvezels aantast. De afgelopen jaren is de interesse voor en de herkenning van deze aandoening sterk toegenomen. Patienten presenteren zich veelal met neuropathische pijnklachten en/of symptomen van autonome disfunctie (vegetatieve klachten). Veel gebruikt neurofysiologisch onderzoek, zoals zenuwgeleidingsonderzoek en electromyografie (EMG), onderzoeken de dikke gemyeliniseerde zenuwvezels en zijn dientengevolge niet afwijkend bij een geisoleerde SFN. Mede hierdoor konden lot voor kort de ernstig beperkende klachten var patiënten met een SFN niet goed verkllaard worden. 
De diagnose SFN wordt gesteld op basis van het klachtenpatroon, een normaal EMG en zenuwgeleidingsonderzoek en abnormale bevindingen bij gespecialiseerde tests van de dunne zenuwvezels. Deze laatste lests worden in hoofdstuk 3 uitgebreid beschreven en betreffen onder andere temperatuursensatie drempel onderzoek, histologisch onderzoek van de intra-epidermale zenuwvezels in een huidbiopt en autonoom functie onderzoek. Een onderliggende oorzaak voor SFN wordt vaak njet gevonden, ook niet na uitgebreid aanvullend onderzoek. De behandeling is dan ook meestal symptomatisch, en gericht op verlichting van neuropathische pijn.

SFN is dus veelal idiopathisch, maar komt ook woor bij een aantal immuungemedieerde ziekten zoals vasculitis, ziekte van Sjögren, systemische lupus erythematosus (SLE), het Guillain-Barré syndroom, en in onze ervaring ook bij de ziekte van Wegener en reumatoide artritis. Er zou dus een gemeenschappelijk imuungemedieerd mechanisme kunnen zijn, dat leidt tot SFN.

SFN gerelateerde symptomen treden bij vele sarcoïdosepatiënten niet parallel op met. andere tekenen van ziekte-activiteit, zoals afwijkingen op de longfoto en bloedonderzoek (bijvoorbeeld een verhoogd angiotensin converting enzyme (ACE). Daarnaast blijkt de standaardbehandeling bij sarcoïdose met corticosteroïden niet effectief. Dit doet vermoeden dat SFN bij sarcoïdose niet direct veroorzaakt wordt door granuloomvorming. Aan het eind van hoofdstuk 3 wordt een aantal mogelijke pathogenetische mechanismen van SFN besproken, zoals tumor necrosis factor (TNF) - $\alpha$ en oxidatieve stress.

Hoewel pijn regelmatig voorkomt bij sarcoïdose is het tot op heden niet systematisch onderzocht. In hoofolstuk 4 wordt onderzoek beschreven naar het voorkomen van pijn en de impact ervan op de kwaliteit van leven bij sarcoïdose patiënten. Leden van de Nederlandse Sarcoidose Vereniging (sarcoidosepatienten zonder co-morbiditeit) namen deel aan deze studie ( $n=821$ ). De World Health Organisation Quality of Life vragenlijst (WHOQOL-100; zie appendix) werd ingevuld en ook een vragenlijst gericht op het voorkomen van verschillende typen pijn. Pijn bleek een belangrijk probleem, en kwam voor bij $72 \%$ van de onderzochte sarcoïdosepatienten. Hoewel negatieve gedachten en vermoeidheid gerelateerd bleken aan pijn konden zij de pijn niet verklaren. Een ander onderliggend mechanisme lijkt dus aannemelijk.

Naast pijn klagen veel sarcoidosepatiënten over vermoeidheid en slaapstoomissen. Recent werd aangetoond dat obstructieve slaap apnoes (OSA) relatief veel voorkomen bij sarcoildose. Daarnaast worden door sarcoïdosepatiënten ook klachten geuit van dekenintolerantie, pijnlijke benen en rusteloze benen, mogelijk samenhangend met SFN. Al deze symptomen kunnen interfereren met de kwaliteit van de slaap en zouden theoretisch tot vermoeidheid kunnen leiden. Om objectieve en subjectieve 
slaapstoornissen te analyseren werd in 46 chronische sarcoijdose patienten die aangaven vermoeld wakker te worden. slaapanalyse (polysomnografie) verricht, inclusief EMG analyse van de beenbewegingen (hoofdstuk 5). Zowel slaapstoornissen (OSA enlof periodic leg movements (PLM)) en restless legs syndrome (RLS) werden gevonden bij meer dan de helft van de onderzochte sarcoïdosepatienten. Eerder werd al aangetoond dat RLS een eerste teken van SFN kan zijn. De relatie van OSA, PLM en RLS met SFN en vermoeidheid bij sarcoïdose dient nader onderzocht te worden.

Nadat wij ontdekten dat bij sarcoïdosepatiënten zeer frequent een patroon van symptomen suggestief voor SFN optreedt, werd de aanwezigheid van SFN nader onderzocht met behulp van verschillende diagnostische middelen.

In hoofdstuk 6 wordt een studie beschreven in een populatie van 74 sarcoïdosepatiënten met klachten passend bij een SFN. Al deze patienten ondergingen een temperatuursensatie drempel onderzoek (temperature threshold testing. TTT). sympathische huidreflex (sympathetic skin response, SSR), zenuwgeleidingsonderzoek en EMG. Bovendien werd bij 31 patiënten cardiovasculair autonoom functie onderzoek (CAFT) verricht. TाT was afwijkend bij 51 van de 74 patienten (69\%), passend bij de klinische diagnose SFN. Dit is in overeenstemming met eerdere studies waar een sensitiviteit van het TTT van 60 tot $85 \%$ werd gevonden. Zenuwgeleidingsonderzoek toonde lichte afwijkingen bij 6 van de 74 patienten; deze 6 hadden allen ook een afwijkend TTT. De SSR was afwezig aan de voet bij 7 van de 74 patiënten. CAFT bleek afwijkend te zijn bij slechts éen van de 31 geteste patiënten. Dit is ook in overeenstemming met eerdere onderzoeken waar een lage sensitiviteit van het CAFT werd gevonden bij patiënten met SFN.

De conclusie van deze studie was dat bij een subgroep sarcolidosepatiënten TTT afwijkingen in overeenstemming met SFN werden gevonden. De diagnostische waarde wan SSR en CAFT bleken echter beperkt te zijn.

In hoofdstuk 7 werd de aanwezigheid van SFN nader onderzocht door het aantal zenuwvezels in een huidbiopt te bepalen (intra-epidermal nerve fiber density, IENFD). Kwantificatie van epidermale zenuwvezels in een huidbiopt is een objectieve en waardevolle methode om SFN aan te tonen. Een afgenomen IENFD blijkt de eerste en enige objectiveerbare afwijking te kunnen zijn bij patiënten mel pijntijke neuropathie. Bij Topeenvolgende sarcoildosepatiénten en 6 leeftijdsgematchte gezonde controles werd een huidbilopt afgenomen en de IENFD bepaald. Een significante afname van de IENFD, passend bij SFN, werd gevonden bij alle 7 patienten ten opzichte van de 6 gezonde controles. 
Diagnostische middelen om SFN te onderzoeken zijn slechts zeer beperkt beschikbaar. Er is dus behoefte aan een eenvoudig te gebruken instrument om patienten te screenen op de aanwezigheid van SFN. Hierdoor zou aanvullende diagnostiek gerichter geinitieerd kunnen worden. In hoofdstuk 8 beschrijven wij de ontwikkeling en validatie van een vragentijst gericht op het screenen van patiènten met SFN. Een dergelike vragenlijst kan naast diagnostische doeleinden in de klinische setting ook gebruikt worden voor wetenschappelijke doelen, bijvoorbeeld voor prevalentie studies, natuurlijk beloop studies en therapeutische trials.

In een groep van 84 sarcoildosepatiënten werd op basis van een uitgebreide klachten analyse een korte en eenvoudig af te nemen vragenlijst ontwikkeld, de Small Fiber Neuropathy Screening List (SFNSL). Afkapwaarden werden bepaald aan de hand van TTT resultaten. Vervolgens werd in een andere groep van 55 sarcoidosepatienten de SFNSL opnieuw gevalideerd. Dezelfde afkapwaarden bleken toepasbaar. De interne consistentie van de SFNSL was goed (Cronbach's alpha 0.90 ). Bovendien toonde exploratieve factoranalyse dat de SFNSL slechts 1 onderliggende factor meet. Deze resultaten ondersteunen sterk het concept van SFN als een uniforme ziekte-entiteit en maken een onderliggende psychogene factor erg onwaarschijnlijk.

Naast vermoeidheid en perifere pijn hebben veel sarcoildosepatiënten symptomen die gerelateerd kunnen worden aan cardiale autonome disfunctie, zoals orthostatische intolerantie, herhaaldelijk flauwvallen onder de douche, of pijn in het kleerhanger gebied bij staan. Echter, zoals beschreven in hoofdstuk 5 , is CAFT normaal bij een groot deel van hen. Herkenning van cardiale autonome disfunctie is van belang aangezien dit cardiale arrythmieën kan induceren en een sterke voorspeller lijkt van morbiditeit en ook mortaliteit. In hoofdstuk 9 beschrijven wij de analyse van cardiale sympathetische innervatie met behulp van ${ }^{123}$ /.MIBG (metaiodobenzylguanidine) cardiale scintigraphy bij sarcoidose patienten. Cardiale sympathische disfunctie bleek inderdaad gerelateerd aan de aanwerigheid van SFN. De mogelijke prognostische en therapeutische implicaties van cardiale sympatische disfunctie behoeft nader onderzoek.

Bij het ontstaan van sarcoïdose spelen genetische factoren een belangrijke rol. $\mathrm{Er}$ is een associatie gevonden met het human leucocyte antigen (HLA), met name het DQB1 gen. In hoofdstuk 10 wordt de analyse naar de associatie tussen HLA en SFN in sarcoildose beschreven. Laag resolutie HLA typering werd toegepast bij 103 sarcoidosepatiënten met serologische en moleculaire methoden, hoog resolutie DQB1 werd verkregen door sequence-based typering. De aanwezigheid van SFN werd geanalyseerd middels TTT. Een afwijkend TTT werd gevonden bij 67 patiènten $(S F N+)$, 36 patienten thadden een normaal TTT (SFN-). Vergelijking van HLA typering van SFN+ patiënten, SFN-patiènten en controles toonde een significante toename van HLA 
klasse II allel DQB1*0602 bij SFN+ patienten vergeleken met controles. Ook werden verschillen gevonden in ziekte-progressie. Binnen de SFN+ groep had een hoger percentage persisterende ziekte-activiteit vergeleken met de SFN-groep. Dit betekent dat zowel de aanwezigheid van DQB1*0602 als het optreden wan SFN bij sarcoïdosepatiënten gerelateerd zoudien kunnen zijn aan een ernstiger beloop van de ziekte.

Hoewel patiënten aangeven baat te hebben bij de wetenschap dat SFN een groot deel van thun klachten kan werklaren, zijn de klachten vaak zo enstig dat ontwikkeling van een effectieve therapie van groot belang is. Corticosteroiden en methotrexaat, de hoekstenen van de therapie bij sarcoildose, lijken niet werkzaam bij SFN (eigen ervaring). Dientengevolge is de behandeling voornamelijk symptomatisch en gericht op vermindering van neuropathische pijn. Echter, de meeste effectieve medicamenten reduceren de pijnintensiteit slechts met $30-50 \%$. Een dergelijke reductie voldoet meestal niet aan de verwachting van de patiènt. Goede behandeling van autonome disfunctie is zoniet nog moeilijker. In hoofostuk 11 beschrijven wij een patiënt met zeer enstige SFN gepaard gaande met autonome disfunctie. Deze patiënt werd experimenteel behandeld met infliximab, een anti-TNF- $\alpha$ therapie. Zijn symptomen verdwenen geheel. en afwijkingen bij TTT en CAFT verbeterden opmerkelijk na de therapie. Bovendien heeft hij zijn werkzaamheden volledig kunnen hervatten.

Dit voorbeeld toont twee belangrijke zaken. Ten eerste blijkI SFN reversibel te kunnen zijn, zelfs in ernstige gevallen. Ten tweede toont het dat TNF- $\alpha$ een cruciaal cytokine in de pathogenese van SFN bij sarcoïdose, en eventueel ook bij andere immuungemedieerde inflammatoire ziekten, zou kunnen zijn. TNF-a is belangrijk bij de ontwikkeling van neuropathische pijn, en is gerelateerd aan ziekte-activiteit bij het Guillain-Barré syndroom. Bovendien, zoals eerder vermeld, blikt SFN vaak voor te komen bij andere immuungemedieerde ziekten. Een gemeenschappelijk mechanisme leidend tot SFN lijkt dus aannemelijk. Mogelijk dat dit gemeenschappelijke mechamisme gerelateerd is aan cytokineproductie

Dit proefschrift beschrijft het spectrum van neurologische complicaties van sarcoildose. Een niet eerder aangetoonde complicatie is SFN. Symptomen die tot nog toe niet goed konden worden verklaard, blijken te berusten op de aanwezigheid wan SFN. Herkenning hiervan is van belang, omdat patienten aangeven baat te hebben bij een goede verklaring van hun klachten. De verschillende aspecten van SFN bij sarcoïdose worden besproken, inclusief pijn, slaapstoornissen, en autonome cardiale disfunctie. Met name deze laatste aspecten zouden prognostische en therapeutische implicaties kunnen hebben. Dit behoeft nader onderzoek in longitudinale, prognostische studies. Een SFN vragenlijst werd ontwikkeld en gevalideerd. Deze lijst is eenvoudig toepasbaar en vergt 
weinig tijd. In de klinische praktijk kan de vragenlijst als screeningsinstrument gebruikt worden. Daarnaast is deze lijst ook bruikbaar woor wetenschappelijke doeleinden in toekomstige studies. HLA typering toonde aan dat de aanwezigheid van HLA-DQB1*0602 gerelateerd was aan de aanwezigheid van TIT afwijkingen en aan een ernstiger beloop van de ziekte. Tenslotte bleek een patiënt met ernstige SFN volledig van zijn klachten te herstellen na behandeling anti-TNF-a therapie. Dit opent de discussie over de mogelijke pathofysiologie van SFN gerelateerd aan sarcoïdose, en roept vele vragen op, welke interessant zijn voor verder wetenschappelijk onderzoek. 
Dankwoord 


\section{Dankwoord}

"Afscheid nemen is met dankbare handen aannemen al wat herinnering waard is." Het schrijven van dit dankwoord woelt een beetje als afscheid nemen. Afscheid nemen van een intensieve periode waar ik met welen meer dan prettig heb mogen samemwerken. De herinneringen aan de afgelopen jaren zijn talloos en veel te veel om hier samen te watten. Toch will ik een poging wagen de vele mensen die een prominente rol speeiden hier te bedanken

In de eerste plaats de sarcoildose patiënten. Zij hebben mij geïnspireerd en zonder hun bereidheid om uitgebreid hun verhaal te doen en mee te werken aan de verschillende onderzoeken was dit onderzoek niet van de grond gekomen. Patiënten met sarcoildose blijken niet alleen zelf zeer gemotiveerd om meer over hun aandoening te weten te komen, maar tonen ook grote betrokkenheid met (toekomstige) lotgenoten. Zondler hen gieen onderzoek, geen proefschrift!

Mijn fantastische co-promotoren, Dr. M. Drent en Dr. C.G. Faber.

Marjolein, al vanaf de allereerste keer dat we elkaar spraken klikte het en bleken we op dezelfde golflengte te zitten. Jouw enorme, onstuitbare enthousiasme en de vele gedreven gesprekken waarin we ideeën ontwikkelden en onderzoeksplannen maakten zijn de meest waardevolle momenten van deze onderzoeksperiode geweest! Hopelijk kunnen we die momenten in de toekomst voortzetten!

Karin, ik vind het een eer je eerste promovenda te zijn! Je bent voor mij een groot woorbeeld hoe je naast toegewijd neuroloog ook toegewijd moeder kunt zijn. Je adviezen over de planning van dit boekje, het moederschap, en je positieve kijk op de zaken hebben me erg geholpen.

Mijn promotoren, Prof. dr. J. Troost en Prof. dr. F. Spaans.

Jaap, wanaf het allereerste moment dat ik voorzichtig mijn hypothese van een frequente dunne vezel neuropathie bil sarcoïdose opperde heb je me direct en volledig ondersteund, vele mogelijkheden geschapen en vertrouwen gesteld in mij en mijn plannen. Daarbij heeft je belangstelling en warme schouderklop in moeilijke tijden me veel goed gedaan. U bent een opleider uit duizenden!

Frank, ik ben er trots op de klinische neurofysiologie van jou te hebben mogen leren. Jouw grondige, heldere commentaar en kritische geest hebben me af en toe wel eens doen zuchten, maar ik heb er erg veel profijt van gehad. De heldere manier van formuleren die je me leerde neem ik mee in de toekomst! En "last but not least", door jouw inzet kon Esther mij als student-assistent bijstaan. 
Esther, grote dank voor je hulp. gezelligheid en doorzettingsvermogen bij hel kleuren van de huidbiopten. Helaas bleek dit avontuur veel lastiger dan gedacht, maar je volharding pleit voor je en ik hoop nog altijd dat jij dit onderzoek zult voortzetten...

Mijn huidigle opleider, Prof.dr.M. Limburg. Martien, dank voor de extra bagage, zoals CAT"s, die je tijdens het laatsite deel wan mijn opleiding nog in mijn rugzak hebt weten te proppen!

Dr. M. de Baets, Marc, jij was het die direct bereid was om contact te leggen met prof. dr. Toyka in Würburg zodat we daar de huidbiopten konden laten kleuren. Hiermee werd een belangrijk begin van dit onderzoek gelegd. De tijd in Duitsland en de ritten samen er naar toe deden een woor mij oud motto herleven: Utile Dulcil

Prof. dr. K.V.Toyka, Dr. C. Sommer und Dr. M. Marziniak "vielen Dank für ihren Hilfe und Gastfreiheit in Würzburg.

De mensen van het lab neuro- en cognitiewetenschappen, en in het bijzonder Barbie en Helen, dank woor jullie hulp, advies en gastvrijheid bij thet verwerken van de huidbiopten!

Jolanda De Vries, je hulp bij het analyseren en construeren van de SFNSL waren van grote waarde. De leuke gesprekken in Venetie zullen een blijvende goede herinnering zijn!

Prof.dr. "uncle" Sharma, already when we first met in Venice you showed me an interest and openness, both professionally and personally that moved me. I feel very privileged to have had the opportunity to share time with you in a Californian Japanese restaurant, in your hospital, and behind the computer working on the papers.

Tiny Wouters, reeds geroemd in vele dankwoorden. Jouw hulp bij het opmaken van dit proefschrift, de goede adviezen woor de lay-out en de prettige samenwerking maken dat ik alle toekomstig promovendi toewens dat ze door jou geholpen kunnen worden! Ik moet je ook namens onze kleine Joren bedanken die dankzij jou de aandacht heeft kunnen krijgen die hij nodig heeft, de eerste weken van zijn leven...

Christien Voorter en Prof.Dr. Ella van den Berg-Loonen mijn dank voor de HLA typeringen.

Johan Verbraecken, fantastisch dat jij de slaap analyses hebt kunnen doen!

Marijke van Santen-Hoeufft, bedankt voor de enorm prettige samenwerking, met name biij de behandeling van onze patiënten! 
De ardeling nucleaire geneeskunde, met name Servé Halders, Prof.dr. Heidendal, en Dr. Kroonenburg, veel dank voor alle overleg, hulp en het vertichten van de MIBG scans!

Petal Wijnen, dank voor je bijdrage aan helt ordenen van de chaos van gegevens in een overkoepelende database.

Ann Hilton, fijn dat je direct bereidwilligheid was on de SFNSL te vertaten en Engelse taal correcties uit te voeren.

De ardeling KNF: Jos, Werner, Vivianne en alle laboranten. Bij en door jullie is heel veel werk voor dit boekje verricht! Dank voor de gezelligheid, voor jullie betrokkenheild en voor het steeds weer verrichten van alle tijdrovende temperatuur drempel onderzoeken en autonome functie onderzoeken! Jas, ik hoop dat we in de toekomst verder kunnen samenwerken op gebied van de autonome disfunctie en dunne vezel neuropathie!

Huib, je hulp bij het werven van sponsoring was erg welkom en lucratief en de telefoontjes erover erg gezellig. Dank daarvoor!

Tenslotte allen dank voor de o zo belangrijke morele steun;

Van mijn vrienden wil ik er een paar in het bijzonder noemen. In de eerste plaats mijn paranymfen, Selima en Maaike, bedankt voor de onvoorwaardelijke vriendschap en voor alle tranen van de lach en van verdriet die we samen hebben kunnen delen. Afscheid nemen betekent ook een nieuw begin, en ik zie ernaar uit weer wat dichter in de buurt te komen!

Krista jouw positieve kijk op het leven maakt op mij een diepe indruk en toon mij vaak hoe betrekkelijk alles is.

Barbara, jouw hulp en aanwezigheid hier in Maastricht in moellijke tijden hebben me gesterkt in de moeilike beginfase van deze promotie. De buikpinn van het lachen en de koekjes zal ik straks, als ik weer wat dichter in de buurt woon, niet meer zo lang hoeven missen!

De assistenten neurologie: Vaak lees je dat promoveren een eenzame klus is. Zo heb ik dat niet ervaren. Mede dankzij alle borrels, feestjes en het medeleven dat ik heb mogen ondervinden. Daar afscheid van te moeten nemen doet een beetje pijn.

Merinke en Snjezana, dank voor de gezellige avonden samen eten, tickel-toetjes, hulp en adviezen rond de promotie! 
Gernout, ik kan hier in woorden niet uitdrukken wat jouw betrokkenheid, liefde en steun in de beginfase van dit boekje voor me betekent. Mijn diepe dank daarvoor!

\section{Liefste papa en mama...}

Begin van alles...

Warme thuishaven en onvoorwaardelijke steun in heftige stormen... Ik omhels jullie...

Liefste Lotis en Joren...

Als laatste en met afstand...

... Dank woor je Liefde, het enige echt onmisbare...

... en Joren, bedankt voor je perfecte timing...! 
List of publications 


\section{List of publications}

Halaby $T$, Hoitsma E, Hupperts $R$, Spanjaard L, Luirink M, Jacobs JA. Streptococcus suis meningitis, a poacher's risk. Eur. J Clin Microbiol Infect Dis 2000:19:943-5.

Hoitsma E, Lame IE, Weber WEJ. Chronische pijn en sarcoidose (Chronic pain and sarcoidosis). Ned Tijdschr Pijn Pijnbestr 2001:21:10-3.

Hoitsma E, Wilmink JT, Lodder J. Bilateral thallamic stroke may result from wenous rather than arterial stroke. J Cerebrovaso Dis Stroke 2002;11:47-50.

Hoitsma $E$, Marziniak $M$ Faber $C G_{n}$ Sommer $C$. Reulen JPH. De Baets $M$ "Drent M. Small fiber neuropathy in sarcoidosis. Lancet 2002;359:2085 6 .

Hoitsma $E$, De Vries $\Downarrow$, wan Santen-Hoeufft M, Faber CG, Drent M. Impact of pain in a Dutch sarcaidosis patient population. Sarcoidosis Vasc Diffuse Lung Dis 2003;20:33-9.

Hoitsma E. Drent M, Verstraete E. Faber CG, Troost J, Spaans F, Reulen JPH. Abnormal warm and cold sensation thresholds suggestive of small fiber neuropathy in sarcoidosis. Clin Neurophysiol 2003:114:2326-33.

Verbraecken J, Hoitsma E, van der Grinten CPM, Cobben NAM. Wouters EFM. Drent M. Sleep efficiency associated with periadic leg movements in chronic sarcoidosis patients. Sarcoidosis Vasc Diffuse Lung Dis 2004;21:137m46.

Hoitsma E. Faber CG, Drent M, Sharma OP. Neurosarcoidosis: a clinicial dillemma. Lancet Neurology 2004;3:397-407.

Hoitsma $E$, Reulen JPH, de Baets M. Drent M, Spaans F. Faber CG. Small fiber neuropathy: A common and important clinical disorder. INeurol Soi 2004;227:119-30.

Hoitsma E, Faber CG, wan Kroonenburgh MJPG, Gorgels APM, Halders SGEA, Heidendal GAK, Kessels AGH, Reulen JPH. Drent M. Association of small fiber neuropathy with cardiac sympathetic dysfunction in sarcoidosis. Sarcoidosis Vasc Diffuse Lung Dis 2005; accepted for publication.

Hoitsma E. Sharma OP. Neurosarcoidosis. Eur Respir Mon 2005: accepted for publication

Voorter CEM. Drent M. Hoitsma E, Faber CG, van den Berg-Loonen PM. Association of HLA DQB1*0602 in sarcoidosis patients with small fiber neuropathy. Sarcoidosis Vasc Diffuse Lung Dis 2005; accepted for publication.

Hoitsma $E$, Faber $C G$. Drent $M$ Spectacular improvernent of small fiber neuropathy in a sarcoidiosis patient after treatment with Infliximab. Submitted.

Hoitsma $E$, De Vries J, Faber CG. Drent M. The small fiber neuropathy screening fist (SFNSL): Construction and cross-walidation in sarcoidosis patients. Submitted. 
212 
Curriculum vitae 
214 


\section{Curriculum valae}

Elske Hoitsma was born on December 21, 1971 in Geldrop, The Netherlands. In 1991 she finished secondary school at the Coornhert Gymnasium in Gouda. Afterwards, her propedeutics Biomedical Sciences were finished in 1992. Subsequently, she started her medical training at the University of Leiden and obtained her medical degree in 1999. During her studies she assisted as a tutor several courses in anatomy, neuroanatomy and cell biology. In 1995 she started her philosophical training and graduated from ancient philosophy, ethics, history of western philosophy, anthropological philosophy, medieval philosophy, logistics, philosophy of science and metaphysics. From 1995 to 1996 she did a research project and studied the ultrastructure and synaptology of Onuf's nucleus with light and electron microscopy under supervision of Dr. H.K.P. Feirabend. In this period she also participated in clinical trials with anti-migraine drugs under supervision of Dr. M.D. Ferrari and Dr. K.I. Roon. In 1997 she did voluntary work in a medical post in a slum area in India and in 1998 she did an internship 'family medicine" in Barbados. She started as a resident at the Department of Neurology: Maastricht University Hospital (Prof. dr.J. Troosit and Prof. dr. M. Limburg) in March 1999. During her residency she started the research described in this thesis on small fiber neuropathy in sarcoidosis under supervision of $\mathrm{Dr}$. M. Drent, Dr. C.G.Faber, Prof. dr. F. Spaans and Prof. dr. J. Troost. Part of the research was awarded with the Young Investigators Award of the WASOG, of the Dutch Association of Clinical Neurophysiology and of the European Congress of Clinical Neurophysiology, with the Pelerin's Award and the van der Linden's Award of the University Hospital Maastricht and with the Prinses Beatrix Fonds Award. She is a member of the Sarcoidosis Management Center Maastricht from the very first beginning. 
218 
Appendix 
http:/Www.neuromaas.nilprotoNeuromusculair.htm

Small fiber neuropathy (dunne vezel neuropathie), questionnaire (vragenlijst) English / Nederlands 


\section{Small fiber neuropathy screening list (SFNSL)}

Below are a number of questions about possible complaints. Please circla the answer to each question that is applicable to you. Please give an answer to each question, ewen if you do not have any conplatis at the moment. The aim of this questionnaire is to find out how you experience your complatists. There are no conrect of incorrect answers. It is important that you are honest.

Part 1: These questions are aimed at finding out how ofter you experience the following complaints:

1. I have paintul arms

2. I suffer from palpitations

3. I have problems with my bowel movements

4. I have difficulties with urinating (either in emptying my bladder or being able to hold my water)

5. My food does not seem to go down weit

6. I suffer from muscle cramps

7. My feet andior hands are colder than I am used to

8. I have chest pain never / somelimes / Ructuating / often / always

never $/$ sormetimes / fluctuating / often / always never / sometimes / fuctuating / often / aways

never / somethmes / fluctuating / ofter / always

never / sometimes / fuctuating / often / always never / sometimes / fluotuating / often / always never / sometimes / fluctuating / often / alwaws newer / sometimes / fluctuating / often / always

Part 2: These questions are aimed all finding out how serious your complaints arre

9. Ihave the feeling that my food gets stuck in my throat

10. At night I throw the bedclothes of my legs

11. I have difficulities with urinating (either emptying my bladder or being able to hold my watery

12. I thave dry eyes

13. I have blurred vision

14. I feel dizzy when I get up

15. I have sudden hot filushes

16. My feet andior hands are cotder than I am used to

17. I have painful arms

18. The skin of my legs is over-sensitive

19. I have a tinging sensation in my hands (pins and needles)

20. I have a tingling sensation in my legs (pins and needtes)

21. I have chest pain not at all / slightly / fluctuating / moderately / seriously not al all / slightiy / fluctuating / moderately / serously not al all/slightly / fluctuating / moderately / seriously not at al / slightly / fluctuating / moderately / seriously irot at all / shghty / nuotuating / moderately / sariously not at all / stighlly / fuctuating / maderatein/ seriously not at all / slightly / fluctuating / monderately / seriousty not al all / slightiy / fluctuating / moderately / seriously not at all / shighty / fluchating / moderately / seriousty not at all / slightly / fuctuating / moderately / seriously not alt al / stighnly / fluctuating / moder ately / seriously not at al / slightly / fuctwating / moderately / seriously not af all / sigintly / fluctuating / moderately / sariously 